UNIVERSIDADE DE SÃO PAULO

ESCOLA DE ENGENHARIA DE SÃO CARLOS

DEPARTAMENTO DE GEOTECNIA

\title{
COMPORTAMENTO DE ESTACAS ESCAVADAS EM SOLOS COLAPSÍVEIS
}

DISSERTAÇÃO DE MESTRADO APRESENTADA À ESCOLA DE ENGENHARIA DE SÃO CARLOS - UNIVERSIDADE DE SÃO PAULO, COMO REQUISITO PARA OBTENÇÃO DO TÍTULO DE MESTRE EM GEOTECNIA.

AUTOR: CORNÉLIO ZAMPIER TEIXEIRA ORIENTADOR: PROFESSOR DR. JOSÉ HENRIQUE ALBIERO

SÃO CARLOS (SP), AGOSTO DE 1993 


\section{AGRADECIMENTOS}

Ao Professor Dr. José Henrique Albiero: pelo tema, o que já não é pouco; pela orientação serena e pelas demonstrações de amizade e confiança.

Aos Professores Francis Bogossian, Paulo César Corrêa Lopes e Fernando Emmanuel Barata, a quem devo os primeiros estímulos para iniciação à Geotecnia.

A todos os que vieram antes: desde os grandes, que edificaram a Ciência, até os simples operários, como nós, cuja missão de abrir caminhos não lhes minimiza a importância.

Aos Professores do Departamento de Geotecnia da USP - São Carlos, sem distinção. Sempre que solicitados, jamais tiveram avareza em emprestar conhecimentos, materiais e paciência.

Aos meus colegas do Departamento de Engenharia Agrícola da ESAL - Escola Superior de Agricultura de Lavras, que permitiram meu afastamento.

À Bibliotecária, pela paciência; às Secretárias, pela constante boa vontade; aos demais funcionários e laboratoristas, principalmente pela convivência amena e harmoniosa, que em muitos momentos serviu de restauração do cansaço. 


\section{RESUMO}

TEIXEIRA, C. Z. Comportamento de estacas escavadas em solos colapsíveis. São Carlos, Faculdade de Engenharia, Universidade de São Paulo, 1993. Dissertação de Mestrado.

Este trabalho se propõe a analisar os efeitos produzidos pela inundação do solo em estacas escavadas, isoladas, submetidas a esforços de compressão. Os resultados obtidos referem-se à execução de três provas de carga lentas em estacas com diâmetros de $0,40 \mathrm{~m}$ e $0,50 \mathrm{~m}$ (2 provas de carga distintas) e comprimentos de $10,0 \mathrm{~m}$, submetidas anteriormente a uma série de carregamentos (duas provas de carga rápidas e duas lentas). Os resultados relativos aos deslocamentos medidos no topo das estacas e os obtidos pela instrumentação instalada ao longo do fuste são então comparados com a sequência dos resultados anteriores, para avaliação do efeito de umedecimento no comportamento "carga $x$ recalque" e nos mecanismos de transferência de carga. É feita ainda uma descrição minuciosa do processo utilizado para inundação do solo e uma breve consideração sobre os efeitos da não reposição de cargas em ensaios lentos, de longa duração.

Palavras-chave: solos colapsíveis, provas de carga à compressão, estacas escavadas instrumentadas, transferência de carga, comportamento carga-recalque. 


\begin{abstract}
TEIXEIRA, C. Z. Behavior of excavated piles in collapsible soils. São Carlos, Faculdade de Engenharia, Universidade de São Paulo, 1993. Master thesis.

This work intends to analyze the effects produced by the flooding of the soilexcavated piles, isolated, subjected to compression efforts. The results refer to the execution of three slow load tests on piles with diameters of $0.40 \mathrm{~m}$ and $0.50 \mathrm{~m}(2$ distinct load tests) and $10.0 \mathrm{~m}$ lengths, submitted previously to a number of shipments (two slow and two quick load). The results concerning offsets measured at the top of the stakes and those obtained by the instrumentation installed along the forend are then compared with the sequence of the previous results, to evaluate the effect of damping in behavior "load x settlement" and load transfer mechanisms. It was also made a thorough description of the process used to flood the ground and a brief consideration of the effects of non-replacement of loads in slow, long-term trials.
\end{abstract}

Keywords: collapsible soils, compressive load tests, excavated piles instrumented, load transfer, load-discharge behavior. 


\section{RESUMO}

LISTA DE FIGURAS ……………................................................ i

LISTA DE TABELAS ……………………...................................... vii

LISTA DE FOTOS …………………............................................ ix

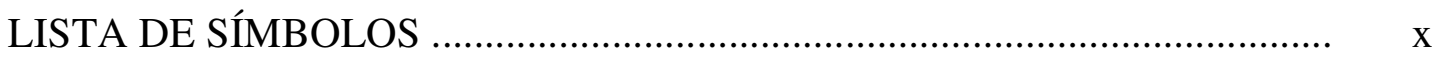

CAPÍTULO 1 - INTRODUÇÃO ............................................................... 1

CAPÍTULO 2 - REVISÃO BIBLIOGRÁFICA …………………………….... 5

2.1 - Colapsibilidade: mecanismos de formação ……………………………….. 5

2.2 - Modos de inundação dos solos colapsíveis ................................................. 9

2.3 - Influência do aumento do teor de umidade do solo de fundação ............... 11

2.4 - Capacidade de carga de estacas escavadas ................................................ 12

2.4.1 - Revisão do problema .................................................................... 12

2.4.2 - A prática brasileira ............................................................................ 14

2.4.3 - Capacidade de carga de estacas escavadas em solos colapsíveis 14 inundados

2.5 - Análise do comportamento de estacas ................................................... 16

2.5.1 - Recalques: uma revisão sobre os métodos clássicos ........................... 16

2.5.2 - Estimativa de recalques em estacas isoladas ..................................... 18

2.6 - Transferência de carga ....................................................................... 18

2.6.1 - Função "transferência de carga" ........................................................ 18

2.6.2 - Parâmetros básicos da transferência de carga .................................... 24

2.7 - Provas de carga ............................................................................... 26

2.7.1 - Finalidades, procedimentos e métodos .............................................. 26

2.7.2 - Definição da carga de ruptura ....................................................... 28

2.8 - Métodos de separação das parcelas de resistência lateral e de ponta ........ 29

2.9 - Métodos de previsão da curva carga x recalque ………………………... $\quad 30$

2.10 - Estacas sujeitas a carregamentos múltiplos. Tensões residuais ............... 31

CAPÍTULO 3 - CARACTERÍSTICAS DO CAMPO EXPERIMENTAL DA USP - SÃO CARLOS

3.1 - Breve histórico ............................................................................... 38

3.2 - A geologia local ................................................................... 40

3.3 - Localização do campo experimental ....................................................... 40

3.4 - Caracterização geotécnica do material estudado ......................................... 41 
3.4.1 - Ensaios de simples caracterização ………………………………...... 43

3.4.2 - Permeabilidade .................................................................... 45

3.4.3 - Resistência e compressibilidade ....................................................... $\quad 46$

3.4.4 - Sondagens de reconhecimento ....................................................... 46

3.4.5 - Correlações entre os diversos parâmetros do solo ............................... 47

CAPÍTULO 4 - PROVAS DE CARGA: OBJETIVOS, MATERIAIS E 48 MÉTODOS

4.1 - Estacas ensaiadas e instrumentação ........................................................ 48

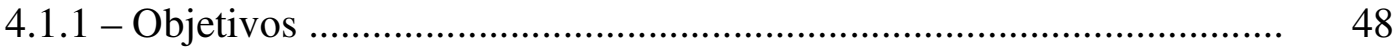

4.1.2 - Descrição das estacas de prova ......................................................... 49

4.1.3 - Instrumentação das estacas ............................................................ $\quad 50$

4.1.4 - Histórico do carregamento das estacas .............................................. 51

4.2 - Módulo de elasticidade longitudinal do material das estacas ................... 53

4.3 - Montagem das provas de carga. Equipamentos e métodos ........................ 55

4.4 - Procedimento adotado para inundação do solo .......................................... 58

4.5 - Algumas observações registradas durante as provas de carga .................. $\quad 70$

4.5.1 - Influência do processo de amostragem no teor de umidade .............. 70

4.5.2 - Efeitos da não reposição de cargas durante a realização das provas de carga

4.5.3 - Influência da inundação na reversão dos recalques lidos ................... 71

CAPÍTULO 5 - APRESENTAÇÃO DOS RESULTADOS .............................. 74

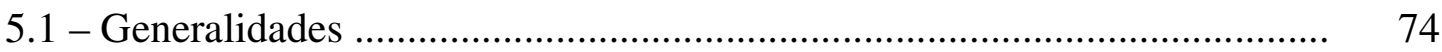

5.2 - Comportamento "carga x deslocamentos" das provas de carga ……......... 76

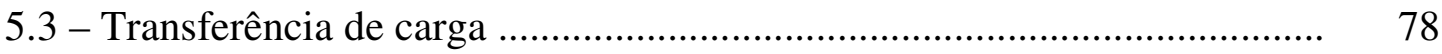

5.3.1 - Tensões laterais $\mathrm{x}$ deslocamentos ................................................. 87

5.3.2 - Resistência de ponta $\mathrm{x}$ deslocamentos ............................................... 91

CAPÍTULO 6 - ANÁLISE DOS RESULTADOS ........................................... 94

6.1 - Carga última …………………….................................................. 94

6.2 - Análise da evolução da carga de ponta das estacas ..................................... 96

6.3 - Análise das variações $\mathrm{Q}_{\mathrm{p}} / \mathrm{Q}_{0}$ e $\mathrm{Q}_{\mathrm{s}} / \mathrm{Q}_{\mathrm{p}}$ com o carregamento ....................... 98

6.4 - Análise da variação da resistência lateral com a profundidade ................. 103

6.5 - Análise da variação das resistências lateral e de ponta com os 104 deslocamentos da estaca

6.6 - Análise do fator de mobilização $\left(\mathrm{m}_{\mathrm{s}}\right)$....................................................... 108

6.7 - Análise dos recalques ....................................................................... 112

6.8 - Análise das cargas residuais .................................................................. 114 
6.9 - Separação das cargas lateral e de ponta .................................................... 115

6.10 - Equivalência de chuva ao processo de inundação adotado ...................... 118

CAPÍTULO 7 - CONCLUSÕES ........................................................... 119

CAPÍTULO 8 - SUGESTÕES PARA CONTINUAÇÃO DAS PESQUISAS 126

REFERÊNCIAS BIBLIOGRÁFICAS ........................................................ 128

ANEXO - CRONOGRAMA DE ATIVIDADES DE CAMPO ......................... 141 


\section{LISTA DE FIGURAS}

Figura 1.1 Algumas regiões do estado de São Paulo com potencialidade de ocorrer perfis similares à área de São Carlos 3

Figura 2.1 Variação do teor de umidade e do grau de saturação com a profundidade (NADELO \&VIDELA,1975b) .10

Figura 2.2 Curvas para estimativa de recalques em estacas escavadas segundo POULOS (1989) .19

Figura 2.3 Variação do atrito lateral com a profundidade para diversos níveis de carregamento (FONTOURA, 1982) 21

Figura 2.4 Curvas típicas de distribuição de $\mathrm{f}_{\mathrm{s}}$ (VESIC, 1970b, apud SANTOS JR. (1988) .22

Figura 2.5 Relação “tensão lateral x deslocamentos" segundo FONTOURA (1982) .23

Figura 2.6 Relação “tensão lateral x deslocamentos” segundo CLYLE \& SULAIMAN (1967) .23

Figura 2.7 Relação “tensão lateral x deslocamentos” segundo REESE et al. (1976) ..23 Figura 2.8 Carga admissível de estacas segundo a NBR 6121 (ALONSO, 1991) .......30

Figura 2.9 Curvas de transferência de carga do primeiro e segundo carregamento (MASSAD, 1991a) .34

Curva 2.10 Mobilização da resistência lateral unitária em função dos deslocamentos e leis de CAMBEFORT (MASSAD, 1991a) ............................................................35

Figura 3.1 Plano de implantação do campo experimental da USP - São Carlos .......42

Figura 4.1 Seção típica (longitudinal) de uma estaca, com a localização dos pontos instrumentados .......................................................................................5

Figura 4.2 Afundamentos das estacas após as 4 primeiras provas de carga ...............53

Figura 4.3 Cavas experimentais para estudos preliminares do processo de inundação

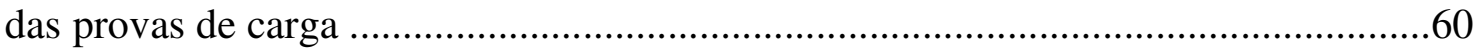

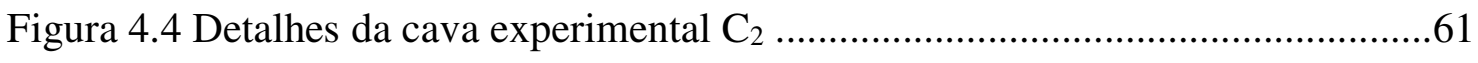

Figura 4.5 Resultados das observações sobre a inundação da estaca $\mathrm{E}_{2}$...................63

Figura 4.6 vazão diária ingressante nas cavas das estacas de prova ........................64 
Figura 4.7 Curvas de enchimento da cava $\mathrm{C}_{2}$ .65

Figura 4.8 Curvas de esvaziamento da cava experimental $\mathrm{C}_{2}$ .66

Figura 4.9 Variação da altura da lâmina d'água da cava experimental $\mathrm{C}_{2}$ durante o esvaziamento . .66

Figura 4.10 Comparação entre umidades naturais obtidas por meio de amostras indeformadas e tradagem manual e efeito da migração da água para paredes do furo.70 Figura 4.11 Curvas "recalque x $\log$ t" correspondentes aos estágios do colapso inicial das estacas $\mathrm{E}_{2}$ e $\mathrm{E}_{3}$ .72

Figura 4.12 Fenômeno da diminuição de recalques com o tempo e do aumento de cargas durante a inundação . .73

Figura 4.13 Variação diária das temperaturas do ar e da água utilizada nas provas de carga . .73

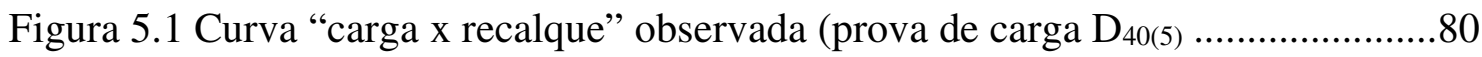

Figura 5.2 Curva "carga x recalque observada (prova de carga $\mathrm{D}_{50(5)} \ldots \ldots \ldots \ldots . . . . . . . . . . . . . . .81$

Figura 5.3 Curva "carga x recalque" observada (prova de carga $\mathrm{D}_{50(6)} \ldots \ldots \ldots . . . . . . . . . . . . . . . .82$

Figura 5.4 Comparação entre as curvas "carga x recalque" das provas de carga $\mathrm{D}_{40(5)} \mathrm{e}$

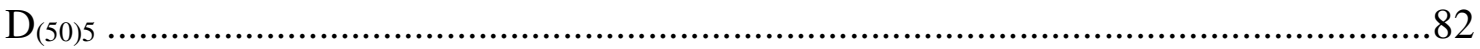

Figura 5.5 Prova de carga $\mathrm{D}_{50(6)}$ mostrando a diferença entre os recalques imediatos e

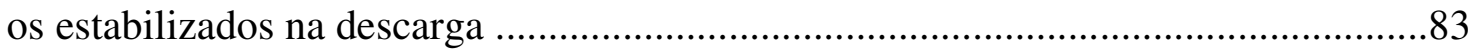

Figura 5.6 Comparação entre leituras manométricas e de células de carga .................83

Figura 5.7 Variações “carga x deformações” $\left(\mathrm{D}_{50(6)}\right)$.................................................85

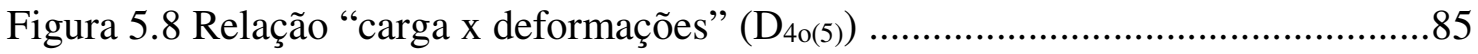

Figura 5.9 Relação “carga x deformações” $\left(\mathrm{D}_{50(5)}\right)$....................................................86

Figura 5.10 Curvas de transferência de carga $\left(\mathrm{D}_{40(5)}\right)$.................................................8

Figura 5.11 Curvas de transferência de carga $\left(\mathrm{D}_{50(5)}\right)$...............................................8

Figura 5.12 Curvas de transferência de carga $\left(\mathrm{D}_{50(6)}\right)$...............................................8

Figura 5.13 Variação de $\mathrm{f}_{\mathrm{s}} \mathrm{com}$ a profundidade $\left(\mathrm{D}_{40(5)}\right)$.............................................92

Figura 5.14 Variação de $\mathrm{f}_{\mathrm{s}}$ com a profundidade $\left(\mathrm{D}_{50(5)}\right)$..............................................93

Figura 5.15 Variação de $f_{s}$ com a profundidade $\left(D_{50(6)}\right)$............................................ 93

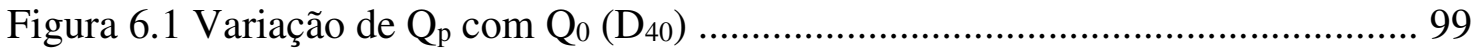

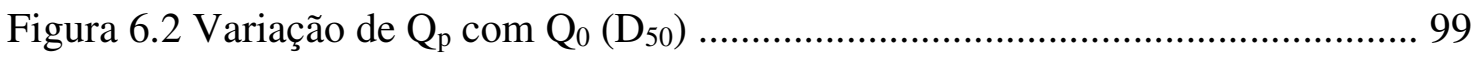


Figura 6.3 Variação de $\mathrm{Q}_{\mathrm{p}} / \mathrm{Q}_{0}$ com $\mathrm{Q}_{0}$

Figura 6.4 Variação de $\mathrm{Q}_{s} / \mathrm{Q}_{\mathrm{p}}$ com $\mathrm{Q}_{0}$ 102

Figura 6.5 Variação das tensões laterais com os deslocamentos, para cada nível instrumentado $\left(\mathrm{D}_{40(5)}\right)$ 105

Figura 6.6 Variação das tensões laterais com os deslocamentos, para cada nível instrumentado (D $\left.\mathrm{D}_{50(5)}\right)$ 105

Figura 6.7 Variação das tensões laterais com os deslocamentos para cada nível instrumentado $\left(\mathrm{D}_{50(6)}\right)$ 105

Figura 6.8 Variação da resistência unitária de ponta com os deslocamentos para as 3 provas de carga ..... 107

Figura 6.9 Variação de $\mathrm{m}_{\mathrm{s}}$ com a profundidade $\left(\mathrm{D}_{40(5)}\right)$..........................................110

Figura 6.10 Variação de $\mathrm{m}_{\mathrm{s}}$ com a profundidade $\left(\mathrm{D}_{50(5)}\right)$.........................................110

Figura 6.11 Variação de $\mathrm{m}_{\mathrm{s}} \mathrm{com}$ a profundidade $\left(\mathrm{D}_{50(6)}\right)$..........................................111

Figura 6.12 Relação entre recalques e diâmetros para as estacas ensaiadas, com e sem inundação 113

Figura 6.13 Carga aprisionada ao final do descarregamento $\left(\mathrm{D}_{50(6)}\right)$........................115

Figura 6.14 Separação das cargas lateral e de ponta $\left(\mathrm{D}_{40(5)}\right)$......................................117

Figura 6.15 Separação das cargas lateral e de ponta $\left(\mathrm{D}_{50(5)}\right)$....................................117

Figura 8.1 Ilustração da possibilidade de uma pesquisa ............................................127 


\section{TABELAS}

Tabela 2.1 Movimentos necessários para mobilização da resistência de ponta ........ 25

Tabela 2.2 Movimentos necessários para mobilização da resistência lateral ............ 26

Tabela 3.1 Caracterização do solo do campo experimental da USP - São Carlos ..... 45

Tabela 3.2 Resultados dos ensaios de penetração do campo experimental ................46

Tabela 4.1 Evolução das cargas últimas das estacas $\mathrm{E}_{1}, \mathrm{E}_{2}$ e $\mathrm{E}_{3}$.............................53

Tabela 4.2 Valores dos módulos de Young das estacas do campo experimental ........54

Tabela 4.3 Estimativa do volume de água necessário para saturar uma coluna de solo

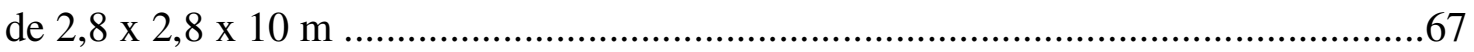

Tabela 4.4 Variação do pH da água de inundação ..................................................68

Tabela 5.1 Sequência da realização das provas de carga …......................................74

Tabela 5.2 Dados para traçado da curva "carga x recalque" $\left(\mathrm{D}_{40(5)}\right)$.........................76

Tabela 5.3 Dados para traçado da curva "carga x recalque" ( $\left.\mathrm{D}_{50(5)}\right)$..........................77

Tabela 5.4 Dados para traçado da curva "carga x recalque" $\left(\mathrm{D}_{50(6)}\right)$..........................77

Tabela 5.5 Valores das seções homogeneizadas das estacas ..................................79

Tabela 5.6 Deformações e cargas para as diversas seções instrumentadas $\left(\mathrm{D}_{50(6)}\right) \ldots . .84$

Tabela 5.7 Deformações e cargas para as diversas seções instrumentadas $\left(\mathrm{D}_{40(5)}\right)$.....84

Tabela 5.8 Deformações e cargas para as diversas seções instrumentadas $\left(\mathrm{D}_{50(6)}\right)$.....84

Tabela 5.9 Cálculo de Q a partir dos dados de transferência de carga $\left(\mathrm{D}_{40(5)}\right)$............90

Tabela 5.10 Tensões laterais e deslocamentos, por trechos $\left(\mathrm{D}_{40(5)}\right)$..........................90

Tabela 5.11 Tensões laterais e deslocamentos, por trechos $\left(\mathrm{D}_{50(5)}\right)$.........................91

Tabela 5.12 Tensões laterais e deslocamentos, por trechos $\left(\mathrm{D}_{50(6)}\right)$..........................91

Tabela 5.13 Valores de "resistência unitária de ponta x deslocamentos" .................92

Tabela 6.1 Resistência de ponta das diversas provas de carga $\left(\mathrm{D}_{40}\right)$........................97

Tabela 6.2 Resistência de ponta das diversas provas de carga $\left(\mathrm{D}_{50}\right)$........................97

Tabela 6.3 Variação de $\mathrm{Q}_{\mathrm{s}} / \mathrm{Q}_{\mathrm{p}}$ e $\mathrm{Q}_{\mathrm{p}} / \mathrm{Q}_{0}$ com o carregamento $\left(\mathrm{D}_{40(5)}\right)$........................100

Tabela 6.4 Variação de $\mathrm{Q}_{\mathrm{s}} / \mathrm{Q}_{\mathrm{p}}$ e $\mathrm{Q}_{\mathrm{p}} / \mathrm{Q}_{0}$ com o carregamento $\left(\mathrm{D}_{50(5)}\right)$........................100 
Tabela 6.5 Variação de $\mathrm{Q}_{\mathrm{s}} / \mathrm{Q}_{\mathrm{p}}$ e $\mathrm{Q}_{\mathrm{p}} / \mathrm{Q}_{0}$ com o carregamento ( $\left.\mathrm{D}_{50(6)}\right)$.........................100

Tabela 6.6 Variação de $\mathrm{m}_{\mathrm{s}}$ com a profundidade $\left(\mathrm{D}_{50(6)}\right)$........................................108

Tabela 6.7 Variação de $\mathrm{m}_{\mathrm{s}}$ com a profundidade (D40(5)) .......................................109

Tabela 6.8 Variação de $\mathrm{m}_{\mathrm{s}}$ com a profundidade $\left(\mathrm{D}_{50(5)}\right)$.......................................109

Tabela 6.9 Separação das cargas (lateral e de ponta) nas provas de carga ...............116 


\section{FOTOS}

Foto1 Trincas produzidas por recalque diferencial em residência na zona urbana de

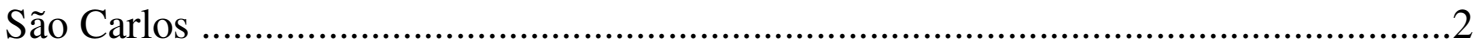

Foto 2 Vista do campo experimental da USP - São Carlos ..................................47

Foto 3 Montagem de uma prova de carga típica ........................................................56

Foto 4 Cava experimental $\mathrm{C}_{2}$ com detalhe do revestimento .................................59

Foto 5 Tentativa de cravação de um tubo plástico de 4" para introdução de sonda de nêutrons 


\section{LISTA DE SÍMBOLOS}

a - parâmetro de Van der Veen que define o formato da curva exponencial da função "carga $\mathrm{x}$ recalque"

$d_{i}$ - deformação (observada ou calculada) em uma seção genérica da estaca, a partir de leituras do indicador de deformações correspondentes ao nível instrumentado deste seção

$\mathrm{e}_{0}$ - índice de vazios do solo na sua condição natural

$\mathrm{f}_{\mathrm{p}}$ - reação unitária de ponta

$\mathrm{f}_{\mathrm{s}}$ - atrito lateral unitário

$\mathrm{h}$ - comprimento (ou altura) de uma estaca

$\mathrm{k}$ - rigidez do sistema "solo-estaca"

m - mobilização da reação de ponta no momento da ruptura do terreno de fundação

$\mathrm{m}_{\mathrm{s}}$ - fator de mobilização do atrito lateral

$\mathrm{p}$ - perímetro da estaca

$\mathrm{q}_{\mathrm{c}}$ - resistência de ponta do ensaio de cone (deepsounding)

$\mathrm{s}$ - resistência ao cisalhamento (envoltória de Mohr - Coulomb)

y - deslocamento da estaca em uma seção genérica, a qualquer profundidade " $\mathrm{z}$ "

$\mathrm{y}_{1}$ - deslocamento da ponta da estaca quando todo o atrito lateral é mobilizado ao longo da estaca (saturação do fuste)

$\mathrm{y}_{\mathrm{r}}$ - deslocamento residual registrado ao final de um carregamento anterior em uma sequência de provas de carga

Z - profundidade do solo ao longo da qual a estaca encontra-se instalada

$\mathrm{w}$ - teor de umidade

A - área da seção transversal da estaca

$A_{h, i}$ - área homogeneizada de concreto na seção "i”, considerando média ponderada entre o concreto efetivo e a armadura da seção

$\mathrm{A}_{1}$ - resistência lateral da luva de Begemann no ensaio de cone (deepsounding)

$A_{1 r}$ - atrito lateral da estaca, na ruptura

$A_{p}$ - área da ponta (ou base) da estaca 
$\mathrm{A}_{\mathrm{s}}$ - área lateral da estaca (ou do segmento de estaca)

B - $1^{\circ}$ parâmetro de Cambefort (1964)

D - diâmetro da estaca em uma seção qualquer

$\mathrm{D}_{\mathrm{b}}$ - diâmetro da base da estaca

E - módulo de deformação longitudinal de um material

$\mathrm{E}_{\mathrm{p}}$ - módulo de elasticidade longitudinal do material da estaca

$\mathrm{K}_{\mathrm{c}}$ - fator de sensibilidade do indicador de deformações

$\mathrm{L}$ - comprimento da estaca

N - número de golpes necessários para penetração do barrilete amostrador padrão (SPT) dos últimos $30 \mathrm{~cm}$ do comprimento total

$\mathrm{P}$ - carga genérica aplicada na cabeça de uma estaca durante prova de carga

$\mathrm{P}_{\mathrm{u}}$ - carga última (carga-limite ou capacidade de carga) de uma estaca de prova

Q - carga genérica aplicada a uma estaca em condições de trabalho ou de ensaio

$\mathrm{Q}_{\mathrm{i}}$ - carga calculada numa seção genérica “i”, em função das leituras de deformações na correspondente seção instrumentada

$\mathrm{Q}_{\mathrm{p}}$ - carga na base da estaca

$\mathrm{Q}_{\mathrm{s}}$ - parcela lateral da carga total resistida pela estaca

$\mathrm{Q}(\mathrm{z})$ - função "distribuição do carregamento x profundidade"

$\mathrm{Q}_{\mathrm{w}}$ - carga de trabalho da estaca

$\mathrm{Q}_{0}$ - carga aplicada na cabeça da estaca durante a realização de prova de carga

$\mathrm{Q}_{25}$ - carregamento da prova de carga que produz um recalque de $25 \mathrm{~mm}$

$\mathrm{R}-2^{\circ}$ parâmetro de Cambefort (1964)

$\mathrm{S}$ - perímetro da estaca

$S_{\mathrm{r}}$ - grau de saturação do solo

$\rho$ - deslocamento ou recalque do topo da estaca

$\rho$ - massa específica aparente do solo natural

$\rho_{\mathrm{d}}$ - massa específica aparente do solo seco

$\rho_{\mathrm{e}}$ - recalque elástico, recuperado ao final do descarregamento de uma prova de carga

$\rho_{p}$ - recalque calculado da ponta da estaca 
$\rho_{\mathrm{s}}$ - massa específica dos sólidos

$\rho_{\mathrm{t}}$ - recalque total considerando a soma das parcelas: recalque elástico e recalque plástico

$\rho_{0}$ - recalque observado no topo da estaca através dos extensômetros, durante a prova de carga

$\bar{\rho}$ - recalque admissível (neste trabalho considerou-se, arbitrariamente, igual a 25 $\mathrm{mm}$ )

$v$ - coeficiente de Poisson

$\sigma$ - tensão normal a uma superfície horizontal do solo em qualquer profundidade " $z$ "

$\tau(z)$ - função "transferência de carga" (ou distribuição do atrito lateral) ao longo da profundidade " $\mathrm{z}$ ". 


\section{CAPÍTULO 1 - INTRODUÇÃO}

Numerosas pequenas construções na cidade de São Carlos (SP) exibem fissuras típicas de recalques diferenciais de fundações, mormente nas regiões periféricas e em zonas onde estão concentradas construções mais antigas. São frequentes alguns danos bastante relevantes, extrapolando níveis de trincas e fendas, às vezes inviabilizando estética e estruturalmente a construção. Subsidência de pisos e passeios públicos são também notáveis, geralmente associados à infiltração de águas pluviais e ao rompimento de tubulações de esgotos sanitários.

SILVEIRA \& SILVEIRA (1958) afirmam: "há (em São Carlos) elevado número de casas "trincadas" que são, entretanto, generalizadamente admitidas sob a alegação de que não seria compensador, em face do valor das obras comuns, um melhor estudo do problema".

Ainda nos dias atuais, este quadro não precisa ser modificado (FOTO 1) e o caráter colapsível destes solos é o principal agente formador de tais danos.

A inquestionável vocação geotécnica da Escola de Engenharia de São Carlos - USP, cujo berço está ligado aos anos 50 com Victor de Mello e Alberto H. Teixeira, acumulou, ao longo de mais de três décadas, um respeitado acervo de informações geológico-geotécnicas do interior do Estado de São Paulo, em áreas de notável significado econômico.

Portanto, ao se estudar os solos de São Carlos, do ponto de vista de fundações, isto equivale a estender determinadas conclusões para algumas regiões similares (FIGURA 1.1).

Nos últimos anos o crescimento vertical tem sido a tônica da maioria das cidades de médio porte, acarretando um considerável aumento das cargas de trabalho. Justifica-se, assim, investigar as reais condições da capacidade de carga, a evolução dos recalques com o carregamento e os mecanismos de transferência de carga do sistema solo-estaca em fundações profundas. 


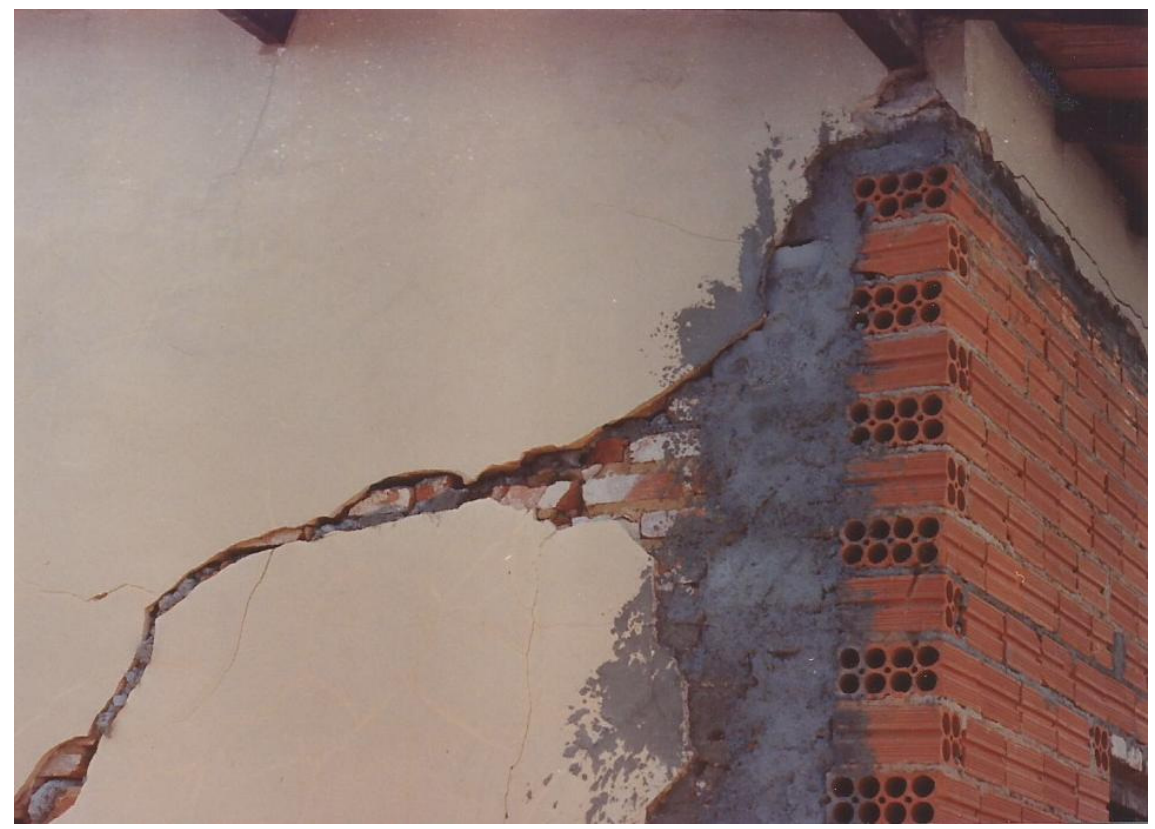

FOTO 1 - Construção na zona urbana de São Carlos exibindo sinais externos de danos severos em função de recalques diferenciais

Esta pesquisa está inserida em um estudo global implantado com esta finalidade; cabe-lhe determinar como as estacas escavadas se comportam em um solo colapsível sob inundação, complementando estudos precedentes sobre as mesmas estacas sob condições não inundadas, em carregamento lento (MANTILLA, 1993) e rápido (SACILLOTO, 1993).

O tipo de estaca, objeto deste estudo, é a escavada mecanicamente e concretada "in loco". Esta modalidade vem encontrando crescente aceitação da parte de projetistas e construtores em função de vantagens como: a) baixo custo; b) ausência de vibração quando de sua instalação; c) flexibilização de seu comprimento, possibilitando ainda visualizar o subsolo atravessado.

Por tudo isto, as duas últimas décadas assistiram a um rápido desenvolvimento de métodos construtivos, porém não acompanhado por processos de cálculo confiáveis. Certos conhecimentos clássicos, implícitos nas teorias de capacidade de carga e de deformabilidade de estacas cravadas, escapam de seu domínio (a menos que algumas idealizações sejam feitas, principalmente sob o ponto de vista do verdadeiro estado de tensões após a sua instalação. Caminha-se, portanto, no sentido de um amplo favorecimento de formulações empíricas. 


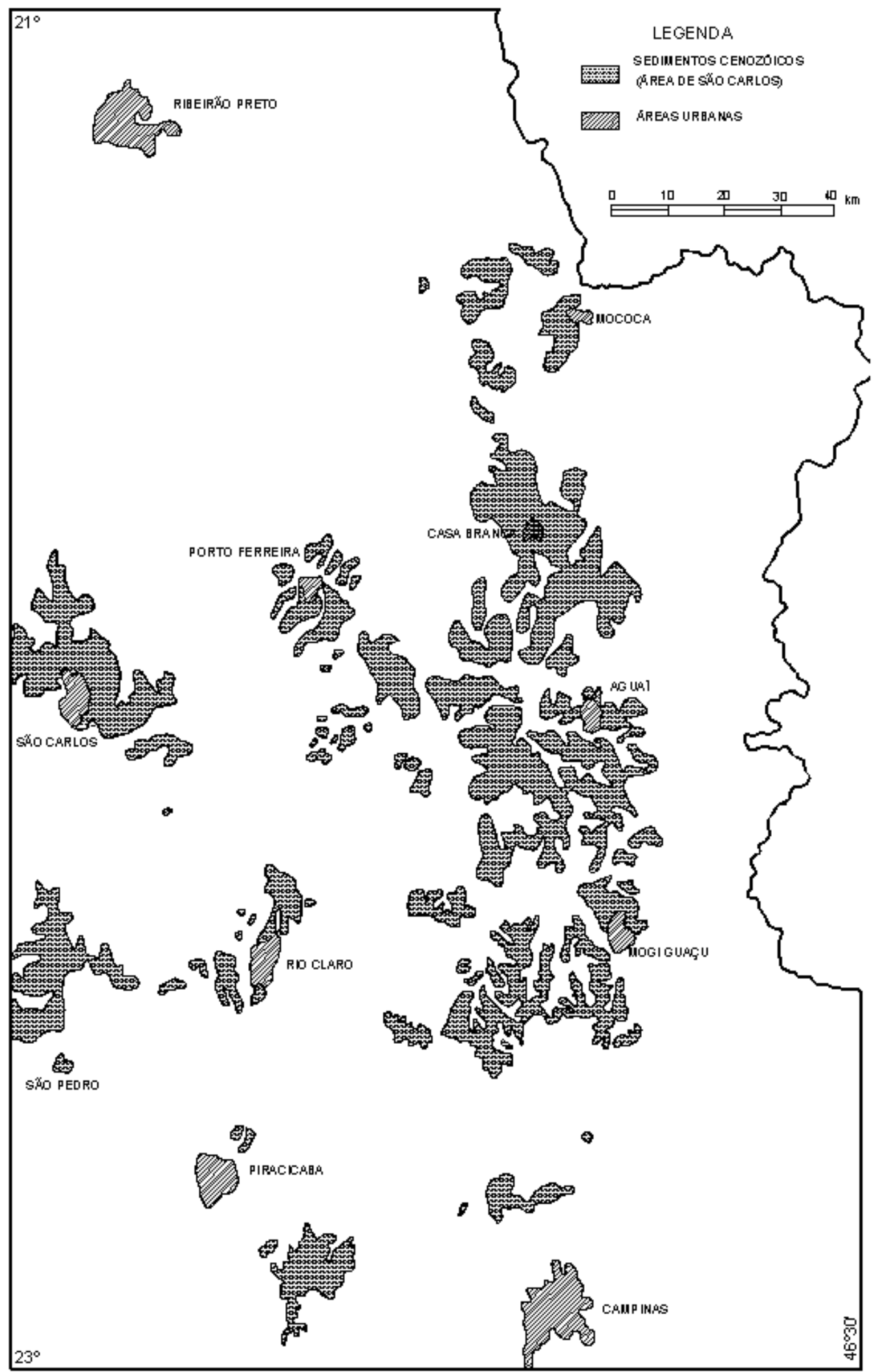

FIGURA 1.1 - Algumas regiões do estado de São Paulo com potencialidade de ocorrer perfis similares à área de São Carlos (GIACHETI, 1991) 
Assim, torna-se justificável enfatizar as pesquisas regionais, onde processos construtivos e condições peculiares de subsolo sejam razoavelmente similares.

Esta é uma pesquisa comparada. Seus objetivos serão claramente definidos em (4.1.1). Estabelecem-se como premissas:

1) Qual a redução da capacidade de carga do terreno de fundação nas condições de solo inundado?

2) Qual a influência da inundação na interação entre as resistências, lateral e de ponta?

Para este fim, dispõe-se de informações preliminares, principalmente MANTILLA (1993). Tais dados serão tomados como parâmetros-guia para efeito de comparação. 


\section{CAPÍTULO 2 - REVISÃO BIBLIOGRÁFICA}

A fim de atender algumas necessidades de cálculo e, principalmente, respaldar discussões, análises e conclusões, serão levantados os resultados, conceitos e proposições disponíveis. Na medida do possível, as pesquisas locais e regionais serão valorizadas.

\section{1 - COLAPSIBILIDADE: MECANISMOS DE FORMAÇÃO}

Entende-se por solo colapsível aquele de estrutura metaestável, com baixo grau de saturação e que, por efeito de molhagem e/ou de carregamento (sobrecarga ou peso próprio) é conduzido a um radical rearranjo de partículas, acarretando sensível redução de volume.

Os pré-requisitos fundamentais para a instalação do colapso são:

1) Índice de vazios elevado

2) Umidade natural inferior à umidade de saturação

3) Resistência provisória produzida por:

a. Agentes cimentantes

b. Tensões capilares capazes de serem desenvolvidas para teores de umidade in situ inferiores ao limite de contração, gerando pressões neutras negativas (DUDLEY, 1970).

Tem sido generalizadamente empregada a expressão "colapso por saturação", contradizendo conclusões já bem estabelecidas no histórico da descrição de solos colapsíveis. MOORE (apud DUDLEY, 1970) reconhece a existência da "saturação ótima”, inferior a 100\%, para a qual se dá o colapso. Informa ainda que a perda de resistência é iniciada quando o grau de saturação cresce além de 50\% a 60\%.

O postulado clássico de DUDLEY (1970), segundo o qual as ligações cimentantes têm origem essencialmente nas tensões capilares, tem precedentes: HOLTZ \& HILF (1961) admitem que o colapso proveniente da inundação do solo 
resulta em destruição das pressões capilares para um grau de saturação vizinho a $100 \%$, onde o círculo de MOHR se desloca para a esquerda e intercepta a envoltória de resistência do solo.

Também BURLAND (1965) postula, nesta mesma linha de raciocínio, que o decréscimo das pressões negativas existentes nos contatos pontuais entre as partículas durante a inundação origina escorregamento e distorções irrecuperáveis dos sólidos, com a consequente diminuição de volume.

Há um generalizado pressuposto, equivocado ademais, segundo o qual os solos naturais, e somente eles, são potencialmente colapsíveis. A aceitação deste princípio deve ser combatida, sob o risco de se tentar impor a compactação como uma solução universal para as fundações problemáticas. Até um passado bem recente, era mais ou menos consensual que o colapso é um fenômeno primordialmente sensível à mudança no comportamento "tensão x deformação" do solo e que só pode ocorrer à custa da aplicação de uma certa tensão, inferior à de ruptura.

Sendo assim, a tendência de se produzir colapso em uma massa de solo após sujeitá-lo a um determinado nível de pressões, poderia ser simplesmente combatido atuando-se na condição de "ser" do solo, pela introdução de novas características oriundas da compactação. Esta distorção conceitual passa por novas revisões, sob enfoques mais modernos e discutidos à luz dos conhecimentos sobre solos parcialmente saturados, embora existam evidências de percepção desta questão desde a constatação de HOLTZ (1948) da existência de colapso em aterros, posteriormente confirmado por BARDEN et al. (1973).

Nas raízes da abordagem teórica desta conceituação encontra-se o trabalho de FOSS (1973), onde se constata a existência de uma relação linear decrescente entre a porcentagem de colapso e a densidade seca para solos compactados no ramo seco.

Simultaneamente, ESCARIO \& SAEZ (1973) demonstram, experimentalmente, que a variação de volume durante o colapso de solos não saturados está relacionada com a variação da matriz de sucção, enquanto se controlam as pressões do ar e da água. 
A conclusão de FOSS (1973) é confirmada por POPESCU (1986) e parcialmente referendada por BENDELFADHEL (1989), que encontra uma relação parabólica para teores de umidade muito baixos.

Dentro deste novo enfoque devem ser destacados os trabalhos de FREDLUND (1976; 1979), FREDLUND \& MORGENSTERN (1976; 1977), culminando com um trabalho mais recente de TADEPALLI \& FREDLUND (1991). Neste último são feitos ensaios edométricos em amostras inundadas antes, durante e após os ensaios com dois objetivos: 1) demonstrar a unicidade da relação envolvendo a matriz e sucção e a variação de volume total durante o colapso; 2) demonstrar a validade da teoria de adensamento unidirecional proposta para os solos não saturados.

Não obstante a persistente tendência de se averiguar a colapsibilidade em solos compactados (COX, 1978; CLAYTON, 1980) ser útil para justificar a ocorrência de colapso em estacas sucessivamente ensaiadas, é ainda a abordagem clássica que mais se aproxima dos fins práticos direcionados aos estudos sobre fundações. Apesar desta ressalva, deve-se levar em consideração estes novos conhecimentos, pelo menos como uma perspectiva interessante sobre o assunto.

No caso concreto dos solos de São Carlos, a identificação mais remota da colapsibilidade pode ser associada aos relatórios 2269 e 2181 do IPT (1954), que forneceram elementos de projeto para edificações no campus da USP - São Carlos. GRIM \&GRADLEY (1963), estudando a mineralogia de uma amostra local, dão subsídios para esta evidência. Trabalhos acadêmicos e ensaios de rotina em laboratório acumularam-se durante os anos seguintes, sem, contudo, merecer qualquer divulgação formal para a comunidade técnica. $\mathrm{O}$ marco pioneiro, que pode ser tomado como um estudo definitivo nesta área, deve ser atribuído a VILAR (1979). Embora a pesquisa tenha utilizado amostras de pequena profundidade (inferiores a $2 \mathrm{~m}$ ), os resultados e as conclusões são plenamente favoráveis à sua adoção, tendo sido realizados 72 ensaios de adensamento em solos provenientes de três áreas distintas, sendo uma delas próxima ao local onde se encontra o atual campo experimental de fundações da USP - São Carlos. 
Os critérios adotados por VILAR (1979) para identificação dos solos colapsíveis de São Carlos são os clássicos, que utilizam índices físicos ou propriedades índices, baseados no conceito geral de saturação do solo para um teor de umidade correspondente ao limite de liquidez (DENISOV, 1951; PRIKLONSKIJ, 1952; FEDA, 1966; GIBBS \& BARA, 1967) e a metodologia para quantificação dos recalques por colapso provocados por inundação do solo foi baseada em ensaios edométricos (JENNINGS \& KNIGHT, 1957; REGINATTO \& FERRERO, 1973).

Para efeito de discussão é sugestivo questionar até que ponto a quantificação de recalques por colapso pelo processo do ensaio edométrico é válida. Com efeito, grande parte dos deslocamentos iniciais não mobilizam nenhuma reação de ponta no caso de estacas escavadas virgens. Haveria, deste modo, alguma reserva a ser imposta a este tipo de ensaio? Parece que sim, até mesmo para fundações rasas (JIMENEZ SALAS, 1987; HOUSTON et al., 1988).

NADEO \& VIDELA (1975a) discutem esta questão e afirmam que o grau de colapsibilidade dos ensaios edométricos é mais severo do que se passa nas estacas. Assim, qualquer modelo de estimativa de recalque que envolva variação do índice de vazios deve ser substituído por outros que se baseiam em parâmetros de resistência, sendo sugeridos ensaios drenados como representativos das propriedades mecânicas dos solos colapsíveis inundados.

Um adequado respaldo para esta ideia consta da conclusão de KANE (apud NUÑEZ, 1975), segundo a qual o mecanismo de colapso dos solos sob compressão confinada é um fenômeno puro de cisalhamento. Houve a constatação, através de ensaios de placa, de uma ruptura típica de punção, sem deformações laterais, o que possibilita a tradução deste fenômeno por uma quantificação da perda de resistência.

Para o caso específico de estacas, é também válido questionar a real utilidade do ensaio edométrico, contrapondo-se a seguinte dúvida: a pressão que leva um determinado solo ao início do colapso é variável com a profundidade? SILVA (1990) argumenta a este respeito sem apresentar respostas. 
Igualmente defensável é o ponto de vista da existência de uma pressão-limite, a partir da qual os recalques não mais se processam por colapso, sendo completamente ineficiente a saturação para exercer qualquer efeito, quer seja na dissolução dos meniscos capilares, quer seja na destruição das ligações cimentantes (VARGAS, 1974; MILITITSKY, 1986).

Sob o aspecto dos solos colapsíveis de São Carlos registram-se ainda outras contribuições de interesse.

NOGUEIRA et al. (1985) analisam a influência da molhagem do solo na sua compressibilidade, utilizando um ensaio de placa. As conclusões apresentadas foram: 1) para pressões inferiores a $80 \mathrm{kPa}$ os recalques registrados na situação de solo inundado foram menores que os ocorridos na condição de solo natural (da ordem de $75 \%$ ); 2) para pressões superiores a $80 \mathrm{kPa}$ os recalques verificados durante a inundação alcançaram 50\% dos recalques totais durante o ensaio.

NEVES (1987) introduz um novo processo para investigar a colapsibilidade dos solos de São Carlos, trabalhando com amostras do sedimento cenozoico, também de pequenas profundidades. Análises com uso de microscópio eletrônico revelaram a natureza dos vínculos cimentantes, constituídos por partículas de silte e argila ou então por óxidos e hidróxidos de ferro. Foi também observado que a inundação produz um rearranjo estrutural e um bloqueio dos canalículos. Níveis de tensão superiores a $50 \mathrm{kPa}$ são bastante significativos nas reduções de volume (aumento do coeficiente de colapso).

\section{2 - MODOS DE INUNDAÇÃO DOS SOLOS COLAPSÍVEIS}

Um dos relatos pioneiros sobre sistemas de inundação para provas de carga procede de DONALDSON (1967), tendo sido utilizados quatro furos com diâmetros de $10 \mathrm{~cm}$, diametralmente opostos em relação às estacas e distantes de $90 \mathrm{~cm}$ dos fustes, sendo alimentados por 39 dias seguidos. A eficiência do sistema não é comentada. 
NADEO \& VIDELA (1975b) comparam a eficiência de dois processos distintos, concluindo que o uso de tubos perfurados não produz resultados tão bons quanto os conseguidos pela simples alimentação, permanente, de uma cava. Nas cavas, a taxa de infiltração verificada para o caso estudado é próxima dos 17 litros/hora. Para as três estacas de prova são apresentados na FIGURA 2.1a os teores de umidade do solo em seu estado natural e após o período de inundação, obtidos através de amostras coletadas de furos feitos antes e após a inundação. Na FIGURA 2.1b são apresentados os graus de saturação alcançados pelo solo em diferentes níveis, calculados para cada estaca. A curva A, representativa da solução de inundação somente pelo fundo da cava, mostra que a saturação total pode ser alcançada até os 4 primeiros metros, provavelmente devido à elevada porosidade do solo superficial. As demais correspondem aos casos de inundação somente por meio de tubos perfurados e mostram uma melhor distribuição da saturação ao longo do perfil, ficando porém, na média, em torno do grau de saturação de $80 \%$.
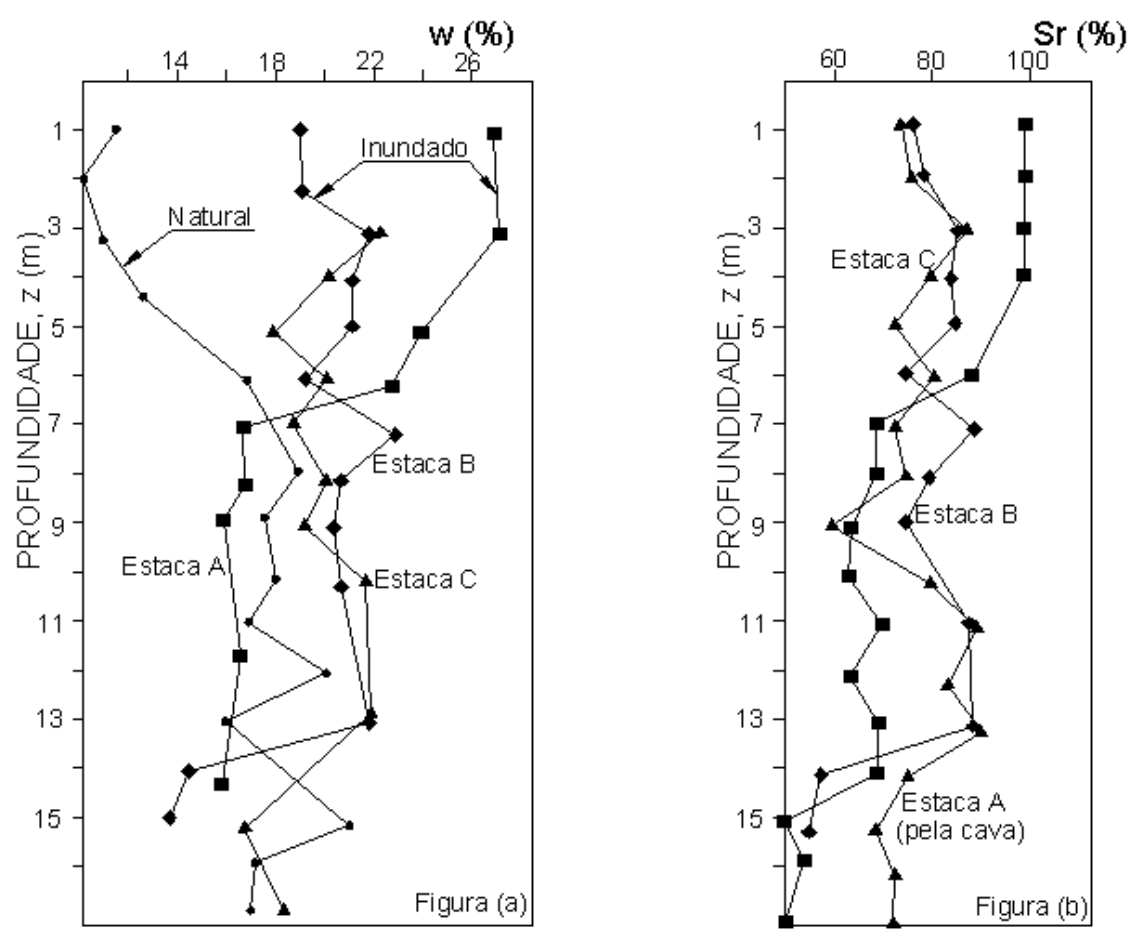

FIGURA 2.1 - a) variação do teor de umidade com a profundidade, em condições de solo natural e inundado; b) variação do grau de saturação com a profundidade para as três estacas de prova (NADEO \& VIDELA, 1975b) 
BARA (1975) também compara os efeitos de inundação por meio de irrigação e por meio de furos, concluindo que este último processo é rápido e eficiente.

LOBO (1991), descrevendo a experiência em solo colapsível em Bauru (SP) utiliza cava quadrada de $1,3 \mathrm{~m}$ de lado e $0,4 \mathrm{~m}$ de profundidade, associada a 4 furos com $10 \mathrm{~cm}$ de diâmetro, situados nos cantos, mas não informa o tempo de inundação e nem relata a eficiência dos resultados.

Situação bem similar é descrita por CARVALHO \& SOUZA (1990), em experiência feita para fundações rasas e estacas tipo broca em Ilha Solteira (SP).

HOUSTON et al. (1988) descrevem a inundação do solo para ensaios de placa utilizando uma área bem maior que a cava de fundação, onde colocaram sucessivas lâminas d'água sobre uma superfície de contorno, adjacente à fundação, limitada por pequenas bermas.

AGNELLI (1992), executando diversas provas de carga diretas no campus da UNESP em Bauru (SP) descreve um processo de inundação concebido através da simples alimentação, sob fluxo controlado de 200 litros/hora, de água potável da rede pública, capaz de manter constante uma lâmina d'água de cerca de $4 \mathrm{~cm}$. É difícil de ser interpretada a taxa de consumo, desde que considerações da evolução do grau de saturação, em vários pontos (em planta e em profundidade), além da influência dos coeficientes de permeabilidade horizontal e vertical, deveriam estar disponíveis para esta finalidade.

MELLIOS (1985) descreve a inundação de estacas tipo broca em Jupiá (SP), mas o nível de detalhes do relato é insuficiente. É informado apenas que ela é feita "através de alimentação com água a partir da superfície". Similar experiência é reportada por MONTEIRO (1985).

\section{3 - INFLUÊNCIA DO AUMENTO DO TEOR DE UMIDADE DO SOLO DE FUNDAÇÃO}

É fato incontestável que o incremento da umidade produz certa degradação na resistência ao cisalhamento dos solos. 
Isto ganha importância no caso específico dos solos inundados, já que, a partir de uma umidade natural, há uma sensível evolução deste estado, de modo a interferir nos parâmetros de resistência, com óbvios prejuízos para a capacidade de carga das fundações profundas.

Algumas contribuições a este respeito, embora originalmente estudadas para solos tipicamente argilosos e sem nenhuma especificidade para as fundações profundas, podem ser levadas em conta. Contribuição de vulto é a proporcionada por SKEMPTON (1959, p.65) ao apresentar um gráfico da variação da resistência ao cisalhamento com a umidade para as argilas de Londres, com base em grande quantidade de dados.

MOHAN \& CHANDRA (1961), para argilas da Índia, também concluem que a adesão diminui com o aumento do teor de umidade, tendo havido a preocupação de medir a variação, em um mesmo nível de profundidade, em diferentes distâncias do fuste. Foi constatada a tendência de migração de água para a interface solo-estaca, com teores de umidade de $2 \%$ a $3 \%$ superiores aos que ocorrem a distâncias de aproximadamente $5 \mathrm{~cm}$ do fuste. Os autores não informam o procedimento adotado para a medição destes teores de umidade.

\section{4 - CAPACIDADE DE CARGA DE ESTACAS ESCAVADAS}

\subsection{1 - Revisão do problema}

A capacidade de carga, carga última (ou carga-limite, como querem uns) de uma estaca, pode ser definida, preliminarmente, como aquela que produz deslocamentos incompatíveis com os que a estrutura que suporta pode tolerar.

Considerando-se que as estacas escavadas são uma inovação construtiva relativamente recente, não é de se estranhar que os métodos teóricos de previsão sejam raros e pouco divulgados. Predominam aqueles de base empírica ou semi-empírica, sempre produzindo algum tipo de controvérsia.

A polêmica em torno deste tema ainda é grande, não obstante os anos 80 tenham proporcionado consideráveis avanços nesta área. Este progresso é derivado, 
principalmente, de pesquisas empreendidas por Universidades. Geralmente, elas envolvem provas de carga em estacas instrumentadas. Além disso, a ocorrência de eventos especiais despertou na comunidade especializada proveitosas discussões a respeito.

Na seção de debates do $1^{\circ}$ Seminário de Fundações Especiais (SEFE I, São Paulo, 1985) há esta declaração textual: "a primeira obra que fizemos, cerca de 8 anos atrás, o pavor tomou conta dos projetistas, dada a completa ausência de informações confiáveis sobre como calcular a capacidade de carga de uma estaca escavada".

De fato, o assunto era ainda muito nebuloso à época da referida construção e a atitude refletia a pouca experiência brasileira.

A revisão bibliográfica sobre este tema indica uns poucos métodos: WARD \& GREEN (1952); SKEMPTON (1959; REESE et al. (1976); SEARLE (1979); GRANDE \& NORDAL (1980) e AIJ (1976, apud HORIUCHI, 1985) propõem formulações de caráter semi-empírico ou teórico, de pequena comprovação e/ou, mais geralmente, desconhecidas em nossos meios técnicos.

Soluções que talvez pudessem ser examinadas com mais atenção, tais como as sugestões de MEYERHOF (1976; 1982; 1983) são, contudo, de aplicação complexa, pois misturam fórmulas de estacas cravadas e escavadas, obtidas em função de ensaios de cone (raros entre nós) e envolvem, no caso de areias, a sua densidade relativa. Sendo esta normalmente obtida através de correlações, surge aqui um elemento de embaraço, pois as condições brasileiras são muito variáveis e as correlações até agora produzidas são em número muito reduzido.

No caso de estacas escavadas de grande diâmetro parece interessante testar as sugestões de CHANG \& BROMS (1991), por causa de algumas similaridades das condições de Cingapura (onde foram estudadas) com as nossas, isto é, em solos de formação tropical e onde também prevalece o uso do SPT. 
Uma expressão teórica é vista em POULOS \& DAVIS (1980), cujo aspecto algo sofisticado não esconde nenhuma novidade, serve para estimar a carga última de uma estaca escavada isolada, sujeita a carregamento vertical em areias.

\subsection{2 - A prática brasileira}

A experiência brasileira está praticamente calcada em algumas fórmulas clássicas em nossos meios técnicos. São exemplos as de AOKI \& VELLOSO (1975), DÉCOURT \& QUARESMA (1978), VELLOSO (1981) e PHILIPPONNAT (1979). Deve ser observado que, exceto o método de DÉCOURT \& QUARESMA (1978), a validade destas fórmulas exige a utilização de resultados do CPT ou, na sua ausência, de correlações do tipo $\mathrm{q}_{\mathrm{c}}=\mathrm{KN}$, obtidas para solos regionais, como as produzidas por ALBIERO (1990) ou MENEZES (1990). Além disso, a calibração dos parâmetros $F_{1}$ e $\mathrm{F}_{2}$ de AOKI \& VELLOSO (1975) é necessária, do modo como o fizeram MANTILLA (1993) e SACILOTTO (1993) para as condições de São Carlos, com base nos resultados penetrométricos do campo experimental da USP - São Carlos.

\subsection{3 - Capacidade de carga de estacas escavadas em solos colapsíveis inundados}

Não se encontram registros acessíveis de fórmulas específicas para este caso.

Tudo leva a crer que a única dificuldade estaria em se conhecer a verdadeira distribuição da resistência ao cisalhamento do solo ao longo da profundidade da estaca, em condições de umidade diferentes da natural, porém muito dificilmente mensuráveis após um certo período de inundação.

Portanto, uma revisão a este respeito tem por finalidade tão somente identificar algumas experiências similares que descrevem a "perda" da capacidade de suporte da fundação após a inundação, de modo a se obter comparações para efeito de análise. Além disso, estes relatos são instrutivos no sentido de previsão do fator de segurança mais conveniente a ser aplicado nos projetos de fundação de estacas escavadas em solos colapsíveis, quando estiver prevista inundação potencial. 
HOLTZ \& GIBBS (1953) analisaram a capacidade de carga e os recalques de várias estacas instaladas em solos colapsíveis loéssicos inundados, apresentando então algumas conclusões:

1) As capacidades de carga são diferentes quando os processos de instalação das estacas são diferentes, não recomendando a sua execução em furos escavados a seco, por constatarem que tais procedimentos levam a grandes recalques após a inundação do solo

2) As estacas de ponta, apoiadas em camada de solo não colapsível, apresentaram boa capacidade de carga, mesmo após a inundação; se sujeitas apenas a carregamento axial, sua capacidade de carga revelou-se dependente do tipo de instalação

3) A prévia inundação do solo faz com que as estacas apresentem melhor comportamento sob carga.

MONTEIRO (1985) e MELLIOS (1985) apresentam resultados de provas de carga sobre estacas broca de pequeno comprimento $(3,5 \mathrm{~m}$ a 5,0 $\mathrm{m})$ na região noroeste do estado de São Paulo, onde se constata a existência de solos colapsíveis com potencial de colapso de até $6 \%$ após a inundação das amostras de solo. Concluem que há redução da capacidade de carga em torno de $50 \%$ pelo efeito de inundação do solo.

CARVALHO \& SOUZA (1990) analisam resultados de provas de carga em 2 estacas escavadas em Ilha Solteira (SP), com $\mathrm{D}=0,25 \mathrm{~m}$ e $\mathrm{L}=6,0 \mathrm{~m}$, discretamente apiloadas, em solo colapsível inundado. Foi verificado que:

1) A inundação produziu colapso, mesmo para um nível de carregamento da ordem de um terço da carga última verificada através de ensaio prévio

2) O atrito lateral unitário, na umidade natural, era da ordem de $30 \mathrm{kPa}$

3) Uma redução da ordem de $70 \%$ na capacidade de carga das estacas foi constatada após a inundação.

LOBO et al. (1991b) analisam a influência da inundação sobre a carga última de estacas escavadas em Bauru (SP), tendo concluído que as perdas de carga variam 
de $35 \%$ a $43 \%$ (com média de 39\%). Neste trabalho é feita uma comparação com estacas apiloadas de pequeno diâmetro, havendo a conclusão de que a inundação sensibiliza mais as estacas escavadas em termos de perda de capacidade de suporte. Diversos métodos teóricos para previsão de carga última foram testados a partir dos resultados de provas de carga, apresentando resultados similares por causa da boa definição da curva "carga x recalque".

SILVA (1990) analisa a capacidade de carga de estacas escavadas curtas do tipo broca, de pequeno diâmetro, em solo colapsível e sujeito a inundação. Concluiu ter havido redução na capacidade de carga de $77 \%$ nos locais onde houve inundação do solo (durante 15 horas) e o pré-carregamento não levou o solo ao colapso (a carga última passou de $58 \mathrm{kN}$ para apenas $13 \mathrm{kN}$ ). Os resultados foram comparados com previsões de carga última feitas por um método teórico (POULOS \& DAVIS, 1980) e

por métodos empíricos (AOKI \& VELLOSO, 1975; DÉCOURT \& QUARESMA, 1978). O autor não informa o modo como os parâmetros de entrada do solo, nesta condição de inundação, foram obtidos.

A maior aptidão de uma estaca escavada em suportar carregamento sob menores deslocamentos quando o solo envolvente à estaca é previamente inundado é destacado no trabalho de NADEO \& VIDELA (1975a). Ainda neste trabalho apresentam resultados de provas de carga em estacas escavadas, reensaiadas, com comprimentos e diâmetros bastante próximos aos existentes no campo experimental da USP - São Carlos. Embora os dados não sejam bem explicitados, pode-se inferir que a redução na capacidade de carga varia entre $30 \%$ e $35 \%$ após a inundação do fuste e da ponta.

\section{5 - ANÁLISE DO COMPORTAMENTO DE ESTACAS}

\subsection{1 - Recalques: uma revisão sobre os métodos clássicos}

Historicamente, deve-se a RUDERMAN (1939) o método pioneiro que tratou os problemas de carga $\mathrm{x}$ recalque e de transferência de carga, utilizando a solução de MINDLIN (1936). A tentativa não foi bem sucedida. 
Métodos clássicos são frequentemente encontrados nos anos 60 (D’APPOLONIA \& ROMUALDI, 1963; 1964. 1965; THURMAN \& D’APPOLONIA, 1965), porém criticáveis pela excessiva idealização nas suas hipóteses. Entretanto, eles têm a vantagem de incluir também o cálculo simultâneo da distribuição de tensões no solo. O método de NAIR (1967) é muito útil para se obter as características de carga x recalque e de transferência de carga por método elástico.

Porém, é dentro da chamada análise não elástica que surgiram os métodos mais utilizados e que, ainda hoje, são adotados com bons resultados: REESE et al. (1955); SEED \& REESE (1957); MANSUR \& KAUFMAN (1958); D'APPOLONIA \& HRIBAR (1963); SEED \& REESE (1964); COYLE \& REESE (1966) e KOIZUMI \& ITO (1967). Entre os métodos clássicos podem ainda ser mencionados alguns empíricos, como se vê em MEYEERHOF (1959), válido para areias, e FOCHT (1967), válido para argilas.

De todos esses métodos destaca-se o de COYLE \& REESE (1966). O principal objetivo na definição dos próprios autores é a obtenção de uma família de curvas (uma para cada nível da estaca), relacionando os deslocamentos em abscissas com a relação "transferência de carga/resistência ao cisalhamento do solo" ao longo da profundidade. Esta relação, nas estacas instrumentadas, pode ser subentendida como o atrito lateral unitário calculado para cada trecho entre diferentes níveis instrumentados.

O método de COYLE \& REESE (1966) tem conclusões e corolários importantes. São exemplos:

1) A carga transferida da estaca para o solo, em qualquer profundidade, não é função apenas da resistência ao cisalhamento do solo, mas também do quanto a estaca se movimenta neste ponto

2) A transferência de carga não é uniforme ao longo da estaca; o máximo de transferência se dá para um ponto ligeiramente acima de seu ponto médio e as menores taxas de transferência são nas extremidades, sendo mínima na ponta 
REESE et al. (1969) sugerem que a tensão lateral máxima pode ser uma função do SPT e, para condições particulares de suas provas de carga apresentam o valor N/35 (tf/sqf), equivalente a N/324 (MPA) No si.

Uma nova tendência é desenvolvida com os métodos elásticos, sobretudo a partir dos anos 70, onde o solo é modelizado como um meio contínuo. Contribuições nesta linha são apresentadas por BUTTERFIELD \& BANERJEE (1971), BANERJEE (1978), BANERJEE \& DAVIS (1978) e POULOS \& DAVIS (1980).

Este último é, sem dúvida, um dos métodos mais difundidos em análise de comportamento de estacas. Sua base de cálculo pode ser acompanhada pelos trabalhos de POULOS \& DAVIS (1968), POULOS (1972) e POULOS (1979). Uma descrição bem detalhada deste e de outros métodos elásticos pode ser apreciada em SANTOS JR. (1988).

\subsection{2 - Estimativa de recalques em estacas isoladas}

O recalque (ou deslocamento) de uma estaca pode ser visto como a soma de três componentes mais importantes: 1) devido à compressão elástica da própria estaca; 2) devido à compressão do solo, em sua fase elástica; 3) devido à deformação irreversível do solo, verificada na cabeça da estaca, após o seu descarregamento (recalque plástico).

2.5.2.1 - Métodos de estimativa de recalques baseados em correlações com o diâmetro

1) COOKE (1979): $(0,3$ a $0,4 \%) \times D$

2) FRANK (1985) 0,6 x D (estacas escavadas isoladas)

3) VAN WEELE (1982): 0,7\% x D

4) BRIAUD \& TUCKER (1984): 1,25\% x D (máximo)

2.5.2.2 - Método de POULOS (1989) para estimativa com base no comprimento da estaca (FIGURA 2.2)

\section{6 - TRANSFERÊNCIA DE CARGA}

\subsection{1 - Função "transferência de carga"}


A transferência de carga da estaca para o solo pode ser devidamente calculada desde que se possua dados obtidos da instrumentação da estaca. Estes dados são os relativos à distribuição de carga axial ou à distribuição de seu deslocamento vertical.

A distribuição do atrito lateral é um dos mais importantes corolários da transferência de carga. Pode ser calculada como uma função da distribuição da carga axial do seguinte modo:

$$
\tau(z)=\frac{1}{S} \cdot \frac{d Q(z)}{d z}
$$

Onde:

$\mathrm{S}=$ perímetro da estaca

$\mathrm{Q}(\mathrm{z})=$ carga axial existente, à profundidade “ $\mathrm{z}$ ".
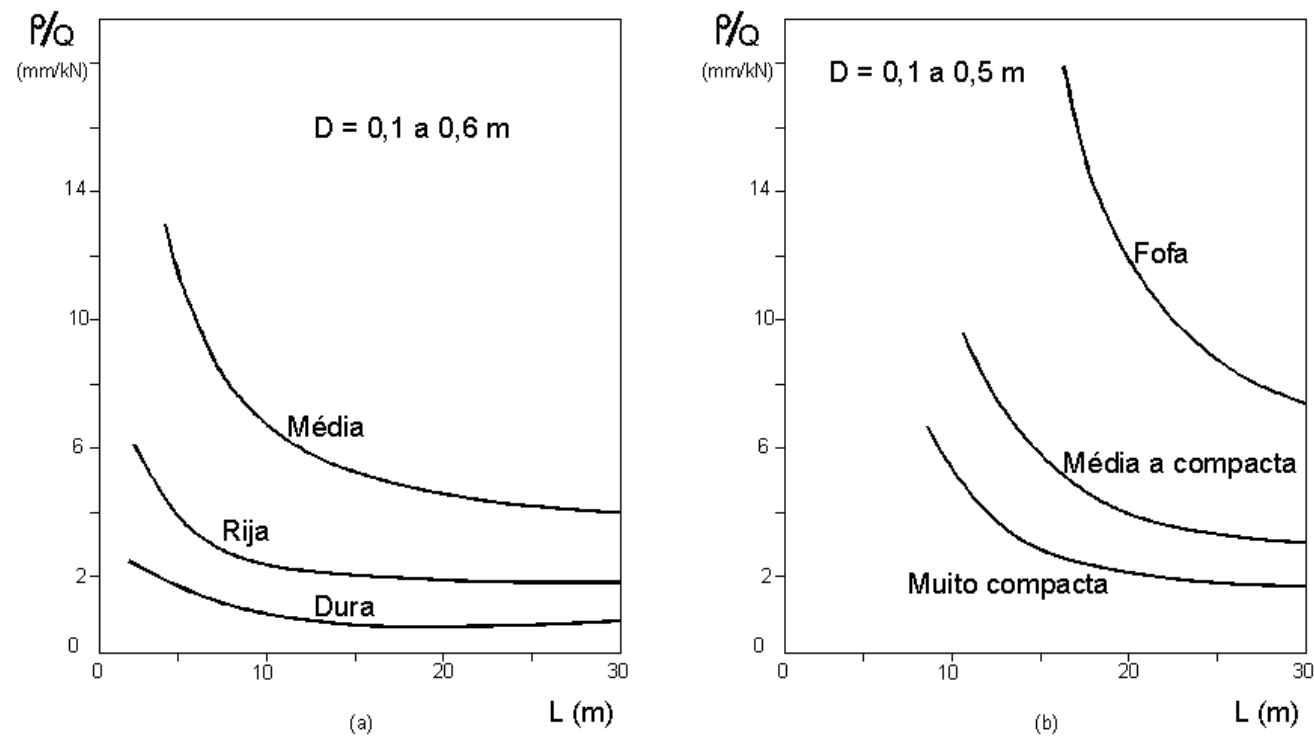

FIGURA 2.2 - Curvas para estimativa de recalques em estacas escavadas: a) em argilas; b) em areias (POULOS, 1989)

Se o deslocamento da estaca, em qualquer profundidade z, estiver disponível, esta distribuição poderá ser calculada por:

$$
\tau(z)=\frac{A \cdot E}{S} \cdot \frac{d^{2}(\rho)}{d z^{2}}
$$

Onde: 
$\mathrm{A}=$ área da seção transversal da estaca

$\mathrm{D}=$ módulo de deformação longitudinal do material da estaca

$\rho=$ deslocamento do topo da estaca.

A quantificação desta distribuição é importante para a análise de comportamento. Na prática, pode ser usada para estimar os recalques de uma estaca sujeita a uma determinada carga de trabalho, $\mathrm{Q}_{\mathrm{w}}$.

É claramente observável uma diferença qualitativa no mecanismo de transferência de carga, à medida em que o carregamento aumenta nas provas de carga. Geralmente, a parte superior é a mais mobilizada, como se pode ver em REESE et al. (1976) e FONTOURA (1982). Isto é essencialmente verdadeiro para estacas virgens.

Mais recentemente, alguns estudos de MASSAD (1991a; 1991b; 1991c) comprovam que isto ocorre somente enquanto não há a saturação pode inteiro do atrito lateral. À medida em que o valor da carga total vai ocorrendo, uma progressiva mudança verifica-se, no sentido de desenvolver as maiores tensões cisalhantes no trecho médio da estaca.

Na região da ponta verificam-se baixos valores da tensão cisalhante, mesmo quando o carregamento imposto é elevado, conforme ROCHA FILHO \& AMARAL (1980). Ao ser novamente ensaiada, a mobilização da ponta da estaca se modifica e o aspecto da distribuição pode ser bem diferente. Esta hipótese de que na vizinhança da ponta da estaca há uma interação dos estados de tensão provenientes das reações laterais e de ponta tem mais defensores, como ELLISON et al. (1971), que resolvem o problema através de um modelo de análise numérica.

FOUTOURA (1982) apresenta curvas de variação do atrito lateral com a profundidade, onde se destacam apenas algumas delas na FIGURA 2.3. Tais curvas foram obtidas através de provas de carga em estacas com instrumentação em muitos níveis. Nelas, percebe-se uma tendência inicial do atrito lateral, logo na vizinhança do topo da estaca, diminuir drasticamente até atingir um limite residual, mais ou menos constante, antes de um esgotamento abrupto. Esta tendência se inverte à medida em que o carregamento aumenta. As extremidades da estaca apresentam-se pouco 
mobilizadas enquanto que os máximos se dão na sua parte central, num aspecto similar a uma curva em forma de sino.

Em trabalho clássico sobre transferência de carga VESIC, 1970b (apud FONTOURA 1982) atesta que a condição necessária e suficiente para se calcular a transferência de carga da estaca para o solo é obtida através da prova de carga instrumentada, com dados sobre a distribuição de carga axial e do deslocamento axial da estaca, ambos ao longo de todo o seu comprimento.

Pelo menos em parte esta afirmativa tem origem mais remota (SEED \& REESE, 1957), onde são estabelecidas curvas básicas relacionando as tensões laterais com os deslocamentos correspondentes, servindo como base para o método clássico de COYLE \& REESE (1966).

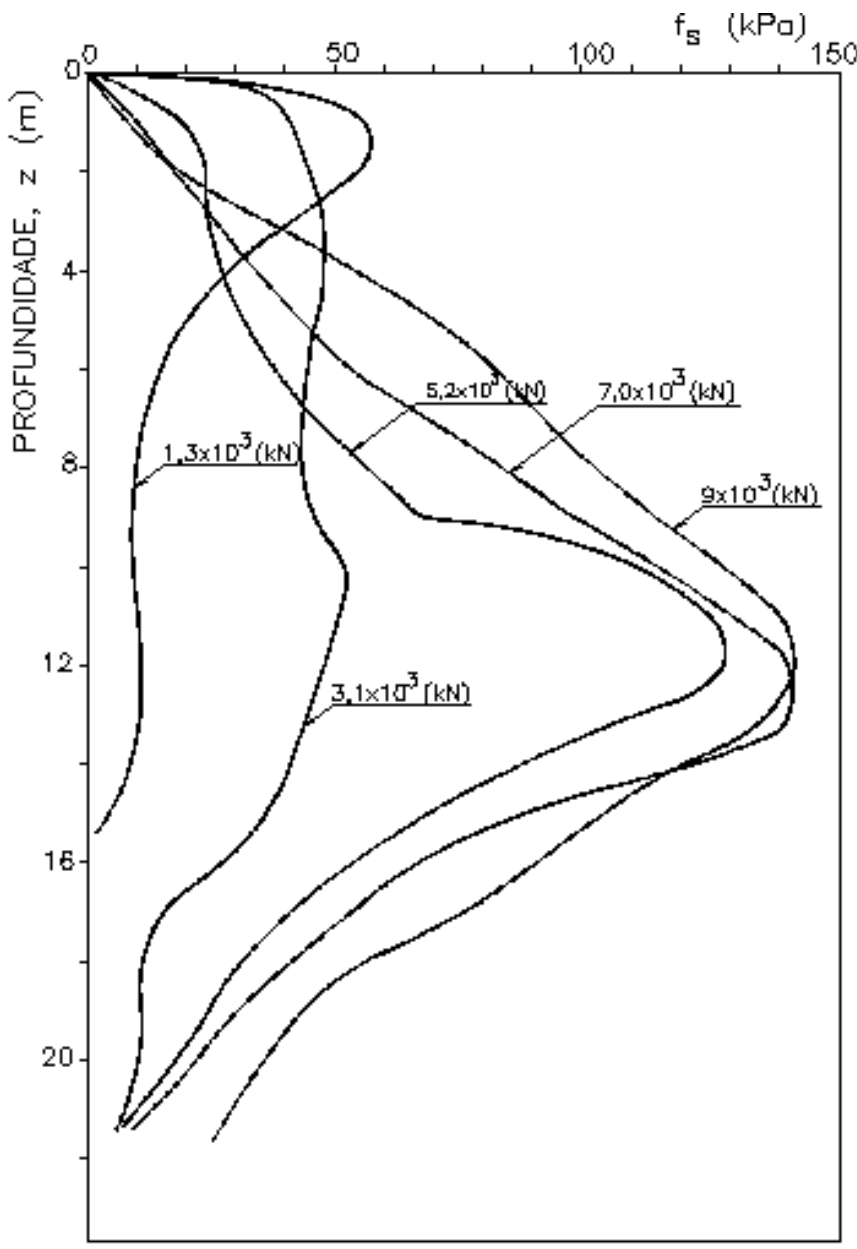

FIGURA 2.3 - Variação do atrito lateral com a profundidade, para diversos níveis de carregamento (FONTOURA, 1982) 
No já referido trabalho de VESIC (1970b) são sugeridas algumas curvas típicas da distribuição do atrito lateral ao longo da estaca, como se vê na FIGURA 2.4.

Embora sendo um meio oneroso, é a instrumentação o caminho mais confiável para se chegar às fórmulas de capacidade de carga. Mesmo possuindo embasamento empírico, nelas estaria embutido o comportamento mais fiel da verdadeira distribuição da resistência da estaca.

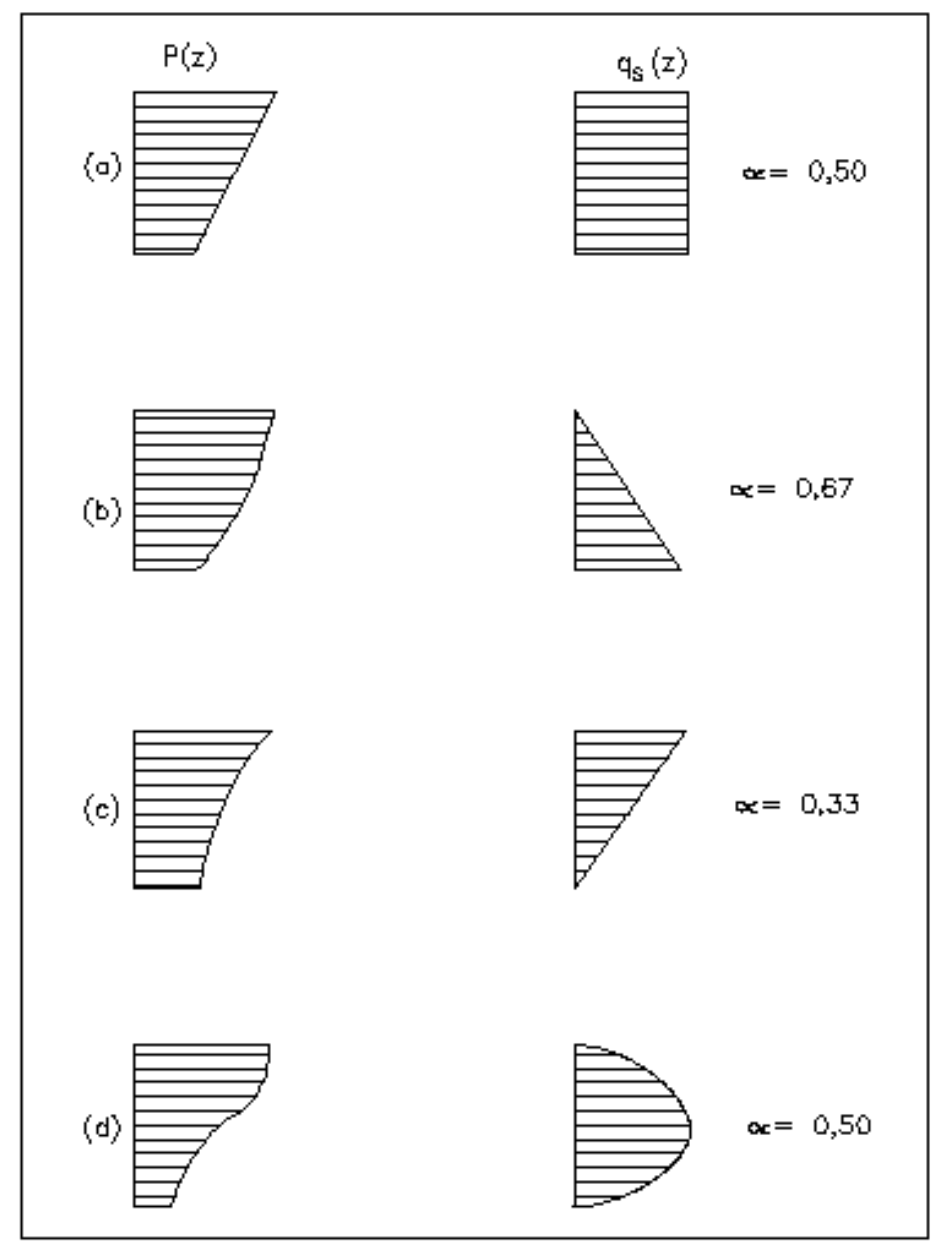

FIGURA 2.4 - Curvas típicas de distribuição de f $\mathrm{s}_{\mathrm{s}}$ (VESIC, 1970b, apud SANTOS JR., 1988)

A este respeito, vê-se em FONTOURA (1982) uma análise comparativa entre os resultados obtidos pela aplicação de fórmulas empíricas tradicionais (AOKI \& VELLOSO, 1975); DÉCOURT \& QUARESMA, 1978; VELLOSO, 1981) e os resultados obtidos através de provas de carga em estacas instrumentadas. É interessante a conclusão de que os métodos empíricos superestimam a capacidade de carga em aproximadamente $20 \%$ e que, além do mais, os erros encontrados na 
estimativa das resistências, lateral e de ponta, são bem superiores, porém autocompensáveis.

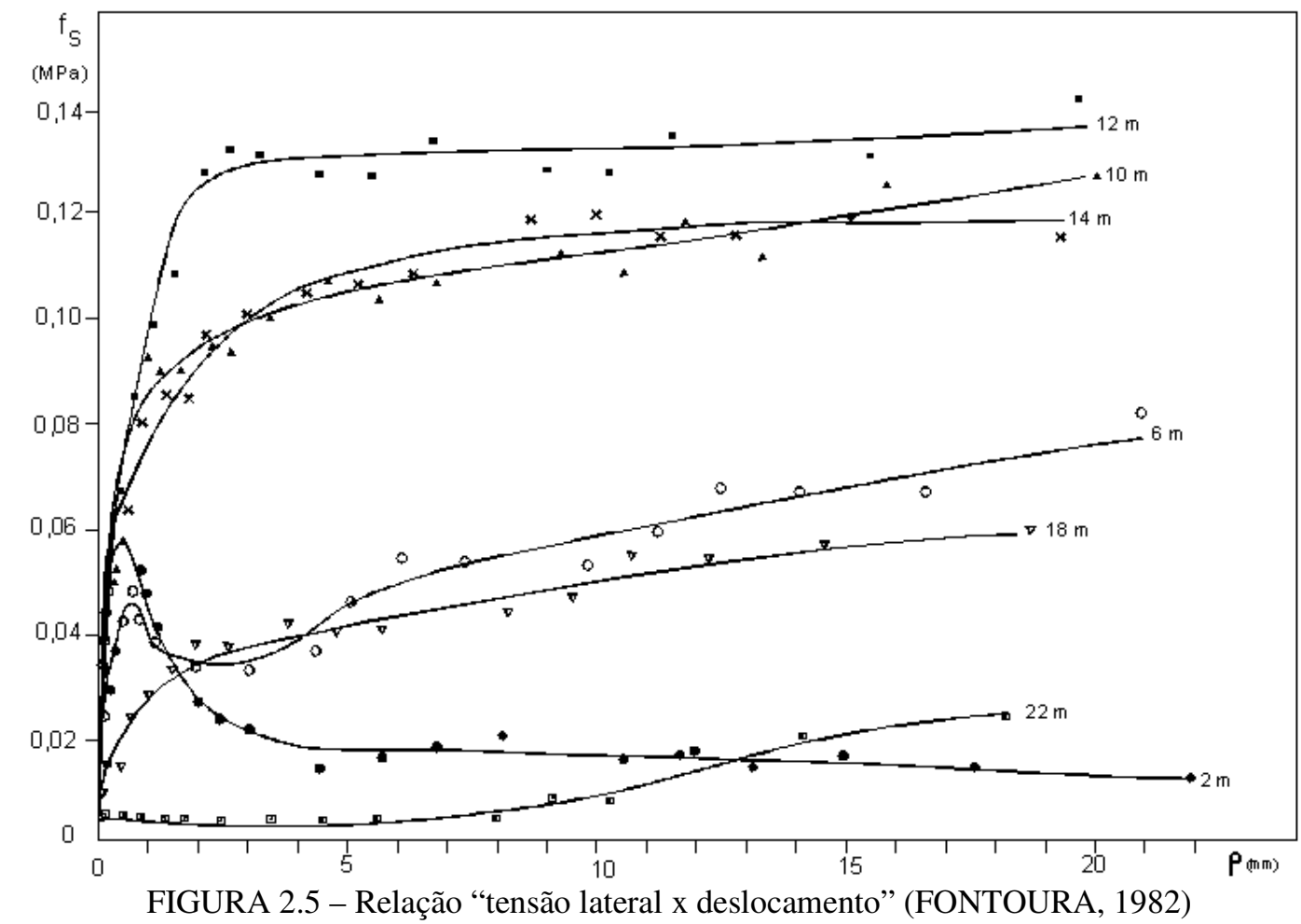

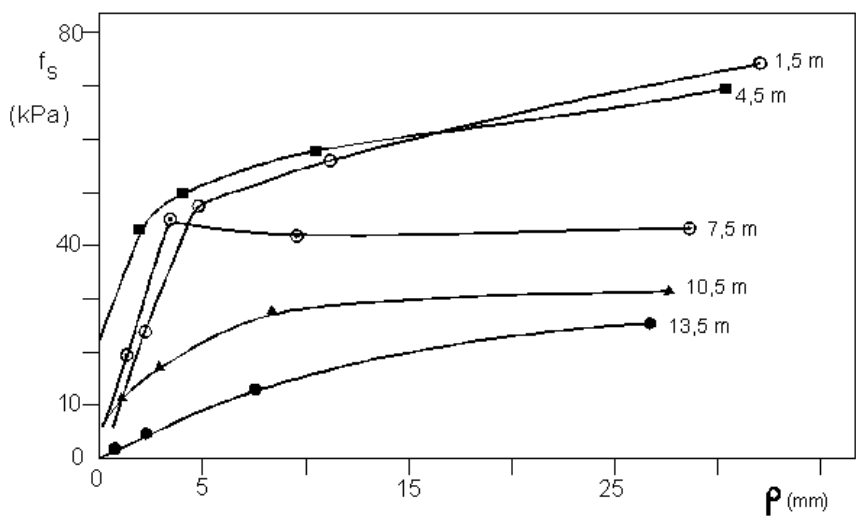

FIGURA 2.6 - Relação "tensão lateral x deslocamento" (COYLE \& SULAIMAN, 1967)

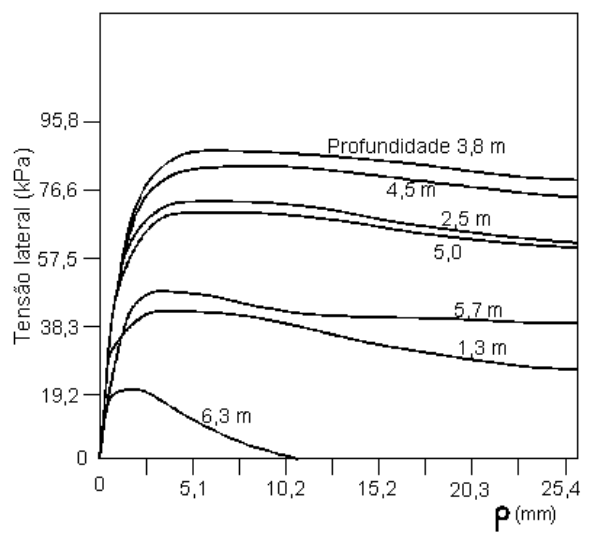

FIGURA 2.7 - Relação "tensão lateral x deslocamento" (REESE et al., 1976)

As figuras anteriores (FIGURA 2.5, FIGURA 2.6 e FIGURA 2.7) foram inseridas como juízo crítico, para serem utilizadas posteriormente como referencial de comparação. 
Não se pode inferir qualquer regra que generalize o comportamento dessas curvas, exceto que a resistência lateral é crescente para deslocamentos muito pequenos (da ordem de poucos $\mathrm{mm}$ ), estabilizando-se ou decrescendo a partir de então. Entretanto, os fatos aleatórios predominam, sendo observáveis curvas de valor crescente, mesmo para deslocamentos bem superiores.

É frequente encontrar curvas que se interceptam e outras que passam por um máximo após um deslocamento muito pequeno e depois caem a zero ou a níveis estabilizados bastante baixos.

Em nenhum desses casos foi apresentada qualquer explicação conclusiva e as observações tem se revelado muito passivas a este respeito. As discussões ficam sempre em aberto, como se os resultados fossem casuísticos ou consequência do imponderável. E, de fat6o, a questão parece escapar a qualquer ideia de generalidade.

\subsection{2 - Parâmetros básicos da transferência de carga}

\subsubsection{1 - Resistência mobilizada de ponta}

Nos estágios iniciais de carregamento a carga aplicada no topo da estaca é inteiramente absorvida por atrito, sendo que as camadas superiores recebem o máximo (MOHAN et al., 1963). À medida em que o carregamento prossegue, uma parte começa a ser transferida para a ponta e, em determinado estágio, quando a estaca cisalha o solo, uma parcela de carga é transferida para a ponta. Esta fase corresponde ao esgotamento de sua capacidade de resistência lateral.

A resistência oferecida por atrito, pelo solo, nos estágios iniciais de carregamento, cresce até uma certa profundidade e depois diminui. O comportamento descrito é singularmente idêntico a um ensaio de cisalhamento direto em laboratório, quando se observa a resistência residual inferior à resistência de pico.

Como se constata, a carga transferida para a ponta é baixa. Seguem sugestões de alguns autores: 1) REESE et al., 1969: 25\% da carga no topo; 2) TOH et al., 1989: $10 \%$ a $20 \%$ da carga no topo; 3) CHANG \& BROMS, 1991: 10\% da carga no topo (para estacas escavadas). 
Numa situação particular de estaca escavada em solos colapsíveis após inundação não foram localizadas recomendações a este respeito.

\subsubsection{2 - $\underline{\text { Resistência lateral mobilizada }}$}

A variação do módulo não drenado afeta a distribuição da transferência de carga, sem, contudo, impor qualquer vinculação com a distribuição da resistência ao cisalhamento.

Para estacas curtas, a proporção dos deslocamentos de ponta, em relação ao comprimento da estaca, aumenta. LLOYD \& GOWAN (1975) usam este último fato como um argumento para explicar o porquê da maior transferência de carga por atrito lateral nas proximidades da base, em relação ao topo.

Porém, é consensual que existe bem pouca transferência de carga para a ponta até que a máxima resistência lateral seja esgotada. À medida em que a estaca é progressivamente descarregada, observa-se menos carga na sua superfície lateral, havendo menos perda de carga na ponta (O'RIORDAN, 1982).

REESE et al. (1976), em estacas escavadas de grande diâmetro, encontraram $65 \%$ da carga total sendo resistida por atrito lateral.

\subsubsection{3 - Movimentos necessários para a mobilização de carga}

Diversos autores manifestam opiniões acerca dos movimentos requeridos para mobilizar as resistências, lateral e de ponta. Um resumo das principais contribuições é apresentado nas TABELAS 2.1 e 22 apresentadas a seguir.

Este assunto também não encontra registros acessíveis no caso de estacas escavadas em solos colapsíveis após inundação.

TABELA 2.1 - Movimentos necessários para mobilização da resistência de ponta

\begin{tabular}{|l|c|c|c|}
\hline \multicolumn{1}{|c|}{ AUTOR } & ANO & DESLOCAMENTOS & \multicolumn{1}{c|}{ OBSERVAÇÕES } \\
\hline COOKE \& WHITAKEER & 1961 & $(0,1 \mathrm{a} 0,15) \times \mathrm{D}_{\mathrm{b}}$ & \multicolumn{1}{c|}{-} \\
\hline COYLE \& REESE & 1966 & $0,1 \times \mathrm{D}$ & $\begin{array}{l}\text { Proporcional ao comprimento } \\
\text { da estaca }\end{array}$ \\
\hline VESIC & 1975 & - & $\begin{array}{l}\text { Descartam deslocamentos de } \\
\text { ponta para as cargas de trabalho }\end{array}$ \\
\hline WOODWARD et al. & 1972 & - & - \\
\hline LLOYD \& GOWAN & 1975 & $0,1 \times \mathrm{D}$ & \\
\hline
\end{tabular}




\begin{tabular}{|l|c|c|l|}
\hline REESE et al. & 1976 & 25,0 a $3,08 \mathrm{~mm}$ & $\begin{array}{l}\text { Estacas escavadas de grandes } \\
\text { diâmetros }\end{array}$ \\
\hline AURORA \& REESE & 1977 & $(0,05 \mathrm{a} 0,1) \times \mathrm{D}$ & - \\
\hline
\end{tabular}

TABELA 2.2 - Movimentos necessários para mobilização da resistência lateral

\begin{tabular}{|l|c|c|l|}
\hline \multicolumn{1}{|c|}{ AUTOR } & ANO & DESLOCAMENTOS & \multicolumn{1}{c|}{ OBSERVAÇÕES } \\
\hline DUBOSE & 1957 & $2,5 \mathrm{~mm}$ & $\begin{array}{l}\text { Comparável com o ensaio de } \\
\text { cisalhamento direto }\end{array}$ \\
\hline SKEMPTON & 1959 & $10,0 \mathrm{~mm}$ & \multicolumn{1}{|c|}{-} \\
\hline LLOYD \& GOWAN & 1975 & $5,0 \mathrm{~mm}$ & \begin{tabular}{l} 
Escavadas em argila \\
\hline REESE et al.
\end{tabular} \\
\hline MEYERHOF & 1976 & $6,0 \mathrm{a} 13,0 \mathrm{~mm}$ & $\begin{array}{l}\text { escavadite inferior para estacas } \\
\text { em argilas silto-arenosas }\end{array}$ \\
\hline MEYERHOF & 1976 & $6,0 \mathrm{a} 13,0 \mathrm{~mm}$ & Estacas curtas \\
\hline WHITAKER \& COOKE & 1976 & $1,5 \mathrm{a} 6,0 \mathrm{~mm}$ & Estacas longas \\
\hline O'NEILL \& REESE & 1966 & $5,0 \mathrm{a} 6,0 \mathrm{~mm}$ & - \\
\hline O'RIORDAN & 1982 & $5,0 \mathrm{a} 10 \mathrm{~mm}$ & - \\
\hline O'RIORDAN & 1982 & $2,00 \mathrm{MM}$ & Argilas de Londres \\
\hline
\end{tabular}

\section{7 - PROVAS DE CARGA}

\subsection{1 - Finalidades, procedimentos e métodos}

As provas de carga são realizadas visando, principalmente, os objetivos de: 1) prover dados para projetos; 2) avaliar fundações já executadas em uma determinada obra; 3 ) estudar as características de comportamento do conjunto solo-estaca.

É neste último objetivo que se inserem as pesquisas acadêmicas com maior frequência.

Muitos são os procedimentos que podem ser seguidos para sua execução. Os mais citados são: ABNT (1986); ASTM (1981); FELLENIUS (1975); FELLENIUS (1980); MOHAN et al. (1967); VAN WEELE (1957); WHITAKER (1957); WHITAKER (1963); WHITAKER \& COOKE (1962).

Os modos de conduzi-las costumam merecer um critério de classificação como segue:

Primeiro tipo: SML (slow maintained load), ou ensaio lento

É conduzida a incrementos iguais até determinado nível de carga, superior à carga de trabalho. A partir de uma definição de "estabilização de recalques" cada 
estágio deve ser sustentado até que ela seja alcançada. A perfeita obediência aos critérios de estabilização é necessária para melhor interpretação dos resultados em termos de fluência (FERREIRA \& LOPES, 1985). Há bastante consistência nos argumentos que justificam certas vantagens inerentes a este método. Analisando-se o real comportamento das fundações pode-se, de imediato, separá-las em dois grupos: 1) as que são submetidas a um carregamento lento e de longa duração; 2) as que são sujeitas a cargas rápidas ou dinâmicas (vento, ondas, choques). Sendo a resistência ao cisalhamento das argilas dependente da velocidade de carregamento, o comportamento das estacas instaladas em solos argilosos deverá ser também dependente da velocidade de carregamento.

Verifica-se, em ensaios, que cargas aplicadas rapidamente tendem a produzir um aumento da capacidade de carga, bem como da rigidez do sistema solo-estaca, capaz de modificar as relações entre as cargas e os recalques. Isto induz a acreditar que as provas de cargas lentas são mais realistas (BRIAUD \& GARLAND, 1985, apud MILITITSKY, 1991).

Nas situações onde se aguarda a plena estabilização dos recalques, o comportamento "carga x recalque" é diferente daquelas onde essa estabilização não é respeitada (LOPES, 1986).

Segundo tipo: QML (quick maintained load), ou ensaio rápido

Neste tipo a estaca é carregada em incrementos iguais até determinado nível de carga, superior à de trabalho, devendo cada estágio ser mantido por um intervalo de tempo pré-fixado. FELLENIUS (1975) sugere vinte estágios, cada um da ordem de $15 \%$ da carga de trabalho prevista, com manutenção por 15 minutos e leitura dos deslocamentos de $3-3$ minutos.

\section{Terceiro tipo: CRP (constant rate of penetration)}

Neste tipo de ensaio a estaca é forçada a recalcar em velocidade constante, medindo-se a força necessária. O ensaio deve ser conduzido até um certo nível de 
deslocamentos, variável de $50 \mathrm{~mm}$ a $75 \mathrm{~mm}$. WHITAKER (1957) indica que o carregamento deve ser aplicado até que a carga não mais cresça com a penetração.

Quarto tipo: CLT (cyclic load test)

A estaca é carregada até $1 / 3$ da carga de projeto e em seguida é descarregada para a metade deste valor. O ciclo é repetido por 20 vezes, a partir do qual é aumentado o valor de pico da carga em $50 \%$. O procedimento se repete até a ruptura.

\subsection{2 - Definição da carga de ruptura}

É uma das questões mais controvertidas da Engenharia de Fundações. Não há uma definição de consenso e tampouco o simples traçado da curva carga $\mathrm{x}$ recalque mostra-se suficiente para encontrar uma convergência de opiniões (VAN WEELE, 1982). Mesmo porque a carga última é dependente da escala gráfica adotada (VAN DER VEEN, 1953), além de outros fatores, sendo o tempo o mais importante.

No Brasil o critério da NBR 6121/86 é coincidente com o adotado pelo CANADIAN FOUNDATION ENGINEERING MANUAL - PART 3 (1975) e fixa o valor da carga última $\left(\mathrm{P}_{\mathrm{u}}\right)$ em função da deformação elástica da estaca (parcela P.L/E.A) e de seu diâmetro:

$$
P_{u}=\frac{P . L}{E . A}+\frac{D}{30}
$$

Outras definiçõoes de ruptura, colocadas à disposição para interpretação das provas de carga podem ser destacadas:

1) DE BEER (1967): “a carga de ruptura corresponde ao ponto de máxima curvatura da linha $\log ($ deslocamentos $) \times \log (p)$ "

2) VAN DER VEEN (1953): postula que o comportamento carga $\mathrm{x}$ recalque é matematicamente consistente com a função:

$$
P=P_{u}\left(1-e^{-a . \rho}\right)
$$

A definição de VAN DER VEEN (1953), por ser puramente teórica, permite extrapolar os resultados de uma prova de carga, obtendo-se o 
valor de ruptura quando o parâmetro "a”, que define o formato da curva exponencial, fica definido.

3) FELLENIUS (1975): a carga de ruptura é aproximadamente definida pelo ponto de interseção de duas tangentes, sendo uma ao trecho inicial e outra ao trecho final da curva "carga $\mathrm{x}$ recalque"

4) ZEEVAERT (1972): a carga de ruptura pode ser dada, aproximadamente, por um ponto bem definido da mudança de comportamento do solo, que se manifesta em um gráfico "log p x log recalque", através de uma deflexão brusca

5) CHELLIS (1961): a carga de ruptura é aquela onde a curva "carga $x$ recalque" tem uma inclinação de aproximadamente $0,13 \mathrm{~mm} / \mathrm{kN}$.

Esta ampla faixa de definições tem produzido uma intensa confusão nos meios técnicos. A adoção de critérios diferentes leva a valores igualmente diferenciados na obtenção da carga última. VAN WEELE (1982) divulga os resultados de interpretação de diversos especialistas renomados em uma prova de carga. Há discrepâncias que vão de 4050 kN a 7050 kN, sem nenhuma coincidência.

\section{8 - MÉTODOS DE SEPARAÇÃO DAS PARCELAS DE RESISTÊNCIA LATERAL E DE PONTA}

Quando uma prova de carga é realizada sobre uma estaca instrumentada no fuste, as parcelas do atrito lateral e de ponta, componentes da resistência total mobilizada pela estaca, podem ser facilmente obtidas para qualquer estágio de aplicação do carregamento.

Este estudo é fundamental para análise do comportamento "carga x recalque" de fundações profundas. VARGAS (1983) apresenta uma discussão exaustiva sobre o assunto, cujos primórdios podem ser remetidos a REESE et al. (1951) e CAMBEFORT (1953). Algumas das primeiras referências brasileiras são: VELLOSO et al. (1978), COSTA NUNES et al. (1979), GAMA E SILVA et al. (1982) e FONTOURA et al. (1982). 
VARGAS (1983) apresenta um aspecto idealizado do comportamento "carga de ponta x recalque" e "carga lateral x recalque" e fornece um modelo que permite fazer esta separação. Porém, em que pese a consistência matemática da proposta, ela não é aplicável aos casos onde a distribuição da resistência lateral unitária seja variável ao longo do fuste.

FONTOURA (1982) mostra a separação das cargas, lateral e de ponta, para estaca escavada de grande diâmetro em solo argiloso com N. A. elevado (aproximadamente $8 \mathrm{~m}$ ) e o que se percebe é o crescimento de ambas as resistências. As curvas são praticamente paralelas após a fase de deformações elásticas do sistema.

Processos clássicos para esta separação, em estacas sem instrumentação, são devidos a VAN DER VEEN \& BOERSMA (1957), VAN WEELE (1957) e MOHAN et al. (1963). VELLOSO (1981) também sugere HANNA (1971) e WOODWARD et al. (1972).

\section{9 - MÉTODOS DE PREVISÃO DA CURVA CARGA x RECALQUE}

O melhor conhecimento possível da curva "carga x recalque" é preconizado como uma ferramenta indispensável na definição da carga admissível.

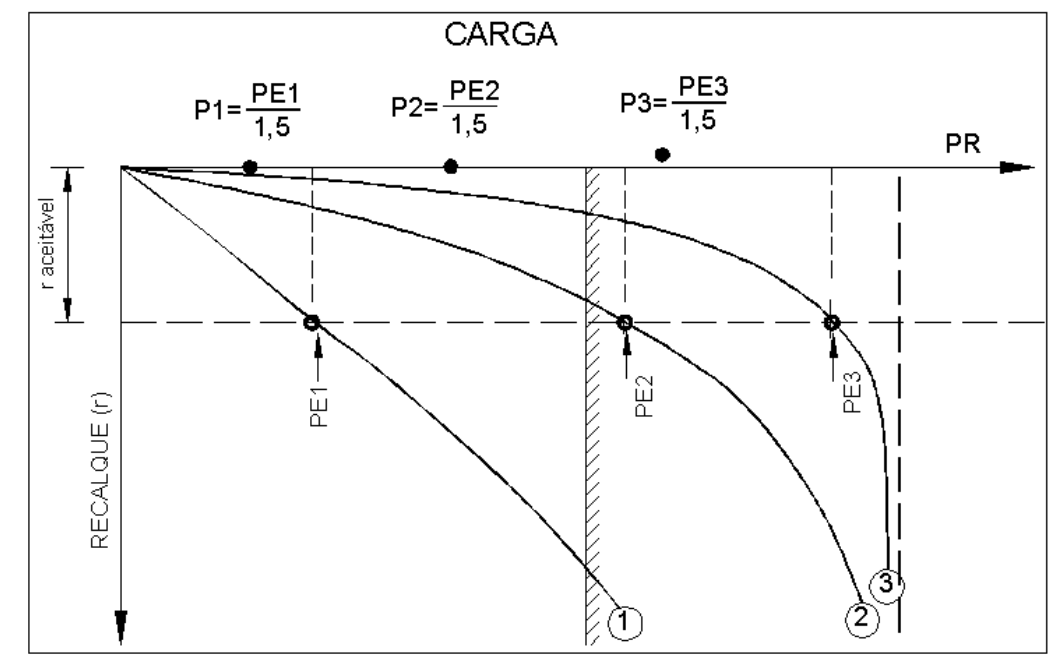

FIGURA 2.8 - Carga admissível de estacas segundo a NBR 6121 (ALONSO, 1991)

A FIGURA 2.8 evidencia, principalmente, que a carga admissível de uma estaca é aquela que, aplicada à mesma, produz apenas recalques toleráveis pela 
estrutura e ainda que, concomitantemente, representa segurança contra a ruptura do solo.

No entanto, apesar de sua importância, é notado com frequência que a previsão da curva "carga x recalque" tem sido desprezada em favor da determinação da carga última. Registre-se, porém, a disponibilidade de uns tantos métodos para este fim, sendo dignos de menção: AOKI \& LOPES (1975), POULOS \& DAVIS (1980) e GAMA E SILVA et al. (1982).

Mais recentemente, surgiram alguns modelos hiperbólicos bastante interessantes (TEJCHMAN \& GWIZDALLA, 1988; HIRAYAMA, 199), porém redundantes em suas finalidades, já que, à semelhança dos métodos clássicos de previsão teoria de carga última também requerem o uso de constantes de ajustamento e fatores de correção, dependentes de resultados de ensaios (Q, SPT, CPT, principalmente este último).

\subsection{0 - ESTACAS SUJEITAS A CARREGAMENTOS MÚLTIPLOS. TENSÕES RESIDUAIS}

Alguns programas de pesquisas desenvolvidos em Universidades impõem como é o caso - a necessidade de ensaiar uma mesma estaca por diversas vezes, com o escopo de simular diferentes situações. Assim, as estacas escavadas passam por um processo de crescentes incrementos na mobilização da resistência de ponta, havendo ainda evidências de memorização de tensões residuais provenientes de carregamentos anteriores.

As cargas residuais exercem uma importante influência no comportamento de estacas escavadas. Surgem por causa de diferenças nas taxas de mobilização no fuste e na ponta, à medida em que a estaca é deslocada, seja durante a instalação, seja por ação de carregamento à compressão (COOKE, 1979a). Em estacas escavadas, estas forças residuais podem resultar da retração do concreto, tracionando o fuste, para equilibrar forças compressivas existentes no solo envolvente. Assim, o papel destas forças é reduzir a magnitude da componente de ponta, registrando-se casos onde a transferência de tensões é negativa na parte superior do fuste. 
Ainda segundo COOKE (1979a) as cargas residuais em estacas escavadas são pequenas. Em provas de carga à compressão sua magnitude raramente ultrapassa o peso do concreto fresco da estaca. A carga mobilizada pela ponta é uma fração bastante pequena da carga de trabalho.

Uma revisão abrangente sobre o assunto indica o interesse de alguns pesquisadores pelo tema, notadamente a partir dos anos 60 .

WHITAKER \& COOKE (1966) indicam que, na descarga de uma prova de carga em solo argiloso, o fuste permanece em compressão sob a ação de uma carga residual na base. Em decorrência, é mobilizado atrito negativo. Esta condição de equilíbrio, necessária em estacas escavadas após serem recalcadas sob carregamento, é similar àquela que existe imediatamente após a instalação de uma estaca cravada.

KÉRISEL \& ADAM (1969) também registram a existência de carga residual na ponta, de considerável magnitude (praticamente igual à reação de ponta original).

Aparentemente, a primeira verificação experimental do fenômeno de cargas residuais e sua adequada quantificação se deve a HUNTER \& DAVISSON (1969). Relatam a existência de forças de tração (aparentes), de considerável intensidade, na base de estacas cravadas em solo arenoso, em provas de carga à compressão sucedida por tração. O inexplicável significado físico desta ocorrência levou os autores à interpretação de que o seu aparecimento devia-se à não consideração de cargas residuais na interpretação das provas de carga.

Também O’NEILL \& REESE (1972) descrevem um caso de uma estaca escavada, isolada, carregada com $1300 \mathrm{kN}$, dos quais $450 \mathrm{kN}$ foram transferidos para a ponta. Após a descarga, houve retenção de 200 kN.

HANNA \& TAN (1973) concluíram que a magnitude do diagrama "carga x recalque" para uma estaca é influenciada pelo estado de tensões residuais e que também o comportamento da estaca depende de sua história de carregamento.

O fecho da primeira parte de tais conclusões é dado por VESIC (1977) que indica serem as cargas residuais a resultante de uma concentração de resistência lateral 
na parte superior do fuste, podendo produzir uma substancial redução nos recalques. Esse autor relata duas experiências, uma envolvendo grupos de estacas cravadas em solo variado, onde os recalques obtidos foram da ordem de 1/6 dos previstos por métodos convencionais e uma outra, em estacas isoladas, onde também a consideração da carga residual levou ao resultado de apenas $1 \mathrm{~cm}$ de recalque, contra uma previsão de $2,5 \mathrm{~cm}$ no caso de não ser levada em conta.

DARRAG \& LOVELL (1989) ressaltam que as tensões residuais são provenientes de um mecanismo "carga - descarga - recarga" na instalação das estacas cravadas. Detalhes deste fenômeno podem ser encontrados em BRIAUD \& TUCKER (1984). Embora a existência de tensões residuais não afete a capacidade de carga total das estacas, elas podem alterar significativamente os mecanismos de transferência de carga, nas cargas de trabalho, em um certo nível de deformações, afetando ainda os recalques e a cravabilidade. Sugerem que a interpretação dos resultados de uma prova de carga poderá ser errônea se a transferência de carga real não for observada.

A proporção da carga de trabalho carregada pela ponta, comparada com aquela mobilizada pelo fuste, poderá bastante elevada no caso de estacas curtas. Neste caso, a relação "recalque/diâmetro" da estaca, para esta carga de trabalho, poderá ser superior a $0,3 \%$. Quando a relação "comprimento/diâmetro" é maior do que 10, a estaca passa a ter características de estaca de atrito e então a relação "recalque/diâmetro" estabiliza em torno de $0,22 \%$. Tais observações constam do trabalho de COOKE (1979a).

Dentre os vários métodos disponíveis para avaliar as tensões residuais destacam-se:

1) Medições diretas (RIEKE \& CROWSER, 1987), de pouco uso

2) Avaliação indireta, usando uma sequência de provas de carga à compressão e à tração, onde se assume que os ensaios à tração não produzem tensões residuais e que a distribuição do atrito lateral no carregamento é a mesma nos descarregamentos (HUNTER \& DAVISSON, 1969) 
3) Correlações com o SPT, que é um método expedito, porém muito simplista. Ademais, não considera alguns parâmetros de reconhecida influência neste processo (BRIAUD \& TUCKER, 1984)

4) Método dos elementos de fronteira (POULOS, 1987) e método da análise da equação de ondas (HOLLOWAY et al., 1975).

Em termos brasileiros, há que se registrar algumas contribuições relevantes nesta área.

MASSAD (1991a) analisa o verdadeiro comportamento da ponta de uma estaca submetida a novo carregamento, verificando a existência de carga residual já no início do segundo carregamento, como se vê na FIGURA 2.9a.

Outro objetivo desse trabalho é demonstrar a validade das conhecidas relações de CAMBEFORT (1964) - FIGURAS 2.10b e 2.10c - envolvendo "atrito lateral x deslocamentos" e "reação de ponta x deslocamentos".
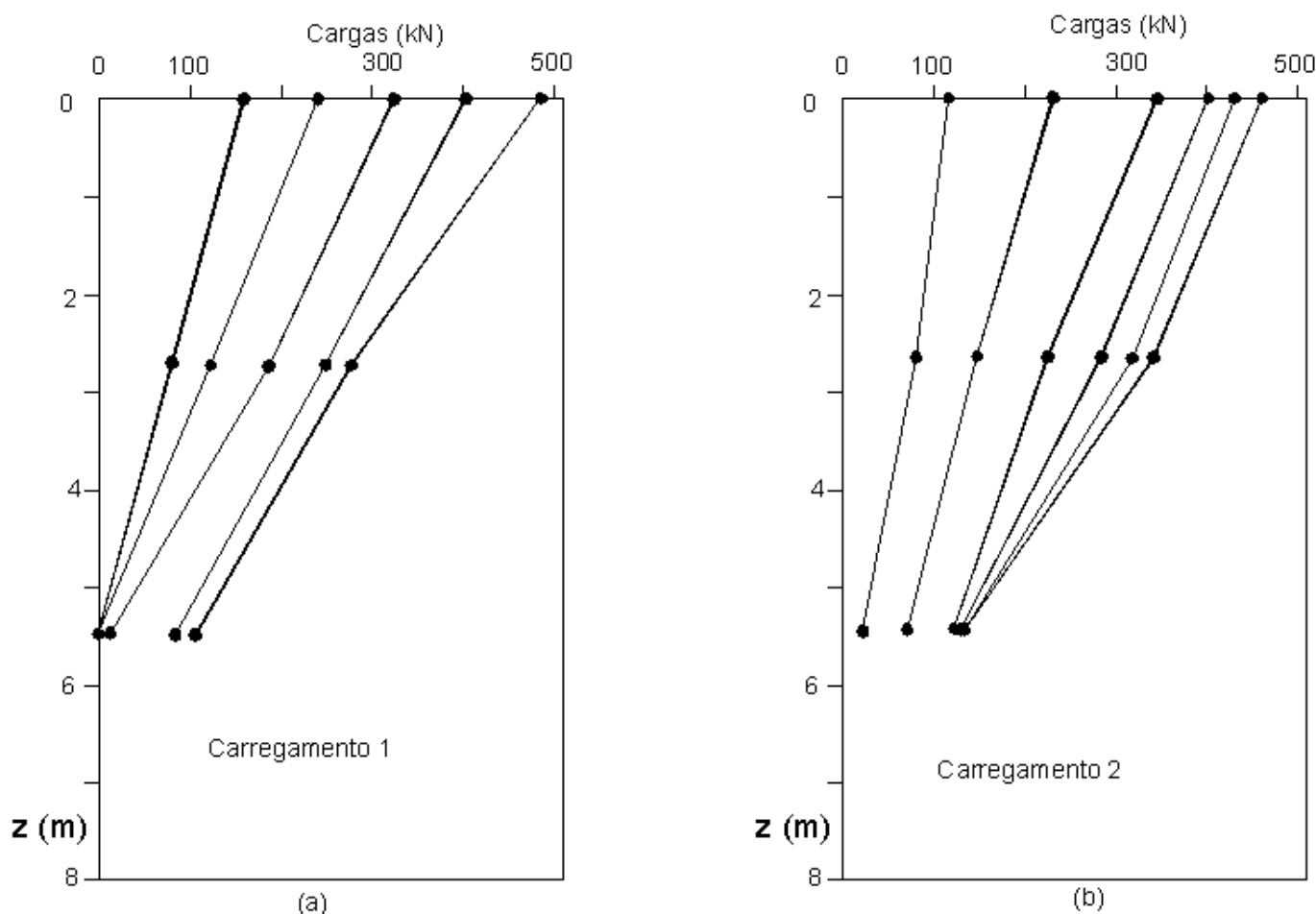

FIGURA 2.9 - a) curvas de transferência de carga do primeiro carregamento; b) curvas de transferência de carga do segundo carregamento (MASSAD, 1991a)

A FIGURA 2.10a mostra os resultados obtidos por MASSAD (1991a), podendo-se notar uma razoável aproximação entre o modelo e os dados observados. 
Uma conclusão importante constatada nesse trabalho é que a reação de ponta de estacas escavadas, submetidas a um novo carregamento, é muito pequena no momento em que o atrito lateral atinge o seu máximo. Para o carregamento seguinte, elas reagem com uma carga de ponta bem superior, denotando a ocorrência de resíduo do primeiro carregamento. Apresentam-se, a seguir, as referidas figuras.
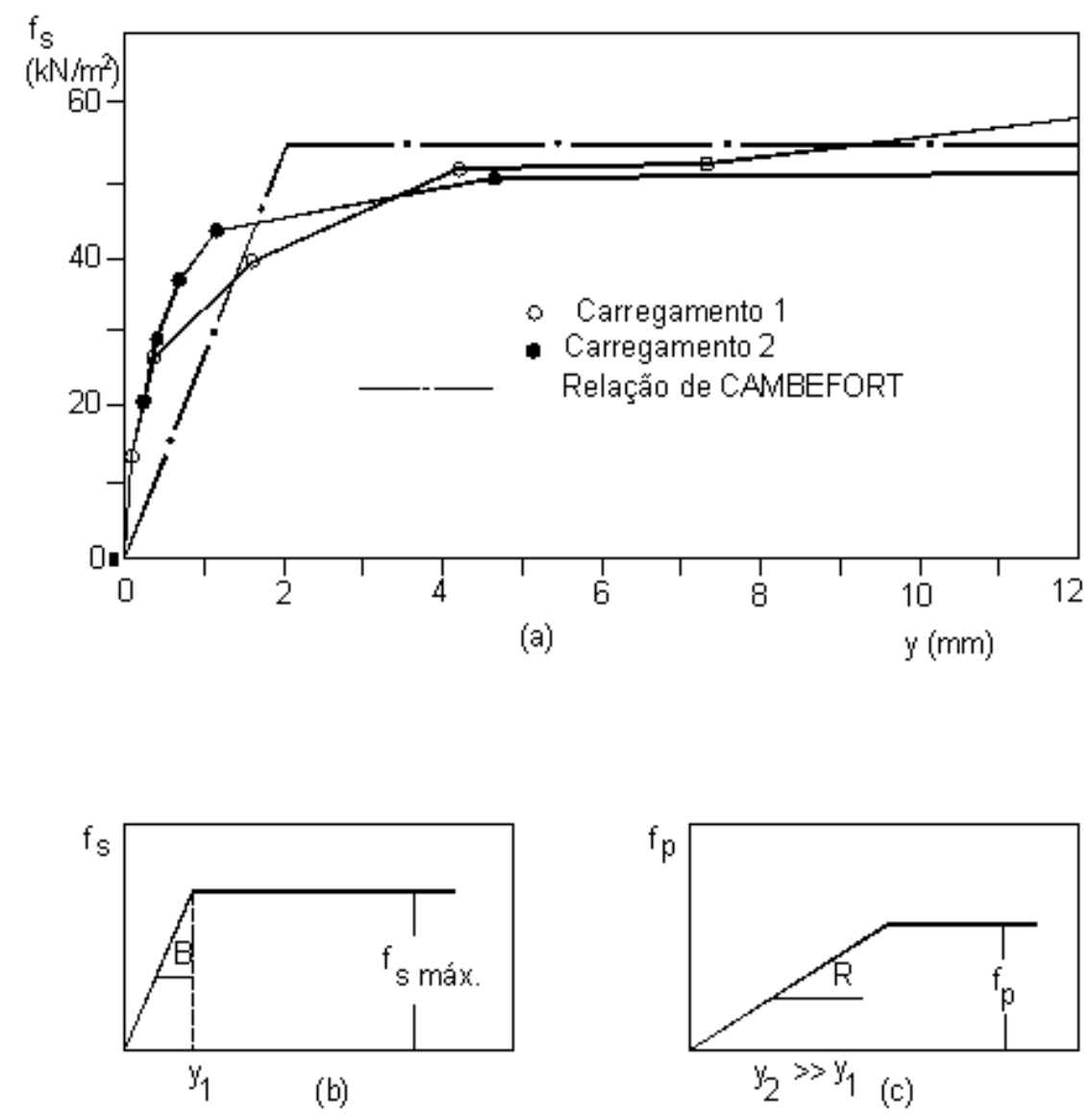

FIGURA 2.10 - a) mobilização da resistência lateral (unitária) em função dos deslocamentos; b) leis ou relações de CAMBEFORT (1964) para o atrito late4ral; c) idem, para a reação de ponta (MASSAD, 1991a)

A quantificação das cargas residuais de ponta é sugerida por MASSAD (1991a) através da expressão:

$$
Q_{p, 2}=R \cdot y_{r}
$$

Onde:

$$
\mathrm{Q}_{\mathrm{p}, 2}=\text { carga residual no segundo carregamento }
$$


$\mathrm{R}$ = parâmetro de CAMBEFORT (em MASSAD, 1991c, é feita uma proposta para sua avaliação em termos do SPT)

$\mathrm{y}_{\mathrm{r}}=$ deslocamento residual ou elástico, ao final do carregamento anterior.

Nota-se, assim, que a previsão da carga residual de ponta pode ser feita com bastante simplicidade, desde que se conheça o SPT na região da ponta da estaca e os resultados de uma prova de carga anterior.

A análise de dados de provas de carga em estacas submetidas a carregamentos múltiplos fica facilidade com a intermediação de dois parâmetros importantes, que são R (equação 2.5) e B (equação 2.6).

$$
k=4\left[\left(\frac{h}{D}\right)^{2} \cdot\left(\frac{B \cdot D}{E_{p}}\right)\right]
$$

Onde:

h, D = altura e diâmetro da estaca, respectivamente

$\mathrm{B}=$ parâmetro de CAMBEFORT ( $1^{\mathrm{a}}$ relação), também definido por MASSAD (1991c) em função do SPT e do tipo de solo, com a diferença que agora interesse o solo ao longo do fuste

$\mathrm{E}_{\mathrm{p}}=$ módulo de elasticidade longitudinal do material da estaca.

Em trabalho mais recente (MASSAD, 1992) é proposta a definição de " $k$ " através da equação (2.6), substituindo uma formulação clássica que não realça tanto a expressão física deste parâmetro, que é, em primeira instância, um aferidor da rigidez do solo e do material da estaca. Com efeito, vê-se que a estaca incompressível (do modo mais radical possível) apresenta $\mathrm{k}=0$.

Ora, esta condição implica $\mathrm{B}=0 \mathrm{ou}$, em outras palavras, mesmo que não ocorra nenhum deslocamento $(\mathrm{y}=0)$, o atrito lateral atinge o seu máximo, instantaneamente, em toda a extensão da estaca.

Vista no outro extremo, esta equação pode apresentar $\mathrm{k}=\infty$, o que implica a absurda condição de $\mathrm{E}_{\mathrm{p}}=0$ (deformabilidade infinita) ou então D 0 (esbeltez muito 
elevada da estaca, implicando igualmente em deformabilidade infinita). Na prática, é necessário trabalhar com valores plausíveis para k. Assim, costuma-se distinguir as estacas em longas $(\mathrm{k}>10)$ ou curtas $(\mathrm{k}<3)$. MASSAD (1992) assinala que os valores intermediários devem ser analisados com cautela.

O outro parâmetro importante (“m”), definido por MASSAD (1992) como uma relação entre a reação de ponta no momento em que todo o atrito lateral foi mobilizado ao longo do fuste e este atrito lateral na ruptura $\left(\mathrm{A}_{1 \mathrm{r}}\right)$. Matematicamente:

$$
m=R . S . \frac{y_{1}}{A_{1 r}}
$$

Onde:

$\mathrm{S}=$ área da seção transversal da estaca

$\mathrm{Y}_{1}=$ deslocamento da ponta da estaca necessário para que o atrito lateral seja totalmente mobilizado.

Há, ainda, registro de outras experiências brasileiras envolvendo o tema. ROCHA \& DANTAS (1986) fazem a análise da transferência de carga em estacas raiz que há haviam sido previamente submetidas a três carregamentos, com a realização de mais duas provas de carga. Estas, denominadas 4 e 5, mostram um comportamento "carga x deslocamento" praticamente coincidentes, desde que desprezados os recalques residuais, demonstrando ainda a existência de dois comportamentos bem distintos: um elasto-plástico e um visco-plástico (no trecho final da curva "carga $\mathrm{x}$ recalque").

CARVALHO et al. (1991) fazem análise teórica utilizando dados experimentais de algumas estacas raiz, à tração e à compressão, do campo experimental da USP - São Carlos. Todas as fases de mobilização do modelo foram perfeitamente identificadas. 


\section{CAPÍTULO 3 - CARACTERÍSTICAS DO CAMPO EXPERIMENTAL DA USP - SÃO CARLOS}

\section{1 - BREVE HISTÓRICO}

$\mathrm{O}$ embrião das pesquisas envolvendo fundações por estacas na Escola de Engenharia da USP - São Carlos deve ser creditado ao trabalho pioneiro de ALBIERO (1972), que estudou o comportamento de 16 estacas escavadas, isoladas, tipo broca, em localização próxima à do atual campo experimental. Naquela ocasião foram utilizados resultados de 5 sondagens SPT e 4 ensaios CPT. Além disto, foi feita uma caracterização completa do subsolo, com a determinação de índices físicos e parâmetros geomecânicos (obtidos através de ensaios de compressão simples e triaxiais).

No referido trabalho já é ressaltada a redução na carga de ruptura das estacas na estação chuvosa, como orientação para futuros projetos.

Num segundo passo (CINTRA, 1987) introduziu o estudo da extensometria elétrica, ao estudar, em laboratório, modelos de grupos de estacas cravadas em areia.

Esta base é, por conseguinte, fundamental para fazer a associação de dois elementos-chave no alavancamento do atual campo experimental, isto é, um conjunto de propostas obtidas do primeiro trabalho - que serviu de arcabouço para implementação de um amplo programa de pesquisas - somado à experiência adquirida com a instrumentação, necessária para dotar as novas pesquisas de recursos mais modernos na análise de comportamento do sistema solo-estaca.

NEVES (1987) estuda, sob novos aspectos, a colapsibilidade dos sedimentos cenozoicos de São Carlos, introduzindo o estudo da microscopia eletrônica para analisar o efeito da destruição das ligações cimentantes deste tipo de solo sob efeito de umidificação. Esta mesma pesquisa produz um minucioso estudo do ponto de vista de 
permeabilidade dos solos de São Carlos, com amostras que podem ser consideradas representativas das condições encontradas no campo experimental.

Finalmente, em 1988, graças a um substancial financiamento da FAPESP, é implementado o primeiro módulo do campo, com nova localização, porém preservando todas as condições de representatividade dos solos descritos sob o ponto de vista geológico por BORTOLUCCI (1983) e do ponto de vista de colapsibilidade (VILAR, 1979).

Neste primeiro estágio de implantação foi ocupada uma área com cerca de $400 \mathrm{~m}^{2}$ (CINTRA et al., 1991) para experimentações, envolvendo vários projetos parcelados, sobre estacas isoladas à tração e à compressão, do tipo escavadas (concretadas "in loco") e escavadas injetadas (tipo raiz), sob carregamento lento e rápido, em condições de umidade natural e em condições de inundação.

Esses trabalhos envolvem diversos pesquisadores. MENEZES (1990) estudou amplamente os parâmetros do solo deste primeiro módulo, através de sua completa caracterização e da determinação dos parâmetros de resistência e deformabilidade. Diversas correlações foram então produzidas, envolvendo estas variáveis e os resultados obtidos em sondagens a percussão (SPT) e com penetração contínua estática (CPT).

Os primeiros resultados obtidos em estacas à tração foram divulgados por CARVALHO (1991). MANTILLA (1993) ensaiou estacas à compressão em ensaios lentos e SACILOTTO (1993) em estacas à compressão, ensaios rápidos. No presente trabalho estão se esgotando os propósitos da primeira fase do módulo I com ensaios lentos, sob inundação do solo de fundação das estacas à compressão.

Em 1991 o campo experimental foi ampliado com a adição de mais $200 \mathrm{~m}^{2}$ à planta original, agora com a finalidade de desenvolver pesquisas sobre $\mathrm{o}$ comportamento geotécnico-estrutural de grupos de estacas e de obter os parâmetros dinâmicos do solo. Dentre desta área adicional todos os parâmetros do solo foram reestudados para confirmação e visando, principalmente, a obtenção de parâmetros dinâmicos através de ensaios "cross-hole” (GIACHETTI, 1991). 
O trabalho coletivo dos vários pesquisadores envolvidos nestes projetos, sobretudo quanto ao aspecto das fundações em solos colapsíveis, tem despertado o reconhecimento da comunidade geotécnica brasileira, sendo um exemplo GOLOMBEK (1985) quando afirma: “the São Carlos Engineering School, University of São Paulo, being located in a region of Sandy collapsible soils has been doing a lot of research on the subject".

\section{2 - A GEOLOGIA LOCAL}

Como aspecto geral, a geomorfologia regional é caracterizada por um relevo bem movimentado, onde a erosão introduzida por rios que entalham o planalto de São Carlos produziram mesas e morros isolados por erosão intensa. O centro urbano da cidade está localizado entre as cotas de 775 m e 910 m (BORTOLUCCI, 1983).

A área de interesse assenta-se sobre rochas do Grupo São Bento, que são constituídas por arenitos da Formação Botucatu, principalmente. Sobre elas ocorrem formações conglomeráticas e arenitos do Grupo Bauru.

Finalmente, surge como material superficial os sedimentos cenozoicos, de dominância arenosa, originados do retrabalhamento dos materiais do Grupo Bauru e das Formações Serra Geral e Botucatu. Sua baixa compacidade influencia o SPT, que é também baixo, e a alta porosidade torna-os bastante permeáveis. Apresentam ainda um baixo teor de umidade natural (característica, aliás, comum aos solos de formação tropical) e colapso estrutural quando inundados.

No campo experimental de fundações esta cobertura cenozoica tem uma espessura da ordem de $6 \mathrm{~m}$. Uma linha de seixos, com espessura de aproximadamente $10 \mathrm{~cm}$, aparece então na transição com outro material, decomposto do Grupo Bauru. O nível freático está localizado a uma profundidade aproximada de $10 \mathrm{~m}$.

\section{3 - LOCALIZAÇÃO DO CAMPO EXPERIMENTAL}

A sua localização foi determinada por alguns condicionantes prévios, dentre três posições disponíveis no interior do campus, tendo sido decisivo o fato de ser o mais representativo quanto ao comportamento do solo de fundação da zona urbana de 
São Carlos, além da posição favorável do N. A., situada a mais ou menos $10 \mathrm{~m}$, de modo que estacas projetadas pudessem ser escavadas em uso de lama bentonítica.

Sua relativa proximidade com uma zona onde estão concentradas as edificações mais altas da cidade certamente o capacita à produção de resultados que poderão servir de subsídios para futuros projetos de fundações de grande porte.

O plano de implantação do campo experimental, em sua primeira etapa, consistiu na execução de sondagens preliminares (sendo realizados os ensaios de penetração estática e deepsounding, em número de cinco cada um) e na abertura de um poço (P-1) para coleta de amostras indeformadas e caracterização completa do subsolo.

Para início das pesquisas envolvendo provas de carga foram instaladas seis estacas escavadas e concretadas "in loco", nos diâmetros de 0,35 m, 0,40 m e 0,50 m, três das quais para serem ensaiadas à tração e três à compressão. Foram, além disso, projetadas diversas estacas-raiz como elementos de ancoragem para realização das provas de carga (15 ao todo) e duas outras destinadas a ensaios.

É dentro deste plano, visualizado na FIGURA 3.1, que está inserido o projeto de pesquisas que ora se apresenta.

\section{4 - CARACTERIZAÇÃO GEOTÉCNICA DO MATERIAL ESTUDADO}

Os solos de São Carlos, de um modo geral, apresentam características pouco variáveis em sua primeira camada. A partir de um grande número de observações acumuladas durante anos no laboratório de Geotecnia da USP - São Carlos, seus valores médios por ser resumidos do seguinte modo:

1) Solo no estado natural

a. Teor de umidade $=13 \%$

b. Massa específica $=15,6 \mathrm{MN} / \mathrm{m}^{3}$

c. Massa específica aparente seca $=13,9 \mathrm{MN} / \mathrm{m}^{3}$

d. Índice de vazios $=0,96$ 
e. Massa específica dos sólidos $=27,0 \mathrm{MN} / \mathrm{m}^{3}$

f. Grau de saturação $=37 \%$
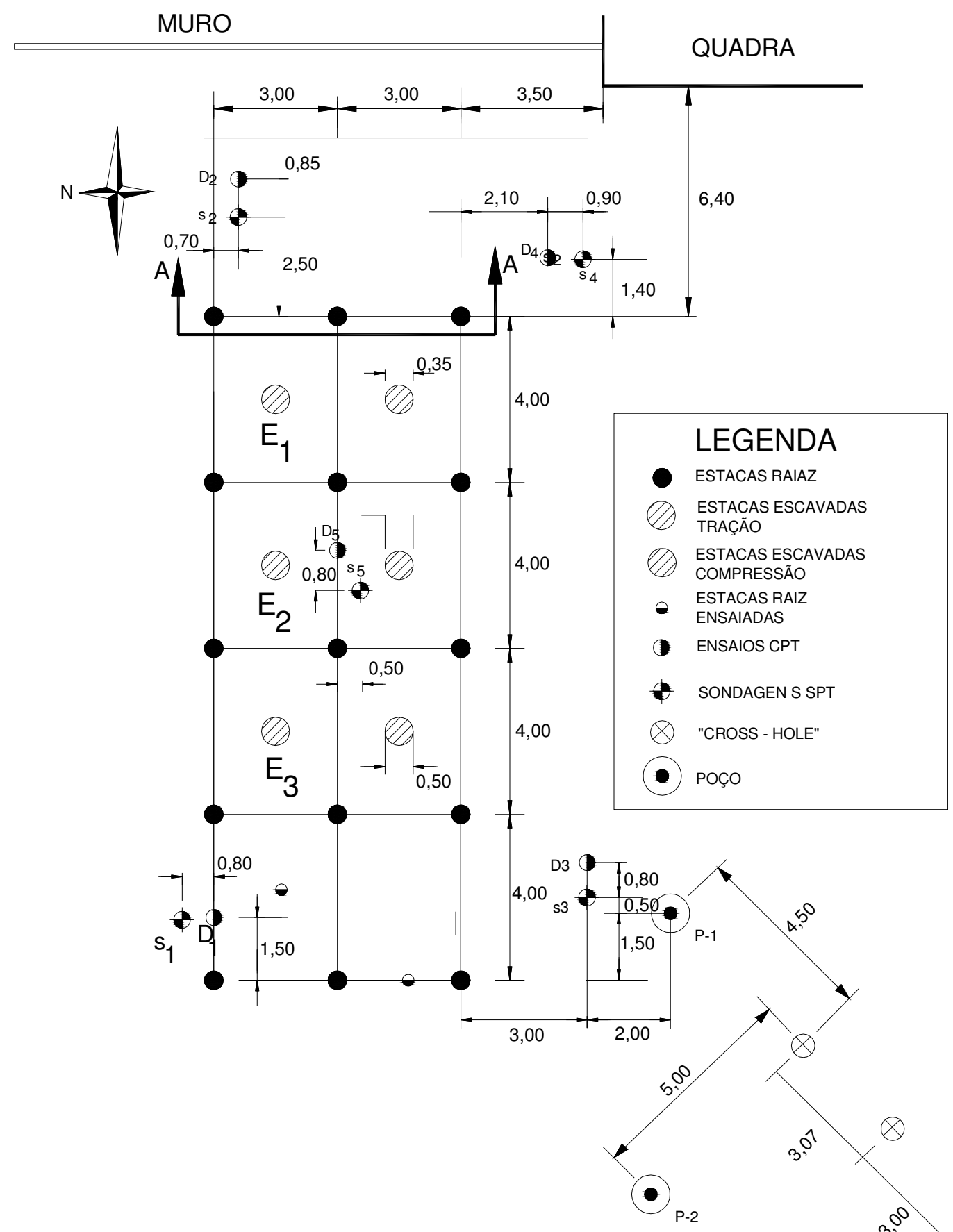

MEDIDAS EM METROS

FIGURA 3.1 - Plano de implantação do campo experimental da USP - São Carlos (CINTRA et al., 1991) 
1) Solo compactado na energia do Proctor Normal

a. Umidade ótima $=15,5 \%$

b. Massa específica seca máxima $=18,8 \mathrm{MN} / \mathrm{m}^{3}$

c. Índice de vazios após compactado $=0,49$

d. Grau de saturação $=85 \%$

2) Solo no limite de liquidez (saturação de 100\%)

a. Teor de umidade (LL) $=24 \%$

b. Índice de vazios no $L L=0,65$

3) Limites de consistência

a. Limite de Liquidez $=24 \%$

b. Limite de Plasticidade $=17 \%$.

Testes mais específicos, com materiais da área do campo experimental, fornecem dados um pouco diferentes, porém consideravelmente dentro dos limites de variabilidade e de precisão normalmente aceitos quando se consideram os ensaios de laboratório. MANTILLA (1993) relaciona uma série destas características através de seus valores médios.

Apresenta-se a seguir um conjunto de informações, sem a preocupação de detalhamento, haja visto que a divulgação dos dados em documentos originais recentes assim o dispensa.

\subsection{1 - Ensaios de simples caracterização}

\subsubsection{1 - Granulometria}

A distribuição é similar nas duas camadas (excluída a linha de seixos), em um conjunto de 10 amostras coletadas de metro - metro, desde a profundidade de 1,3 m até 10,3 m. A classificação granulométrica é a de um solo areno-argiloso. Estudos originais foram procedidos por MENEZES (1990) e posteriormente confirmados por GIACHETTI (1991). 


\subsubsection{2 - Limites de Consistência}

O solo do campo experimental é pouco plástico e as duas camadas apresentam, sob este aspecto, comportamento similar: a plasticidade aumenta discretamente do topo para a base de cada camada sem crescimento do teor de finos em níveis significativos. A média de 10\% para o IP verificada no campo experimental é comparável com os dados gerais dos solos de São Carlos (média de 7\%).

O comportamento dos limites de Atterberg é inteiramente análogo quanto à sua distribuição em perfil vertical. Os resultados apresentados por MENEZES (1990) e GIACHETTI (1991) são muito bem comparáveis.

\subsubsection{3 - Massas específicas}

As massas específicas, natural e seca, são crescentes com a profundidade, de modo quase linear. A massa específica dos sólidos pouco varia, em função da boa homogeneidade do solo local e, principalmente, devido à predominância da fração areia (silicosa) em ambos os horizontes. As informações de MENEZES (1990) e GIACHETTI (1991) são consistentes a este respeito.

\subsubsection{4 - Índice de vazios e grau de saturação}

O índice de vazios é decrescente com a profundidade. Este índice é importante sob o aspecto de caracterização da colapsibilidade do solo, sendo utilizado diretamente em vários critérios de identificação, como DENISOV (1951) e MIHEEV (1962) ou indiretamente, através de possíveis correlações com as massas específicas, seca e dos sólidos (GIBBS \& BARA, 1967; HOLTZ \& HILF, 1961 - apud NEVES, 1987).

Pelo critério de DENISOV (1951), tomando-se por base o índice de vazios no LL $(0,64)$ teríamos que os solos altamente colapsíveis deveriam ter índices de vazios entre 0,87 e 1,3. Conclui-se, pela observação dos dados apresentados na TABELA 3.1 vista a seguir que toda a camada do sedimento cenozoico comporta-se como sendo colapsível. 
Sob o ponto de vista de colapsibilidade, o grau de saturação $\left(\mathrm{S}_{\mathrm{r}}\right)$ é também importante. Pelo critério de MIHEEV (1962), também conhecido como "Código da (ex)URSS", tomando-se ainda por base o índice de vazios no Limite de Liquidez $(0,65)$, o solo seria colapsível se duas situações ocorressem simultaneamente: índice de vazios superior a 0,5 e grau de saturação inferior a 0,6.

Como se pode ver na TABELA 3.1, esta condição é improvável para o solo da segunda camada (residual da Formação Bauru), situada abaixo da linha de seixos. Ademais, pelo critério de DENISOV (1951), esta hipótese estaria confirmada. A não colapsibilidade desta camada carece de estudos específicos, mas esta pré-análise possui boas evidências de ser confirmada.

É interessante observar que, não obstante o N. A. estar virtualmente na posição correspondente à profundidade de 10,0 m (com pequenas variações sazonais de 0,2 m a 0,3 m), o grau de saturação não alcança os $100 \%$ nesta fronteira. Em solos de permeabilidade razoavelmente elevada, este fato é de avaliação complexa à luz da Mecânica dos Solos clássica.

TABELA 3.1 - Caracterização do solo do campo experimental (MENEZES, 1990)

\begin{tabular}{|c|c|c|c|c|c|c|c|c|c|c|c|c|}
\hline \multirow{2}{*}{$\begin{array}{c}\text { PROF } \\
\text { (m) }\end{array}$} & \multicolumn{4}{|c|}{ GRANULOMETRIA } & \multicolumn{3}{|c|}{ UMIDADE (\%) } & \multirow{2}{*}{$\begin{array}{l}\mathbf{S}_{\mathbf{r}} \\
\%\end{array}$} & \multicolumn{3}{|c|}{ M. ESPECÍFICA $\left(t / \mathbf{m}^{3}\right)$} & \multirow{2}{*}{ e0 } \\
\hline & $\mathbf{A M}_{\mathbf{M}}$ & $\mathbf{A}_{\mathbf{F}}$ & SILTE & ARG & $\mathbf{L L}$ & IP & w0 & & $\rho$ & pd & $\rho_{s}$ & \\
\hline 1,3 & 12 & 51 & 11 & 26 & 25 & 9 & 14 & 35 & 1,535 & 1,346 & 2,749 & 0,99 \\
\hline 2,3 & 10 & 55 & 14 & 21 & 26 & 8 & 16 & 40 & 1,540 & 1,327 & 2,682 & 1,01 \\
\hline 3,3 & 10 & 51 & 8 & 31 & 27 & 7 & 17 & 46 & 1,565 & 1,332 & 2,719 & 0,99 \\
\hline 4,3 & 5 & 56 & 11 & 28 & 28 & 10 & 17 & 47 & 1,660 & 1,422 & 2,731 & 0,87 \\
\hline 5,3 & 9 & 54 & 17 & 20 & 30 & 11 & 17 & 53 & 1,730 & 1,485 & 2,762 & 0,82 \\
\hline 6,3 & 8 & 54 & 16 & 22 & 31 & 9 & 18 & 59 & 1,735 & 1,468 & 2,745 & 0,90 \\
\hline 7,3 & 10 & 57 & 14 & 19 & 31 & 9 & 16 & 61 & 1,855 & 1,596 & 2,729 & 0,72 \\
\hline 8,3 & 16 & 54 & 9 & 21 & 34 & 14 & 17 & 60 & 1,850 & 1,580 & 2,773 & 0,68 \\
\hline 9,3 & 17 & 56 & 10 & 17 & 30 & 11 & 16 & 65 & 1,870 & 1,606 & 2,768 & 0,74 \\
\hline 10,3 & 16 & 56 & 8 & 20 & 32 & 14 & 18 & 72 & 1,896 & 1,601 & 2,767 & 0,71 \\
\hline
\end{tabular}

NOTAS: $A_{M}=$ areia média; $A_{F}=$ areia fina

\subsection{2 - Permeabilidade}

Dados de permeabilidade do solo do campo experimental foram obtidos por MENEZES (1990) através de ensaios edométricos em diversas amostras indeformadas. Os resultados obtidos são da ordem de $10^{-7}$ a $10^{-8} \mathrm{~cm} / \mathrm{s}$, o que equivale a dizer que este método não se mostrou adequado para a quantificação deste 
parâmetro, tendo em vista uma análise preliminar das características de granulometria e índice de vazios (TABELA 3.1).

Os ensaios procedidos por NEVES (1987), executados em permeâmetro de carga constante, conduziram a números mais realistas, da ordem de $10^{-3}$ a $10^{-4} \mathrm{~cm} / \mathrm{s}$.

Em qualquer dos casos, as amostras foram ensaiadas de modo que o fluxo processado estivesse na vertical, em relação à posição do material no campo, de modo que a relação entre as permeabilidades, horizontal e vertical, não pode ser obtida.

\subsection{3 - Resistência e compressibilidade}

MENEZES (1990) estudou os parâmetros de resistência por meio de corpos de prova tirados de amostras indeformadas do poço P-1, de metro em metro, desde a profundidade de 1,3 até 10,3 m. Foram executados ensaios de compressão simples e triaxiais (tipos $\mathrm{S}$ e $\mathrm{R}$ ).

As envoltórias de resistência (critério de MOHR-COULOMB) dos ensaios triaxiais forneceram:

1) Para os ensaios lentos: $\mathrm{s}=13+\sigma \cdot \operatorname{tg} 26,6^{\circ}(\mathrm{kPa})$

2) Para os ensaios rápidos: $\mathrm{s}=18,1+\sigma . \operatorname{tg} 20,8^{\circ}(\mathrm{kPa})$

MENEZES (1990), GIACHETTI (1991) e MANTILLA (1992) dão informações mais detalhadas sobre os parâmetros de resistência e deformabilidade.

\subsection{4 - Sondagens de reconhecimento}

Os resultados das sondagens de penetração dinâmica e estática, analisadas por MENEZES (1990) estão registrados na TABELA 3.2.

TABELA 3.2 - Resultados dos ensaios de penetração do campo experimental

\begin{tabular}{|c|c|c|c|}
\hline \multirow{2}{*}{ PROFUNDIDADE (m) } & \multirow{2}{*}{ SPT (médio) } & \multicolumn{2}{|c|}{ CPT (médio) } \\
\cline { 3 - 4 } & 5 & 1,66 & $\mathbf{A}_{\mathbf{L}}$ \\
\hline 1,3 & 2 & 1,06 & 40,5 \\
\hline 2,3 & 4 & 0,78 & 43,6 \\
\hline 3,3 & 3 & 0,90 & 52,0 \\
\hline 4,3 & 4 & 0,96 & 60,5 \\
\hline 5,3 & 5 & 1,24 & 66,1 \\
\hline 6,3 & & & \\
\hline
\end{tabular}




\begin{tabular}{|c|l|l|l|}
\hline 7,3 & 7 & 1,90 & 115,3 \\
\hline 8,3 & 9 & 2,82 & 178,5 \\
\hline 9,3 & 9 & 1,88 & 181,3 \\
\hline 10,3 & 7 & 2,96 & 208,0 \\
\hline
\end{tabular}

\subsection{5 - Correlações entre os diversos parâmetros do solo}

MENEZES (1990) e MENEZES et al. (1991) apresentam correlações entre SPT e CPT, bem como entre os diversos parâmetros e outros resultados de caracterização e resistência encontrados nos ensaios de laboratório. Estas correlações podem ser utilizadas na previsão da capacidade de carga e do comportamento "carga $\mathrm{x}$ recalque" de fundações da zona estudada, sendo, ainda, indicativo de orientação geral para projetos em regiões com certa identidade nas características do subsolo.

Outras correlações, estas envolvendo apenas as variáveis $\mathrm{q}_{\mathrm{c}} \mathrm{e} \mathrm{N}$, provenientes dos ensaios de penetração, foram apresentadas em ALBIERO (1990) e CARVALHO (1991).

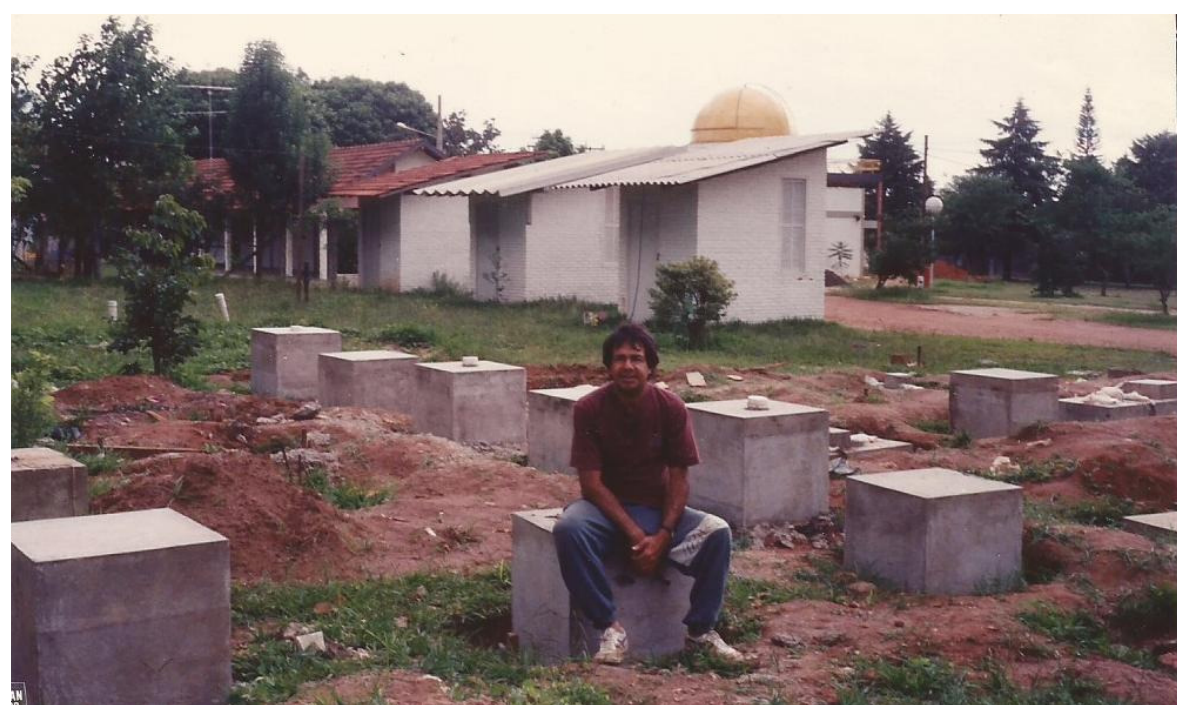

FOTO 2 - Vista do campo experimental da USP - São Carlos 


\section{CAPÍtulo 4 - PROVAS DE CARGa: ObJetivos, MATERIAIS E MÉTODOS}

\section{1 - ESTACAS ENSAIADAS E INSTRUMENTAÇÃO}

\subsection{1 - Objetivos}

A intenção deste trabalho esgota-se nos seguintes fins:

1) Analisar procedimentos convencionais para inundação do solo durante a realização das provas de carga e fornecer alguma contribuição para futuras pesquisas em condições similares

2) Analisar os efeitos exercidos pela inundação de solos colapsíveis de São Carlos em termos de:

a. Capacidade de carga das estacas

b. Comportamento "carga x recalque"

c. Processos de transferência de carga

d. Variação das resistências unitárias (lateral e de ponta).

Um planejamento de atividades, visando à consecução de tais objetivos, remete-nos, preliminarmente, a certas indagações:

1) Como inundar o solo de modo eficiente e rápido?

2) Que tipo de prova de carga é mais adequado e qual o seu tempo de duração?

3) Em quantos estágios deverão ser programadas as provas de carga, especialmente na fase de inundação e de que modo será feito o acompanhamento?

4) É possível o desenvolvimento de atrito negativo com a ocorrência do colapso?

5) As informações oriundas de experiências similares podem, realmente, ser adaptadas para esta pesquisa? 
6) Como prever, teoricamente, a carga última e a carga na qual se dará o colapso?

7) Como escolher o critério de estabilização (Norma? Mais rigoroso?) e como definir o momento de paralisação das provas de carga?

Muitas destas questões produzem um certo sentimento de incerteza e ambiguidade, em vista das lacunas bibliográficas. O norteamento das decisões foi, muitas vezes, guiado pelo bom senso e até mesmo pela intuição.

\subsection{2 - Descrição das estacas de prova}

De acordo com a notação da FIGURA 3.1 as estacas de prova à compressão do campo experimental são denominadas $E_{1}(D=0,35 \mathrm{~m}), \mathrm{E}_{2}(\mathrm{D}=0,40 \mathrm{~m})$ e $\mathrm{E}_{3}(\mathrm{D}=$ $0,50 \mathrm{~m})$, tendo igual comprimento de $10,0 \mathrm{~m}$.

Embora as provas de carga precedentes tenham sido realizadas sobre as três estacas, observou-se a tendência da estaca $E_{1}$ de se aproximar da estaca $E_{2}$ em termos de capacidade de carga, o que invalidaria uma parte dos objetivos da pesquisa. Receava-se, além disso, que os efeitos acumulados da inundação em duas estacas previamente ensaiadas mascarassem o efeito sobre a terceira estaca, prejudicando as análises, no seu aspecto de comparabilidade.

A decisão de substituir a prova de carga sobre $E_{1}$ pelo reensaio da estaca $E_{3}$, inundada desde o início do carregamento, foi julgada conveniente e realista.

Um plano executivo foi então elaborado dentro da sequência:

FASE 1: ensaiar a estaca intermediária $\left(\mathrm{E}_{2}\right)$, conduzindo a prova de carga com o solo em condição de umidade natural até uma suposta carga de trabalho, estimada como a metade da carga última verificada em prova de carga anterior (MATILLA, 1992).

FASE 2: atingida esta carga de trabalho o solo seria imediatamente inundado, com manutenção da carga, na expectativa de ocorrência do colapso.

FASE 3: uma vez atingido o colapso e verificada a estabilização dos deslocamentos para o estágio de carga correspondente, a prova de 
carga prosseguiria, com pequenos incrementos de carga. Ficou também decidido pela continuação da prova de carga mesmo após o esgotamento do curso de $50 \mathrm{~mm}$ dos extensômetros, o que equivale a dizer que os deslocamentos admitidos seriam superiores aos recomendados pela NBR 6121/86 (recalque elástico da estaca mais 0,1 x D). Esta decisão estava coerente com os procedimentos adotados em provas de carga anteriores nestas mesmas condições.

FASE 4: a estaca seria então descarregada, continuando sob inundação. Por precaução, foi previsto um intervalo de 24 horas, desde a constatação da "ruptura" até o início da descarga.

FASE 5: terminada a descarga, seria feita uma leitura final após 12 horas e, somente então, a torneira de abastecimento d'água seria fechada.

Todas estas fases seriam repetidas para a estaca $\mathrm{E}_{3}$. Receava-se, contudo, que devido à proximidade entre as duas, a condição de umidade natural estaria sendo desrespeitada caso a prova de carga fosse executada logo em seguida. Por este motivo, foi reservado um intervalo de 15 dias para tentar o restabelecimento desta condição.

Ao final da Fase 5 da estaca $E_{3}$, em vez de fechar a torneira de alimentação, seria realizada uma nova prova de carga sobre a mesma estaca, com o solo inundado desde o início. Esta prova de carga seria conduzida até o estágio onde fora anteriormente inundada, isto é, até a carga de trabalho. Com isto, visava-se comparar o comportamento da estaca (carga-recalque e transferência de carga), em sua fase elástica, sujeita a duas condições distintas de saturação.

A expectativa inicial era a de que a duração de cada uma das duas provas de carga iniciais fosse de 10 a 15 dias, com base em informações recolhidas de uma experiência similar, descrita por NADEO \& VIDELLA (1975a, 1975b). A previsão praticamente se confirmou (ver o CRONOGRAMA DE ATIVIDADES DE CAMPO, nos anexos).

\subsection{3 - Instrumentação das estacas}


Estas estacas são instrumentadas, em profundidade, em cinco níveis distintos, constando de cinco pares de "strain-gages" colados na armadura em posições diametralmente opostas e ainda de cinco hastes medidoras ("telltales") instaladas nestes mesmos níveis, como se vê na FIGURA 4.1.

Os detalhes desta instrumentação, aqui omitidos por uma questão de brevidade, estão exaustivamente descritos no trabalho pioneiro de CARVALHO (1991). Cumpre lembrar, contudo, que as hastes medidoras de deslocamentos jamais funcionaram a contento, por razões ainda não compreendidas ou explicadas.

Deste modo, todas as leituras de deformações foram tomadas através dos "strain-gages" (medidores elétricos, de resistência, fornecidos por empresa brasileira, com ligação do tipo "Ponte de WHEATSTONE"). Trata-se do modelo KFC-5-D1 1611, KYOWA.

LOPES (1986) discute a eficiência destes "strain-gages" e neles constata simplicidade e acurácia, justificando a sua adoção.

A seção instrumentada no nível 1 (FIGURA 4.1) ficava originalmente livre do solo envolvente, com o objetivo de possibilitar a obtenção do módulo de elasticidade linear do concreto da estaca, já que permaneceria livre da influência do atrito lateral do solo. As deformações observadas nesta seção seriam, de fato, representativas das deformações elásticas do material da estaca.

Entretanto, após uma série de ensaios sobre estas estacas, é visível a existência de uma pequena área de contato com o solo da porção imediatamente acima deste nível, como se pode depreender dos dados de deslocamentos acumulados (FIGURA 4.2).

\subsection{4 - Histórico do carregamento das estacas}

As estacas de prova passaram por sucessivos carregamentos, dentro do programa global de pesquisas que se tinha em mente executar. A evolução da capacidade de carga é uma consequência deste histórico e pode ser apreciada através das previsões teóricas por meio de métodos brasileiros empíricos e das provas de 
carga interpretadas pelo método de VAN DER VEEN (1953) conforme a TABELA 4.1.

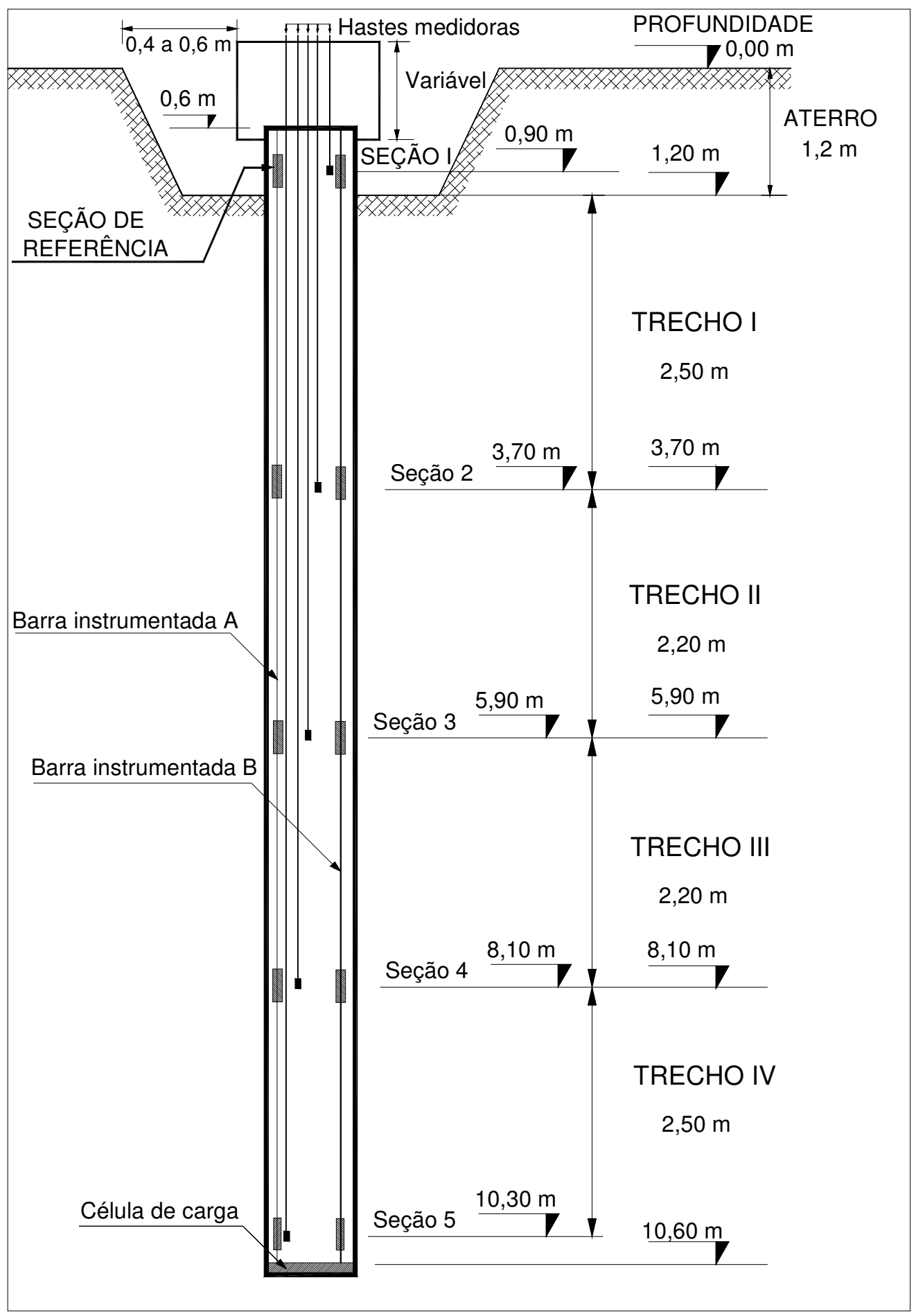

FIGURA 4.1 - Seção típica (longitudinal) de uma estaca, com a localização dos pontos instrumentados (MANTILLA, 1992) 


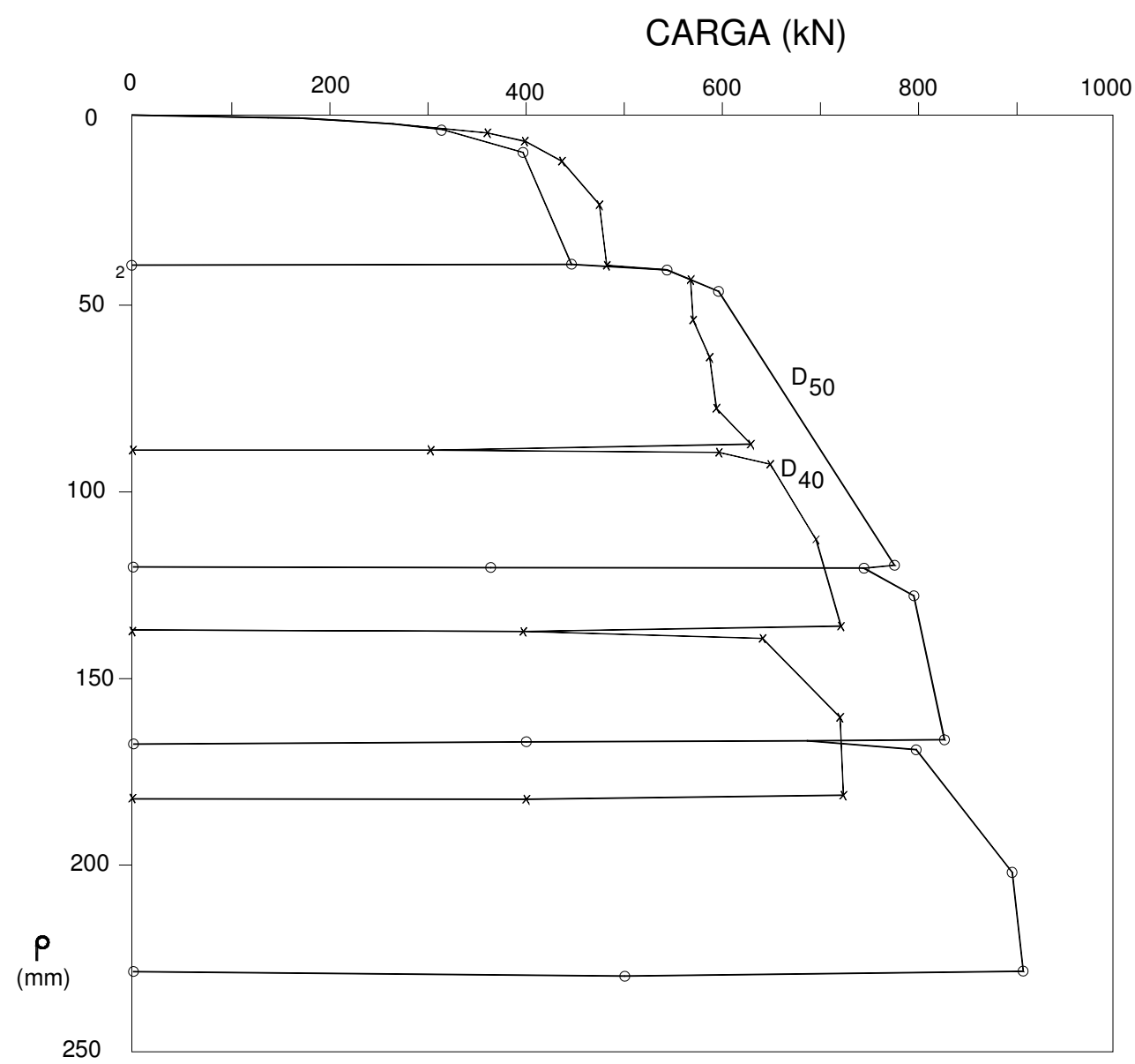

FIGURA 4.2 - Afundamentos das estacas após as 4 primeiras provas de carga (MANTILLA, 1992)

TABELA 4.1 - Evolução das cargas últimas das estacas $E_{1}, E_{2}$ e $E_{3}$, em kN (MANTILLA, 1992)

\begin{tabular}{|l|c|c|c|}
\hline \multirow{2}{*}{\multicolumn{1}{|c|}{ MÉTODO }} & \multicolumn{3}{c|}{ DIÂMETRO DA ESTACA (m) } \\
\cline { 2 - 4 } & 0,35 & 0,40 & 0,50 \\
\hline AOKI \& VELLOSO & 315,5 & 385,8 & 545,1 \\
\hline DÉCOURT \& QUARESMA & 623,0 & 766,5 & 1094,3 \\
\hline VAN DER VEEN: & & & \\
$1^{\text {a }}$ prova de carga (Lenta) & 335,0 & 488,0 & 451,0 \\
$2^{\mathrm{a}}$ prova de carga (Rápida) & 391,0 & 595,0 & 725,0 \\
$3^{\mathrm{a}}$ prova de carga (rápida) & 648,0 & 727,0 & 831,0 \\
$4^{\mathrm{a}}$ prova de carga (lenta) & 645,00 & 726,0 & 911,0 \\
\hline
\end{tabular}

\section{2 - MÓDULO DE ELASTICIDADE LONGITUDINAL DO MATERIAL DAS ESTACAS}

O módulo de YOUNG do material das estacas foi determinado anteriormente por MANTILLA (1993) e SACILLOTO (1993), utilizando correlações lineares entre os valores observados de deformações e tensões da seção 1 (de referência) das estacas. 
Estes valores estão apresentados na TABELA 4.2. As designações das provas de carga que aparecem nesta tabela são consistentes com as que aparecerão na tabela 5.1.

TABELA 4.2 - Evolução das cargas últimas das estacas $E_{1}, E_{2}$ e E $E_{3}$, em kN (MANTILLA, 1992)

\begin{tabular}{|l|c|c|c|c|}
\hline \multirow{2}{*}{ AUTOR } & \multicolumn{2}{|c|}{ PROVA DE CARGA } & \multirow{2}{*}{$\begin{array}{c}\mathrm{E}_{\mathrm{p}} \\
(\mathrm{Mpa})\end{array}$} & $\begin{array}{c}\text { COEF. DE } \\
\text { CORRELAÇÃO R }\end{array}$ \\
\cline { 2 - 3 } & TIPO & DESIGNAÇÃO & $30.736,32$ & 0,998958 \\
\hline MANTILLA (1989) & SML & $\mathrm{D}_{40(1)}$ & 3059 \\
\hline MANTILLA (1989) & SML & $\mathrm{D}_{50(1)}$ & $26.892,98$ & 0,999598 \\
\hline SACILOTTO (1991) & QML & $\mathrm{D}_{40(2)}$ & $21.943,67$ & 0,999452 \\
\hline SACILOTTO (1991) & QML & $\mathrm{D}_{50(2)}$ & $23.716,43$ & 0,969575 \\
\hline SACILOTTO (1992) & QML & $\mathrm{D}_{40(3)}$ & - & - \\
\hline SACILOTTO (1992) & QML & $\mathrm{D}_{50(3)}$ & $28.521,98$ & 0,997733 \\
\hline MANTILLA (1992) & SML & $\mathrm{D}_{40(4)}$ & - & - \\
\hline MANTILLA (1992) & SML & $\mathrm{D}_{50(4)}$ & $26.836,81$ & 0,999724 \\
\hline
\end{tabular}

Observe-se, a partir dos dados da TABELA 4.2, o seguinte:

1) Os valores de $\mathrm{E}$ medidos nas mesmas estacas em ocasiões diferentes $\mathrm{e}$ em tipos distintos de provas de carga são significativamente variáveis

2) Como estas medidas referem-se aos intervalos de deformações elásticas do material, as equações de regressão linear mostram-se muito bem ajustadas, passando pela origem, com $\mathrm{R}^{2}$ praticamente unitário

3) As deformações, no regime elástico, correspondente a uma mesma carga, são diferentes nos ensaios rápido e lento. As tangentes que representam a Lei de HOOKE costumam dar resultados menores nas provas de carga rápidas (menor rigidez do material a solicitações rápidas).

Quando se toma o módulo de elasticidade em um certo nível, vizinho ao topo da estaca e se generaliza este resultado para todo o seu comprimento, há indícios de que se comete algum erro.

A expectativa do aumento de $\mathrm{E}$ com a profundidade é razoável em estacas concretadas "in loco", com o concreto lançado desde a superfície, por causa de um melhor adensamento nas seções próximas à base.

A este respeito ROCHA \& DANTAS (1986) estabelecem algumas conclusões para argamassa de estacas raiz. Foi constatado um acréscimo de $\mathrm{E}_{\mathrm{p}}$ da ordem de 16 
$\mathrm{GPa}$ (na superfície) para aproximadamente $18 \mathrm{GPa}$ (a $9 \mathrm{~m}$ de profundidade). Tais resultados mostram-se muito consistentes com as demais conclusões, da mesma fonte, acerca do decréscimo do volume de vazios e do aumento da massa específica com a profundidade.

AZEVEDO JR. \& NIYAMA (1990) referem-se ao valor de $21 \mathrm{GPa}$, comumente adotado para cálculo de deformações em estacas de concreto armado, como sendo questionável e capaz de produzir erros significativos na interpretação de resultados. Em pesquisa empreendida por esses autores, medindo-se $\mathrm{E}_{\mathrm{p}}$ através de vários procedimentos, ficou comprovada a grande susceptibilidade deste parâmetro a variações importantes. Os principais resultados podem ser assim sumarizados:

1) $\mathrm{E}_{\mathrm{p}}$ medido através de instrumentação em prova de carga: $25 \mathrm{GPa}$

2) Idem, através de corpos de prova extraídos das estacas: $18 \mathrm{GPa}$

3) Idem, através de corpos de prova moldados do concreto fresco: $15 \mathrm{GPa}$

4) Através de ensaios de compressão simples sobre segmentos de estaca, incluindo armadura: $15 \mathrm{GPa}$.

Para esta pesquisa os valores de $\mathrm{E}_{\mathrm{p}}$ adotados serão obtidos através da tabela 4.2 , relativos às provas de carga lenta da primeira sequência.

\section{3 - MONTAGEM DAS PROVAS DE CARGA. EQUIPAMENTOS E MÉTODOS}

A fim de dar maior representatividade possível aos ensaios, a montagem adotada para as provas de carga foi absolutamente similar à da sequência 1-2-3-4 anterior. O mesmo sistema e os mesmos procedimentos na instalação das vigas de referência e nos nivelamentos foram adotados.

Também o equipamento foi o mesmo. Significa dizer que a calibração é a mesma, o que garante um mínimo de comparabilidade para as análises e conclusões.

Fazendo-se uso de uma barraca de lona, as provas de carga foram mantidas ao abrigo das intempéries, provendo garantia do bom funcionamento dos instrumentos de leitura, como recomenda a ABNT (item no 3.1.3 da NBR 6121/86). 
Como elementos de suporte da viga de reação foram utilizadas estacas raiz de $16 \mathrm{~m}$ de comprimento e diâmetro de $0,25 \mathrm{~m}$, projetadas para garantir, isoladamente, cargas de $500 \mathrm{kN}$. Porém, em testes anteriores, comprovou-se um comportamento, sem ruptura, de até $700 \mathrm{kN}$.

A estrutura metálica de reação, descrita em CARVALHO (1991) e MANTILLA (1993) consta de perfis I soldados, estando apta a receber cargas de até $2000 \mathrm{kN}$.

Cuidados especiais foram tomados na composição da coluna (macaco, célula de carga e cilindros metálicos), desde o bloco de coroamento sobre a cabeça da estaca até a estrutura de reação, de modo a minimizar a excentricidade (FOTO 3).

A possibilidade de a inundação do terreno vir a afetar o nível das vigas de referência e a influenciar a leitura dos deslocamentos foi, inadvertidamente, desconsiderada. Esta ressalva tem como propósito alertar para este cuidado em futuras pesquisas em solos colapsíveis inundados.

Para medida dos recalques no topo da estaca foram usados quatro extensômetros MITUTOYO, com curso de leitura de $50 \mathrm{~mm}$ e precisão de $0,01 \mathrm{~mm}$, instalados em posições diametralmente opostas, a cerca de $40 \mathrm{~cm}$ do centro das estacas (FOTO 3).

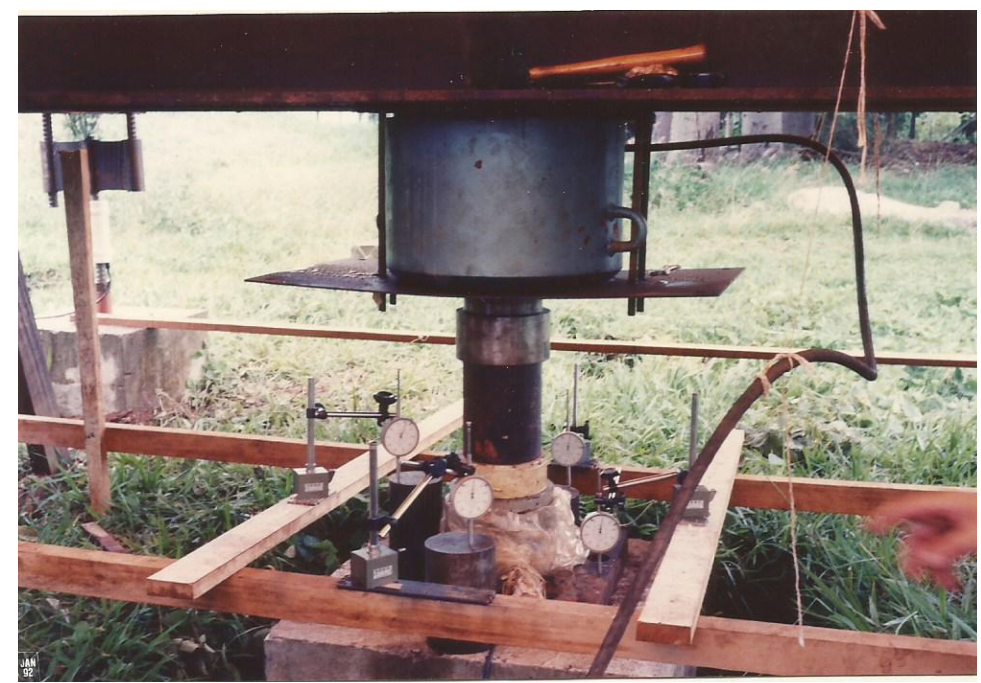

FOTO 3 - Montagem de uma prova de carga típica, observando-se a célula de carga entre os cilindros de extensão e o macaco hidráulico. 
A aplicação de cargas foi feita através de uma bomba manual, munida de manômetro PONTEMAC, graduado de 2 - $2 \mathrm{MPa}$ até a capacidade total de $70 \mathrm{Mpa}$ e macaco hidráulico marca PONTEMAC, modelo MHF-17, com capacidade de carga de $2000 \mathrm{kN}$. Este é o mesmo sistema utilizado nas provas de carga de MANTILLA (1991), também com vistas a obter representatividade nas comparações.

Com a finalidade de medir, com boa precisão, a carga transmitida à cabeça da estaca, foi instalada, em série com o macaco hidráulico, uma célula de carga TRANSDUTEC, $\mathrm{n}^{\circ}$ de série 0667, fator de extensômetro de 2,15 e capacidade de carga de $1200 \mathrm{kN}$.

Esta célula de carga, bem como os 10 "strain-gages" colados, aos pares, em cinco diferentes níveis nas armaduras, forneciam os resultados lidos diretamente em um indicador de deformações TRANSDUTEC, modelo T-832, com capacidade de medição de deformações específicas de $50.000 \times 10^{-5} \mathrm{~mm} / \mathrm{mm}$. As leituras eram fornecidas em 4 dígitos, utilizando o princípio da detecção de zeros no dial. Foram usados 11 canais do seletor, sendo um da célula de carga e dez dos "strain-gages". A caixa seletora é um modelo CS-23T da TRANSDUTEC. Alguns destes canais mostraram leituras flutuantes, sendo prontamente descartados.

O uso da célula de carga é defendido por LOPES (1986) e serve para demonstrar uma certa inaptidão do manômetro em indicar leituras corretas na aplicação das cargas. É relatado por aquele autor uma discrepância de $20 \%$ entre os valores lidos no manômetro do macaco hidráulico e os indicados pela célula de carga.

Todas as provas de carga foram do tipo SML, conforme recomendação da NBR 6121/86 da ABNT. Algumas recomendações inseridas na minuta de proposta de uma nova norma (1991) foram observadas, sempre no sentido de aprimorar os resultados.

A opção pelo método lento, implícito na norma, é bem defendida por VARGAS (1990), tendo por finalidade evitar os efeitos de deformações viscoelásticas intervenientes nos carregamentos rápidos e que são capazes de afetar o comportamento carga-recalque durante a fase crítica do colapso. 
No estágio de carga onde se deu o colapso, as provas de carga foram subsidiadas por um conjunto de leituras muito mais frequente do que o recomendado pela ABNT. Foram feitas de hora em hora, ou até menos, a partir dos convencionados 120 minutos, sem, contudo, prejudicar as leituras em tempos usuais.

Acompanhamento através de curvas "carga $\mathrm{x} \log \mathrm{t}$ " foi providenciado em estágios de longa duração (colapso). Este procedimento é sugerido por FERREIRA \& LOPES (1985).

Os carregamentos foram aplicados em estágios de $10 \%$ da carga de trabalho somente até o instante da inundação. A partir daí, por medida de precaução, os incrementos foram deliberadamente diminuídos para a metade dos acréscimos anteriores, a fim de dar melhor definição à curva "carga x recalque" e, principalmente, detectar com mais sensibilidade a carga de colapso.

Os ciclos de descarga foram feitos em 4 estágios, igualmente espaçados, conforme recomendações expressas pela NBR 6121/86. Este espaçamento só não foi conseguido na prova de carga da estaca $\mathrm{E}_{2}$ por causa de um pequeno acidente com a válvula de pressão do óleo da bomba.

\section{4 - PROCEDIMENTO ADOTADO PARA INUNDAÇÃO DO SOLO}

Durante a fase de planejamento dos trabalhos de campo surgiram estas grandes questões a serem resolvidas antes de qualquer tomada de decisão:

1) Qual o grau de saturação crítico, a partir do qual o solo entraria em colapso?

2) Que volume de água seria demandado para alcançar este estágio?

3) Qual a velocidade de percolação da água nas camadas (ou melhor dizendo, em quanto tempo um certo volume de água levaria o solo ao grau de saturação mobilizador do colapso?).

A superficialidade das informações recolhidas na revisão bibliográfica e as dificuldades de resolver estas questões por qualquer raciocínio lógico constituíram-se em desafio e motivação para desenvolver um estudo mais detalhado do problema. A 
descrição destes resultados objetiva fornecer instrumentos mais válidos que possam ser integrados ao meio técnico como uma contribuição que favoreça a tomada de decisão em futuras situações análogas.

Como se verá a seguir, o pequeno avanço conseguido com os resultados é meramente indicativo de que o problema apresenta dificuldades mais sérias, sugerindo um estudo específico e em profundidade.

As informações seguintes podem ser acompanhadas pela FIGURA 4.3.

Foram construídas duas cavas experimentais $\left(\mathrm{C}_{1}\right.$ e $\left.\mathrm{C}_{2}\right)$, com capacidade de 2.000 litros, aproximadamente. A cava $\mathrm{C}_{2}$ foi totalmente impermeabilizada: as paredes laterais foram revestidas com lona plástica e o fundo, antes de receber recobrimento com a mesma lona, foi tratado com duas demãos de emulsão asfáltica RR-1C, aplicadas à taxa de 2 litros por metro quadrado por demão. Nesta lona de fundo foram deixadas duas aberturas com diâmetros idênticos aos dos furos $(15 \mathrm{~cm})$, feitas com a finalidade de permitir o ingresso da água somente através deles (FOTO 4).

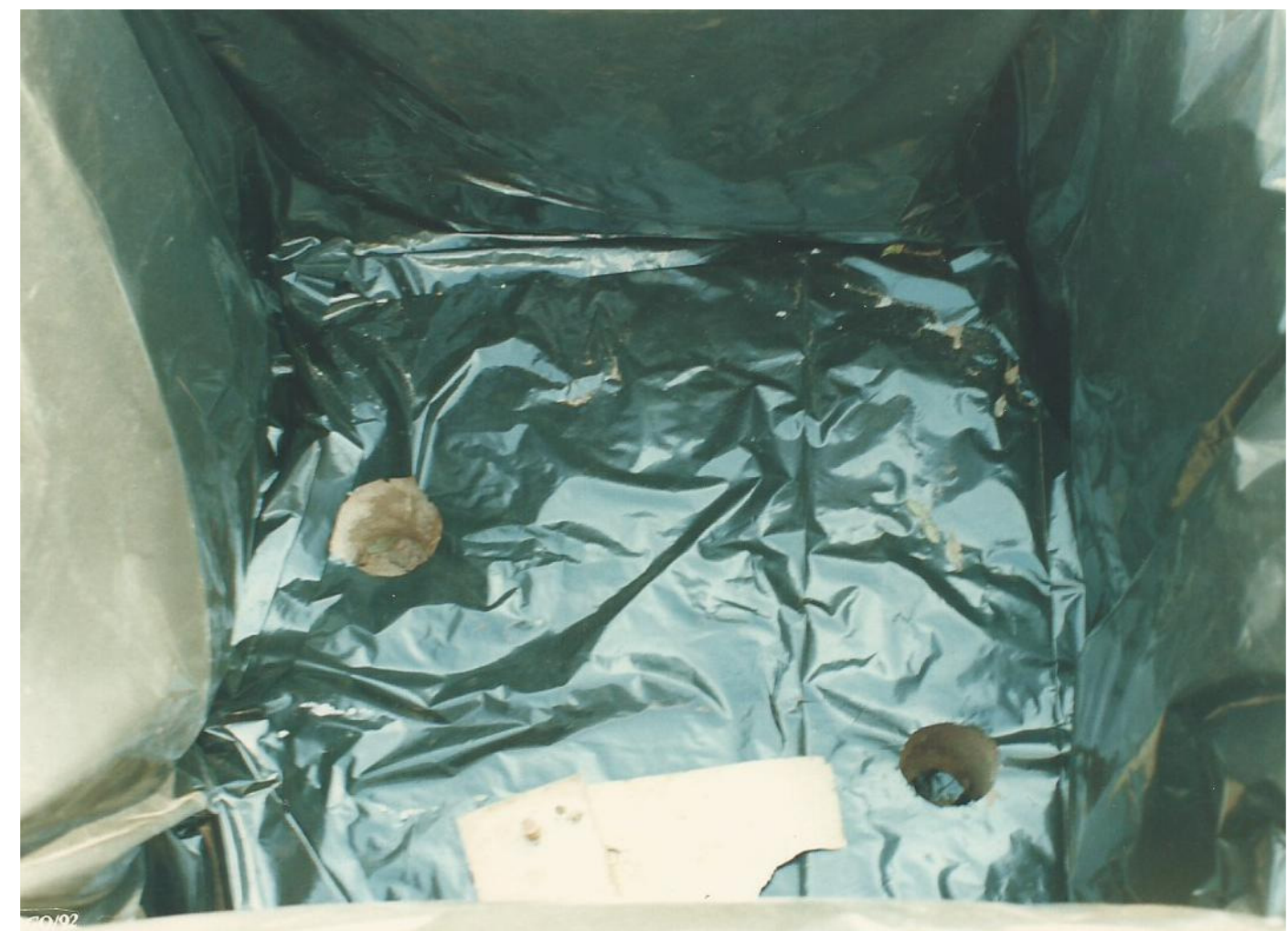

FOTO 4- Cava experimental $\mathrm{C}_{2}$, com detalhe do revestimento impermeabilizante, que permitia o ingresso de água somente pelos furos 


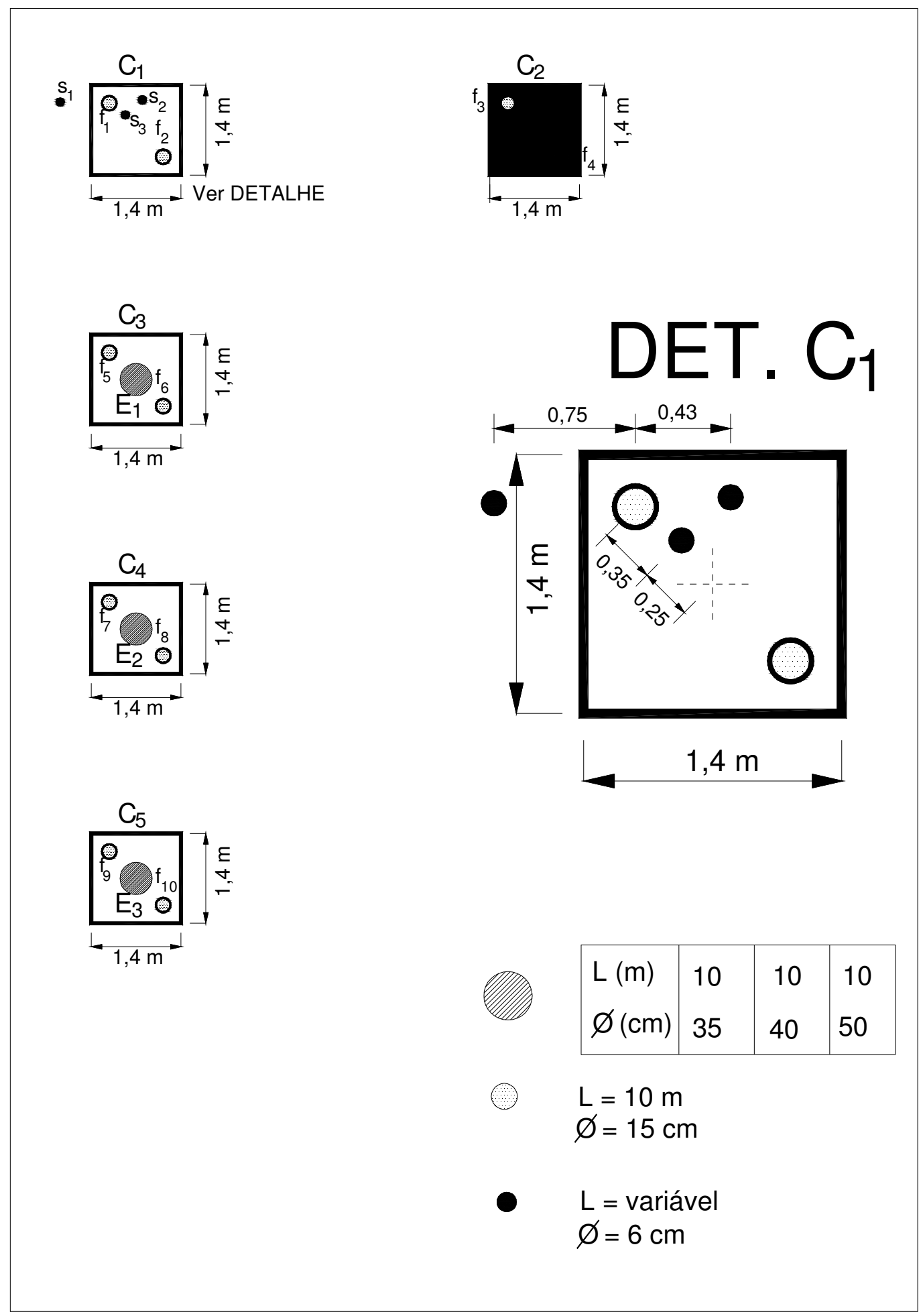

FIGURA 4.3- Cavas experimentais para estudos preliminares do processo de inundação das provas de carga

A FIGURA 4.4 dá maiores indicações destes furos, preenchidos com areia média (permeabilidade da ordem de $10^{-2} \mathrm{~cm} / \mathrm{s}$ ). 


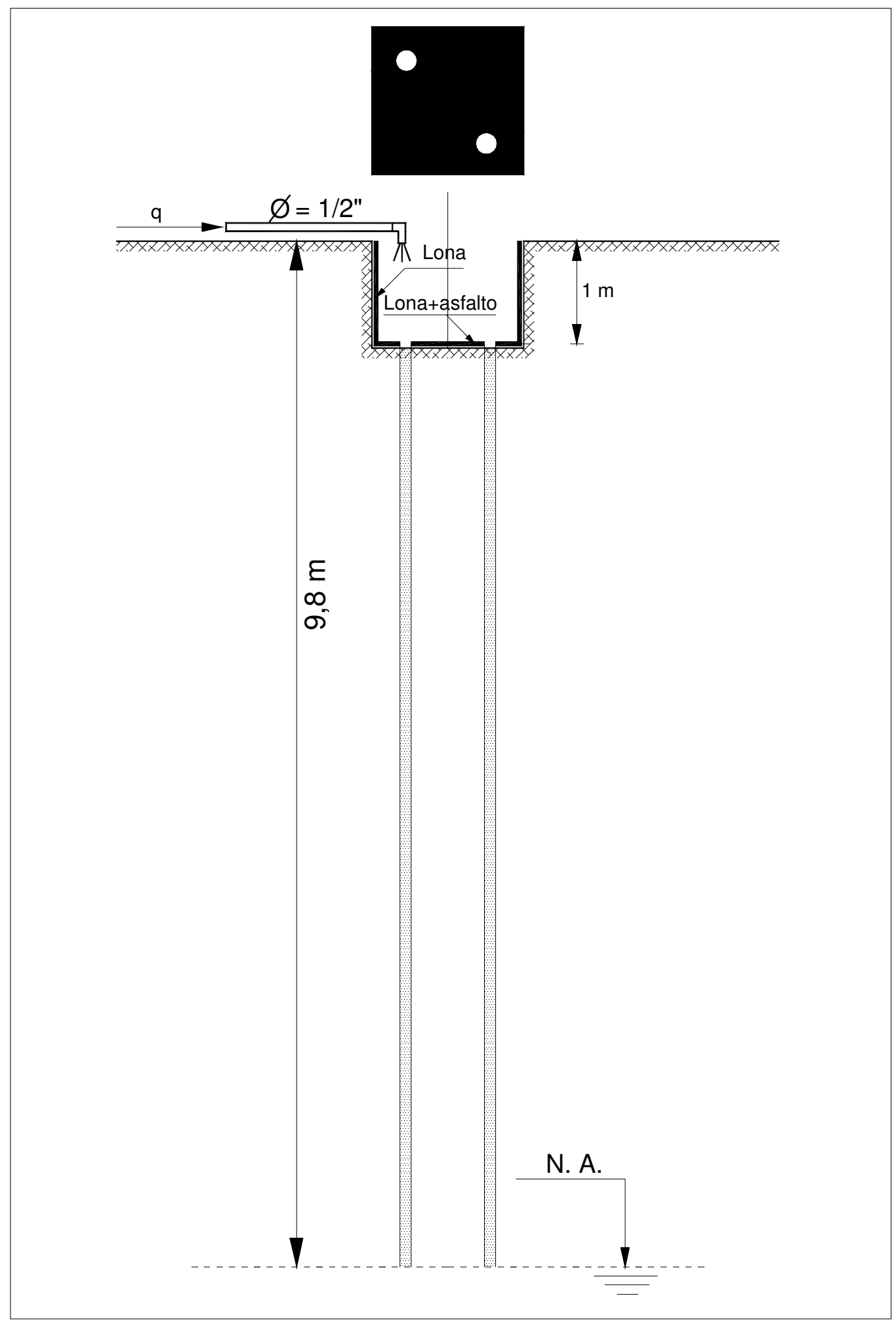

FIGURA 4.4- Detalhes da cava experimental $\mathrm{C}_{2}$ (medidas em metros)

A cava $\mathrm{C}_{1}$ possui algumas diferenças. Uma delas se refere à ausência de revestimento no fundo, permitindo, assim, o ingresso da água pelos furos e pelo 
fundo. A separação da água que penetrava por estes dois tipos de acesso poderia ser quantificada, por meio da comparação de consumo entre as duas cavas.

Preliminarmente, foram feitas diversas observações sobre as vazões instantâneas das tubulações instaladas para inundação das cavas. Isto foi feito no período de 20 a 26 de maio de 1992, antes do início da primeira prova de carga.

As vazões eram medidas diretamente na torneira de alimentação, com frequência horária. A variação diurna verificada mostrou-se grande: mínimo de 0,21 litros por segundo e máximo de 0,28 litros por segundo. No entanto, o período noturno apresentava boa estabilidade (cerca de 0,30 litros por segundo).

Estas observações, feitas sempre com o objetivo de se precisar o volume de água que entrava no solo, teve continuidade quando do início da primeira prova de carga, em 11 de junho de 1992. A concordância com os resultados preliminares validou a experiência antecedente.

Algumas das observações feitas foram representadas nos gráficos das FIGURAS 4.5a e 4.5b. Com isto, foi possível construir o gráfico da FIGURA 4.6 e calcular o volume de água ingressante na cava (em torno de $23 \mathrm{~m}^{3}$ por dia).

Uma das questões pendentes - a taxa de infiltração da água no terreno exigiu a construção de curvas de enchimento (FIGURA 4.7) e de esvaziamento (FIGURA 4.8 e FIGURA 4.9).

Como se vê na FIGURA 4.7 a vazão de enchimento (água admitida) varia linearmente com o tempo e o volume acumulado pode ser calculado pelo gráfico através da área OAB. Esta linearidade, contudo, não é verificada para o volume armazenado. Há uma tendência de estabilização do nível máximo da lâmina d'água em torno de $42 \mathrm{~cm}$.

Somente no início da curva OCB (FIGURA 4.7) se nota um aumento na acumulação. Por volta de 200 minutos a lâmina d'água permaneceu constante, correspondendo ao estágio de equilíbrio entre os volumes admitido e infiltrado. 
Esta característica foi integralmente confirmada durante a realização das provas de carga. Após 2 - 3 horas do início da inundação registravam-se flutuações da lâmina d'água entre $37 \mathrm{~cm}$ e $48 \mathrm{~cm}$, o que dependia, igualmente, da própria oscilação diária das vazões. Em cada caso o período de observação foi de 13 dias.
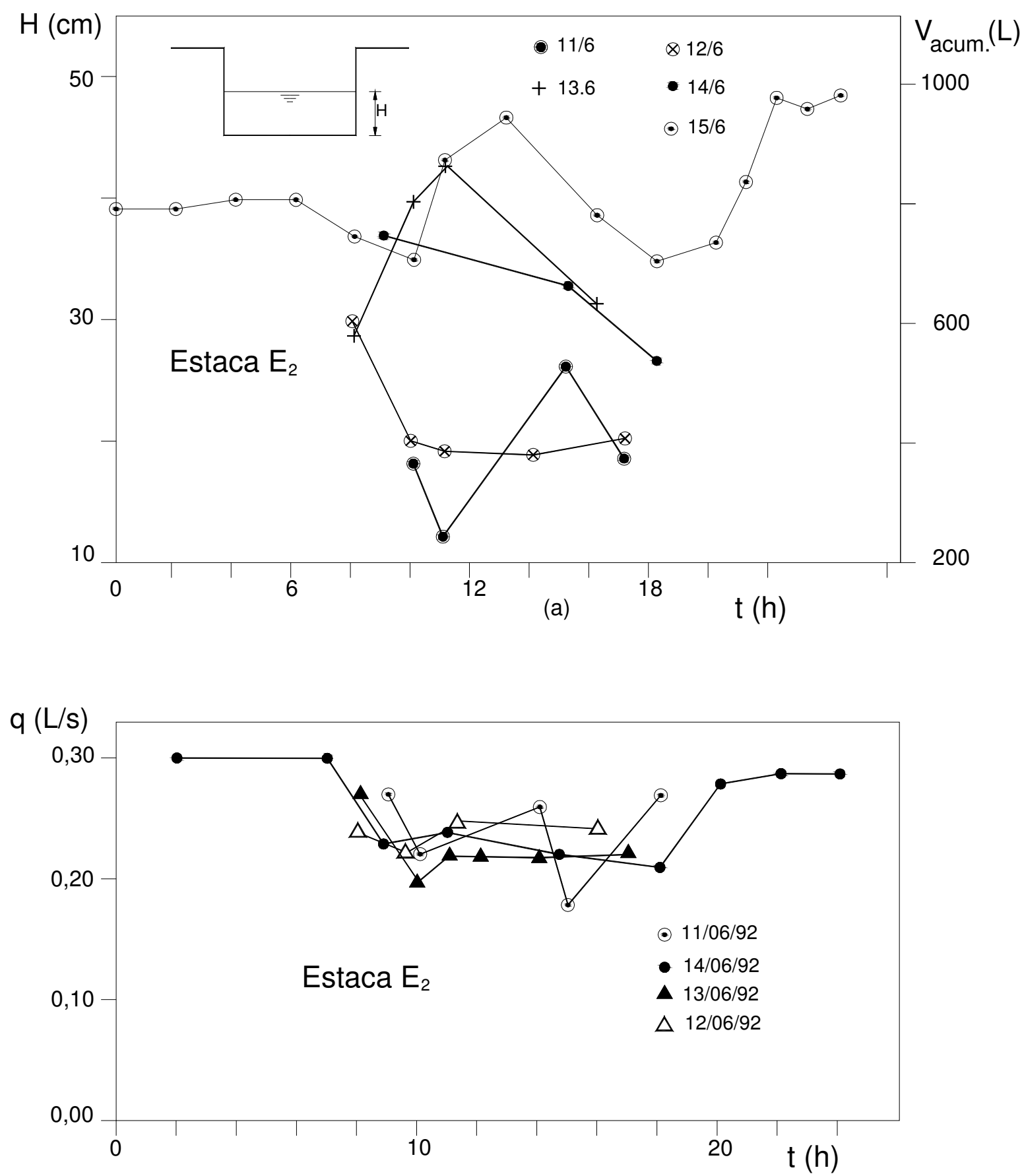

FIGURA 4.5- Resultados das observações sobre a inundação da estaca $E_{2}$ : a) acima: variação da altura da lâmina d'água com o tempo; b) abaixo: idem, da vazão de alimentação (q) com o tempo. 


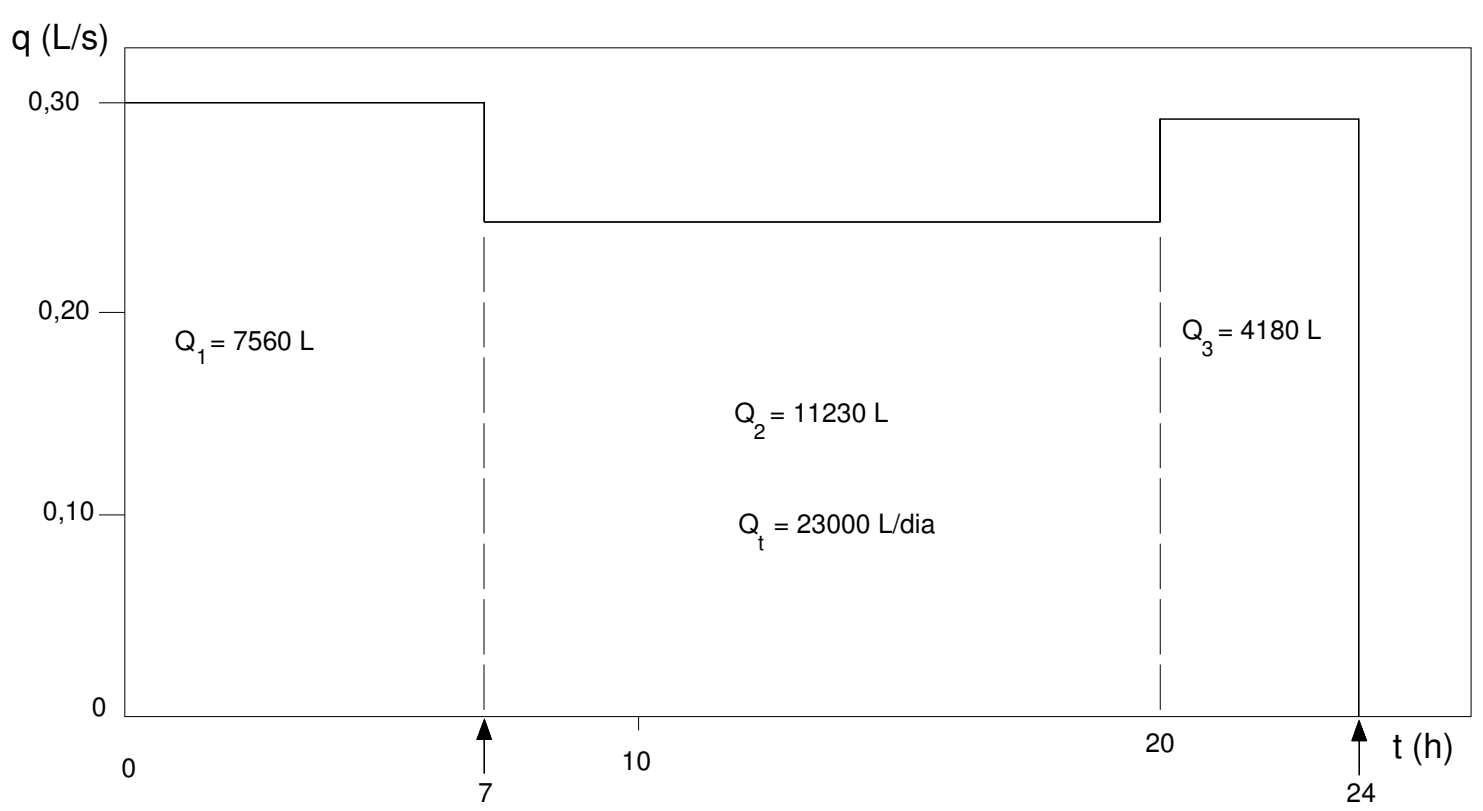

FIGURA 4.6- Vazão diária ingressante nas cavas das estacas de prova

As curvas de esvaziamento (FIGURAS 4.8 e 4.9) confirmam estes dados. A vazão decresce linearmente. Pela FIGURA 4.9 foi possível determinar a vazão de infiltração (0,15 litros por segundo). Este resultado está em conflito com informações anteriores, desde que a vazão de entrada era superior. Então, não haveria razão para esta altura permanecer constante.

Tendo isto em mente é lícito esclarecer que esta curva não é bem representativa, pois foi produzida com dados de apenas uma hora, na primeira experiência (feita em 20 de maio de 1992). Duas novas observações, em outros dias e na mesma cava, forneceram resultados coerentes (FIGURA 4.8). As observações do dia 23 de junho de 1992 forneceram uma curva paralela à primeira por causa de uma maior acumulação (duas fontes de alimentação foram abertas simultaneamente). Se as figuras 4.7 e 4.8 estivessem em uma mesma escala, seria possível verificar que há uma boa aproximação entre os volumes, admitido e infiltrado (áreas OAC na FIGURA 4.7 e OAB na FIGURA 4.8).

Após essas observações torna-se possível estimar, com razoável precisão, que o volume de água consumido nos 13 dias de duração de cada prova de carga foi de aproximadamente 300.000 litros. 
Analisando-se a posição do N. A. (situado a $10 \mathrm{~m}$ de profundidade) e as dimensões da cava, em planta $(1,4$ x 1,4 - metros) é possível indagar sobre a destinação de tão grande volume de água.

O volume teórico para saturar uma coluna de solo de $10 \mathrm{~m}$ de profundidade de seção de 2,8 x 1,8 (m) - TABELA 4.3 - dá suporte para alguma discussão.

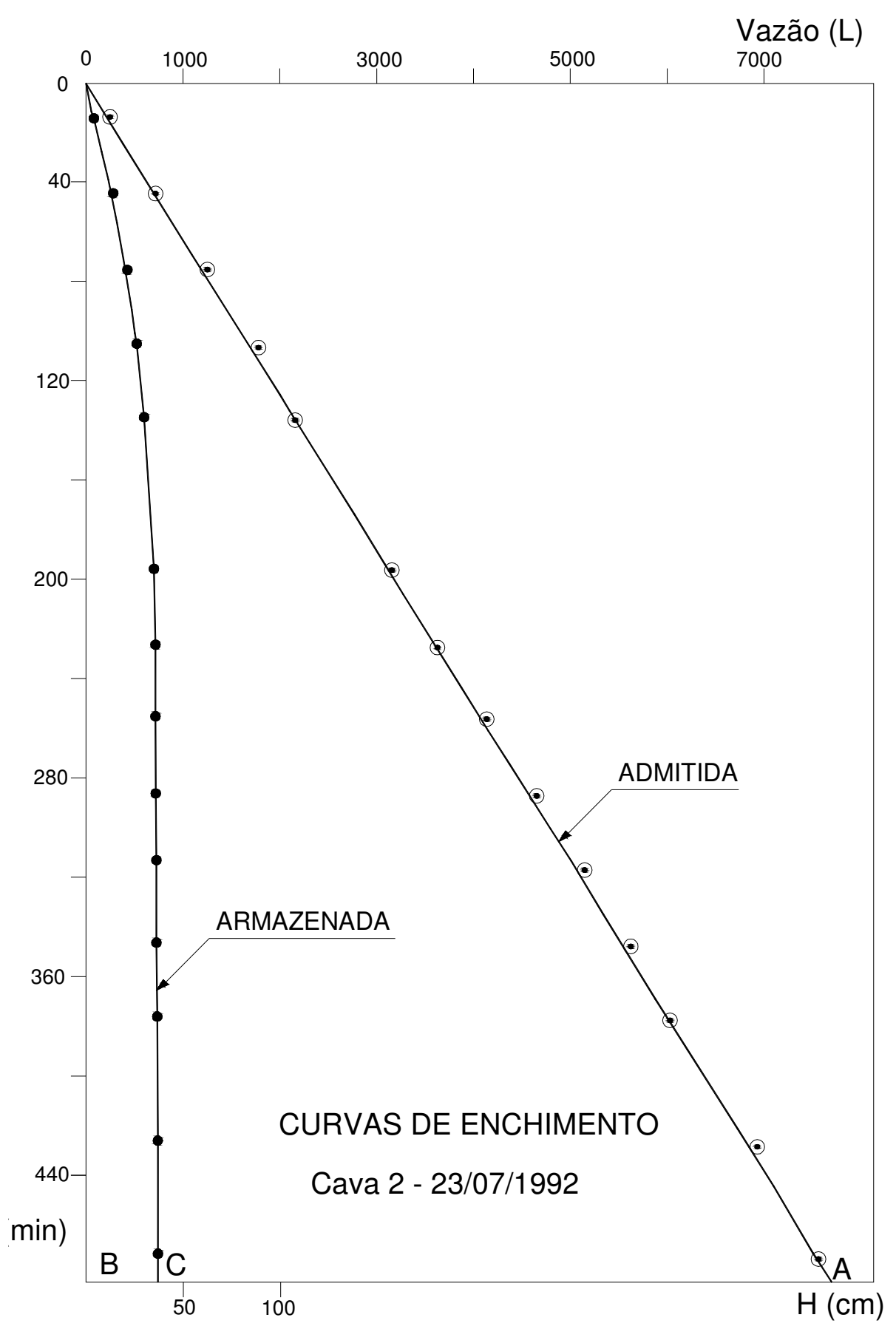

FIGURA 4.7- Curvas de enchimento da cava experimental $C_{2}$ (23/07/1992) 


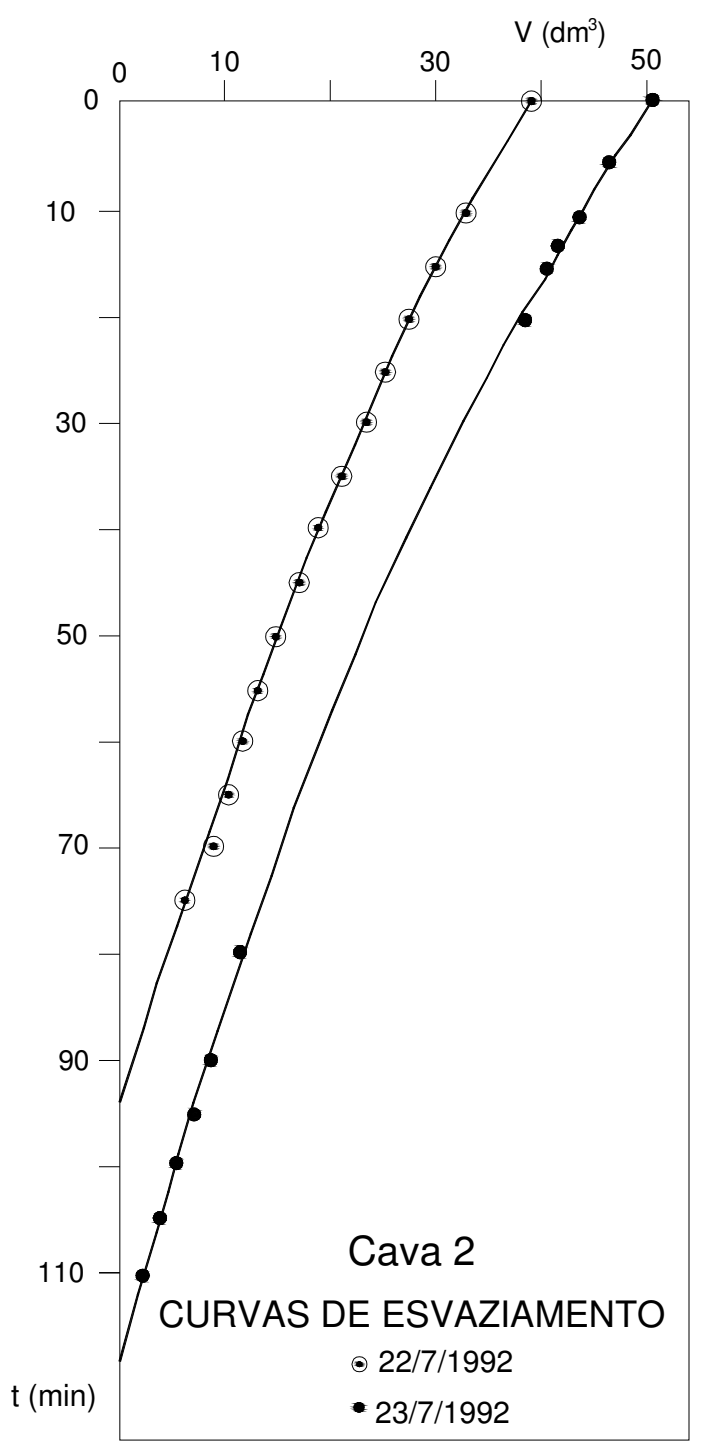

FIGURA 4.8- Curvas de esvaziamento da cava experimental C 2 (22 e 23/07/1992)

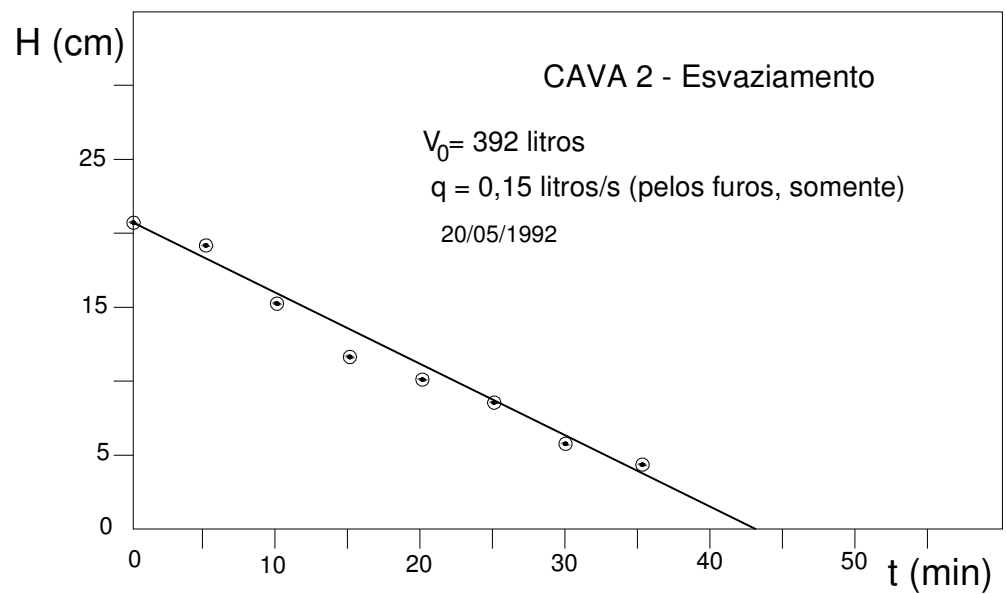

FIGURA 4.9- Curva da variação da altura da lâmina d'água com o tempo da cava experimental $\mathrm{C}_{2}$ durante o esvaziamento (20/05/1992) 
TABELA 4.3 - Estimativa do volume de água necessário para saturar uma coluna de solo de 2,8 x 2,8 x $10(\mathrm{~m})$. Fonte de dados: MENEZES (1990)

\begin{tabular}{|c|c|c|c|c|c|c|c|c|c|c|}
\hline $\begin{array}{c}\text { PROF } \\
(\mathbf{m})\end{array}$ & $\begin{array}{c}\mathbf{V}_{\mathbf{i}} \\
\left(\mathbf{m}^{\mathbf{3}}\right)\end{array}$ & $\begin{array}{c}\mathbf{\rho}_{\mathbf{s}} \\
\left(\mathbf{t} / \mathbf{m}^{\mathbf{3}}\right)\end{array}$ & $\begin{array}{c}\mathbf{\rho} \\
\left(\mathbf{t} / \mathbf{m}^{\mathbf{3}}\right)\end{array}$ & $\mathbf{S}_{\mathbf{r}}(\boldsymbol{\%})$ & $\begin{array}{c}\mathbf{w}_{\mathbf{0}} \\
(\mathbf{\%})\end{array}$ & $\mathbf{e}$ & $\begin{array}{c}\mathbf{w}_{\mathbf{s a t}} \\
(\boldsymbol{\%})\end{array}$ & $\begin{array}{c}\Delta \mathbf{w} \\
(\boldsymbol{\%})\end{array}$ & $\begin{array}{c}\mathbf{\rho}_{\mathbf{d}} \\
\left(\mathbf{t} / \mathbf{m}^{\mathbf{3}}\right)\end{array}$ & $\begin{array}{c}\mathbf{V} \\
(\mathbf{l i t r o s})\end{array}$ \\
\hline $0,0-1,3$ & 10,19 & 2,75 & 1,54 & 38,9 & 14,0 & 0,99 & 36 & 0,22 & 1,35 & 3026 \\
\hline $1,3-2,3$ & 7,83 & 2,72 & 1,54 & 37,5 & 15,0 & 1,00 & 37 & 0,22 & 1,34 & 2310 \\
\hline $2,3-3,3$ & 7,83 & 2,70 & 1,55 & 43,0 & 16,5 & 1,00 & 37 & 0,205 & 1,33 & 2134 \\
\hline $3,3-4,3$ & 7,83 & 2,73 & 1,60 & 46,5 & 17,0 & 0,93 & 34 & 0,17 & 1,38 & 1331 \\
\hline $4,3-5,3$ & 7,83 & 2,75 & 1,70 & 50,0 & 17,0 & 0,86 & 31 & 0,14 & 1,45 & 1095 \\
\hline $5,3-6,3$ & 7,83 & 2,75 & 1,70 & 56,0 & 17,5 & 0,87 & 32 & 0,145 & 1,47 & 1670 \\
\hline $6,3-7,3$ & 7,83 & 2,74 & 1,80 & 60,0 & 17,0 & 0,81 & 30 & 0,13 & 1,54 & 1019 \\
\hline $7,3-8,3$ & 7,83 & 2,75 & 1,85 & 60,5 & 16,5 & 0,70 & 25 & 0,09 & 1,59 & 1098 \\
\hline $8,3-9,3$ & 7,83 & 2,77 & 1,86 & 62,5 & 16,5 & 0,71 & 26 & 0,09 & 1,60 & 1127 \\
\hline $9,3-10,3$ & 5,48 & 2,76 & 1,88 & 68,5 & 17,00 & 0,73 & 26 & 0,09 & 1,61 & 795 \\
\hline TOTAIS & 78,31 & - & - & - & - & - & - & - & - & 15605 \\
\hline \multicolumn{7}{|c|}{ MEDIA: aproximadamente $20 \mathrm{~L} / \mathrm{m}^{3}$} & & & \\
\hline
\end{tabular}

Em resumo, a questão fundamental permaneceu em aberto: o grau de saturação do solo e as zonas de transição separando intervalos distintos de saturação não foram levantados pelas observações de campo.

Com a intenção de resolver este problema foram abertos os furos $s_{1}, s_{2}$ e $s_{3}$ na cava $\mathrm{C}_{1}$ (conforme FIGURA 4.3). A determinação do teor de umidade durante o andamento da fase de inundação seria feita em pesquisa paralela através de uma sonda de nêutrons (emissão de radiação gama através de uma fonte de material radioativo direcionado, dentro dos tubos, para o interior do solo, por meio de sondas, e captados por um Contador GEIGER instalado na superfície do terreno).

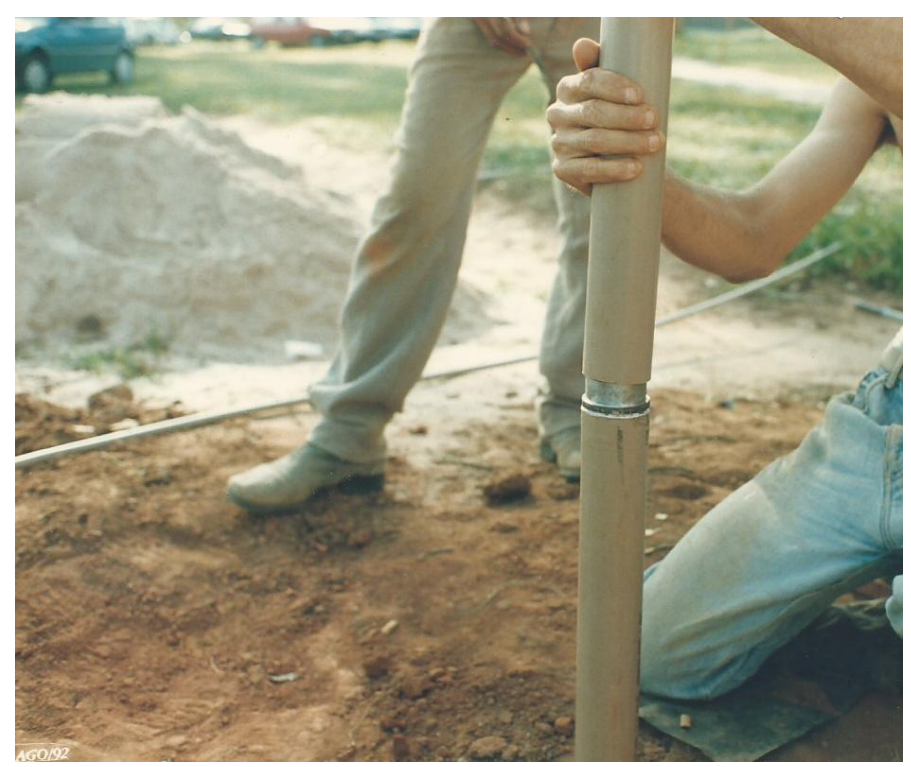

FOTO 5 - Tentativa de instalação de um tubo de 4" de diâmetro para introdução de sonda de nêutrons e medição do teor de umidade do solo 
Entretanto, esta iniciativa falhou devido a dificuldades operacionais imprevistas. A lentidão na abertura manual dos furos provocou um ligeiro fechamento das paredes impossibilitando a instalação dos tubos. Este método costuma ser bem sucedido em Agronomia e Hidráulica por causa das pequenas profundidades alcançadas nestes experimentos (FOTO 5).

Quanto aos furos instalados no fundo das cavas e preenchidos com areia limpa da região de São Carlos ficou demonstrada sua pouca ou nenhuma utilidade neste trabalho. Com efeito, a diferença entre os volumes de água admitidos pelo solo com a presença dos furos ou sem eles é desprezível. Trabalhos posteriores realizados no campo experimental, cujos resultados ainda não foram divulgados, dão conta de que a sua ausência não afeta os prazos de duração das provas de carga. Disto resulta uma apreciável redução de custos de mão de obra na sua abertura.

A água utilizada para inundação do solo foi proveniente da rede de abastecimento público e seu $\mathrm{pH}$ variou de 5,8 a 7,5 no período de realização das provas de carga (TABELA 4.4).

TABELA 4.4 - Variação do pH da água de inundação

\begin{tabular}{|c|c|}
\hline DATA & pH \\
\hline $11 / 06 / 1992$ & 7,5 \\
\hline $15 / 06 / 1992$ & 6,5 \\
\hline $22 / 06 / 1992$ & 6,3 \\
\hline $09 / 07 / 1992$ & 5,8 \\
\hline $12 / 07 / 1992$ & 6,5 \\
\hline
\end{tabular}

A influência do pH na dissolução dos cimentos que levam os solos porosos ao colapso é inquestionável. Há pesquisas específicas a respeito, citando-se o trabalho de MOLL (1975), que relata ensaios edométricos com solos de reação alcalina (pH entre 7,5 e 8,5) empregando três líquidos diferentes, a saber:

1) Água acidulada, proveniente de águas pluviais que atravessam camadas de húmus, com pH entre 5,5 e 7,5

2) Água potável proveniente de abastecimento público e representativa da ruptura de encanamentos e de irrigação de jardins (pH entre 6,5 e 6,8) 
3) Água de esgoto, proveniente de ruptura de tubulações ou infiltração de poços absorventes, fossas, etc. ( $\mathrm{pH}$ entre 8,5 e 9).

Foi então verificado que:

1) Há diminuição de sais solúveis no solo, especialmente os sais sódicos, sendo a máxima diminuição verificada para águas de esgoto, devido ao íon $\mathrm{NH}_{4}$

2) As águas utilizadas apresentam considerável acréscimo de $\mathrm{Na}$ solúvel e pequeno aumento de Ca solúvel, ocorrendo o máximo incremento para o caso de esgoto

3) $\mathrm{O}$ pH aumenta no caso da água atravessar o solo, em qualquer dos três casos, o que indica incorporação de sais solúveis existentes no solo pela água, o que leva o solo à fase dispersiva

4) Há aumento na variação do índice de vazios, bastante considerável em relação ao solo na umidade natural. A água de esgoto é a que produz a maior variação e a água potável produz a menor variação

5) A diminuição das cargas que produzem uma mesma variação no índice de vazios é notória. Há uma carga mínima que corresponde à inundação por água de esgoto. A água acidulada tem posição intermediária.

Isto significa que, nesta pesquisa, o solo não foi submetido à situação extrema, que seria a inundação por água de esgoto, uma possibilidade bem real na prática. No entanto, trata-se de um cenário inviável em ensaios de campo desta natureza.

Por outro lado, informes extraoficiais acerca de resultados obtidos no Laboratório de Hidráulica e Saneamento da USP - São Carlos, ainda não divulgados, dão conta de que os valores médios de $\mathrm{pH}$ de águas servidas, lançadas nos emissários a céu aberto da cidade de São Carlos, são de caráter ácido e não alcalino. Embora isto pareça surpreendente, uma possível explicação para o caso pode estar baseada na hipótese de septibilização do esgoto. 


\section{5 - ALGUMAS OBSERVAÇÕES REGISTRADAS DURANTE AS PROVAS DE CARGA}

\subsection{1 - Influência do processo de amostragem no teor de umidade}

Há evidências de que o teor de umidade determinado a partir de amostras amolgadas pelo processo de extração a trado é significativa e sistematicamente superior àquele verificado a partir de amostras retiradas de blocos indeformados (FIGURA 4.10a). Verifica-se também que, mesmo em solos arenosos, há um certo efeito de migração da água para a superfície lateral dos furos. O furo "f-10" da FIGURA 4.13 serviu para a experiência mostrada na FIGURA 4.10b. As amostras foram coletadas por meio de raspagem das paredes do furo, nas profundidades desejadas, com um pequeno recipiente soldado em um vergalhão. Nas partes superiores do furo, mantido aberto durante o período de observação, a inversão do efeito se deve, provavelmente, a processos de evaporação.

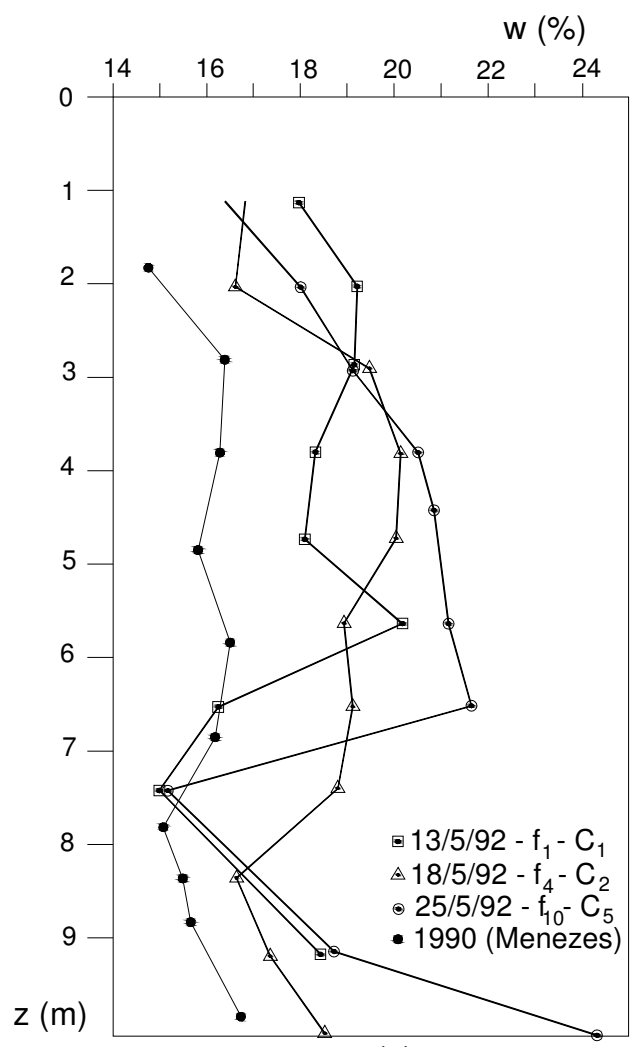

(a)

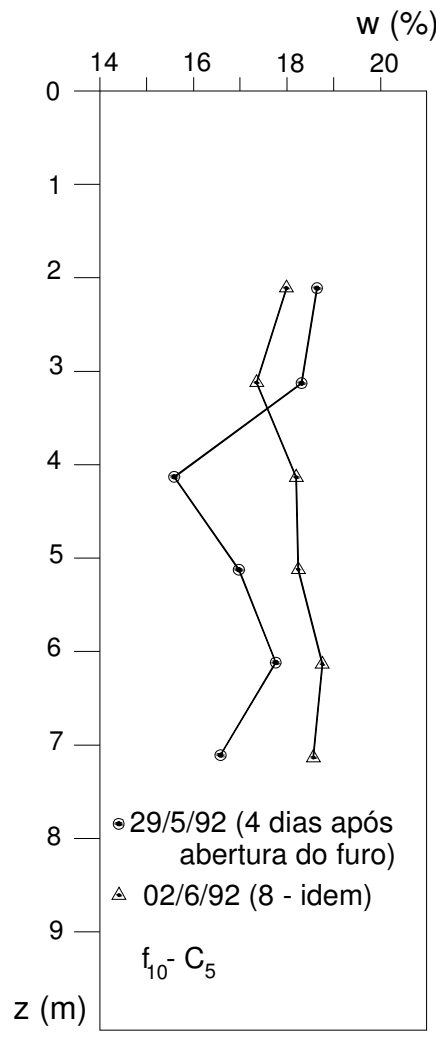

(b)

FIGURA 4.10: a) comparação entre umidades naturais obtidas através de amostras indeformadas (1990) e de extração a trado (1992); b) efeito observado de migração da água para as paredes do furo 


\subsection{2 - Efeitos da não reposição de cargas durante a realização das provas de carga}

A FIGURA 4.11 ilustra bem uma observação feita com este propósito. Ela corresponde ao estágio de $600 \mathrm{kN}$ da prova de carga sobre a estaca $\mathrm{E}_{3}$. No detalhe desta figura estão destacados alguns pontos observados em um intervalo de tempo da ordem de 6 horas. Fica claro o descolamento destes pontos na curva "recalque x log t" e, como consequência, em nenhum ponto deste intervalo o critério de estabilização de recalques preconizado pela NBR 6121/86 poderia ser aplicado.

\subsection{3 - Influência da inundação na reversão dos recalques lidos}

Durante a realização da prova de carga na estaca $\mathrm{E}_{3}$, cerca de uma hora após o início da inundação foi observado que os extensômetros mecânicos iniciaram um retorno, como se ocorresse descarregamento. A célula de carga, simultaneamente, acusava pequeno acréscimo de carga. Este fenômeno já havia sido observado na estaca $\mathrm{E}_{2}$, produzindo os gráficos da FIGURA 4.12a, b.

Como as provas de carga foram realizadas ao abrigo de intempéries, a hipótese de qualquer anomalia gerada pelo efeito de temperatura foi descartada. Mesmo porque, CARVALHO (1991), em condições severas, concluíra que este é um efeito negligenciável.

Foi então examinada a hipótese de ocorrência de expansão do solo. Uma análise microscópica sobre pequenas amostras recolhidas da segunda camada e testes de expansão livre em proveta serviram para eliminá-la.

LAMBE \& WHITMAN (1969) demonstram que a temperatura da água é um fator a ser considerado na expansão dos finos. Tendo isto em mente, foram tomadas as temperaturas do solo através do furo " $\mathrm{s}_{1}$ ", da cava $\mathrm{C}_{1}$. Os resultados mostraram que a temperatura do solo é bastante similar à da água, nas condições da prova de carga (FIGURA 4.13). Com isto, esta hipótese foi também descartada. 


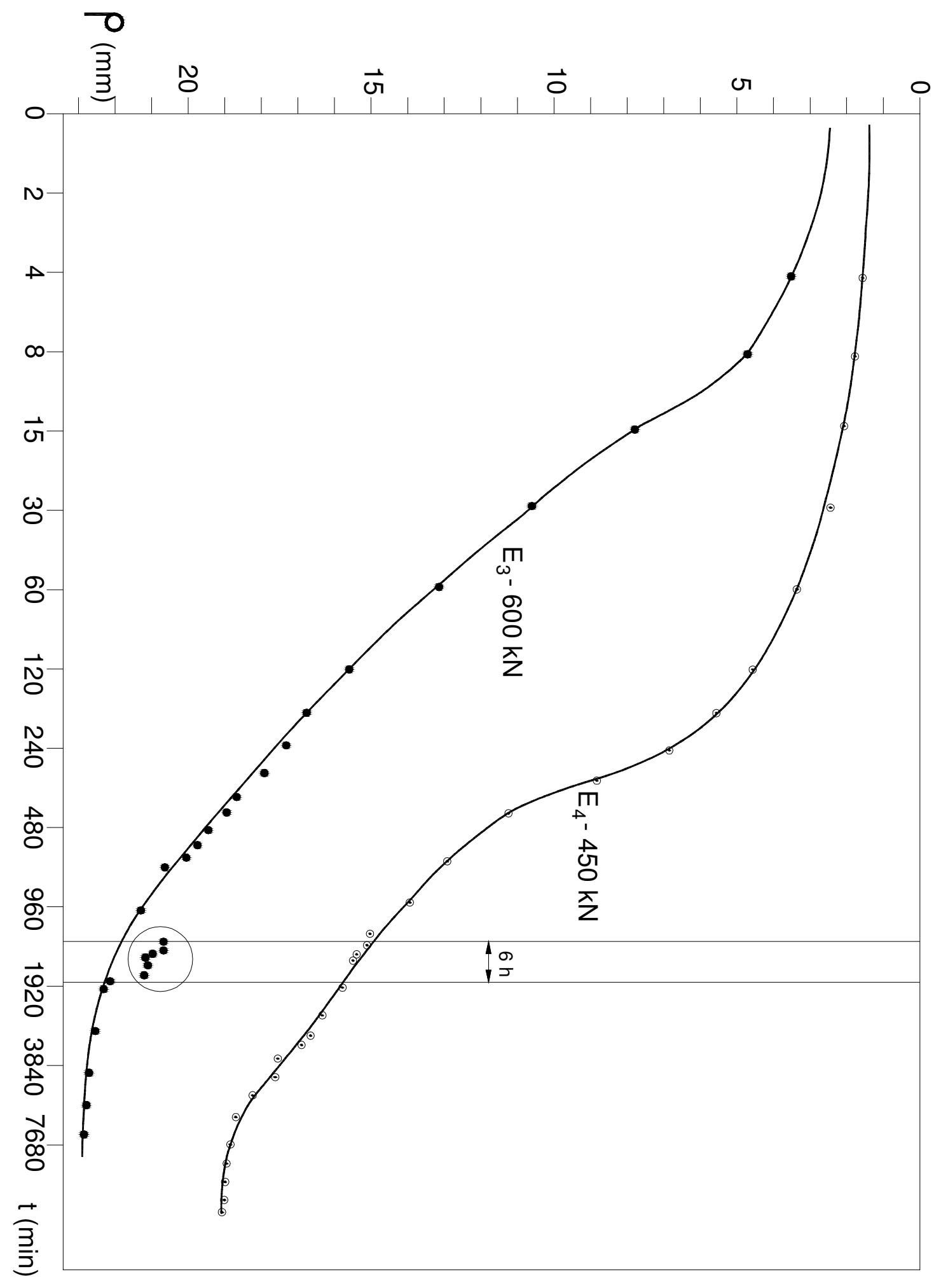

FIGURA 4.11 - Curvas "recalque x log t" correspondentes aos estágios do colapso inicial das estacas $\mathrm{E}_{2} \mathrm{e}_{3}$ 

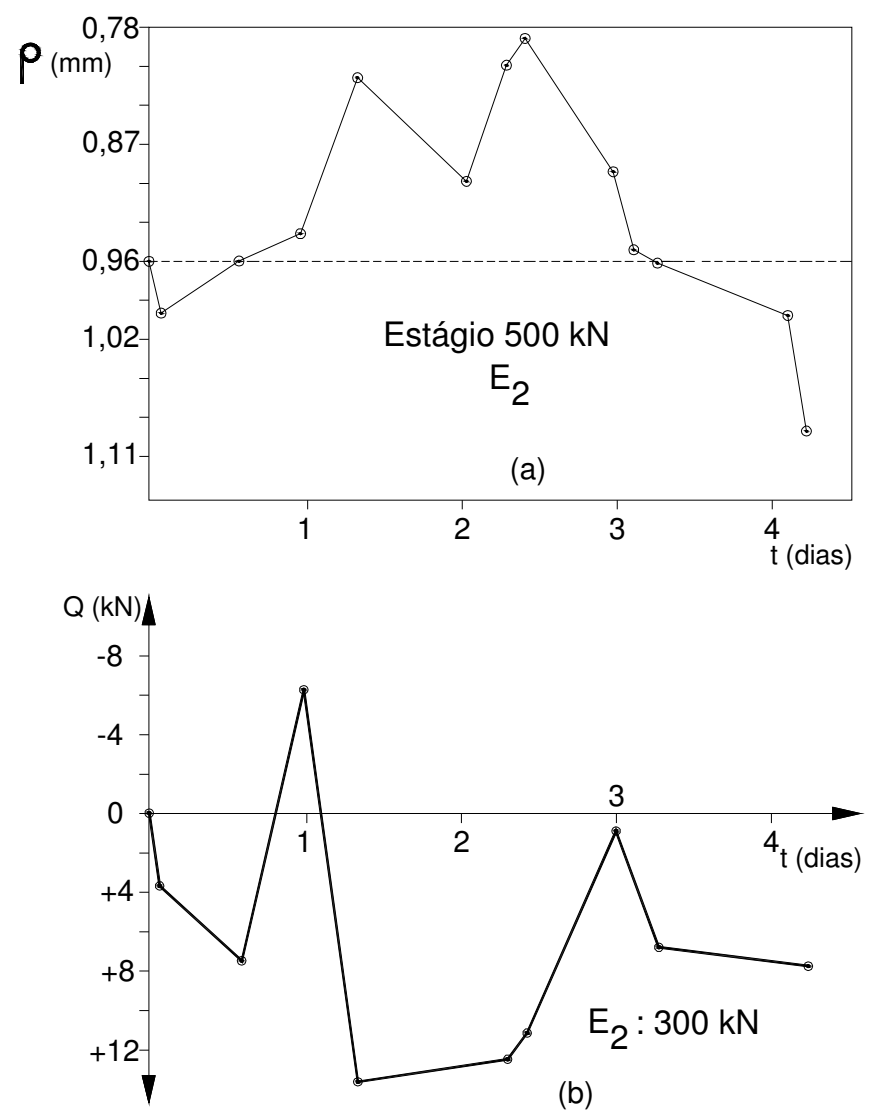

FIGURA 4.12 - a) fenômeno observado da diminuição dos recalques com o tempo, sendo a carga sustentada durante a inundação; b) idem, do aumento de cargas, idem.

Finalmente, restou considerar a possibilidade de ter ocorrido uma pequena subsidência da camada superior pelo efeito da inundação, produzindo, assim, um pequeno deslocamento nas colunas de madeira que suportavam as vigas de referência. Esta situação deve servir de advertência para futuros trabalhos em idênticas condições.

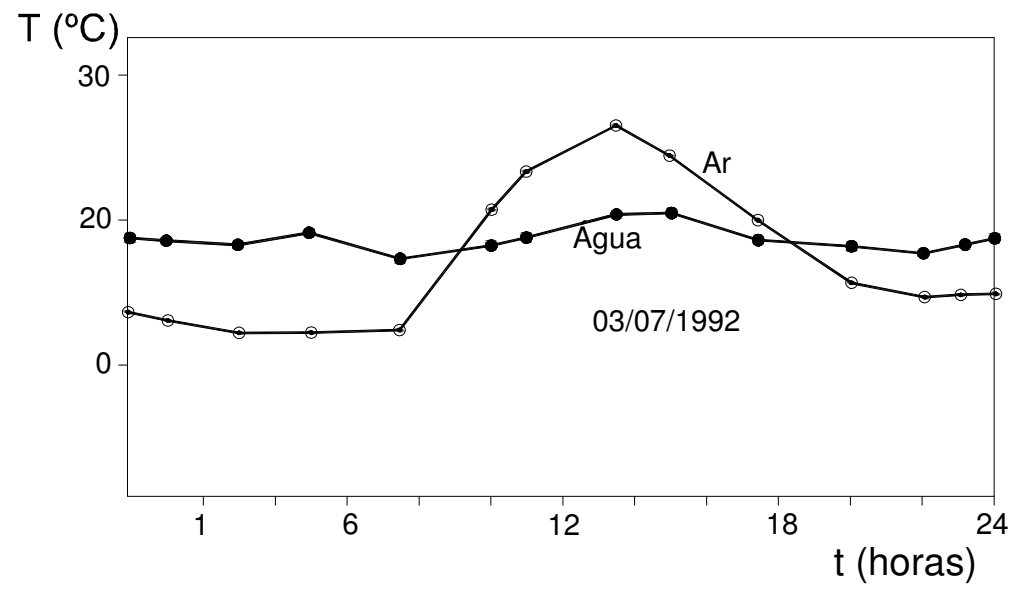

FIGURA 4.13 - Variação diária das temperaturas do ar e da água utilizada nas provas de carga 


\section{CAPÍTULO 5 - APRESENTAÇÃO DOS RESULTADOS}

\section{1 - GENERALIDADES}

Para um melhor acompanhamento do texto, as convenções para as diversas provas de carga serão padronizadas daqui por diante e designadas de conformidade com as convenções constantes da TABELA 5.1.

TABELA 5.1 - Sequência da realização das provas de carga

\begin{tabular}{|c|c|c|c|c|c|c|}
\hline D (cm) & $1^{\mathrm{a}}$ & $2^{a}$ & $3^{\mathbf{a}}$ & $4^{a}$ & $5^{a}$ & $6^{a}$ \\
\hline 35 & $\begin{array}{l}\text { Lenta } \\
\text { MANTILLA } \\
\text { Dez/1989 } \\
D_{35(1)}\end{array}$ & $\begin{array}{l}\text { Rápida } \\
\text { SACILOTTO } \\
\text { Nov/1990 } \\
D_{35(2)}\end{array}$ & $\begin{array}{l}\text { Rápida } \\
\text { SACILOTTO } \\
\text { Jan/1992 } \\
D_{35(3)}\end{array}$ & $\begin{array}{l}\text { Lenta } \\
\text { MANTILLA } \\
\text { Jan/1992 } \\
\text { D }_{35(4)} \\
\end{array}$ & & \\
\hline 40 & $\begin{array}{l}\text { Lenta } \\
\text { MANTILLA } \\
\text { Dez/1989 } \\
\mathrm{D}_{40(1)}\end{array}$ & $\begin{array}{l}\text { Rápida } \\
\text { SACILOTTO } \\
\text { Nov/1990 } \\
\text { D }_{40(2)}\end{array}$ & $\begin{array}{l}\text { Rápida } \\
\text { SACILOTTO } \\
\text { Jan/1992 } \\
D_{40(3)}\end{array}$ & $\begin{array}{l}\text { Lenta } \\
\text { MANTILLA } \\
\text { Jan/1992 } \\
\text { D }_{40(4)}\end{array}$ & $\begin{array}{l}\text { Lenta inund } \\
\text { TEIXEIRA } \\
\text { Jun/1992 } \\
\mathrm{D}_{40(5)} \\
\end{array}$ & \\
\hline 50 & $\begin{array}{l}\text { Lenta } \\
\text { MANTILLA } \\
\text { Dez/1989 } \\
\text { D }_{50(1)}\end{array}$ & $\begin{array}{l}\text { Rápida } \\
\text { SACILOTTO } \\
\text { Nov/1990 } \\
\text { D }_{50(2)}\end{array}$ & $\begin{array}{l}\text { Rápida } \\
\text { SACILOTTO } \\
\text { Jan/1992 } \\
D_{50(3)}\end{array}$ & $\begin{array}{l}\text { Lenta } \\
\text { MANTILLA } \\
\text { Jan/1992 } \\
\text { D }_{50(4)}\end{array}$ & $\begin{array}{l}\text { Lenta inund } \\
\text { TEIXEIRA } \\
\text { Jun/1992 } \\
D_{50(5)}\end{array}$ & $\begin{array}{l}\text { Lenta inund } \\
\text { TEIXEIRA } \\
\text { Jul/1992 } \\
\mathrm{D}_{50(6)}\end{array}$ \\
\hline
\end{tabular}

Na condição de cada prova de carga foi estabelecido um critério particular, procurando ser fiel às recomendações da NBR 6121/86, porém levando em conta a especificidade do caso. Assim é que:

1) $\mathrm{Na}$ prova de carga $\mathrm{D}_{40(5)}$ deliberou-se por inundar o solo no estágio correspondente a uma pressuposta carga de trabalho, fixada em $300 \mathrm{kN}$, com base em estimativas sobre a média dos resultados anteriores. Assim, os estágios de carga, antes da inundação, foram de $20 \%$ dessa referida carga de trabalho. Daí em diante, os estágios foram tomados como a metade deste valor. Os tempos mínimos de 30 minutos por estágio foram rigorosamente observados. Quando do surgimento do colapso a prova de carga foi inteiramente acompanhada pelo traçado simultâneo de uma curva "recalque $\mathrm{x} \log \mathrm{t}$ ", como um recurso auxiliar na definição da estabilização dos recalques. Esperava-se, com a experiência adquirida 
nesta primeira prova de carga, ter uma melhor orientação para a execução da seguinte, principalmente em relação à provável carga de colapso e o tempo necessário para a sua ocorrência, após a inundação.

2) Na prova de carga $D_{50(5)}$ julgou-se, equivocadamente, que a carga de colapso anterior indicasse uma característica do solo, podendo-se esperar um comportamento previsível. Assim, ficou decidido que a inundação seria feita somente após a aplicação de 6 estágios de $80 \mathrm{kN}$, totalizando a carga de $480 \mathrm{kN}$, na qual tinha ocorrido o colapso na prova de carga $\mathrm{D}_{40(5)}$. Esta premissa mostrou-se inconsistente na prática. Com efeito, a pressão-limite que conduz o solo ao colapso em estacas parece relacionar-se com o seu diâmetro.

3) Na prova de carga $\mathrm{D}_{50(6)}$ buscou-se reproduzir uma situação diferente das anteriores. Naquelas, o objetivo era verificar de que modo o eventual rompimento de uma tubulação, inundando o solo onde se encontra instalada uma estaca sustentando determinada carga de trabalho afetaria o comportamento da estaca. Nesta, pretendia-se verificar o desempenho de uma estaca quando submetida, desde o início, ao processo de inundação do solo, para carregamentos crescentes até a carga de trabalho. Esta situação, além de factível e realista, seria útil para comparar o comportamento carga-recalque na fase elástica, em condições naturais e de solo inundado, que ainda não tinha sido testada. Esta prova de carga foi conduzida em 5 estágios de $100 \mathrm{kN}$, com descarga imediata. Os dados de deformação correspondentes ao estágio de $100 \mathrm{kN}$ desta prova de carga foram descartados porque, por erro de operação, o fator de extensômetro do indicador de deformações estava operando de modo errado.

4) Uma das dificuldades pendentes de solução na execução de provas de carga consiste em se ajuizar sobre o momento mais conveniente de paralisá-la, quando levada à ruptura. Já que o conceito de "ruptura" é ambíguo, esta solução passa por uma inevitável pessoalidade e não há 
como fugir da interpretação. Sendo esta uma pesquisa comparada (em relação àquelas produzidas anteriormente por SACILOTTO, 1992 e, principalmente, MANTILLA, 1992), os conceitos antes utilizados foram seguidos de perto, visando uma melhor representatividade de resultados. Deste modo, resultou considerar o encerramento das provas de carga $\mathrm{D}_{40(5)}$ e $\mathrm{D}_{50(5)}$ quando os deslocamentos continuavam "indefinidamente" por mais de uma hora, havendo necessidade incessante de reposição de carga, sem a correspondente evidência de estabilização. Foram considerados como "cargas de ruptura" aquelas que produziram tais deslocamentos incontroláveis. Concomitantemente, foram também registradas as "cargas de equilíbrio", isto é, aquelas que, deixadas livremente, apresentavam estabilização de recalques.

\section{2 - COMPORTAMENTO “CARGA x DESLOCAMENTOS" DAS PROVAS DE CARGA}

Os recalques medidos na cabeça das estacas representam a média das leituras de quatro extensômetros instalados em posições diametralmente opostas. Embora houvesse a maior preocupação em evitar a excentricidade na montagem das provas de carga, constatou-se certo insucesso ao verificar leituras, ligeira e sistematicamente, superiores em dois extensômetros vizinhos.

Os resultados são apresentados nas TABELAS 5.2, 5.3 e 5.4.

A partir destes dados foram traçadas as curvas "carga x recalque" correspondentes (FIGURAS 5.1, 5.2 e 5.3), havendo uma mudança de origem dos recalques para levar em conta os deslocamentos plásticos acumulados nas provas de carga anteriores (FIGURA 4.2).

TABELA 5.2 - Dados para traçado da curva "carga x recalque" - prova de carga $\mathrm{D}_{40(5)}$

\begin{tabular}{|c|c|c|c|c|c|c|}
\hline \multirow{3}{*}{$\begin{array}{c}\text { CARGA } \\
(\mathbf{k N})\end{array}$} & \multirow{3}{*}{$\begin{array}{l}\text { DATA } \\
(1992)\end{array}$} & \multirow{3}{*}{$\begin{array}{c}\text { DURAÇÃO } \\
\text { (min) }\end{array}$} & \multicolumn{4}{|c|}{ RECALQUES MÉDIOS } \\
\hline & & & \multicolumn{2}{|c|}{ NO ESTÁGIO } & \multicolumn{2}{|c|}{ ACUMULADO } \\
\hline & & & Imediato & Estabilizado & Imediato & Estabilizado \\
\hline 60 & $10 / 06$ & 30 & 0,02 & 0,02 & 0,02 & 0,02 \\
\hline 120 & $10 / 06$ & 30 & 0,07 & 0,07 & 0,09 & 0,09 \\
\hline 180 & $10 / 06$ & 30 & 0,06 & 0,08 & 0,15 & 0,17 \\
\hline 240 & $10 / 06$ & 30 & 0,16 & 0,20 & 0,31 & 0,37 \\
\hline
\end{tabular}




\begin{tabular}{|c|c|c|c|c|c|c|}
\hline $300(*)$ & $09-16 / 06$ & 8300 & 0,20 & 0,43 & 0,51 & 0,80 \\
\hline $330(*)$ & $16 / 06$ & 30 & 0,03 & 0,03 & 0,54 & 0,83 \\
\hline $360(*)$ & $16 / 06$ & 30 & 0,03 & 0,06 & 0,57 & 0,89 \\
\hline $390(*)$ & $16 / 06$ & 30 & 0,08 & 0,13 & 0,65 & 1,02 \\
\hline $420(*)$ & $16 / 06$ & 60 & 0,08 & 0,27 & 0,73 & 1,29 \\
\hline $450(* *)$ & $16-22 / 06$ & 8160 & 0,09 & 17,0 & 0,82 & 18,29 \\
\hline 480 & $22 / 06$ & 480 & 0,42 & 9,90 & 1,24 & 28,19 \\
\hline 510 & $22-23 / 06$ & 1020 & 0,51 & 27,1 & 1,75 & 55,29 \\
\hline 373 & $23 / 06$ & 30 & $-0,25$ & $-0,54$ & 1,50 & 54,75 \\
\hline 90 & $23 / 06$ & 30 & $-0,50$ & $-0,53$ & 1,00 & 54,22 \\
\hline 0 & $23 / 06$ & 60 & $-0,78$ & $-0,78$ & 0,22 & 53,44 \\
\hline
\end{tabular}

NOTAS: (*) com inundação, aguardando ocorrência de colapso; (**) ocorrência de colapso

TABELA 5.3 - Dados para traçado da curva "carga x recalque" - prova de carga $\mathrm{D}_{50(5)}$

\begin{tabular}{|c|c|c|c|c|c|c|}
\hline \multirow{3}{*}{$\begin{array}{c}\text { CARGA } \\
(\mathbf{k N})\end{array}$} & \multirow{3}{*}{$\begin{array}{l}\text { DATA } \\
(1992)\end{array}$} & \multirow{3}{*}{$\begin{array}{c}\text { DURAÇÃ } \\
\text { (min) }\end{array}$} & \multicolumn{4}{|c|}{ RECALQUES MÉDIOS } \\
\hline & & & \multicolumn{2}{|c|}{ NO ESTÁGIO } & \multicolumn{2}{|c|}{ ACUMULADO } \\
\hline & & & Imediato & Estabilizado & Imediato & Estabilizado \\
\hline 80 & $08 / 07$ & 30 & 0,04 & 0,04 & 0,04 & 0,04 \\
\hline 160 & $07 / 07$ & 30 & 0,15 & 0,15 & 0,19 & 0,19 \\
\hline 240 & $08 / 07$ & 30 & 0,24 & 0,24 & 0,43 & 043 \\
\hline 320 & $08 / 07$ & 30 & 0,27 & 0,32 & 0,70 & 0,75 \\
\hline 400 & $08 / 07$ & 30 & 0,29 & 0,42 & 1,04 & 1,17 \\
\hline $480(*)$ & $08-12 / 07$ & 6705 & 0,22 & 0,39 & 1,40 & 1,56 \\
\hline $533(*)$ & $13-14 / 07$ & 1410 & 0,68 & 0,76 & 2,24 & 2,32 \\
\hline $560(*)$ & $14 / 07$ & 30 & - & - & 2,24 & 2,32 \\
\hline $600(* *)$ & $14-17 / 07$ & 3380 & 0,18 & 20,20 & 2,42 & 22,52 \\
\hline 630 & $17-18 / 07$ & 1335 & 0,18 & 14,30 & 2,60 & 36,82 \\
\hline 660 & $18 / 07$ & 480 & 5,40 & 17,40 & 8,00 & 54,22 \\
\hline 690 & $18-20 / 07$ & 2400 & 9,33 & 25,10 & 17,33 & 79,32 \\
\hline 479 & $20 / 07$ & 40 & $-0,17$ & $-0,21$ & 17,16 & 79,11 \\
\hline 271 & $20 / 07$ & 20 & $-0,55$ & $-0,76$ & 16,61 & 78,35 \\
\hline 85 & $20 / 07$ & 30 & $-0,50$ & $-0,70$ & 16,11 & 77,65 \\
\hline 0 & $20 / 07$ & 150 & $-1,90$ & $-2,30$ & 14,21 & $75,75,35$ \\
\hline
\end{tabular}

NOTAS: $(*)$ com inundação, aguardando ocorrência de colapso; $(* *)$ ocorrência de colapso

TABELA 5.4 - Dados para traçado da curva "carga x recalque" - prova de carga $\mathrm{D}_{50(6)}$

\begin{tabular}{|c|c|c|c|c|c|c|}
\hline \multirow{3}{*}{$\begin{array}{c}\text { CARGA } \\
(\mathbf{k N})\end{array}$} & \multirow{3}{*}{$\begin{array}{l}\text { DATA } \\
\text { (1992) }\end{array}$} & \multirow{3}{*}{$\begin{array}{c}\text { DURAÇÃO } \\
\text { (min) }\end{array}$} & \multicolumn{4}{|c|}{ RECALQUES MÉDIOS } \\
\hline & & & \multicolumn{2}{|c|}{ NO ESTÁGIO } & \multicolumn{2}{|c|}{ ACUMULADO } \\
\hline & & & Imediato & Estabilizado & Imediato & Estabilizado \\
\hline $0(*)$ & $21 / 07$ & - & - & - & - & - \\
\hline 100 & $21 / 07$ & 30 & 0,08 & 0,19 & 0,08 & 0,19 \\
\hline 200 & $21 / 07$ & 30 & 0,10 & 0,23 & 0,18 & 0,42 \\
\hline 300 & $21 / 07$ & 30 & 0,24 & 0,42 & 0,42 & 0,84 \\
\hline 400 & $21 / 07$ & 30 & 0,70 & 0,80 & 1,12 & 1,64 \\
\hline 500 & $21 / 07$ & 30 & 0,86 & 1,12 & 1,98 & 2,76 \\
\hline 230 & $21 / 07$ & 15 & $-0,30$ & $-0,88$ & 1,68 & 1,88 \\
\hline 0 & $21-22 / 07$ & 900 & $-1,44$ & $-1,85$ & 0,44 & 0,03 \\
\hline
\end{tabular}

NOTA: (*) com inundação desde o início

A FIGURA 5.3 foi desenhada em escala propositadamente ampliada, colocando em destaque a diferença de comportamento quando o solo é inundado. Além disso, tanto nesta, quanto nas duas outras figuras, houve ainda a preocupação de comparar as curvas com a sequência (4) das provas de carga, em condições de 
umidade natural, já que um dos principais objetivos desta pesquisa - a perda da capacidade de carga por efeito de inundação do solo - assim o exige.

Foram registradas as cargas estabilizadas finais de cada uma das provas de carga levadas à ruptura, tendo sido encontrados os valores de $482 \mathrm{kN}$ (prova de carga $\mathrm{D}_{40(5)}$ e $662 \mathrm{kN}$ (prova de carga $\left.\mathrm{D}_{50(5)}\right)$.

A FIGURA 5.4 compara o comportamento "carga $\mathrm{x}$ recalque" das provas de carga $\mathrm{D}_{40(5)}$ e $\mathrm{D}_{50(5)}$. A FIGURA 5.5 procura realçar a grande recuperação imediata dos deslocamentos na prova de carga $\mathrm{D}_{50(6)}$, que exibiu um comportamento elástico não linear, com resíduo de deformação plástica praticamente nulo.

Durante a realização das provas de carga foi possível fazer um confronto das cargas lidas pelo manômetro e as registradas pela célula de carga, lidas no indicador de deformações. O resultado encontra-se na FIGURA 5.6, onde se busca uma correlação entre estas leituras. Observa-se que os pontos estão invariavelmente fora da linha $\mathrm{Y}=\mathrm{X}$, o que significa dizer que não há compatibilidade entre as mesmas.

É visível que a maioria das cargas manométricas nos estágios inferiores a 200 kN superam as leituras da célula de carga. Como estes estágios não são críticos, é importante observar que esta tendência se inverte logo em seguida, com afastamentos ainda maiores e que chegam a 20\%. Depreende-se, daí, que os resultados de uma prova de carga, na ruptura, com o uso apenas de manômetro, subestima a capacidade de carga da estaca ensaiada.

\section{3 - TRANSFERÊNCIA DE CARGA}

Os "strain-gages" instalados nas barras da armadura das estacas, nos diversos níveis, permitiram o cálculo de deformações e de cargas nas seções instrumentadas, exceto na seção de referência (nível 1), para a qual o indicador de deformações não forneceu leituras confiáveis.

Além disso, alguns destes "strain-gages", instalados aos paredes em cada nível, não tiveram bom desempenho em algumas seções. Isto motivou o descarte de 
algumas leituras, com prejuízo para as médias desejadas e que justificam a sua instalação dupla em cada nível.

As deformações foram calculadas através da expressão:

$$
d_{i}=\frac{L_{f}-L_{0}}{2\left(1-v_{a c ̧ o}\right)} \cdot K_{c}
$$

Onde:

$\mathrm{D}_{\mathrm{i}}=$ deformação, em mm, na i-ésima seção instrumentada

$\mathrm{L}_{\mathrm{f}}, \mathrm{L}_{0}=$ leituras do indicador de deformações, no final de um determinado estágio de carregamento e no início da prova de carga, respectivamente

$v_{\text {aço }}=0,3$

$\mathrm{K}_{\mathrm{c}}=$ fator de sensibilidade do instrumento, aproximadamente unitário.

As seções homogeneizadas de concreto, $A_{h, i}$, em cada seção, são uma função da taxa de armadura longitudinal para estas seções e foram tomadas a partir de informações de MANTILLA (1992), conforme TABELA 5.5 apresenta a seguir.

TABELA 5.5 - Valores das seções homogeneizadas das estacas $\left(\mathrm{m}^{2}\right)$

\begin{tabular}{|c|c|c|}
\hline SEÇÃOO & $\mathbf{D}_{40}$ & $D_{50}$ \\
\hline 1 & 0,134859 & 0,205545 \\
\hline 2 & 0,134124 & 0,2048098 \\
\hline 3 & 0,1333898 & 0,2040756 \\
\hline 4 & 0,1326547 & 0,2033405 \\
\hline 5 & 0,1319204 & 0,2026062 \\
\hline
\end{tabular}

As cargas $Q_{i}$ em cada seção homogeneizada $A_{h, i}$ da estaca instrumentada com módulo elástico $\mathrm{E}_{\mathrm{p}}$ foram obtidas por:

$$
Q_{i}=\frac{L_{f}-L_{0}}{2\left(1-v_{a c ̧ o}\right)} \cdot K_{c} \cdot A_{h, i} \cdot E_{p}
$$

Quanto aos módulos elásticos, $\mathrm{E}_{\mathrm{p}}$, eles foram obtidos das provas lentas anteriores (TABELA 4.2), já que a instrumentação da seção de referência não estava funcionando. Assim, os valores considerados foram:

1) $\mathrm{E}_{\mathrm{p}, 40}=30,73632 \times 10^{6} \mathrm{kN} / \mathrm{m}^{2}$ 


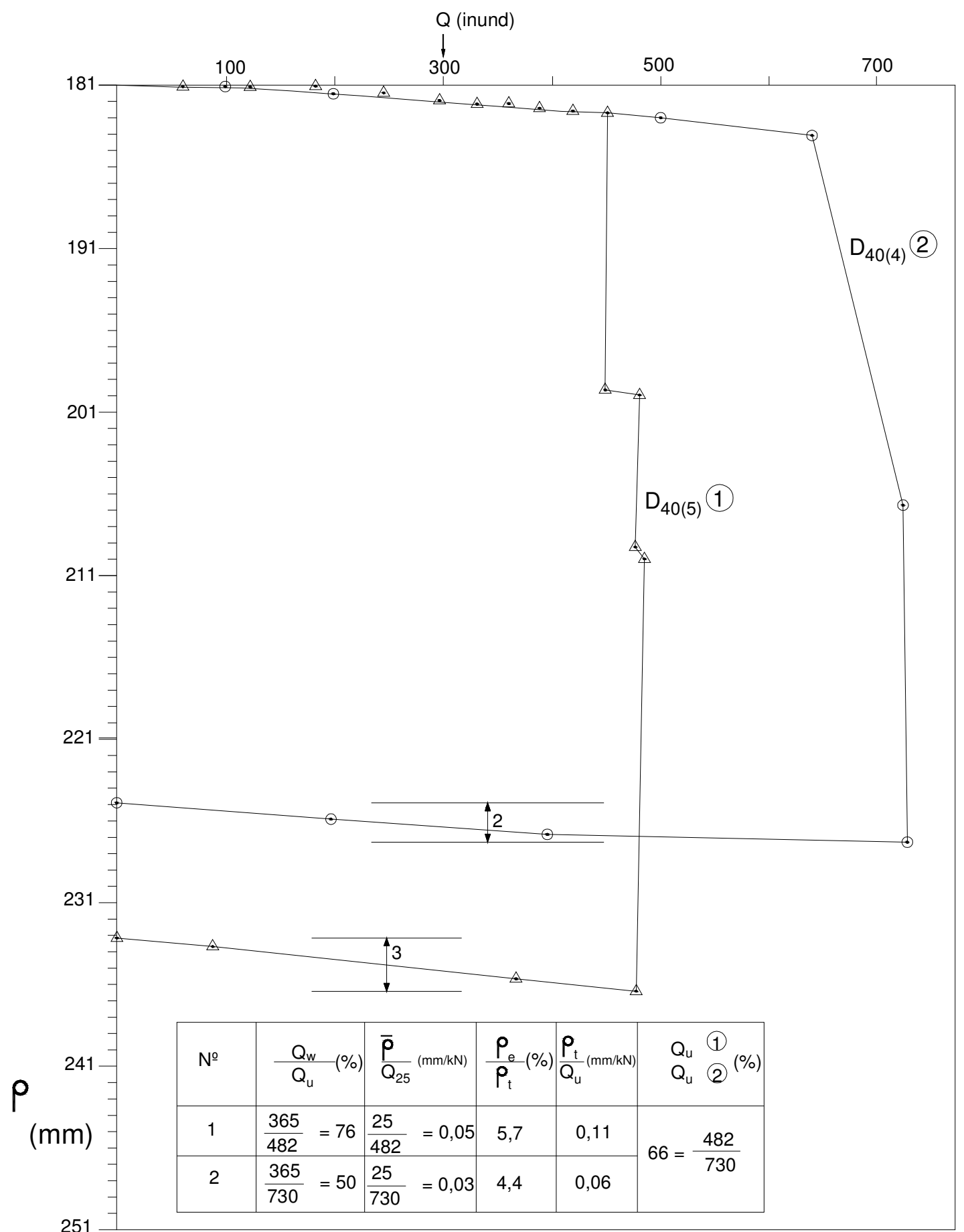

FIGURA 5.1 - Curva "carga x recalque" observada (prova de carga $\mathrm{D}_{40(5)}$ ) com origem deslocada de acordo com a FIGURA 4.2

1) $E_{p, 50}=26,836810 \times 10^{6} \mathrm{kN} / \mathrm{m}^{2}$

Rigorosamente, os módulos de elasticidade das estacas são transientes com o tempo e com a velocidade imposta ao carregamento. Entretanto, devido à 
circunstância acima descrita, tais valores foram aceitos como razoáveis. Na TABELA 4.2 se vê que $D_{50}$ não apresentou variação significativa na sequência anterior das provas de carga e espera-se que $\mathrm{D}_{40}$ tenha comportamento semelhante.

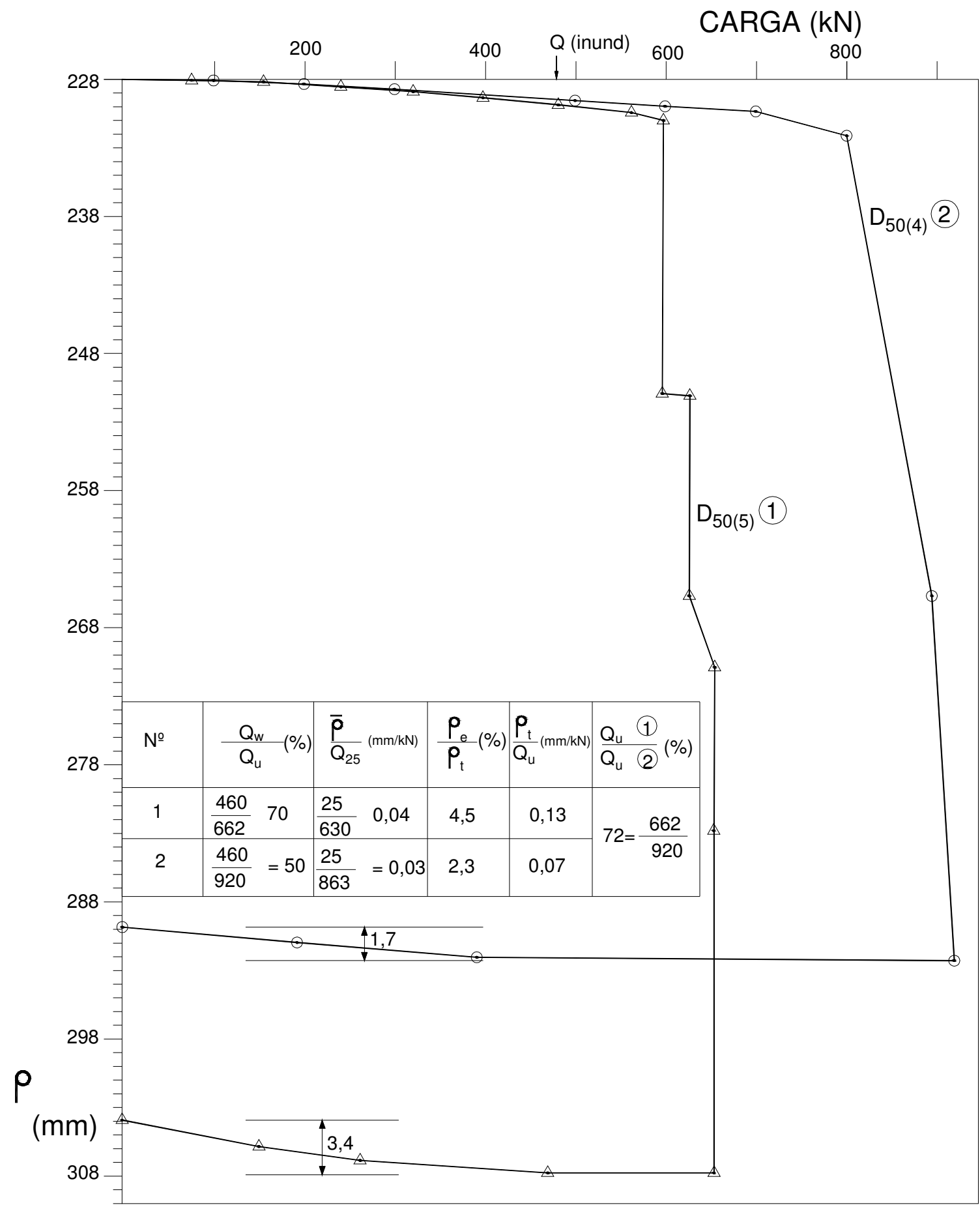

FIGURA 5.2 - Curva "carga x recalque" observada (prova de carga $\mathrm{D}_{50(5)}$ ) com origem deslocada de acordo com a FIGURA 4.2 


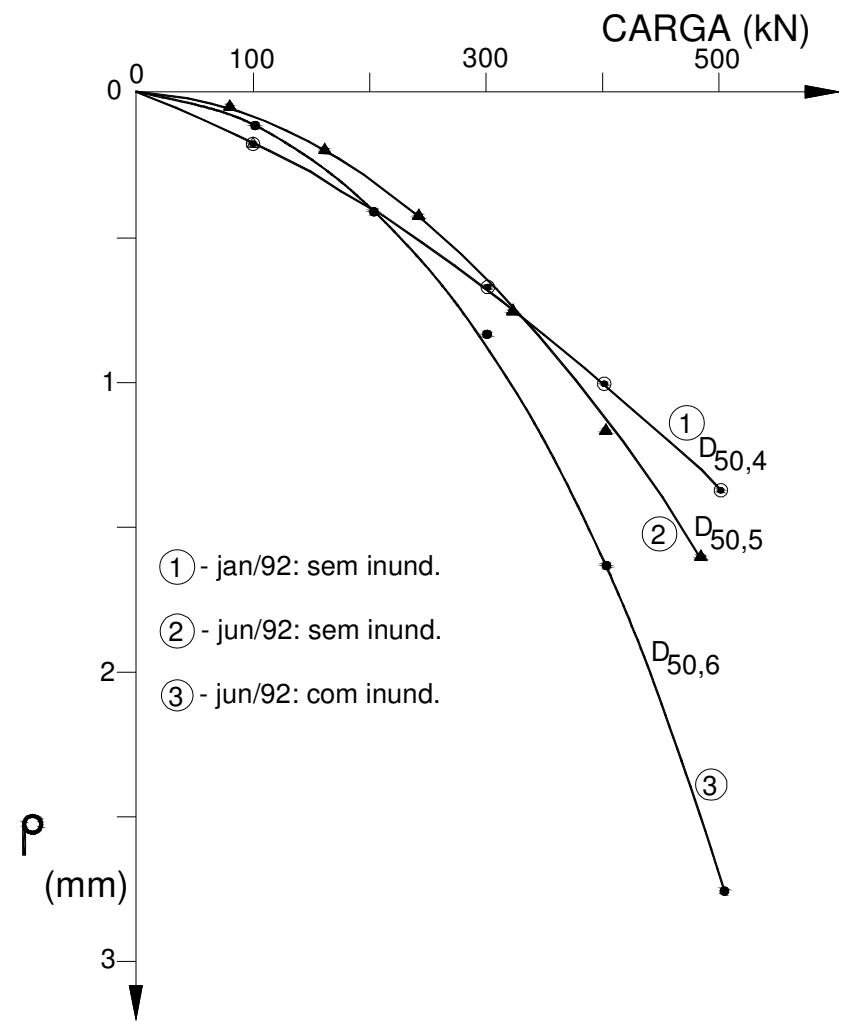

FIGURA 5.3 - Curva "carga x recalque" observada comparada com resultados anteriores (prova de carga $\left.\mathrm{D}_{50(6)}\right)$

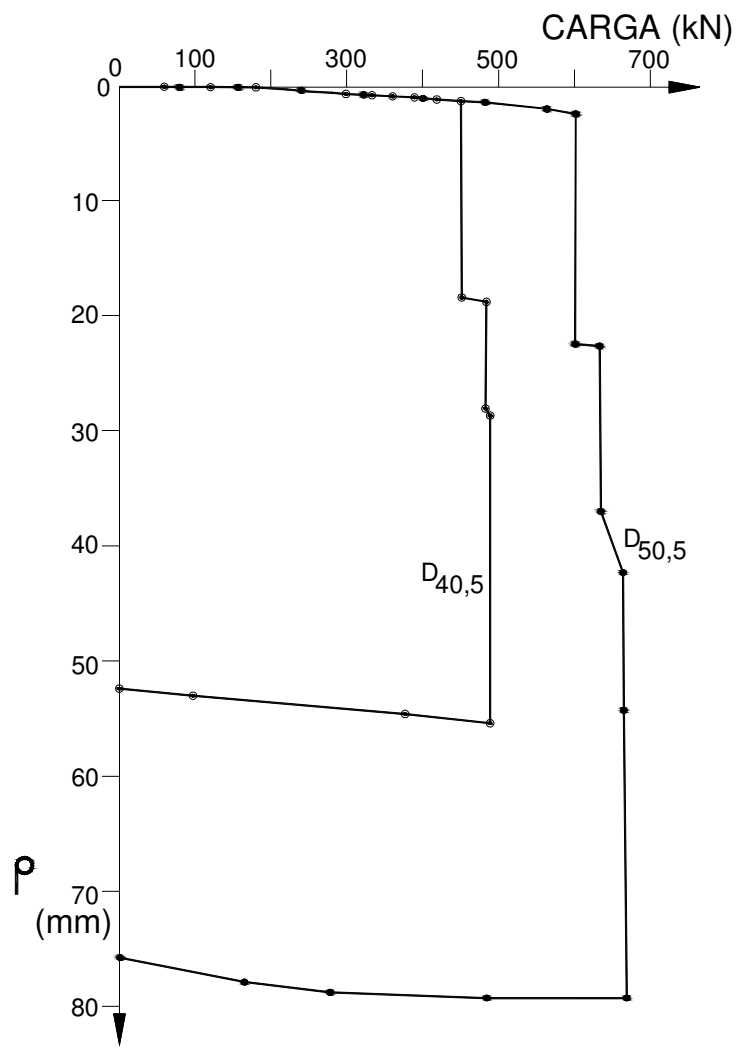

FIGURA 5.4 - Comparação entre as curvas “carga x recalque" das provas de carga $\mathrm{D}_{40(5)}$ e $\mathrm{D}_{50(5)}$ 


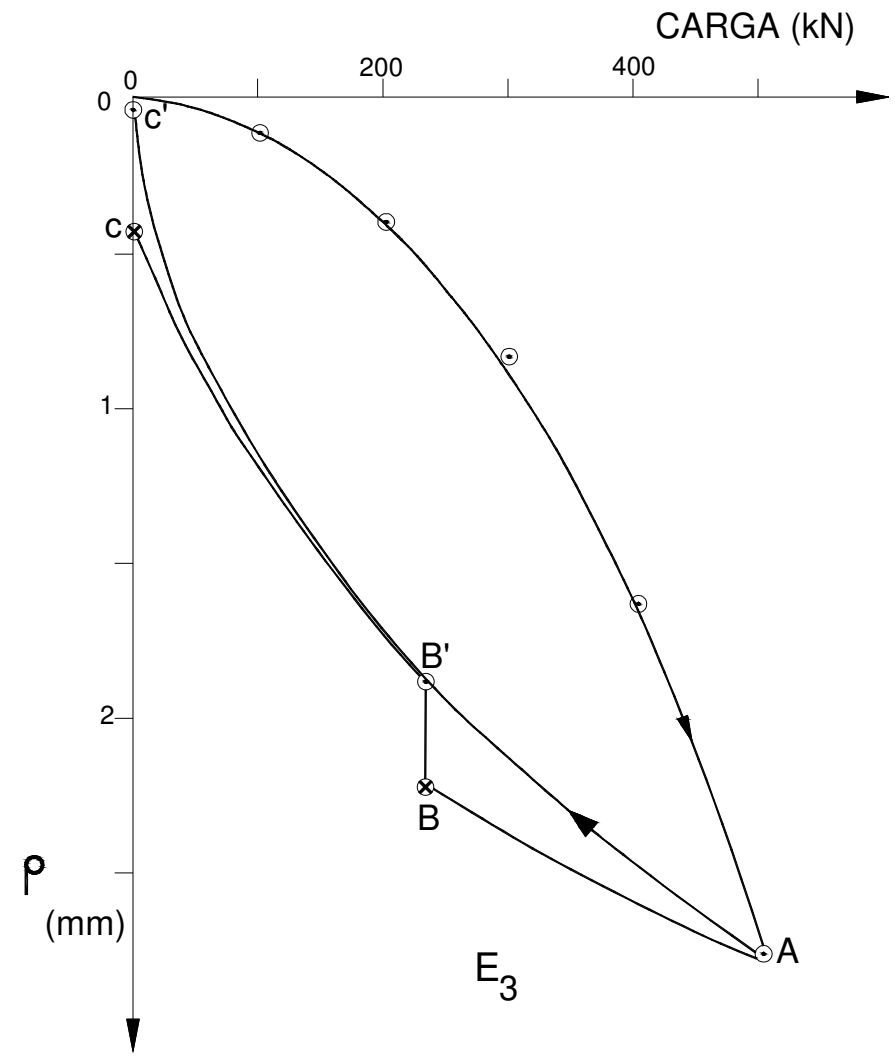

FIGURA 5.5 - Prova de carga $\mathrm{D}_{50(6)}$ mostrando a diferença entre os recalques imediatos e os estabilizados na descarga

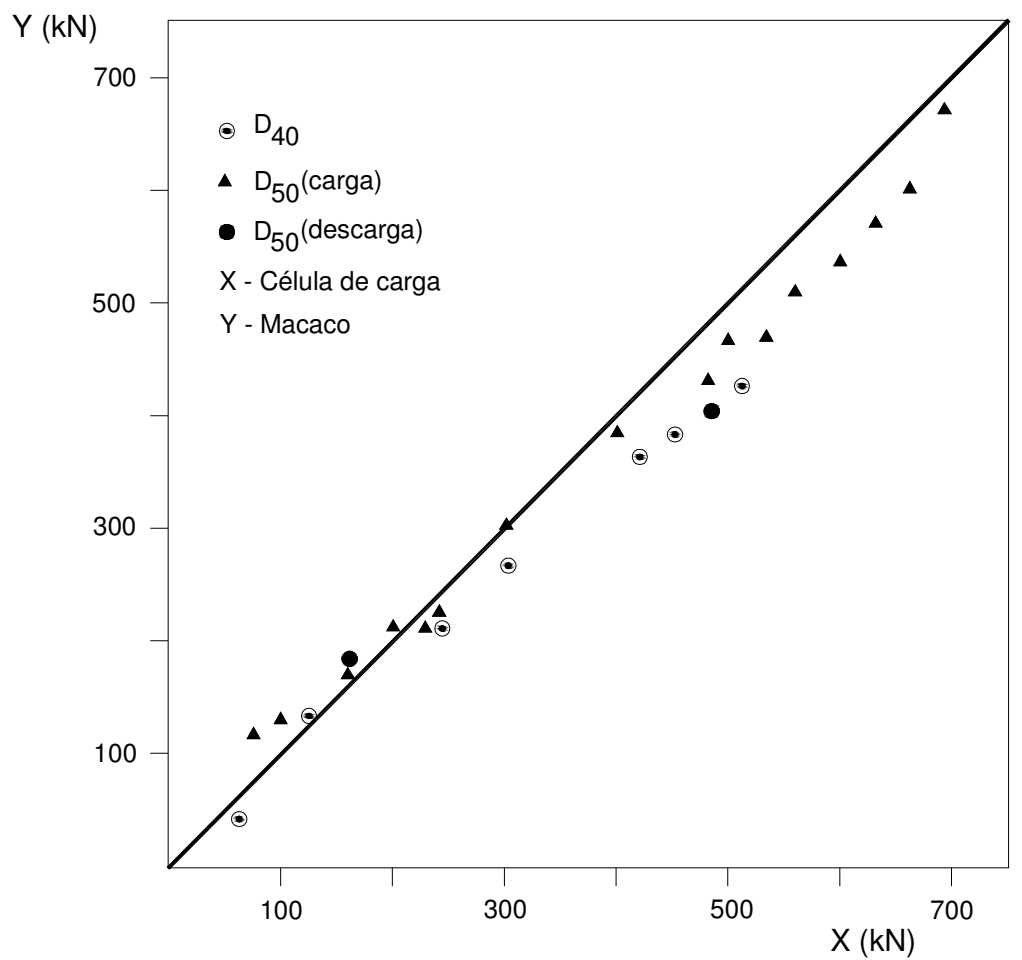

FIGURA 5.6 - Comparação entre leituras manométricas e de célula de carga 
Os valores assim calculados acham-se resumidos nas TABELAS 5.6, 5.7 e

5.8, apresentadas a seguir.

TABELA 5.6 - Deformações e cargas para as diversas seções instrumentadas ( D $\left._{50(6)}\right)$

\begin{tabular}{|c|c|c|c|c|c|c|c|c|}
\hline \multirow{2}{*}{$\begin{array}{c}\mathbf{Q}_{0} \\
(\mathbf{k N})\end{array}$} & \multicolumn{2}{|c|}{ NÍVEL 2} & \multicolumn{2}{|c|}{ NÍVEL 3} & \multicolumn{2}{|c|}{ NÍVEL 4} & \multicolumn{2}{|c|}{ NÍVEL 5} \\
\hline & $d_{2}$ & $\mathbf{Q}_{2}$ & $d_{3}$ & $\mathbf{Q}_{3}$ & $d_{4}$ & $\mathbf{Q}_{4}$ & $\mathrm{~d}_{5}$ & $Q_{5}$ \\
\hline 200 & 27,9 & 153 & 21,8 & 120 & 21,4 & 117 & 17,8 & 95 \\
\hline 300 & 46,8 & 257 & 36,6 & 200 & 29,8 & 163 & 26,9 & 146 \\
\hline 400 & 65,7 & 361 & 51,2 & 280 & 39,9 & 218 & 38,1 & 207 \\
\hline 500 & 84,9 & 467 & 65,7 & 360 & 49,0 & 267 & 47,5 & 258 \\
\hline
\end{tabular}

TABELA 5.7 - Deformações e cargas para as diversas seções instrumentadas $\left(\mathrm{D}_{40(5)}\right)$

\begin{tabular}{|c|c|c|c|c|c|c|c|c|}
\hline \multirow{2}{*}{$\begin{array}{c}\mathbf{Q}_{0} \\
(\mathbf{k N})\end{array}$} & \multicolumn{2}{|c|}{ NÍVEL 2} & \multicolumn{2}{|c|}{ NÍVEL 3} & \multicolumn{2}{|c|}{ NÍVEL 4} & \multicolumn{2}{|c|}{ NÍVEL 5} \\
\hline & $d_{2}$ & $\mathbf{Q}_{2}$ & $d_{3}$ & $\mathbf{Q}_{3}$ & $\mathrm{~d}_{4}$ & $\mathbf{Q}_{4}$ & $d_{5}$ & $\overline{Q_{5}}$ \\
\hline 60 & 8,7 & 48 & 5,1 & 28 & 2,7 & 15 & 1,7 & 9 \\
\hline 120 & 18,9 & 104 & 14,4 & 79 & 9,3 & 51 & 7,4 & 40 \\
\hline 180 & 19,8 & 164 & 22,8 & 125 & 15,4 & 84 & 11,1 & 60 \\
\hline 240 & 40,0 & 220 & 30,7 & 168 & 22,0 & 120 & 16,3 & 88 \\
\hline 300 & 49,1 & 270 & 40,2 & 220 & 29,1 & 159 & 23,7 & 128 \\
\hline 330 & 50,9 & 197 & 46,2 & 256 & 36,8 & 201 & 28,1 & 152 \\
\hline 360 & 61,1 & 336 & 50,0 & 296 & 42,5 & 232 & 33,3 & 180 \\
\hline 390 & 68,3 & 376 & 61,3 & 336 & 49,1 & 268 & 37,7 & 204 \\
\hline 420 & 74,2 & 408 & 68,7 & 376 & 55,2 & 301 & 42,1 & 228 \\
\hline 450 & 79,3 & 436 & 72,7 & 398 & 60,8 & 332 & 47,3 & 256 \\
\hline 480 & 85,1 & 468 & 78,1 & 428 & 66,7 & 364 & 52,3 & 283 \\
\hline 510 & 91,7 & $\begin{array}{l}504 \\
\end{array}$ & 83,3 & 456 & 71,1 & 388 & 54,0 & 292 \\
\hline
\end{tabular}

TABELA 5.8 - Deformações e cargas para as diversas seções instrumentadas $\left(\mathrm{D}_{50(5)}\right)$

\begin{tabular}{|c|c|c|c|c|c|c|c|c|}
\hline \multirow{2}{*}{$\begin{array}{c}\mathrm{Q}_{0} \\
(\mathrm{kN})\end{array}$} & \multicolumn{2}{|c|}{ NÍVEL 2 } & \multicolumn{2}{c|}{ NÍVEL 3 } & \multicolumn{2}{c|}{ NÍVEL 4 } & \multicolumn{2}{c|}{ NÍVEL 5 } \\
\cline { 2 - 9 } & $\mathrm{d}_{2}$ & $\mathrm{Q}_{2}$ & $\mathrm{~d}_{3}$ & $\mathrm{Q}_{3}$ & $\mathrm{~d}_{4}$ & $\mathrm{Q}_{4}$ & $\mathrm{~d}_{5}$ & $\mathrm{Q}_{5}$ \\
\hline 80 & 8,8 & 48,6 & 5,4 & 29,5 & 3,8 & 21,0 & 3,1 & 17,0 \\
\hline 160 & 20,4 & 112,0 & 15,4 & 84,3 & 20,0 & 54,6 & 9,2 & 51,0 \\
\hline 240 & 33,1 & 181,8 & 22,7 & 124,3 & 16,9 & 92,3 & 15,8 & 86,0 \\
\hline 320 & 43,5 & 238,9 & 31,5 & 172,7 & 25,4 & 138,5 & 23,8 & 129,7 \\
\hline 400 & 59,6 & 327,7 & 40,0 & 219,1 & 31,2 & 170,0 & 27,7 & 151,6 \\
\hline 480 & 71,9 & 395,3 & 48,1 & 263,3 & 34,6 & 188,9 & 30,8 & 169,0 \\
\hline 533 & 82,3 & 452,4 & 58,1 & 318,1 & 38,5 & 109,9 & 35,8 & 194,5 \\
\hline 560 & 88,5 & 486,2 & 66,9 & 366,5 & 45,0 & 245,6 & 39,6 & 215,4 \\
\hline 600 & 94,6 & 520,0 & 75,4 & 412,9 & 51,9 & 283,3 & 45,8 & 248,9 \\
\hline 630 & 100,8 & 553,9 & 83,8 & 459,2 & 57,7 & 314,8 & 51,5 & 280,2 \\
\hline 660 & 111,9 & 615,2 & 86,9 & 476,1 & 67,7 & 369,4 & 56,9 & 309,5 \\
\hline 690 & 117,3 & 644,8 & 93,5 & 511,9 & 73,5 & 400,9 & 65,4 & 355,5 \\
\hline
\end{tabular}


A variação das deformações, em função da variação do carregamento Q, pode ser expressa através das variações das leituras $\left(\mathrm{L}_{\mathrm{f}}-\mathrm{L}_{0}\right)$ de acordo com a equação (5.2). Os gráficos das FIGURAS 5.7, 5.8 e 5.9 mostram estas variações.

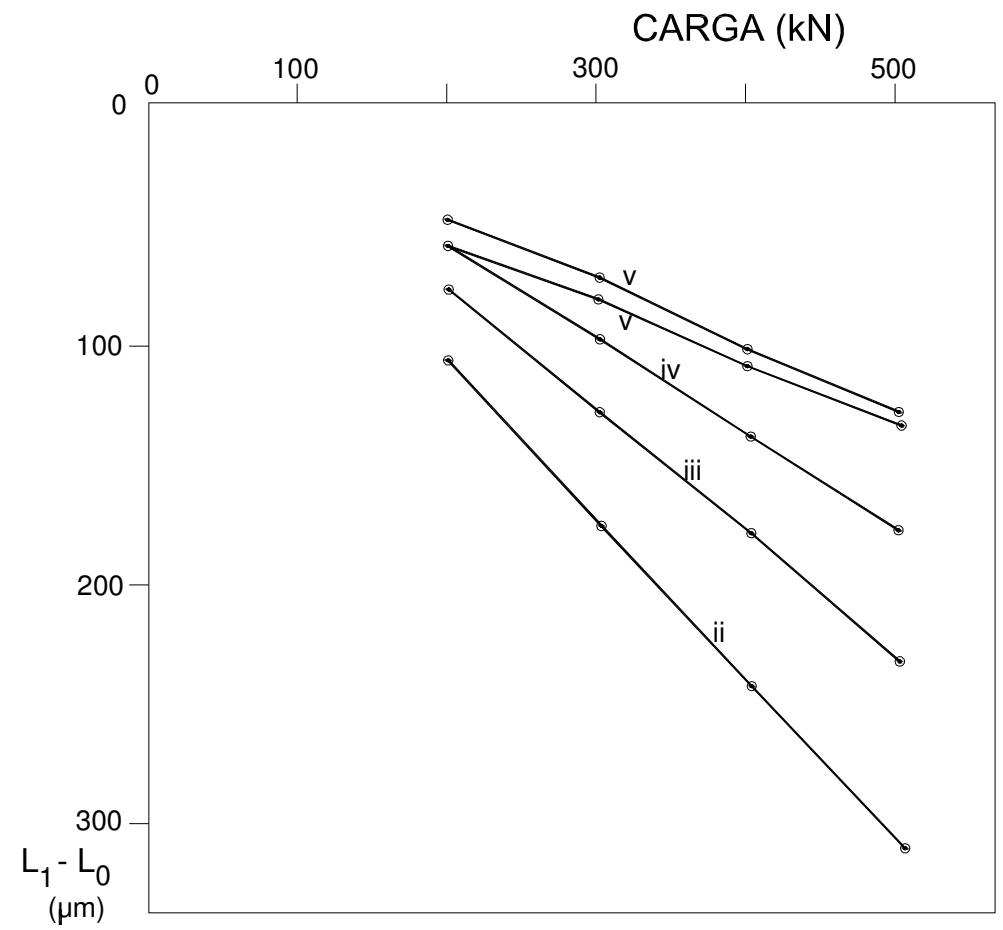

FIGURA 5.7 - Gráfico das variações “carga x deformações” (prova de carga $\mathrm{D}_{50(6)}$ ) para cada nível instrumentado

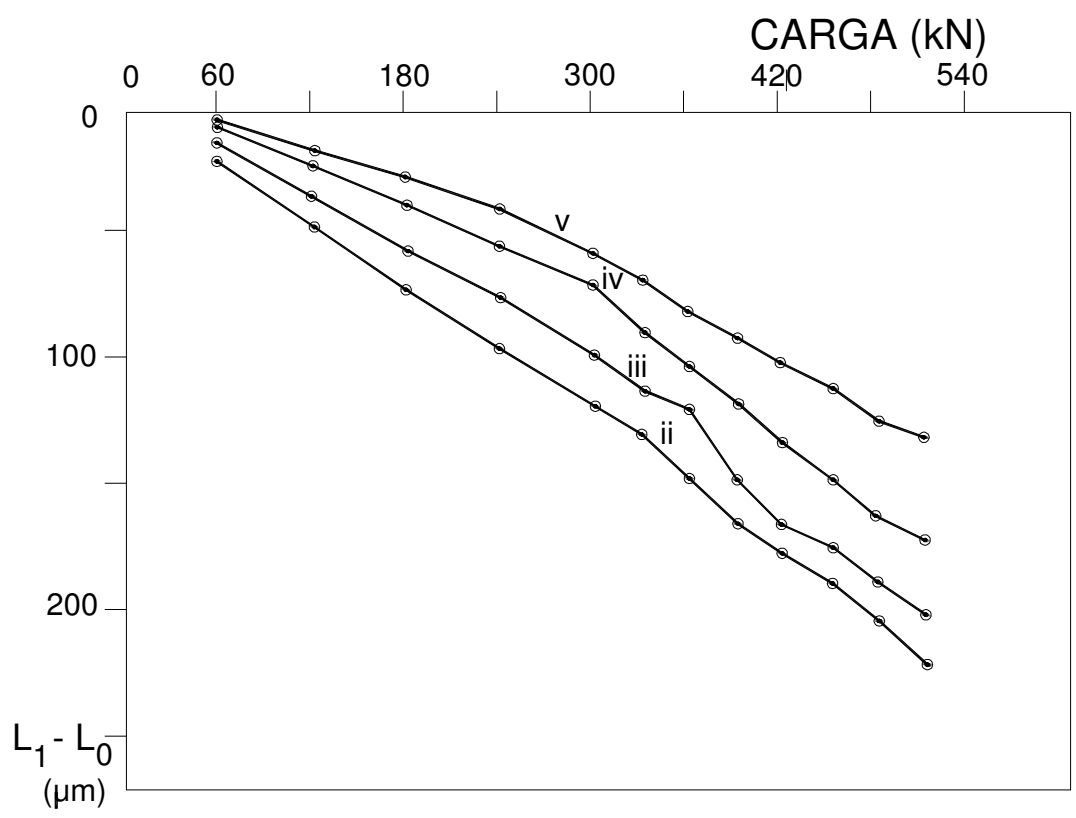

FIGURA 5.8 - Gráfico das variações “carga x deformações” (prova de carga $\mathrm{D}_{40(5)}$ ) para cada nível instrumentado 


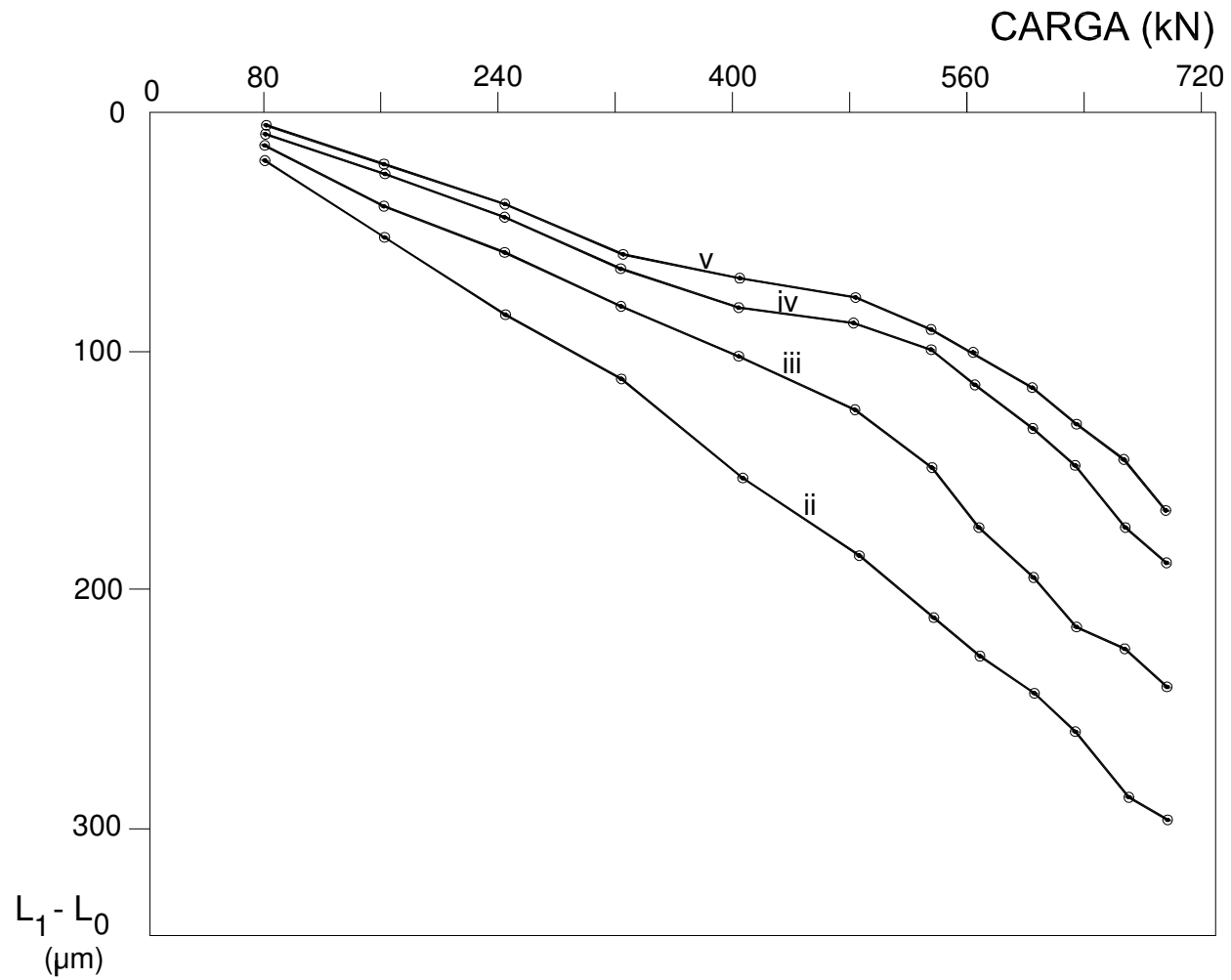

FIGURA 5.9 - Gráfico das variações “carga x deformações” (prova de carga $\mathrm{D}_{50(5)}$ ) para cada nível instrumentado

Conhecendo-se as cargas, para cada estágio de carregamento e para cada seção instrumentada, é possível obter as curvas de transferência de carga, através dos gráficos Q x z (FIGURAS 5.10, 5.11 e 5.12). Nestas figuras destacam-se duas observações:

1) As cargas na seção de referência foram consideradas como sendo as mesmas aplicadas à cabeça das estacas, no estágio. Esta hipótese, geralmente, é verdadeira, desde que acima desta seção não haja nenhuma ligação entre a estaca e o solo. Quando da execução das provas de carga, devido aos afundamentos registrados anteriormente (FIGURA 4.2) é possível verificar-se a existência de uma pequena parcela de atrito. Para fins de cálculo e com base na insignificância desta ligação considerou-se nula a transferência de carga na seção 1

2) $\mathrm{Na}$ ausência de célula de carga na ponta da estaca, é comum aceitar que a carga da base pode ser obtida por uma extrapolação linear das cargas do penúltimo e do último nível (veja-se, por exemplo, CROWTER, 
1988). Esta solução pode ser obtida graficamente, mas implica certa imprecisão. Daí, optou-se por uma solução analítica, baseada em semelhança geométrica. De acordo com os dados da FIGURA 4.1 são válidas as expressões abaixo que, como é óbvio, são restritas exclusivamente a esta situação.

$$
Q_{p}=Q_{5} \cdot \frac{a}{b}
$$

Onde Q5 é a carga calculada na seção 5.

$$
a=L-2,8 ; b=L-2,5 ; L=\frac{2,5 \cdot Q_{4}+Q_{5}}{Q_{4}-Q_{5}}
$$

\subsection{1 - Tensões laterais $x$ deslocamentos}

Conhecidas as cargas em cada nível instrumentado, ao longo da profundidade, é possível obter-se as tensões laterais e os deslocamentos relativos entre solo e estaca ao longo de todo o seu comprimento.

A tensão lateral das estacas é facilmente obtida quando se dispõe destas curvas de transferência de carga. São expressas como uma medida de quantidade de carga que é transferida para o solo entre duas seções consecutivas $\left(Q_{i}-Q_{i-1}\right)$, em relação à casca de solo envolvente à estaca neste segmento. Analiticamente:

$$
f_{s, i}=\frac{Q_{i}-Q_{i-1}}{p \cdot \Delta L}
$$

Onde:

$\mathrm{p}=$ perímetro da estaca (constante para estacas cilíndricas)

$\Delta \mathrm{L}=$ comprimento do segmento da estaca compreendido entre as duas seções instrumentadas. 


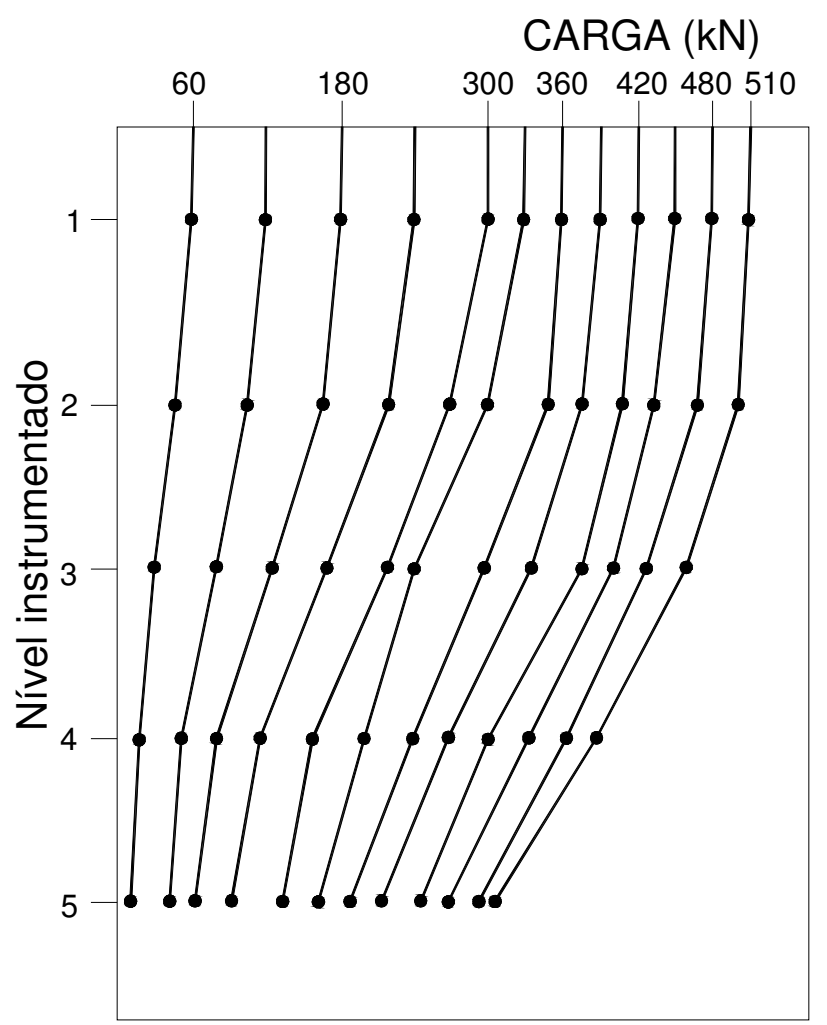

FIGURA 5.10 - Curvas de transferência de carga (prova de carga $\mathrm{D}_{40(5)}$ )

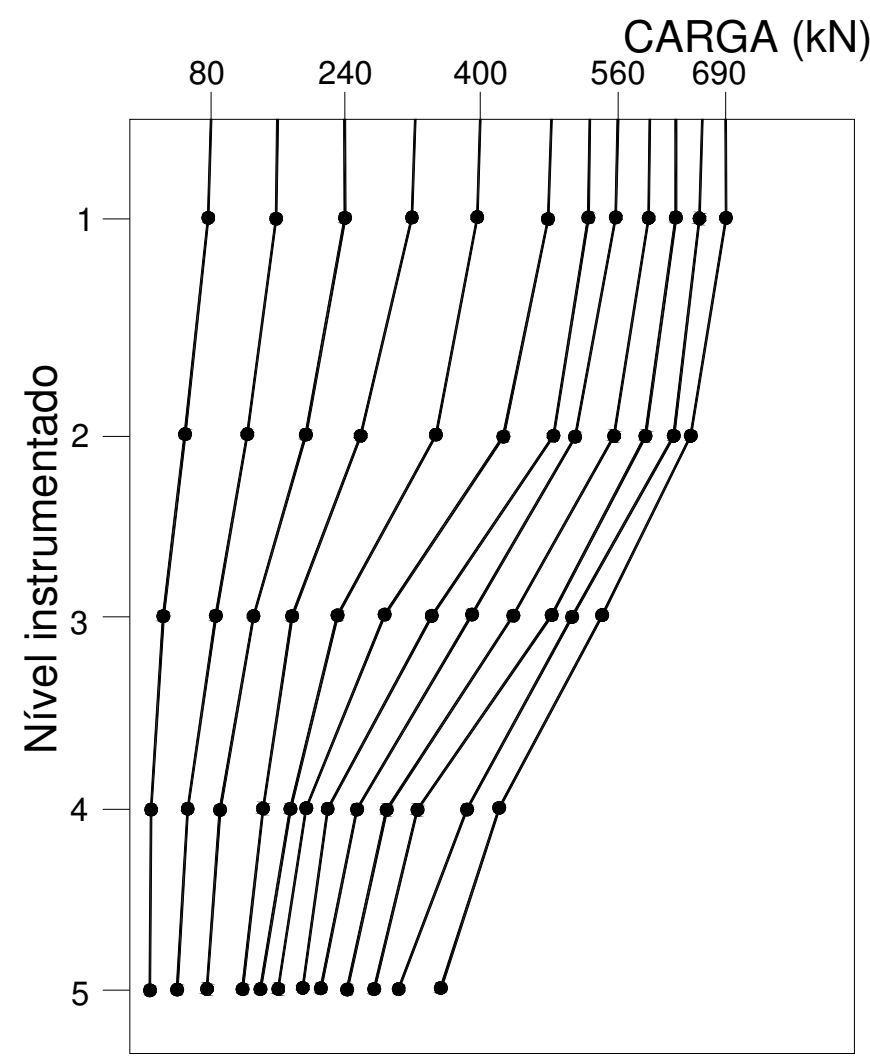

FIGURA 5.11 - Curvas de transferência de carga (prova de carga $\mathrm{D}_{50(5)}$ ) 


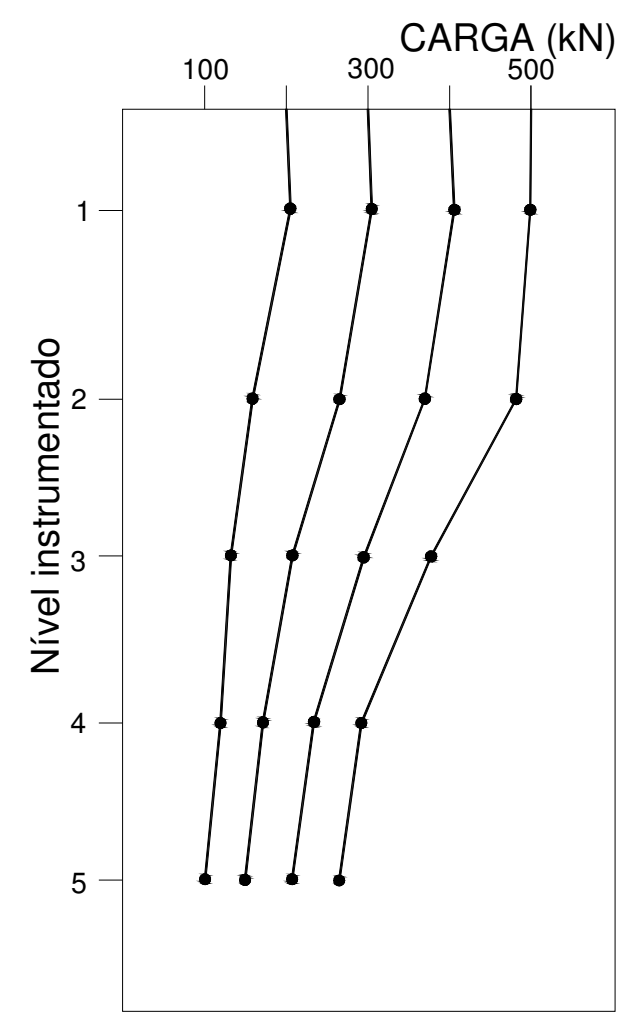

FIGURA 5.12 - Curvas de transferência de carga (prova de carga $\mathrm{D}_{50(6)}$ )

Os deslocamentos são calculados por:

$$
\rho_{i}=\rho_{i-1}-\frac{\bar{Q} \cdot \bar{L}}{E_{p} \cdot \bar{A}_{h}}
$$

Onde:

$\rho_{\mathrm{i}}=$ deslocamento da i-ésima seção. Para $\mathrm{i}=0$ (topo) o deslocamento corresponde à medida dos recalques de superfície tomados como a média das leituras dos extensômetros instalados na cabeça da estaca

$\bar{L}=$ extensão do segmento de estaca compreendido entre as seções i, i-1

$\bar{Q}=$ carga média, obtida dos gráficos de transferência de carga desde a seção i-1 até a seção i. É aceitável a hipótese desta distribuição ser linear entre duas seções consecutivas. Sua validade pode ser comprovada através da TABELA 5.9 onde foi testada. Vê-se ali que a relação entre a carga assim obtida 
(adicionando-se a carga de ponta às várias parcelas de carga lateral) e a carga aplicada durante a prova de carga $\left(\mathrm{Q}_{0}\right)$ é praticamente idêntica $\left(\mathrm{Q}_{\text {calc }} / \mathrm{Q}_{0} \approx 1\right)$

$\overline{A_{h}}=$ seção homogeneizada do concreto da estaca, média entre os valores das seções i, i-1

$\mathrm{E}_{\mathrm{p}}=$ módulo de elasticidade longitudinal do material da estaca.

Destes cálculos, resultam as TABELAS 5.10, 5.11 e 5.12 apresentadas a seguir. Com base nisso, podem ser construídos os gráficos da variação de " $\mathrm{f}_{\mathrm{s}}$ " com a profundidade “z” (FIGURAS 5.13, 5.14 e 5.15). A hipótese anteriormente assumida de que a variação de cargas é linearmente decrescente entre 2 seções adjacentes é aqui utilizada para se supor que a tensão lateral fica constante entre elas.

TABELA 5.9 - Cálculo de Q a partir dos dados de transferência de carga $\left(\mathrm{D}_{40(5)}\right)$

\begin{tabular}{|c|c|c|c|c|c|c|c|}
\hline \multicolumn{7}{|c|}{$Q_{\text {calc }}=Q_{p}+\sum Q_{s, i} ; Q_{s, i}=f_{s, i} \cdot A_{s, i}$} \\
\hline $\mathrm{Q}_{0}(\mathrm{kN})$ & $\mathrm{Q}_{\mathrm{p}}(\mathrm{kN})$ & $\mathrm{Q}_{\mathrm{s} 1}(\mathrm{kN})$ & $\mathrm{Q}_{\mathrm{s} 2}(\mathrm{kN})$ & $\mathrm{Q}_{\mathrm{s} 3}(\mathrm{kN})$ & $\mathrm{Q}_{\mathrm{s} 4}(\mathrm{kN})$ & $\mathrm{Q}_{\text {calc }}(\mathrm{kN})$ & $\mathrm{Q}_{\text {calc }} \mathrm{Q}_{0}(\%)$ \\
\hline 60 & 8,5 & 12,0 & 19,9 & 13,0 & 6,3 & 59,7 & 99,5 \\
\hline 120 & 39,1 & 16,9 & 24,9 & 27,9 & 12,0 & 120,8 & 100,7 \\
\hline 180 & 57,9 & 14,1 & 39,0 & 40,9 & 26,0 & 177,9 & 98,8 \\
\hline 240 & 85,2 & 21,1 & 52,0 & 48,1 & 34,8 & 241,2 & 100,5 \\
\hline 300 & 125,3 & 29,9 & 50,0 & 61,1 & 33,8 & 300,1 & 100,0 \\
\hline 330 & 147,8 & 32,0 & 40,9 & 55,0 & 53,1 & 328,8 & 99,6 \\
\hline 360 & 175,5 & 24,6 & 40,1 & 63,9 & 56,7 & 360,8 & 100,0 \\
\hline 390 & 198,5 & 16,9 & 40,1 & 68,0 & 69,7 & 393,2 & 100,8 \\
\hline 420 & 221,1 & 7,7 & 32,1 & 74,9 & 79,9 & 415,7 & 99,0 \\
\hline 450 & 249,5 & 8,3 & 37,9 & 66,1 & 82,3 & 444,1 & 98,7 \\
\hline 480 & 276,1 & 6,6 & 40,1 & 63,5 & 88,0 & 474,3 & 98,8 \\
\hline 510 & 283,8 & 5,0 & 48,0 & 67,8 & 104,2 & 508,8 & 99,8 \\
\hline
\end{tabular}

TABELA 5.10 - Tensões laterais e deslocamentos, por trechos (prova de carga $\mathrm{D}_{40(5)}$ )

\begin{tabular}{|c|c|c|c|c|c|c|c|}
\hline $\mathrm{f}_{\mathrm{s}}(\mathrm{kPa})$ & $\rho_{1}(\mathrm{~mm})$ & $\mathrm{f}_{\mathrm{s}}(\mathrm{kPa})$ & $\rho_{1}(\mathrm{~mm})$ & $\mathrm{f}_{\mathrm{s}}(\mathrm{kPa})$ & $\rho_{1}(\mathrm{~mm})$ & $\mathrm{f}_{\mathrm{s}}(\mathrm{kPa})$ & $\rho_{1}(\mathrm{~mm})$ \\
\hline 3,4 & 0,001 & 7,2 & $-0,029$ & 4,7 & $-0,049$ & 1,8 & $-0,059$ \\
\hline 4,8 & 0,051 & 9,0 & $-0,009$ & 10,1 & $-0,051$ & 3,4 & $-0,081$ \\
\hline 4,0 & 0,11 & 14,1 & 0,010 & 14,8 & $-0,060$ & 7,4 & $-0,110$ \\
\hline 6,0 & 0,290 & 18,8 & 0,160 & 17,4 & 0,070 & 9,9 & 0,000 \\
\hline 8,5 & 0,700 & 18,1 & 0,540 & 22,1 & 0,420 & 9,6 & 0,320 \\
\hline 9,1 & 0,721 & 14,8 & 0,540 & 19,9 & 0,400 & 15,1 & 0,280 \\
\hline 7,0 & 0,770 & 14,5 & 0,570 & 23,1 & 0,410 & 16,1 & 0,270 \\
\hline 4,8 & 0,890 & 14,5 & 0,670 & 24,6 & 0,490 & 19,8 & 0,330 \\
\hline 2,2 & 1,150 & 11,6 & 0,900 & 27,1 & 0,700 & 0,700 & 0,530 \\
\hline 3,1 & 18,140 & 13,7 & 17,880 & 23,9 & 17,670 & 23,4 & 17,480 \\
\hline
\end{tabular}




\begin{tabular}{|l|l|l|l|l|l|l|l|}
\hline 3,6 & 28,030 & 14,5 & 27,750 & 23,1 & 27,510 & 25,0 & 27,310 \\
\hline 1,7 & 55,120 & 17,4 & 54,820 & 24,6 & 54,570 & 29,6 & 54,350 \\
\hline
\end{tabular}

TABELA 5.11 - Tensões laterais e deslocamentos, por trechos (prova de carga $\mathrm{D}_{50(5)}$ )

\begin{tabular}{|c|c|c|c|c|c|c|c|}
\hline $\mathrm{f}_{\mathrm{s}}(\mathrm{kPa})$ & $\rho_{1}(\mathrm{~mm})$ & $\mathrm{f}_{\mathrm{s}}(\mathrm{kPa})$ & $\rho_{1}(\mathrm{~mm})$ & $\mathrm{f}_{\mathrm{s}}(\mathrm{kPa})$ & $\rho_{1}(\mathrm{~mm})$ & $\mathrm{f}_{\mathrm{s}}(\mathrm{kPa})$ & $\rho_{1}(\mathrm{~mm})$ \\
\hline 7,1 & 0,02 & 5,5 & $-0,01$ & 2,5 & $-0,03$ & 1,0 & $-0,05$ \\
\hline 10,9 & 0,15 & 8,1 & 0,09 & 8,6 & 0,04 & 1,0 & 0,00 \\
\hline 13,2 & 0,37 & 16,6 & 0,29 & 9,3 & 0,23 & 1,5 & 0,17 \\
\hline 18,4 & 0,67 & 19,2 & 0,55 & 9,9 & 0,454 & 2,0 & 0,36 \\
\hline 16,4 & 1,07 & 31,4 & 0,91 & 14,2 & 0,79 & 4,4 & 0,67 \\
\hline 19,3 & 1,44 & 38,2 & 1,23 & 21,5 & 1,08 & 4,9 & 0,94 \\
\hline 18,3 & 2,19 & 38,9 & 1,97 & 31,3 & 1,80 & 3,5 & 1,65 \\
\hline 16,8 & 2,18 & 34,6 & 1,95 & 35,0 & 1,78 & 6,9 & 1,61 \\
\hline 18,2 & 22,37 & 31,0 & 22,12 & 37,5 & 21,92 & 7,8 & 21,73 \\
\hline 17,3 & 36,66 & 27,4 & 36,39 & 41,8 & 36,18 & 7,9 & 35,98 \\
\hline 10,2 & 54,06 & 40,3 & 53,78 & 30,9 & 53,56 & 13,6 & 53,35 \\
\hline 10,3 & 79,15 & 38,5 & 78,86 & 32,1 & 78,62 & 10,3 & 78,39 \\
\hline
\end{tabular}

\subsection{2 - Resistência de ponta $\mathrm{x}$ deslocamentos}

A resistência de ponta da estaca resulta de uma relação simples entre a parcela de carga transferida para a base $\left(\mathrm{Q}_{\mathrm{p}}\right)$ e a sua respectiva área, isto é:

$$
\mathbf{f}_{\mathbf{p}}=\mathbf{Q}_{\mathrm{p}} / \mathbf{A}_{\mathbf{p}}
$$

Quanto ao deslocamento da base da estaca, basta subtrair do movimento da cabeça (medido através dos extensômetros) o encurtamento elástico da estaca quando submetida a uma determinada carga $\mathrm{Q}_{0}$, no topo, em qualquer estágio de carga. Isto é:

$$
\rho_{p}=\rho_{0}-\frac{Q_{0} \cdot L}{E_{p} \cdot \bar{A}_{h}}
$$

Onde $\bar{A}_{h}=$ média de todas as áreas homogeneizadas da TABELA 5.5 para cada estaca. Estes dados estão representados na TABELA 5.13.

TABELA 5.12 - Tensões laterais e deslocamentos por trechos (prova de carga $\mathrm{D}_{50(6)}$ )

\begin{tabular}{|c|c|c|c|c|c|c|c|}
\hline \multicolumn{2}{|c|}{ TRECHO 1 } & \multicolumn{2}{c|}{ TRECHO 2 } & \multicolumn{2}{c|}{ TRECHO 3 } & \multicolumn{2}{c|}{ TRECHO 4 } \\
\hline $\mathbf{f}_{\mathbf{s}}(\mathbf{k P a})$ & $\boldsymbol{\rho}_{\mathbf{1}}(\mathbf{m m})$ & $\mathbf{f}_{\mathbf{s}}(\mathbf{k P a})$ & $\boldsymbol{\rho}_{\mathbf{2}}(\mathbf{m m})$ & $\mathbf{f}_{\mathbf{s}}(\mathbf{k P a})$ & $\boldsymbol{\rho}_{\mathbf{3}}(\mathbf{m m})$ & $\mathbf{f}_{\mathbf{s}}(\mathbf{k P a})$ & $\mathbf{\rho}_{\mathbf{4}}(\mathbf{m m})$ \\
\hline 10,7 & 0,37 & 9,5 & 0,25 & 0,90 & 0,19 & 5,0 & 0,13 \\
\hline 9,8 & 0,77 & 16,5 & 0,65 & 10,70 & 0,55 & 3,9 & 0,46 \\
\hline 8,9 & 1,54 & 23,4 & 1,37 & 17,90 & 1,24 & 2,5 & 1,11 \\
\hline
\end{tabular}




\begin{tabular}{|l|l|l|l|l|l|l|l|}
\hline 7,5 & 2,64 & 31,0 & 2,43 & 26,90 & 2,26 & 2,1 & 2,10 \\
\hline
\end{tabular}

TABELA 5.13 - Valores da "resistência unitária de ponta x deslocamentos"

\begin{tabular}{|c|c|c|c|c|c|c|c|c|}
\hline \multicolumn{3}{|c|}{$\mathbf{D}_{\mathbf{5 0 ( 6 )}}$} & \multicolumn{3}{c|}{$\mathbf{D}_{\mathbf{5 0}(\mathbf{5})}$} & \multicolumn{3}{c|}{$\mathbf{D}_{\mathbf{4 0 ( 5 )}}$} \\
\hline $\mathrm{Q}_{0}(\mathrm{kN})$ & $\mathrm{f}_{\mathrm{p}}(\mathrm{kPa})$ & $\rho_{\mathrm{p}}(\mathrm{mm})$ & $\mathrm{Q}_{0}(\mathrm{kN})$ & $\mathrm{f}_{\mathrm{p}}(\mathrm{kPa})$ & $\rho_{\mathrm{p}}(\mathrm{mm})$ & $\mathrm{Q}_{0}(\mathrm{kN})$ & $\mathrm{f}_{\mathrm{p}}(\mathrm{kPa})$ & $\rho_{\mathrm{p}}(\mathrm{mm})$ \\
\hline 200 & 474,2 & 0,05 & 80 & 84,5 & $-0,11$ & 60 & 67,6 & $-0,13$ \\
\hline 300 & 735,9 & 0,28 & 160 & 256,7 & $-0,10$ & 120 & 311,1 & $-0,20$ \\
\hline 400 & 981,2 & 0,95 & 240 & 432,4 & $-0,01$ & 180 & 460,8 & $-0,27$ \\
\hline 500 & $1.226,6$ & 1,83 & 320 & 659,5 & 0,17 & 240 & 678,0 & $-0,21$ \\
\hline- & - & - & 400 & 755,8 & 0,44 & 300 & 997,1 & 0,07 \\
\hline- & - & - & 480 & 846,4 & 0,68 & 330 & $1.176,2$ & 0,03 \\
\hline- & - & - & 533 & 986,5 & 1,35 & 360 & $1.396,6$ & 0,01 \\
\hline- & - & - & 560 & $1.091,9$ & 1,30 & 390 & $1.579,6$ & 0,07 \\
\hline- & - & - & 600 & $1.263,1$ & 21,42 & 420 & $1.759,5$ & 0,27 \\
\hline- & - & - & 630 & $1.425,5$ & 35,67 & 450 & $1.985,5$ & 17,19 \\
\hline- & - & - & 660 & $1.560,5$ & 53,01 & 480 & $2.197,1$ & 27,02 \\
\hline- & - & - & 690 & $1.800,4$ & 78,06 & 510 & $2.258,4$ & 54,05 \\
\hline
\end{tabular}

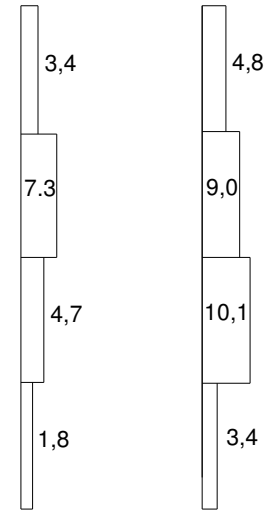

60
120

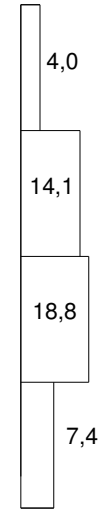

180

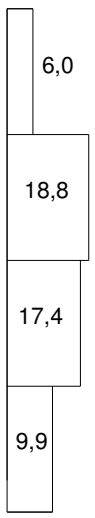

240

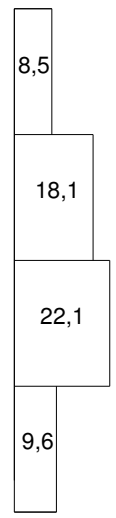

300

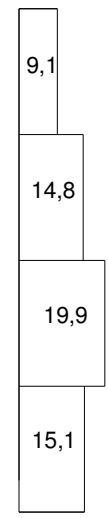

330

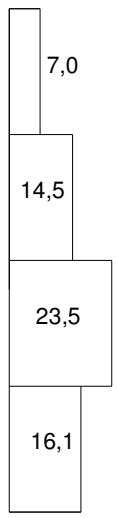

360
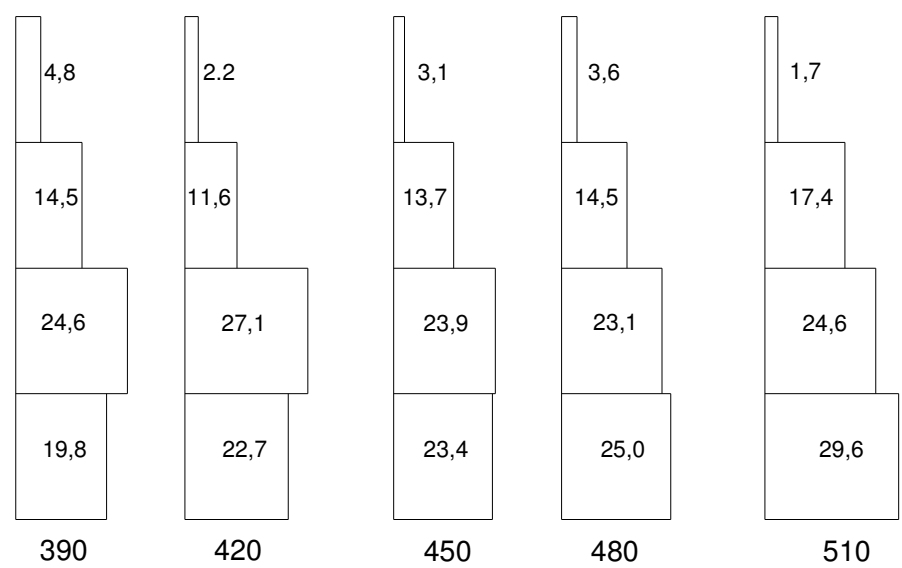

FIGURA 5.13 - Variação de $\mathrm{f}_{\mathrm{s}}(\mathrm{kPa})$ com a profundidade (prova de carga $\mathrm{D}_{40(5)}$ ) para os diversos estágios de carregamento $(\mathrm{kN})$ 

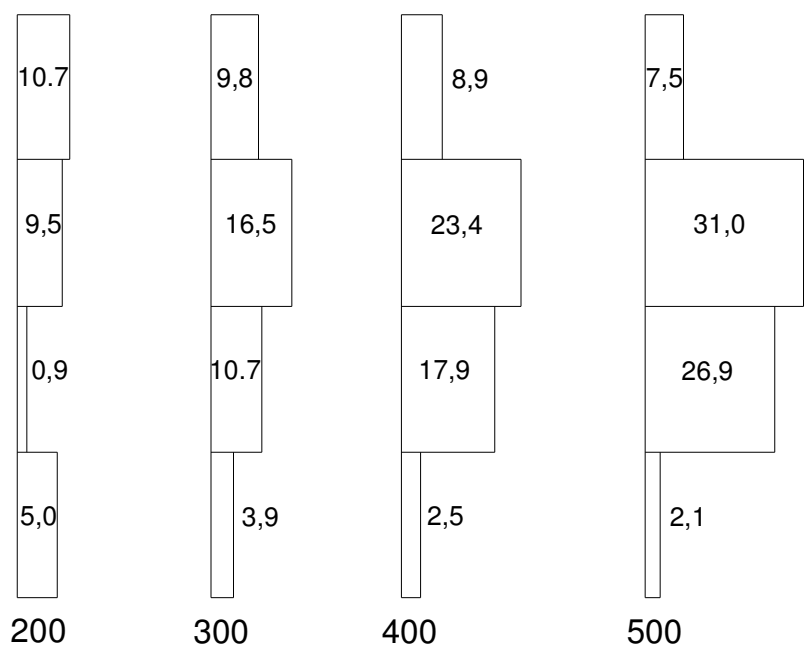

FIGURA 5.14 - Variação de $\mathrm{f}_{\mathrm{s}}(\mathrm{kPa})$ com a profundidade (prova de carga $\left.\mathrm{D}_{50(6)}\right)$ para os diversos estágios de carregamento $(\mathrm{kN})$
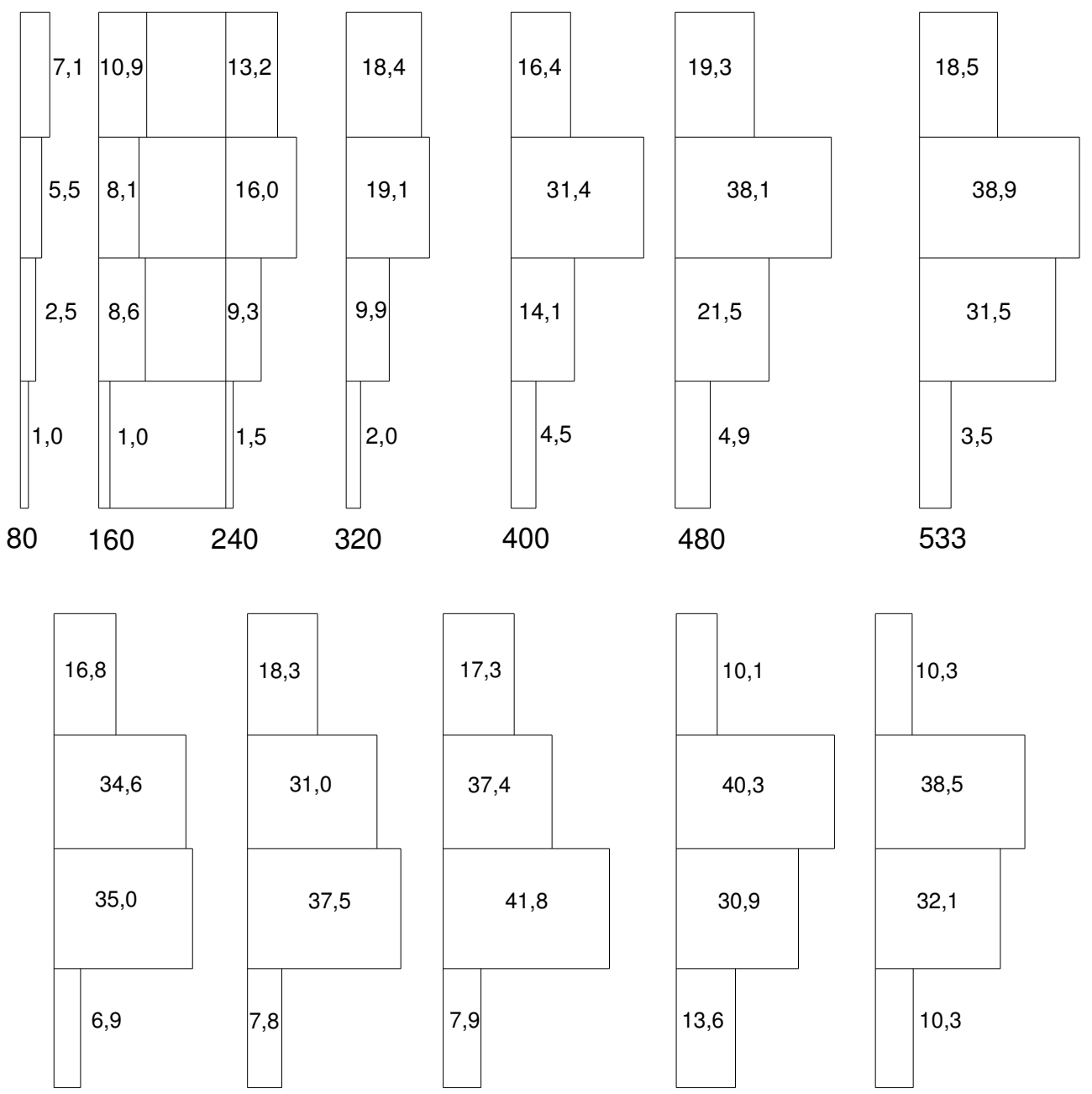

560

600

630

660

690

FIGURA 5.15 - Variação de $\mathrm{f}_{\mathrm{s}}(\mathrm{kPa})$ com a profundidade (prova de carga $\mathrm{D}_{50(5)}$ ) para os diversos estágios de carregamento $(\mathrm{kN})$ 


\section{CAPÍTULO 6 - ANÁLISE DOS RESULTADOS}

\section{1 - CARGA ÚLTIMA}

Uma limitação desta pesquisa, imposta por insuficiência de recursos financeiros, foi a ausência de dados penetrométricos (SPT e CPT) com o solo inundado, nas condições das provas de carga.

A partir deste fato, seria fantasioso propor algum modelo de previsão de carga última para estacas em solos colapsíveis, sob inundação.

As abordagens teóricas clássicas (VAN DER VEEN, MAZURKIEWSKY, CHIN, HYRAIAMA, etc.), que trabalham com funções idealizadas (exponenciais, parabólicas ou hiperbólicas) e permitem fazer extrapolações a partir de pontos observados, não se adaptam bem aos casos de ruptura generalizada, onde o comportamento "carga x recalque" é praticamente constituído por dois segmentos, sendo um na fase elasto-plástica e outro de ruptura brusca, como é frequente nas situações de colapso.

Por outro lado, o comportamento observado nos poucos casos divulgados pelo meio técnico em experiências similares também mostra que o modelo de POULOS \& DAVIS (1980), constituído por três segmentos retos, não está em correspondência com os resultados das provas de carga.

Ademais, a revisão bibliográfica relativa ao tema indica que a tendência é no sentido de estabelecer uma "perda de capacidade de carga" devido ao efeito de inundação, estabelecida em relação à carga última prevista por qualquer dos métodos tradicionais para o solo em condição de umidade natural.

Este será o procedimento aqui adotado, mesmo porque o traçado da curva “carga x recalque" nesta situação já define a carga última com bastante clareza. 
Pelos dados das FIGURAS 5.1 e 5.2 é possível verificar que a perda da capacidade de carga das estacas $\mathrm{D}_{40(5)}$ e $\mathrm{D}_{50(5)}$, por efeito de inundação, em relação às provas de carga lenta da sequência anterior foi de $34 \%$ e $28 \%$, respectivamente.

Estes valores foram obtidos considerando-se, nas provas de carga com o solo inundado, as cargas de equilíbrio, já que o mesmo critério fora utilizado nas provas anteriores.

Considerando, para fins de comparação, os casos relatados no item (2.4.3), é fácil verificar que a pesquisa, sob este aspecto, apresenta os menos valores de perda de carga. Embora haja uma diversidade de fatores a serem considerados, parece realista priorizar o modo de execução e o histórico do carregamento como os mais decisivos.

Por causa de algumas similaridades, é interessante retornar ao caso relatado por NADEO \& VIDELA (1975a) para explorar algumas conclusões. Tais autores descrevem uma situação singular onde somente a ponta foi inundada. Concluíram que este fato não influenciou o comportamento da estaca, já que ela seria capaz de absorver a carga de trabalho prevista apenas por atrito lateral. Deve-se destacar que as estacas do campo experimental da USP - São Carlos estão com a ponta embutida em solo muito próximo ao N. A. (não muito distante da completa saturação). Portanto, a inundação não deveria exercer efeito considerável na reação de ponta.

Outra conclusão desses autores - óbvia, aliás - diz respeito ao contato mais íntimo entre o solo e a estaca após a acumulação de uma certa deformação plástica em prova de carga preliminar. Finalmente, aqueles autores entendem que, decorrido algum tempo após o umedecimento de todo o fuste, processa-se um aumento localizado na resistência lateral do solo, capaz de absorver maiores cargas por atrito lateral.

Estas hipóteses, embora sejam utilizadas para justificar aumento de resistência, parecem absurdas por estarem implicitamente baseadas no raciocínio de que o solo, após cisalhado, recupera a resistência. Não há motivos para se acreditar integralmente nesta hipótese, pelo menos em um pequeno tempo geológico. 
Parece mais razoável justificar ganhos de resistência através do modelo proposto por CAMBEFORT (1964) que prevê, após um pequeno deslocamento vertical da estaca, a saturação do atrito lateral. Assim, a resistência lateral permaneceria indefinidamente constante (o que também é duvidoso por causa da comprovada existência da resistência residual, típica de grandes deslocamentos, inferior à resistência de pico, em solos arenosos), e o aumento da capacidade de carga com a sequência de carregamentos seria devido unicamente ao aumento da resistência de ponta, considerando a memorização de cargas residuais pelo solo.

Entre uma e outra justificativa, há incertezas comprovadas. Não é raro encontrar-se resistências laterais discretamente crescentes ou decrescentes no trecho de deformações onde deveria permanecer constante (veja-se os resultados de SACILOTTO, 1993). Contudo, é razoável afirmar que o efeito da inundação na perda da capacidade de carga deve-se ao decréscimo do atrito lateral, sobretudo nos níveis superiores, por onde a desmobilização é iniciada.

\section{2 - ANÁlise DA EVOLUÇÃo DA CARGa DE PONTA DAS ESTACAS}

Muitas conclusões a respeito dos mecanismos de transferência de carga e a influência da inundação neste processo, poderão advir de uma cuidadosa investigação sobre a evolução das cargas de ponta das estacas nos diversos ensaios a que foram submetidas no campo. As TABELAS 6.1 e 6.2, bem como as FIGURAS 6.1 e 6.2 apresentam dados e ilustram esta variação.

Sob este aspecto, o comportamento das estacas é idêntico. A sequência das provas de carga revela que a inclinação das curvas aumenta à medida em que se impõe à estaca um maior carregamento, sendo notório o acréscimo da carga de ponta com a sucessão dos ensaios.

Quanto ao efeito da inundação parece claro que ele mobiliza instantaneamente a reação de ponta, à custa de uma desmobilização simultânea de parte da resistência lateral (trechos $\mathrm{AB}$ nas FIGURAS 6.1 e 6.2). Isto parece estar confirmado pelo 
comportamento da prova de carga $\mathrm{D}_{50(6)}$, quando a estaca já estava inundada desde o início. Neste caso, a variação da resistência de ponta com o incremento de carga foi praticamente linear.

TABELA 6.1 - Resistência de ponta das diversas provas de carga da estaca $\mathrm{D}_{40}$

\begin{tabular}{|c|c|c|c|c|c|}
\hline \multirow{2}{*}{$\mathbf{Q}_{0}(\mathbf{k N})$} & \multicolumn{5}{|c|}{$Q_{p}(k N)$} \\
\hline & Prova 1: lenta & Prova 2: rápida & Prova 3: rápida & Prova 4: lenta & Prova 5: lenta \\
\hline 30 & - & 7 & - & - & - \\
\hline 40 & 4,4 & - & - & - & - \\
\hline 50 & - & - & 6 & - & - \\
\hline 60 & - & 7 & - & - & 8,5 \\
\hline 80 & 4,8 & - & - & 8,8 & - \\
\hline 90 & - & 8 & - & - & - \\
\hline 120 & - & 6 & - & - & 39,1 \\
\hline 150 & - & 5 & 23 & - & - \\
\hline 160 & 4,8 & - & - & 40 & - \\
\hline 180 & - & 3 & - & - & 57,9 \\
\hline 200 & 14,0 & - & - & - & - \\
\hline 210 & - & 3 & - & - & - \\
\hline 240 & 26,4 & - & - & 57,6 & 85,2 \\
\hline 250 & - & 2 & 57 & - & - \\
\hline 280 & 33,6 & - & - & - & - \\
\hline 300 & - & 6 & 76 & - & 125,3 \\
\hline 320 & 64,0 & 0 & 0 & 76,8 & - \\
\hline 330 & - & 8 & - & - & 147,8 \\
\hline 350 & - & - & 89 & - & - \\
\hline 360 & 97,2 & 14 & - & - & 175,5 \\
\hline 390 & - & 18 & - & - & 198,5 \\
\hline 400 & 144,0 & - & 102 & 124,0 & - \\
\hline 420 & - & 22 & - & - & 221,1 \\
\hline 440 & 211,2 & - & - & - & - \\
\hline 450 & - & 27 & 106 & - & 249,5 \\
\hline 480 & 288,0 & 31 & - & 177,6 & 276,1 \\
\hline 487 & 316,6 & - & - & - & - \\
\hline 500 & - & - & 126 & - & - \\
\hline 510 & - & 38 & - & - & 286,8 \\
\hline 540 & - & 43 & - & - & - \\
\hline 550 & - & - & 135 & - & - \\
\hline 560 & - & - & - & 196,0 & - \\
\hline 570 & - & 47 & - & - & - \\
\hline 600 & - & - & 151 & - & - \\
\hline 603 & - & 45 & - & - & - \\
\hline 640 & - & - & - & 224,0 & - \\
\hline 650 & - & - & 159 & - & - \\
\hline 700 & - & - & 181 & - & - \\
\hline 724 & - & - & 160 & 302,4 & - \\
\hline
\end{tabular}

TABELA 6.2 - Resistência de ponta das diversas provas de carga da estaca $\mathrm{D}_{50}$

\begin{tabular}{|c|c|c|c|c|c|c|}
\hline \multirow{2}{*}{$Q_{0}(k N)$} & \multicolumn{7}{|c|}{$Q_{p}(k N)$} \\
\cline { 2 - 7 } & Prova 1: & Prova 2: & Prova 3: & Prova 4: & Prova 5: & Prova 6: \\
\hline
\end{tabular}




\begin{tabular}{|c|c|c|c|c|c|c|}
\hline & lenta & rápida & rápida & lenta & lenta & lenta \\
\hline 50 & - & 9 & 2 & - & - & - \\
\hline 80 & - & - & - & - & 16,6 & - \\
\hline 100 & 6,7 & 17 & - & 11,9 & - & - \\
\hline 150 & - & 29 & 29 & - & - & - \\
\hline 160 & - & - & - & - & 50,4 & - \\
\hline 200 & 10,7 & 37 & - & 49,4 & - & 93,1 \\
\hline 240 & - & - & - & - & 84,9 & - \\
\hline 250 & - & 47 & 75 & - & - & - \\
\hline 300 & 17,8 & 61 & 77 & 84,7 & - & 144,5 \\
\hline 320 & - & - & - & - & 129,5 & - \\
\hline 350 & - & 69 & 92 & - & - & - \\
\hline 400 & 36,9 & 78 & 107 & 116,1 & 148,4 & 206,1 \\
\hline 450 & 55,4 & 82 & 117 & - & - & - \\
\hline 480 & - & - & - & - & 166,2 & - \\
\hline 500 & - & 85 & 132 & 141,3 & - & 257,2 \\
\hline 533 & - & - & - & - & 193,7 & - \\
\hline 550 & - & 87 & 136 & - & - & - \\
\hline 560 & - & - & - & - & 214,4 & - \\
\hline 600 & - & 111 & 149 & 160,5 & 248,0 & - \\
\hline 630 & - & - & - & - & 279,9 & - \\
\hline 650 & - & 148 & 153 & - & - & - \\
\hline 660 & - & - & - & - & 306,4 & - \\
\hline 690 & - & - & - & - & 353,5 & - \\
\hline 700 & - & 214 & 163 & 178,6 & - & - \\
\hline 750 & - & - & 174 & - & - & - \\
\hline 800 & - & - & 191 & 226,2 & - & - \\
\hline 830 & - & - & 210 & - & - & - \\
\hline 900 & - & - & - & 259,3 & - & - \\
\hline 910 & - & - & - & 262,9 & - & - \\
\hline & & & & & & \\
\hline
\end{tabular}

\section{3 - ANÁLISE DAS VARIAÇÕES $Q_{p} / Q_{0}$ e $Q_{s} / Q_{p} \quad C O M \quad O$ CARREGAMENTO}

Parece intuitivo que, à medida em que se aumenta o carregamento de uma estaca e com a saturação do atrito lateral iniciando do topo para a base, deve aumentar um correspondente incremento da resistência de ponta. Não há razão para se supor que este incremento seja proporcional ao aumento de carga, isto é, a relação $\mathrm{Q}_{\mathrm{p}} / \mathrm{Q}_{0}$ não deve ser constante.

Se forem comparadas as provas de carga anteriores $\left(\mathrm{D}_{40(4)}\right.$ e $\left.\mathrm{D}_{50(4)}\right)$ com as atuais $\left(\mathrm{D}_{40(5)}, \mathrm{D}_{50(5)}\right.$ e $\left.\mathrm{D}_{50(6)}\right)$ estas constatações se cristalizam. Observa-se que a relação $\mathrm{Q}_{\mathrm{p}} / \mathrm{Q}_{0}$ de fato não é linear, porém meramente crescente com o carregamento. 
É notável ainda verificar-se que a estaca de diâmetro mais reduzido ( $D=40$ $\mathrm{cm})$ mobilizou maior porcentagem de resistência de ponta, para uma mesma carga.

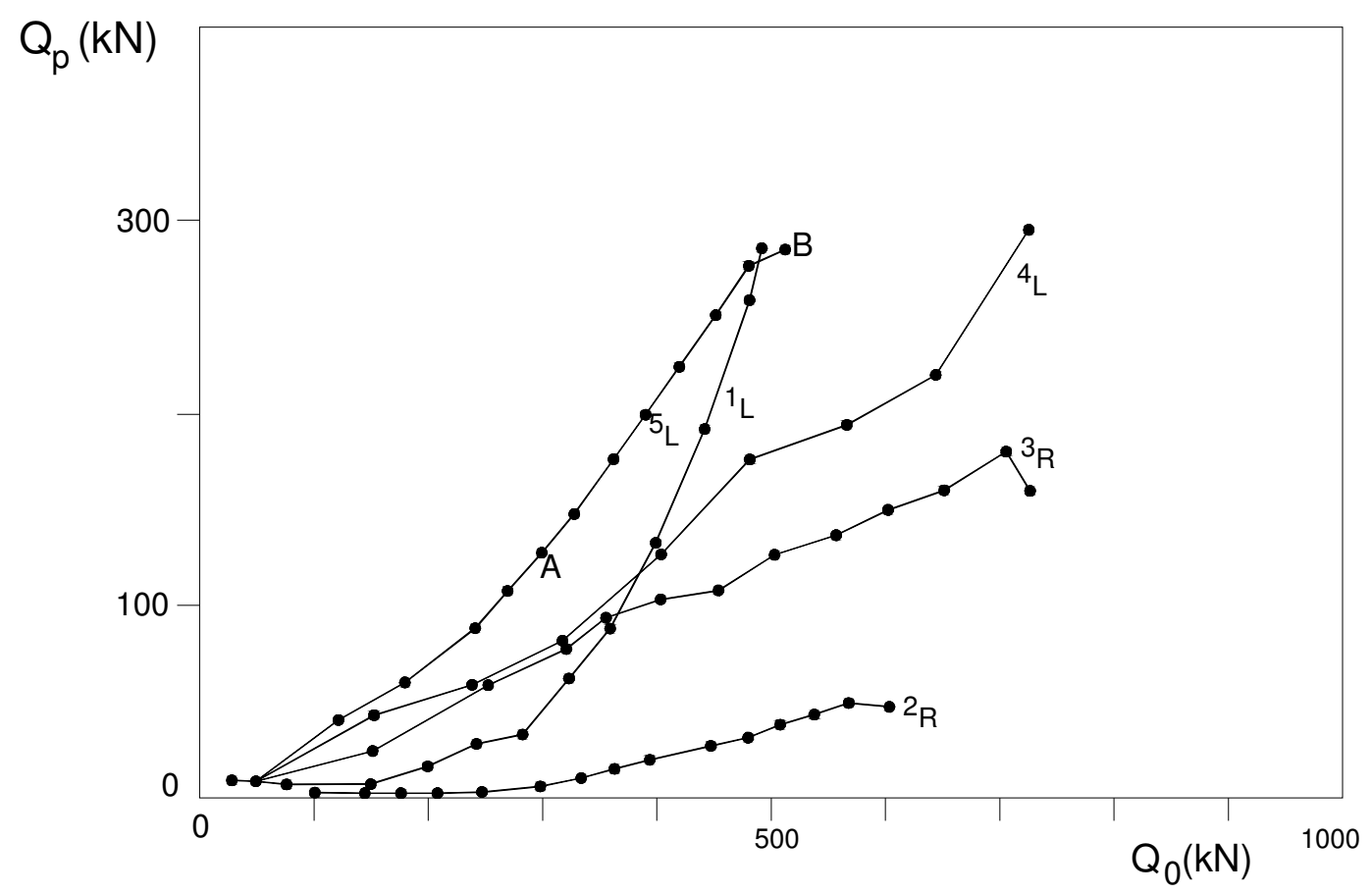

FIGURA 6.1 - Variação da carga de ponta $\left(\mathrm{Q}_{\mathrm{p}}\right)$ com a carga no topo $\left(\mathrm{Q}_{0}\right)$ para as diversas provas de carga da estaca $\mathrm{D}_{40}$

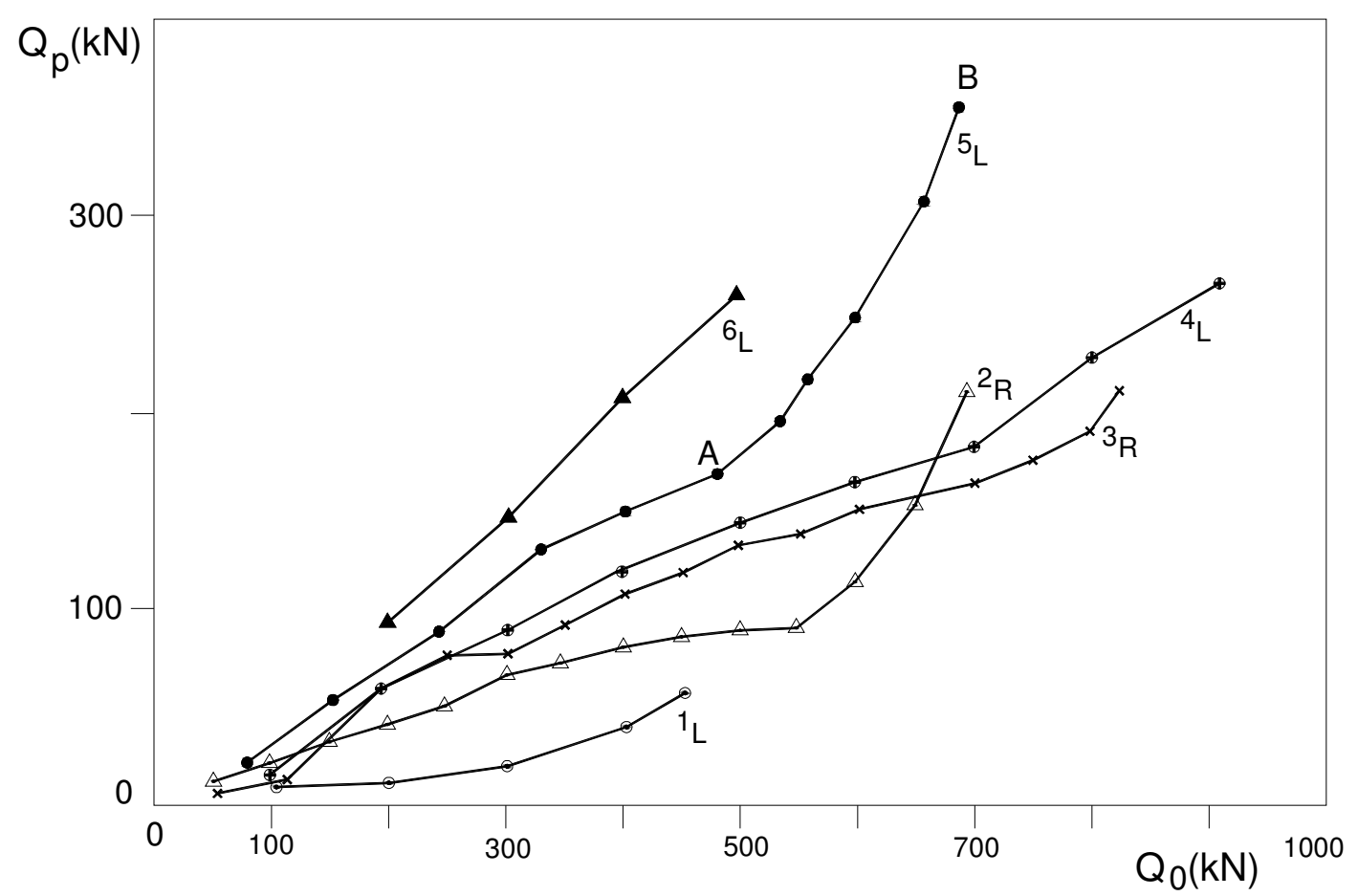

FIGURA 6.2 - Variação da carga de ponta $\left(\mathrm{Q}_{\mathrm{p}}\right)$ com a carga no topo $\left(\mathrm{Q}_{0}\right)$ para as diversas provas de carga da estaca $\mathrm{D}_{50}$ 
Estes dados estão compilados nas TABELAS 6.3, 6.4 e 6.5 e ilustrados na FIGURA 6.3.

TABELA 6.3 - Variação de $\mathrm{Q}_{\mathrm{s}} / \mathrm{Q}_{\mathrm{p}}$ e $\mathrm{Q}_{\mathrm{p}} / \mathrm{Q}_{0}$ com o carregamento $\left(\mathrm{D}_{40(5)}\right)$

\begin{tabular}{|c|c|c|c|c|}
\hline $\mathbf{Q}_{\mathbf{0}}(\mathbf{k N})$ & $\mathbf{Q}_{\mathbf{s}}(\mathbf{k N})$ & $\mathbf{Q}_{\mathbf{p}}(\mathbf{k N})$ & $\mathbf{Q}_{\mathbf{s}} / \mathbf{Q}_{\mathbf{p}}$ & $\mathbf{Q}_{\mathbf{p}} / \mathbf{Q}_{\mathbf{0}}$ \\
\hline 60 & 51,5 & 8,5 & 6,1 & 0,14 \\
\hline 120 & 80,9 & 39,1 & 2,1 & 0,33 \\
\hline 180 & 123,0 & 57,9 & 2,1 & 0,32 \\
\hline 240 & 154,8 & 85,2 & 1,8 & 0,36 \\
\hline 300 & 174,7 & 125,3 & 1,4 & 0,42 \\
\hline 330 & 182,2 & 147,8 & 1,2 & 0,45 \\
\hline 360 & 184,5 & 175,5 & 1,1 & 0,49 \\
\hline 390 & 191,5 & 198,5 & 1,0 & 0,51 \\
\hline 420 & 198,9 & 221,1 & 0,9 & 0,53 \\
\hline 450 & 200,5 & 249,5 & 0,8 & 0,55 \\
\hline 480 & 203,9 & 276,1 & 0,7 & 0,58 \\
\hline 510 & 226,2 & 283,8 & 0,8 & 0,56 \\
\hline
\end{tabular}

TABELA 6.4 - Variação de $\mathrm{Q}_{\mathrm{s}} / \mathrm{Q}_{\mathrm{p}}$ e $\mathrm{Q}_{\mathrm{p}} / \mathrm{Q}_{0}$ com o carregamento $\left(\mathrm{D}_{50(5)}\right)$

\begin{tabular}{|c|c|c|c|c|}
\hline $\mathbf{Q}_{\mathbf{0}}(\mathbf{k N})$ & $\mathbf{Q}_{\mathbf{s}}(\mathbf{k N})$ & $\mathbf{Q}_{\mathbf{p}}(\mathbf{k N})$ & $\mathbf{Q}_{\mathbf{s}} / \mathbf{Q}_{\mathbf{p}}$ & $\mathbf{Q}_{\mathbf{p}} / \mathbf{Q}_{\mathbf{0}}$ \\
\hline 80 & 63,4 & 16,6 & 3,8 & 0,21 \\
\hline 160 & 109,6 & 50,4 & 2,2 & 0,32 \\
\hline 240 & 155,1 & 84,9 & 1,8 & 0,35 \\
\hline 320 & 190,5 & 129,5 & 1,5 & 0,40 \\
\hline 400 & 251,6 & 148,4 & 1,7 & 0,37 \\
\hline 480 & 313,8 & 166,2 & 1,9 & 0,35 \\
\hline 533 & 339,3 & 193,7 & 1,8 & 0,36 \\
\hline 560 & 345,6 & 214,4 & 1,6 & 0,38 \\
\hline 600 & 352,0 & 248,0 & 1,4 & 0,41 \\
\hline 630 & 350,1 & 279,9 & 1,3 & 0,44 \\
\hline 660 & 353,6 & 306,4 & 1,2 & 0,46 \\
\hline 690 & 336,5 & 353,5 & 1,0 & 0,51 \\
\hline
\end{tabular}

TABELA 6.5 - Variação de $\mathrm{Q}_{\mathrm{s}} / \mathrm{Q}_{\mathrm{p}}$ e $\mathrm{Q}_{\mathrm{p}} / \mathrm{Q}_{0}$ com o carregamento $\left(\mathrm{D}_{50(6)}\right)$

\begin{tabular}{|c|c|c|c|c|}
\hline $\mathbf{Q}_{\mathbf{0}}(\mathbf{k N})$ & $\mathbf{Q}_{\mathbf{s}}(\mathbf{k N})$ & $\mathbf{Q}_{\mathbf{p}}(\mathbf{k N})$ & $\mathbf{Q}_{\mathbf{s}} / \mathbf{Q}_{\mathbf{p}}$ & $\mathbf{Q}_{\mathbf{p}} / \mathbf{Q}_{\mathbf{0}}$ \\
\hline 200 & 106,9 & 93,1 & 1,15 & 0,47 \\
\hline 300 & 155,5 & 144,5 & 1,08 & 0,48 \\
\hline 400 & 193,9 & 206,1 & 0,94 & 0,51 \\
\hline 500 & 242,8 & 257,2 & 0,94 & 0,51 \\
\hline
\end{tabular}

Isto parece confirmar a hipótese implícita que, quanto menor a resistência lateral (grosseiramente proporcional ao diâmetro ou perímetro da estaca), mais fácil é esgotar esta resistência para pequenos carregamentos, o que contribui para uma transferência mais rápida e quantitativamente mais significativa para a resistência de ponta, para uma mesma carga. 
O efeito de inundação nesta relação, visto nos trechos AB (FIGURA 6.3) é bem visível na estaca $\mathrm{D}_{50}$ (cujo paralelismo $\mathrm{D}_{50(4)} / / \mathrm{D}_{50(5)}$ desaparece com a inundação), mas parece não ter exercido o mesmo efeito em $\mathrm{D}_{40}$.

Na prova de carga $\mathrm{D}_{50(6)}$, com inundação desde o início, o crescimento da relação com o aumento do carregamento foi muito discreto. A variação pode sugerir que uma extrapolação do trecho $\mathrm{CD}$ da FIGURA 6.3 levaria a uma aparente coincidência dos pontos D e B. Esta hipótese, porém, não é corroborada pelos resultados da FIGURA 4.2, onde evidencia-se uma tendência de continuar aumentando a carga última - e, por conseguinte, a carga de ponta.

A superação deste limite na estaca $\mathrm{D}_{40}$ parece clara, sendo indicada pela inversão no sentido da curva $\mathrm{AB}$ no último estágio de carregamento, já com a estaca inundada.

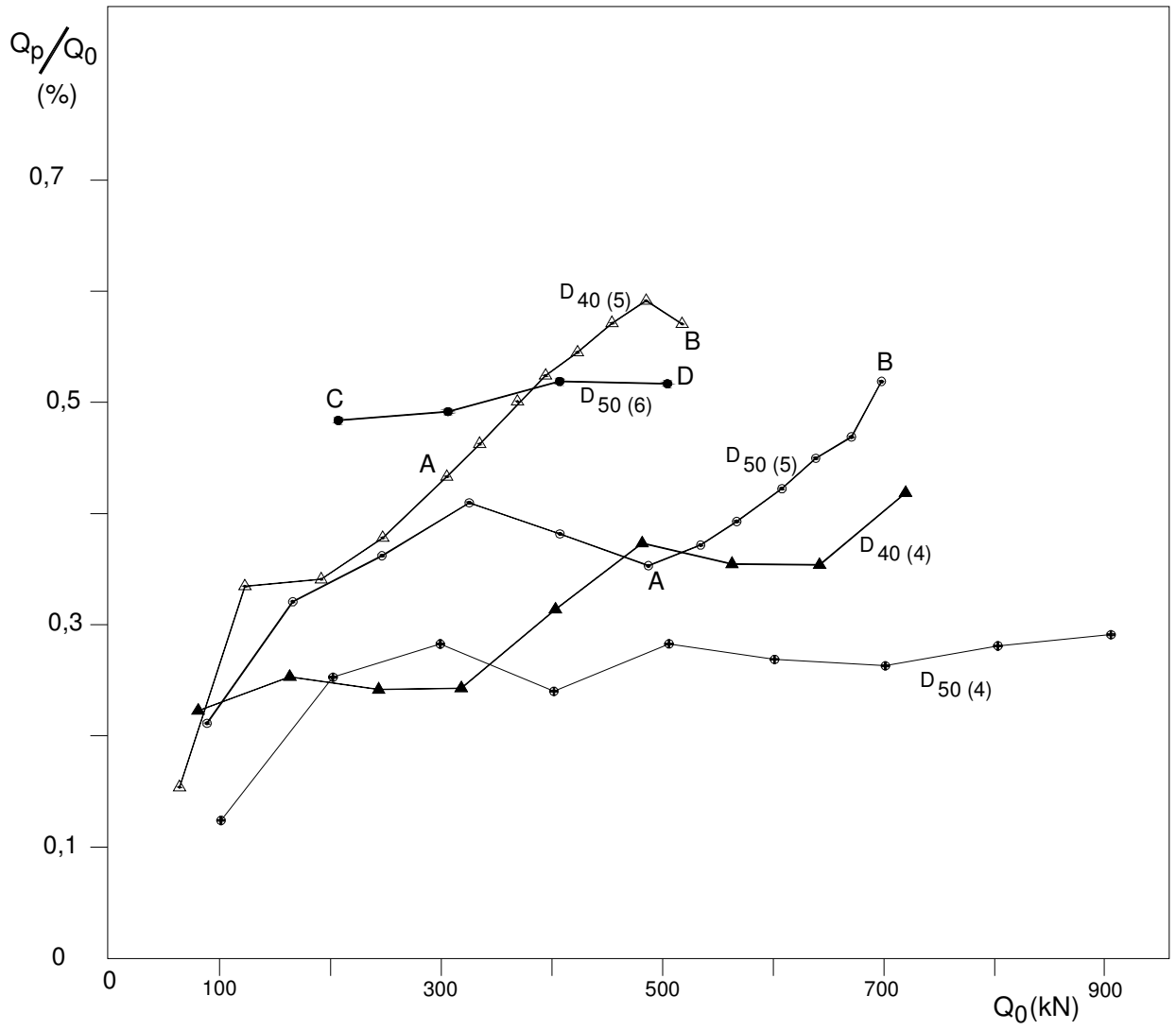

FIGURA 6.3 - Variação de $\mathrm{Q}_{\mathrm{p}} / \mathrm{Q}_{0}$ com o carregamento no topo $\left(\mathrm{Q}_{0}\right)$ 
Estas curvas parecem tender a um patamar de estabilização entre 0,5 e 0,6 , que revela a máxima mobilização de ponta possível para cada estaca. Este nível de mobilização pode ser considerado muito elevado para estacas escavadas. Alguns autores (TOH et al., 1989; REESE et al., 1969 e REESE et al., 1976) sugerem uma variação de $\mathrm{Q}_{\mathrm{p}} / \mathrm{Q}_{0}$ de 0,10 a 0,25 , sendo o limite superior correspondente a estacas de grande diâmetro. Depreende-se daí que o comportamento de estacas escavadas, quando sujeitas a múltiplos carregamentos, tende a assemelhar ao comportamento de estacas cravadas, com o surgimento de tensões residuais.

Por outro lado, a variação $\mathrm{Q}_{\mathrm{s}} / \mathrm{Q}_{\mathrm{p}}$ tem um andamento previsível. Para pequenos carregamentos impostos à estaca a parcela de atrito lateral é muitas vezes superior à parcela de ponta. Porém, à medida que sucessivas solicitações (provas de carga) são exercidas, cada vez menos resistência lateral é oferecida, em contrapartida do aumento substancial da resistência de ponta - o que fica claro na análise da FIGURA 6.4.

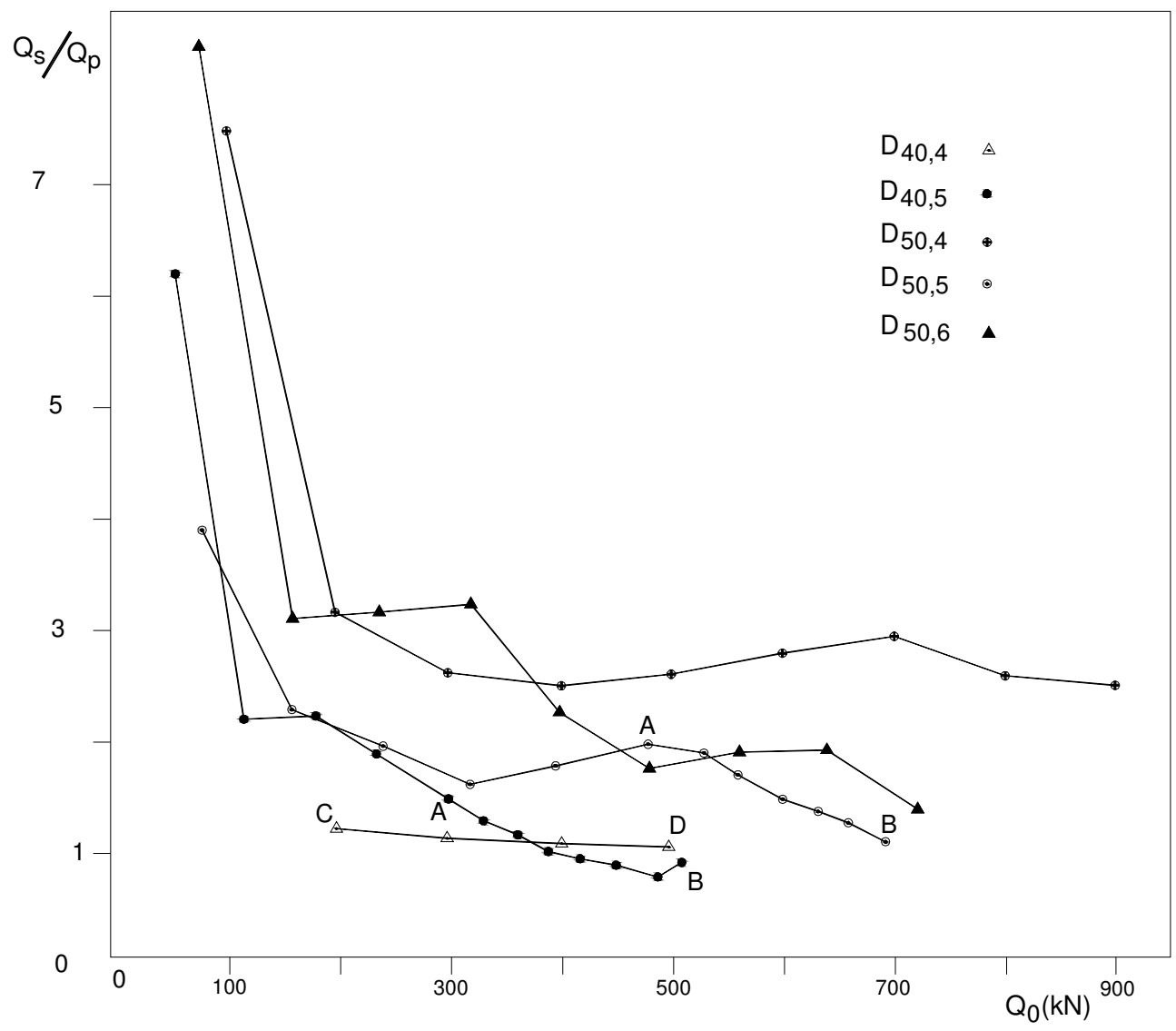

FIGURA 6.4 - Variação de $\mathrm{Q}_{\mathrm{s}} / \mathrm{Q}_{\mathrm{p}}$ com o carregamento no topo $\left(\mathrm{Q}_{0}\right)$ 
Sendo intercambiáveis as parcelas $\mathrm{Q}_{\mathrm{s}}$ e $\mathrm{Q}_{\mathrm{p}}$ - isto é, o aumento de uma implica a diminuição da outra - é óbvio que o comportamento da relação expressa pela FIGURA 6.4 deverá ser grosseiramente inversa do comportamento anterior, sendo a relação $\mathrm{Q}_{\mathrm{s}} / \mathrm{Q}_{\mathrm{p}}$ decrescente com o carregamento e muito mais intensa na fase inicial. Porém apresenta tendência de estabilização.

Esta relação decresce até valores menores que a unidade, como consequência da sucessão de provas de carga feita sobre as mesmas estacas.

A inundação exerce efeito no trecho $\mathrm{AB}$ da FIGURA 6.4 por causa da diminuição do atrito lateral e consequente transferência para a ponta, porém o efeito é igualmente notável na estaca de maior diâmetro por razões já comentadas anteriormente.

Para a prova de carga inundada desde o início do carregamento a relação é quase linear e apresenta uma pequena transferência de carga lateral para a ponta.

\section{4 - ANÁLISE DA VARIAÇÃO DA RESISTÊNCIA LATERAL COM A PROFUNDIDADE}

Uma observação mais atenta nas FIGURAS 5.13, 5.14 e 5.15 revela certos aspectos bem interessantes do comportamento das estacas ensaiadas. $\mathrm{Na}$ prova de carga $\mathrm{D}_{40(5)}$ verifica-se um comportamento não clássico, isto é, ele não corresponde à expectativa de que nos primeiros estágios de carregamento haja uma maior mobilização de resistência lateral nas camadas superiores e decrescendo em direção à base.

A explicação mais razoável parece estar baseada no prévio esgotamento da resistência lateral, já que até o estágio onde o solo foi inundado (300 kN) este comportamento não é sensivelmente modificado.

Após a inundação (FIGURA 5.13) verifica-se uma gradual desmobilização da resistência lateral no trecho superior da estaca, enquanto no trecho médio superior a resistência permanece razoavelmente constante, com evidências de ter atingido a saturação. 
Uma pequena transferência é repassada para o trecho médio inferior, também com indícios de ter atingido a saturação.

Todo este mecanismo se processa à custa de uma transferência preferencial para o último segmento da estaca, mais próximo à base. Este é, justamente, o trecho crítico, de análise complexa. Sendo crescente, mesmo na vizinhança da ruptura esta constatação contraria a hipótese de que a ruptura é a fase final de um processo de esgotamento que atingiu, inclusive, o máximo limite de resistência de ponta, o que só se daria após a inteira mobilização da resistência do fuste.

Quanto à prova de carga da estaca $\mathrm{D}_{50(5)}$ esta apresenta um comportamento previsível. Para fins de comparação basta recorrer às curvas apresentadas por FONTOURA (1982) conforme a FIGURA 2.3.

O fato de não ser nitidamente observável nenhuma influência da inundação do solo, no estágio de $480 \mathrm{kN}$ da prova de carga, talvez possa ter uma explicação para este caso. Com efeito, ao ter sido realizada uma prova de carga em estaca muito próxima $\left(\mathrm{D}_{40(5)}\right)$, com grande volume de água absorvida pelo solo e sem tempo suficiente para o restabelecimento das condições naturais antes do início da prova de carga $\left(\mathrm{D}_{50(5)}\right)$ é provável que a inundação posterior tenha exercido um papel quase redundante neste comportamento.

Quanto à FIGURA 5.14, relativa à prova de carga D50(6), prevalecem a maioria das análises anteriores, com exceção para a anomalia observada no estágio de 200 kN, de difícil explicação.

\section{5 - ANÁLISE DA VARIAÇÃO DAS RESISTÊNCIAS LATERAL E DE PONTA COM OS DESLOCAMENTOS DA ESTACA}

Tendo em vista a importância deste tema, buscou-se estudar a variação do atrito lateral com os deslocamentos da estaca, levando-se ainda em conta uma terceira variável, que é a profundidade.

Assim, foram construídas, para cada prova de carga, as curvas de "tensão lateral x deslocamento", cada uma correspondendo a um determinado nível de 
instrumentação. Os dados utilizados para a construção das FIGURAS 6.5, 6.6 e 6.7 a seguir já foram apresentados anteriormente (TABELAS 5.10, 5.11 e 5.12).

Estas figuras podem ser comparadas com as de número 2.5, 2.6 e 2.7 apresentadas em (2.6.1).

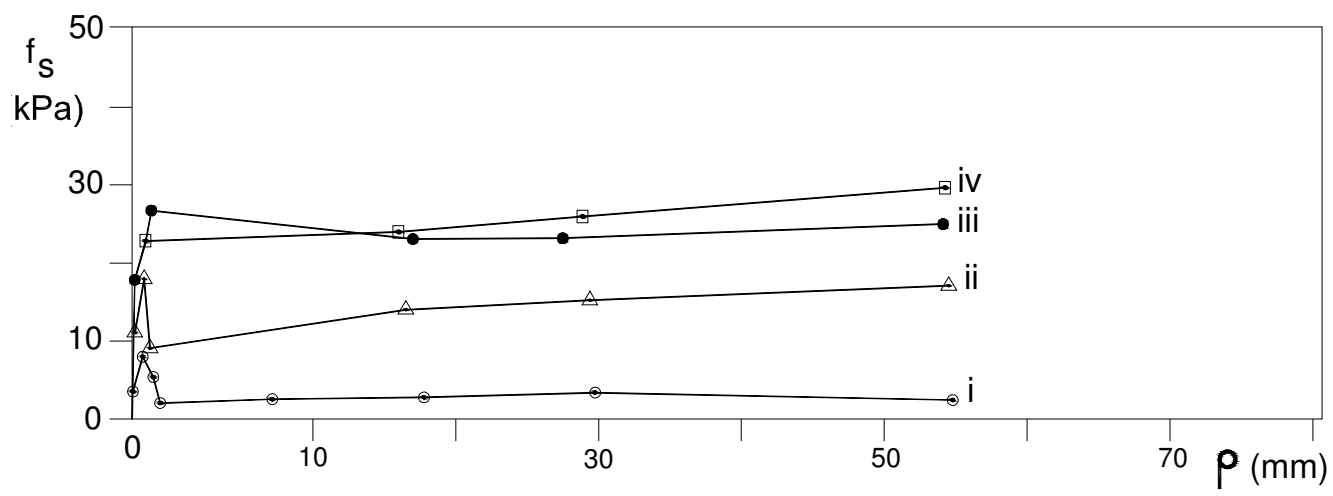

FIGURA 6.5 - Variação da tensão lateral com o deslocamento para cada nível de instrumentação (prova de carga $\mathrm{D}_{40(5)}$ )

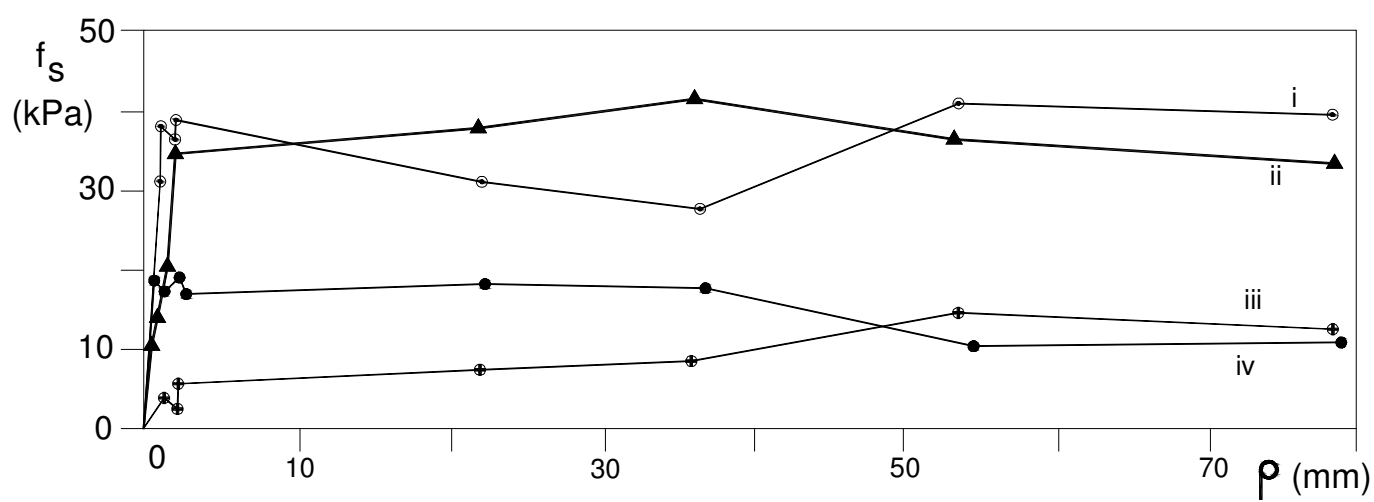

FIGURA 6.6 - Variação da tensão lateral com o deslocamento para cada nível instrumentado (prova de carga $\left.\mathrm{D}_{50(5)}\right)$

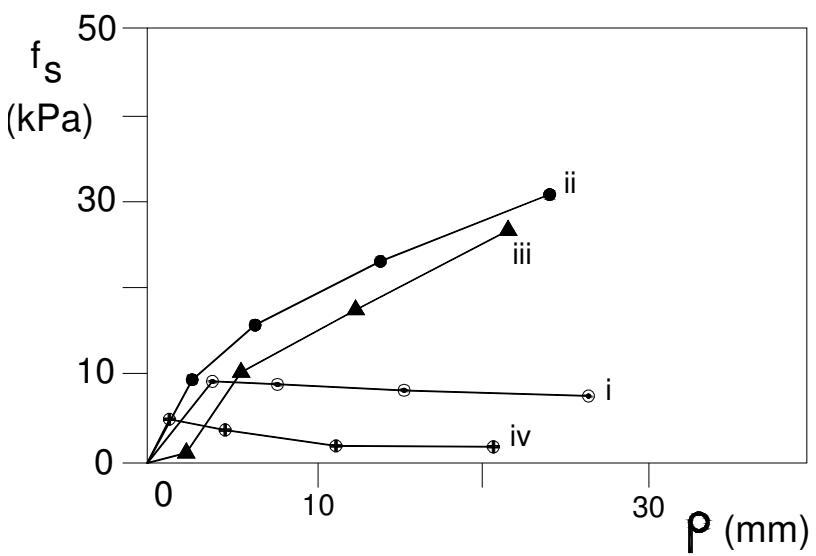

FIGURA 6.7 - Variação da tensão lateral com o deslocamento mobilizado para cada nível de instrumentação (prova de carga $\mathrm{D}_{50(6)}$ ) 
No caso específico desta pesquisa, os resultados apresentam grandes diferenças entre as provas de carga realizadas.

$\mathrm{Na}$ prova de carga $\mathrm{D}_{40(5)}$ pode-se notar que deslocamentos muito pequenos mobilizam inteiramente a resistência lateral (da ordem d 1 a $3 \mathrm{~mm}$ ), na parte superior da estaca. No entanto, enquanto o trecho 1 desce até um patamar onde se estabiliza, o trecho 2 se comporta de modo a registrar uma certa recuperação de resistência, à medida que se registravam deslocamentos de até $20 \mathrm{~mm}$. A partir daí, o crescimento permanece, porém de modo mais discreto.

Os trechos da metade inferior da estaca mobilizam resistências laterais bem mais elevadas, porém necessitam, identicamente, de deslocamentos muito pequenos para atingir o seu máximo. O trecho intermediário inferior apresenta uma diminuição da resistência lateral com o crescimento do deslocamento, ao contrário do que acontece com o último trecho da estaca, adjacente à base.

De um modo geral, vê-se que o comportamento da metade superior da estaca registra um fenômeno similar ao comportamento da resistência ao cisalhamento de uma amostra de solo arenoso ensaiada em laboratório.

Observando-se os resultados divulgados por MANTILLA (1993) a respeito da prova de carga da estaca $\mathrm{D}_{40(4)}$, pode-se tão somente concluir pela grande desmobilização do trecho 2. Caso haja alguma explicação óbvia, ela poderia ser atribuída ao efeito de inundação, justamente na camada de solo colapsível, sensível a maiores pressões e deslocamentos.

Na FIGURA 6.6, correspondente à prova de carga $\mathrm{D}_{50(5)}$, pode-se notar uma certa tendência dos trechos intermediários (2 e 3) e extremos (1 e 4) de comportaremse de modo discreto, porém marcantemente distintos. Na média, ambos se mostram sensíveis a uma estabilização após pequenos deslocamentos, da ordem de $1 \mathrm{~mm}$ a 3 $\mathrm{mm}$, como no caso anterior. São, porém, mais estáveis e poderiam ser enquadrados como apresentando um comportamento visco-elástico à semelhança do modelo de CAMBEFORT. 
A comparação com os resultados apresentados por MANTILLA (1993) não é conclusiva. Vê-se, ali, que o trecho 3 é o que menos mobiliza a tensão lateral, enquanto que o contrário se dá no trecho 2. Os extremos apresentam comportamento intermediário. A mobilização é crescente nos trechos 2 e 4 e decrescente nos trechos 1 e 3. Nada se pode concluir quanto a possíveis efeitos da inundação a este respeito. É provável que a sequência de carregamentos seja mais apta a produzir esta mudança de comportamento.

Finalmente, quando se observa a prova de carga $\mathrm{D}_{50(6)}$, realizada com o solo inundado desde o princípio e conduzida até a carga de trabalho (FIGURA 6.7), o comportamento se normaliza, podendo reconstituir algumas situações típicas observáveis em estacas cravas (FIGURA 2.6).

Quanto ao comportamento da resistência de ponta em relação aos deslocamentos, os resultados são mostrados na FIGURA 6.8.

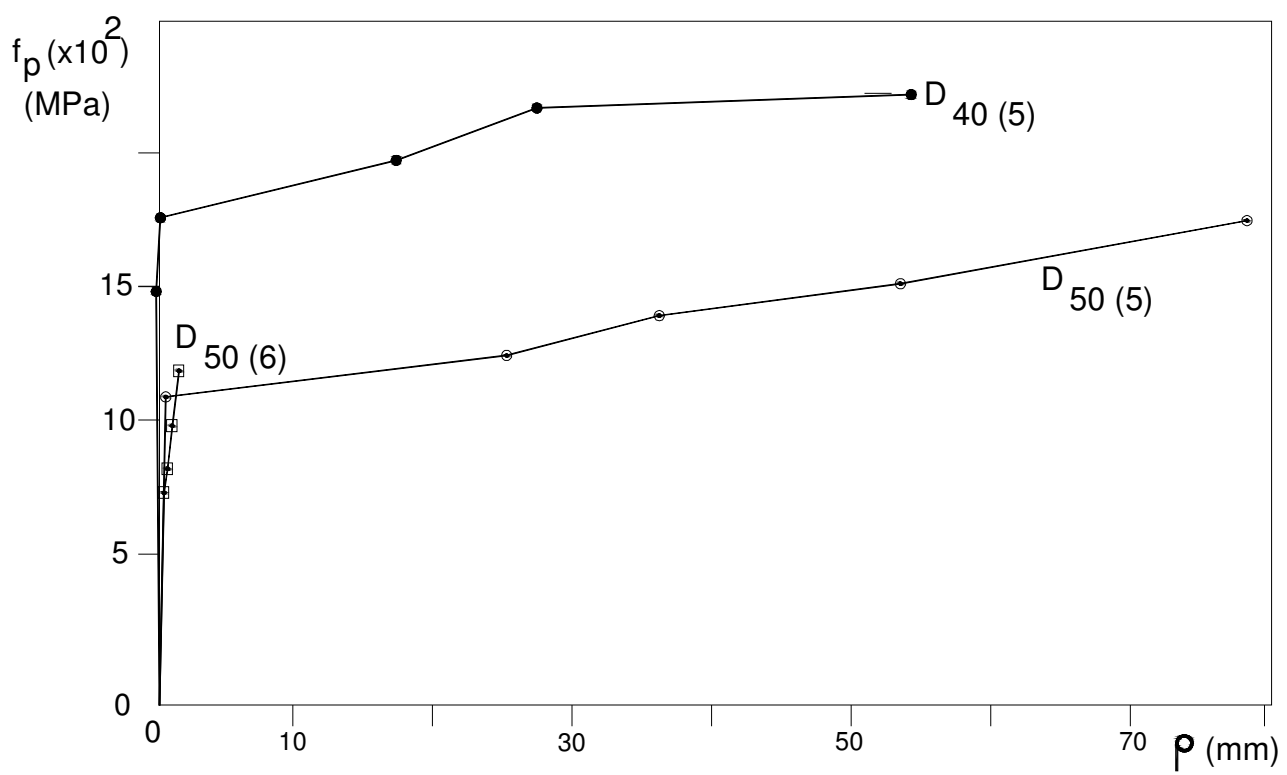

FIGURA 6.8 - Variação da resistência unitária de ponta com os deslocamentos para as três provas de carga inundadas

A mobilização da estaca $\mathrm{D}_{40}$ é similar à da estaca $\mathrm{D}_{50}$, embora a primeira guarde uma certa semelhança com o modelo rígido-elasto-plástico.

Geralmente, aceita-se que os deslocamentos necessários para se mobilizar a resistência de ponta sejam bem superiores àqueles necessários para a mobilização da 
resistência lateral. Tal fato não transparece na FIGURA 6.8, pelo fato de haver um grande número de provas de carga anteriores. Observa-se que a inundação exerce um efeito de relaxação, que pode ser entendido como uma cerca perda de rigidez na estaca $\mathrm{D}_{50(6)}$ quando comparada com $\mathrm{D}_{50(5)}$.

Por comparação com as curvas apresentadas por MANTILLA (1993), percebe-se de imediato que a rigidez do sistema solo-estaca cresce com a sequência de provas de carga.

\section{6 - ANÁLISE DO FATOR DE MOBILIZAÇÃO $\left(\mathrm{m}_{\mathrm{s}}\right)$}

O fator de mobilização, $\mathrm{m}_{\mathrm{s}}$, grandeza adimensional, é expresso pela relação:

$$
m_{s}=\frac{f_{s, i}}{f_{s, m a ́ x}}
$$

Onde:

$\mathrm{f}_{\mathrm{s}, \mathrm{i}}=$ resistência lateral unitária, variável com a profundidade e com o nível de carregamento da estaca

$\mathrm{f}_{\mathrm{s}, \text { máx }}=$ máxima resistência lateral para um certo nível de profundidade.

Sendo assim, este parâmetro reflete a variação da tensão lateral com a profundidade e se constitui em mais um recurso utilizável para visualizar o comportamento de estacas instrumentadas, sob o aspecto de transferência de carga. As TABELAS 6.6, 6.7 e 6.8 contêm as informações numéricas necessárias para a confecção dos gráficos das FIGURAS 6.9, 6.10 e 6.11, que expressam a variação de $\mathrm{m}_{\mathrm{s}}$ com a profundidade.

TABELA 6.6 - Variação do fator de mobilização $\mathrm{f}_{\mathrm{s}}(\mathrm{em} \mathrm{kPa})$ com a profundidade para a prova de carga $\mathrm{D}_{50(6)}$

\begin{tabular}{|c|c|c|c|c|c|c|c|c|}
\hline \multirow{2}{*}{$\mathbf{Q}_{0}(\mathbf{k N})$} & \multicolumn{2}{|c|}{ (1) $f_{s, \text { máx }}=10,7$} & \multicolumn{2}{|c|}{ (2) $\mathbf{f}_{\mathrm{s}, \text { máx }}=31,0$} & \multicolumn{2}{|c|}{ (3) $\mathrm{f}_{\mathrm{s}, \text { máx }}=26,9$} & \multicolumn{2}{|c|}{ (4) $f_{s, m a ́ x}=5,0$} \\
\hline & $\mathbf{f}_{\mathrm{s}}$ & $\mathbf{m}_{\mathrm{s}}$ & $\mathbf{f}_{\mathrm{s}}$ & $\mathbf{m}_{\mathrm{s}}$ & $\mathbf{f}_{\mathrm{s}}$ & $\mathbf{m}_{\mathrm{s}}$ & $\mathbf{f}_{\mathrm{s}}$ & $\mathbf{m}_{\mathrm{s}}$ \\
\hline 100 & 10,7 & 1,00 & 9,5 & 0,31 & 0,9 & 0,03 & 5,0 & 1,00 \\
\hline 300 & 9,8 & 0,92 & 16,5 & 0,53 & 10,7 & 0,40 & 3,9 & 0,78 \\
\hline 400 & 8,9 & 0,83 & 23,4 & 0,75 & 17,9 & 0,67 & 2,5 & 0,50 \\
\hline 500 & 7,5 & 0,70 & 31,0 & 1,00 & 26,9 & 1,00 & 2,1 & 0,42 \\
\hline
\end{tabular}


TABELA 6.7 - Variação do fator de mobilização $\mathrm{f}_{\mathrm{s}}(\mathrm{em} \mathrm{kPa}$ ) com a profundidade para a prova de carga $\mathrm{D}_{40(5)}$

\begin{tabular}{|c|c|c|c|c|c|c|c|c|}
\hline \multirow{2}{*}{$\mathbf{Q}_{0}(\mathbf{k N})$} & \multicolumn{2}{|c|}{ (1) $f_{s, \text { máx }}=9,1$} & \multicolumn{2}{|c|}{ (2) $f_{s, m a ́ x}=18,8$} & \multicolumn{2}{|c|}{ (3) $\mathbf{f}_{\mathrm{s}, \mathrm{m} \text { x }}=27,1$} & \multicolumn{2}{|c|}{ (4) $f_{s, m a ́ x}=29,6$} \\
\hline & $\mathbf{f}_{\mathrm{s}}$ & $\mathbf{m}_{\mathbf{s}}$ & $\mathbf{f}_{\mathrm{s}}$ & $\mathbf{m}_{\mathrm{s}}$ & $\mathbf{f}_{\mathrm{s}}$ & $\mathbf{m}_{\mathbf{s}}$ & $\mathbf{f}_{\mathrm{s}}$ & $\mathbf{m}_{\mathrm{s}}$ \\
\hline 40 & 3,4 & 0,37 & 7,2 & 0,38 & 4,7 & 0,17 & 1,8 & 0,06 \\
\hline 120 & 4,8 & 0,53 & 9,0 & 0,48 & 10,1 & 0,37 & 3,4 & 0,11 \\
\hline 180 & 4,0 & 0,44 & 14,1 & 0,75 & 14,8 & 0,55 & 7,4 & 0,25 \\
\hline 240 & 6,0 & 0,66 & 18,8 & 1,00 & 17,4 & 0,64 & 9,9 & 0,33 \\
\hline 300 & 8,5 & 0,93 & 18,1 & 0,96 & 22,1 & 0,82 & 9,6 & 0,32 \\
\hline 330 & 9,1 & 1,00 & 14,8 & 0,79 & 19,9 & 0,73 & 15,1 & 0,51 \\
\hline 360 & 7,0 & 0,77 & 14,5 & 0,77 & 23,1 & 0,85 & 16,1 & 0,54 \\
\hline 390 & 4,8 & 0,53 & 14,5 & 0,77 & 24,6 & 0,91 & 19,8 & 0,67 \\
\hline 420 & 2,2 & 0,24 & 11,6 & 0,62 & 27,1 & 1,00 & 22,7 & 0,77 \\
\hline 450 & 3,1 & 0,34 & 13,7 & 0,73 & 23,9 & 0,88 & 23,4 & 0,79 \\
\hline 480 & 3,6 & 0,40 & 14,5 & 0,77 & 23,1 & 0,85 & 25,0 & 0,84 \\
\hline 510 & 1,7 & 0,19 & 17,4 & 0,93 & 24,6 & 0,91 & 29,6 & 1,00 \\
\hline
\end{tabular}

TABELA 6.8 - Variação do fator de mobilização $\mathrm{f}_{\mathrm{s}}(\mathrm{em} \mathrm{kPa}$ ) com a profundidade para a prova de carga $\mathrm{D}_{50(5)}$

\begin{tabular}{|c|c|c|c|c|c|c|c|c|}
\hline \multirow{2}{*}{$\mathrm{Q}_{0}(\mathrm{kN})$} & \multicolumn{2}{|c|}{ (1) $f_{s, \text { máx }}=19,3$} & \multicolumn{2}{|c|}{ (2) $f_{s, \text { máx }}=40,3$} & \multicolumn{2}{|c|}{ (3) $f_{s, \text { máx }}=41,8$} & \multicolumn{2}{|c|}{ (4) $f_{s, m a ́ x}=13,6$} \\
\hline & $\mathbf{f}_{\mathrm{s}}$ & $\mathbf{m}_{\mathrm{s}}$ & $\overline{f_{s}}$ & $\mathbf{m}_{\mathrm{s}}$ & $\mathbf{f}_{\mathrm{s}}$ & $\mathbf{m}_{\mathrm{s}}$ & $\mathbf{f}_{\mathrm{s}}$ & $\mathbf{m}_{\mathrm{s}}$ \\
\hline 80 & 7,1 & 0,37 & 5,5 & 0,14 & 2,5 & 0,06 & 1,0 & 0,07 \\
\hline 160 & 10,9 & 0,56 & 8,1 & 0,20 & 8,6 & 0,21 & 1,0 & 0,07 \\
\hline 240 & 13,2 & 0,68 & 16,6 & 0,41 & 9,3 & 0,22 & 1,5 & 0,11 \\
\hline 320 & 18,4 & 0,95 & 19,2 & 0,48 & 9,9 & 0,24 & 2,0 & 0,15 \\
\hline 400 & 16,4 & 0,85 & 31,4 & 0,78 & 14,2 & 0,34 & 4,4 & 0,32 \\
\hline 480 & 19,3 & 1,00 & 38,2 & 0,95 & 21,5 & 0,51 & 4,9 & 0,36 \\
\hline 533 & 18,3 & 0,95 & 38,9 & 0,97 & 31,3 & 0,75 & 3,5 & 0,26 \\
\hline 560 & 16,8 & 0,87 & 34,6 & 0,86 & 35,0 & 0,84 & 6,9 & 0,54 \\
\hline 600 & 18,2 & 0,94 & 31,0 & 0,77 & 37,5 & 0,90 & 7,8 & 0,57 \\
\hline 630 & 17,3 & 0,90 & 27,4 & 0,68 & 41,8 & 1,00 & 7,9 & 0,58 \\
\hline 660 & 10,2 & 0,53 & 40,3 & 1,00 & 30,9 & 0,74 & 13,6 & 1,00 \\
\hline 690 & 10,3 & 0,53 & 38,5 & 0,96 & 32,1 & 0,77 & 10,3 & 0,76 \\
\hline
\end{tabular}

O comportamento exibido pela prova de carga $\mathrm{D}_{40(5)}$ mostra que, antes da inundação, a mobilização é preferencialmente crescente do topo para o nível intermediário superior. A partir daí, o grau de mobilização é sistematicamente decrescente.

Revela, também, que quanto mais elevado é o estágio de carregamento, maior é a mobilização. Em seguida, o papel exercido pela inundação reflete claramente a 
desmobilização do trecho superior, em favor de uma desmobilização mais intensa do trecho inferior.

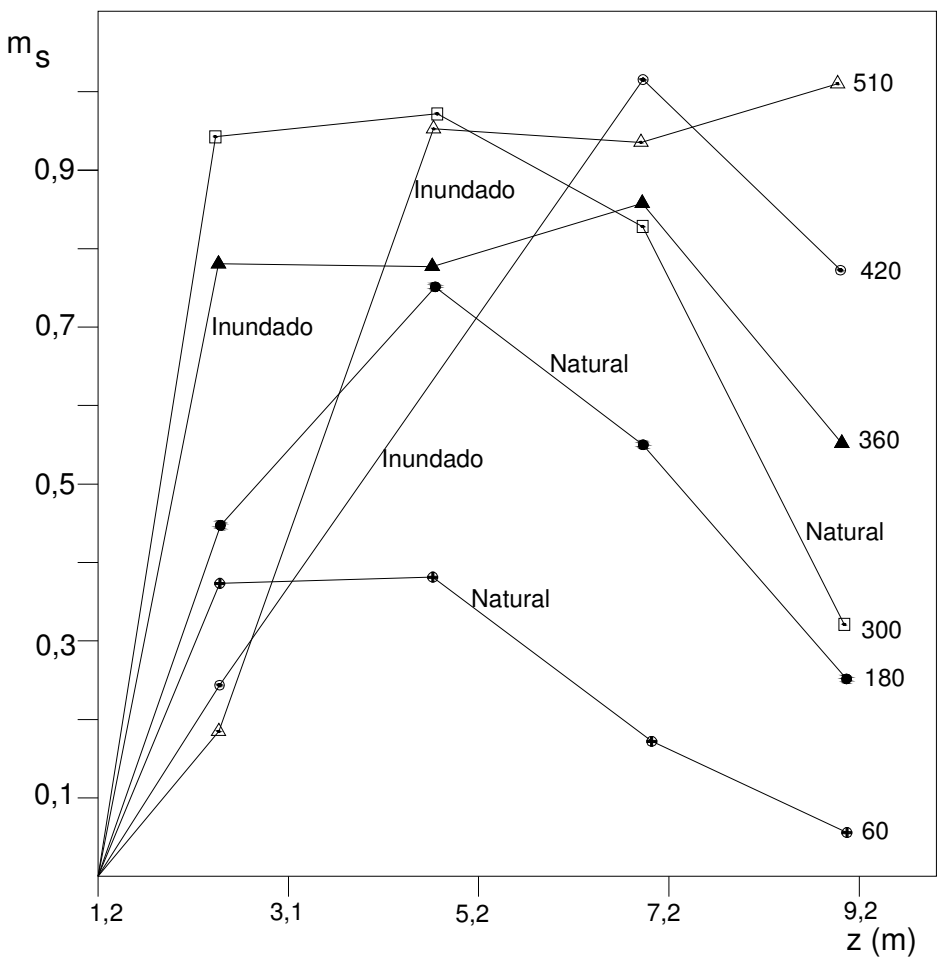

FIGURA 6.9 - Variação de $m_{s}$ com a profundidade para a prova de carga $\mathrm{D}_{40(5)}$

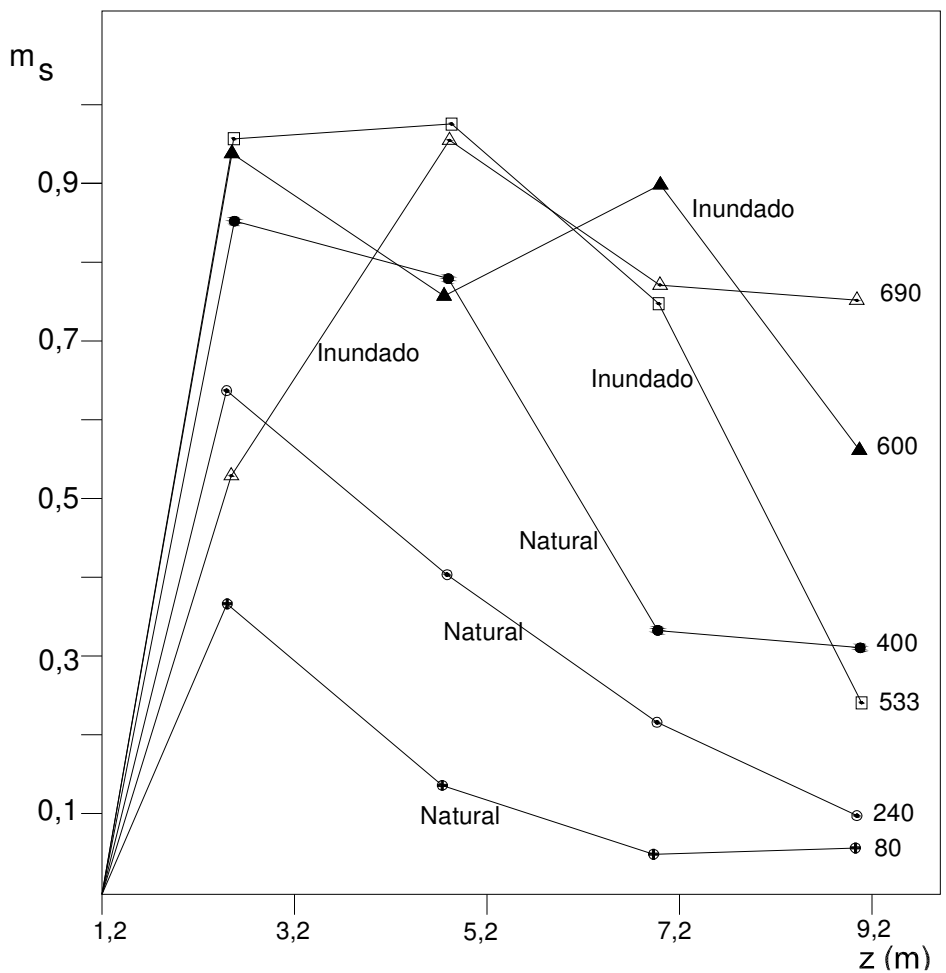

FIGURA 6.10 - Variação de $\mathrm{m}_{\mathrm{s}}$ com a profundidade para a prova de carga $\mathrm{D} 5_{0(5)}$ 


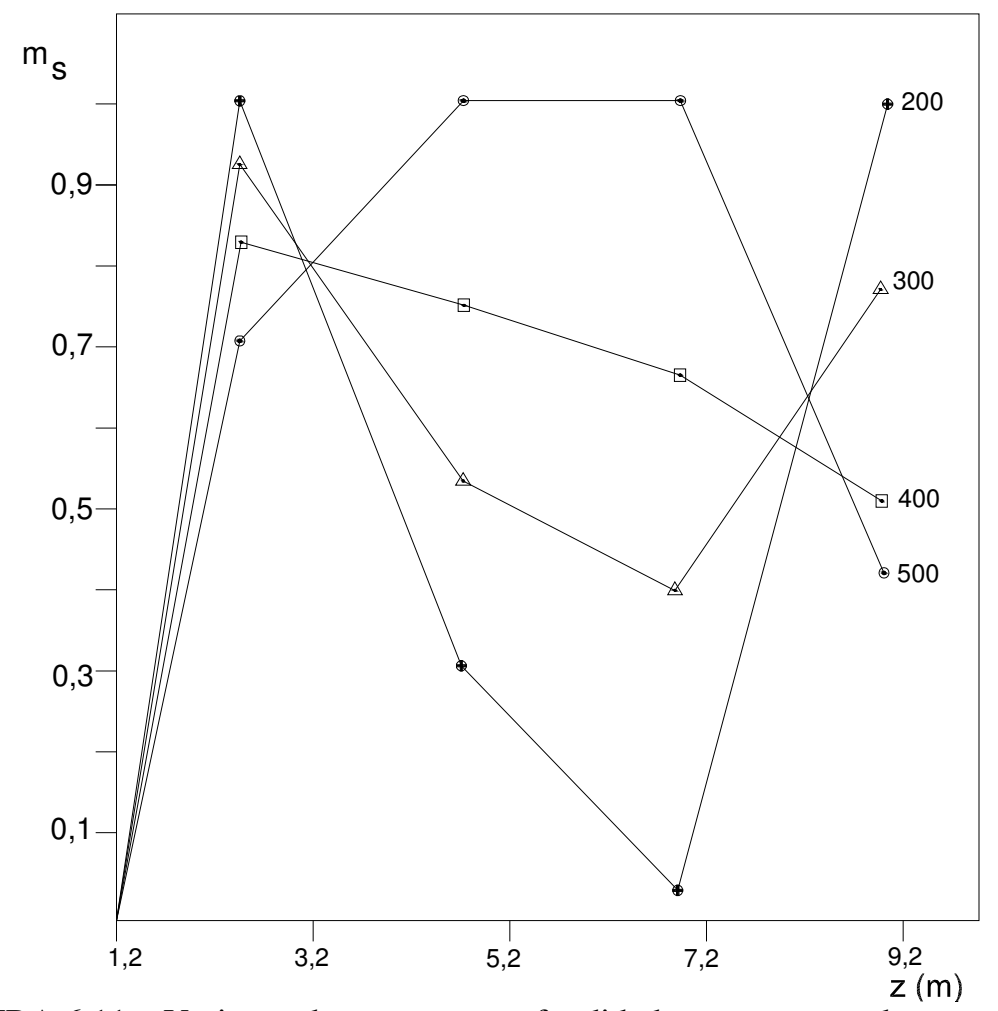

FIGURA 6.11 - Variação de $m_{s}$ com a profundidade para a prova de carga $D_{50(6)}$

Estas observações são consistentes com o que seria de se esperar de um solo colapsível que atinge um grau de saturação e um estado de solicitação aptos a desenvolver a requerida condição de metaestabilidade, característica de grandes deformações por colapso.

A FIGURA 6.10, relativa à prova de carga $\mathrm{D}_{50(5)}$, mostra uma performance da estaca bastante semelhante em relação aos estágios de carga com o solo em condição natural. No entanto, uma significativa mudança é percebida, no que diz respeito à fase de ensaio correspondente ao solo inundado, onde se pode notar que é alto o grau de mobilização. Isto se verifica, de um modo geral, nos trechos 1,2 e 3 , havendo ligeira desmobilização no trecho 4. Esta conclusão não tem uma explicação razoável.

A observação da prova de carga $\mathrm{D}_{50(6)}$, com o solo inundado em todos os estágios de carregamento, indica que há uma mobilização geralmente elevada no trecho superior e fica bastante errática nos demais trechos. É destacável o fato de que a região mais próxima da ponta desmobiliza o atrito lateral à medida que se aumenta o 
carregamento, fato este que combina perfeitamente com o que se notou no trecho adjacente à cabeça da estaca.

\section{7 - ANÁLISE DOS RECALQUES}

As provas de carga levadas à ruptura mostraram, invariavelmente, grandes deformações plásticas.

Sendo os recalques o fator dominante no critério de projetos de fundações, este tipo de análise ganha um contorno especial.

Muitos autores têm sugerido que é possível se fazer uma estimativa de recalques de estacas isoladas, para as cargas de trabalho, através de simples correlações com o diâmetro (COOKE, 1979; FRANK, 1985; VAN WEELLE, 1983; BRIAUD \& TUCKEER, 1984; POULOS, 1989). As estimativas conduzem a valores que flutuam entre 0,3 e 1,25\% do diâmetro, como se vê no item (2.5.2).

Tal estimativa mostrou-se razoável para as estacas nas provas de carga anteriores e revela-se insatisfatória para o caso de inundação do solo, quando os recalques observados aumentam.

Na FIGURA 6.12 são apresentados os recalques em função do diâmetro para as provas de carga $\mathrm{D}_{40(4)}, \mathrm{D}_{50(4)}$. $\mathrm{D}_{40(5)}$ e $\mathrm{D}_{50(5)}$. São destacados os recalques totais e os plásticos. Note-se a pequena diferença entre eles.

Os segmentos $\mathrm{AB}$ e A'B' guardam certo paralelismo, indicativo da influência da inundação.

Insiste-se uma vez mais nesta observação fundamental: a indefinição do conceito de ruptura torna incomparáveis os recalques medidos em duas provas de carga distintas, quando executadas por pessoas diferentes, em uma mesma estaca. Porém, quando se pré-determina um certo nível de carga, abaixo da carga de ruptura (como, por exemplo, a carga de trabalho), os resultados já são comparáveis.

Assim, fica a impressão que os conceitos de "carga de trabalho" e "recalque admissível" são mais úteis para uma análise deste comportamento. Embora 
reconhecendo que não há nenhuma razão especial para isto, mas por força de hábito, o recalque de $25 \mathrm{~mm}$ está sendo tomado como referência para comparação. Sob este aspecto, as FIGURAS 5.1 e 5.2 mostram uma relação interessante, que é a que se verifica entre as cargas que o produzem nas condições de solo natural e solo inundado.

Para a estaca $\mathrm{D}_{40}$ a relação entre as cargas últimas, na condição de solo

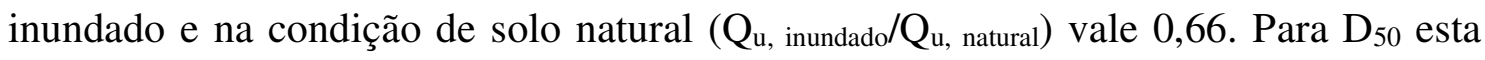
mesma relação vale 0,73 . Estes valores estão em coincidência com uma relação semelhante a esta, onde as cargas são apenas substituídas por aquelas que produzem os recalques de $25 \mathrm{~mm}$, nas mesmas condições de solo inundado e natural.

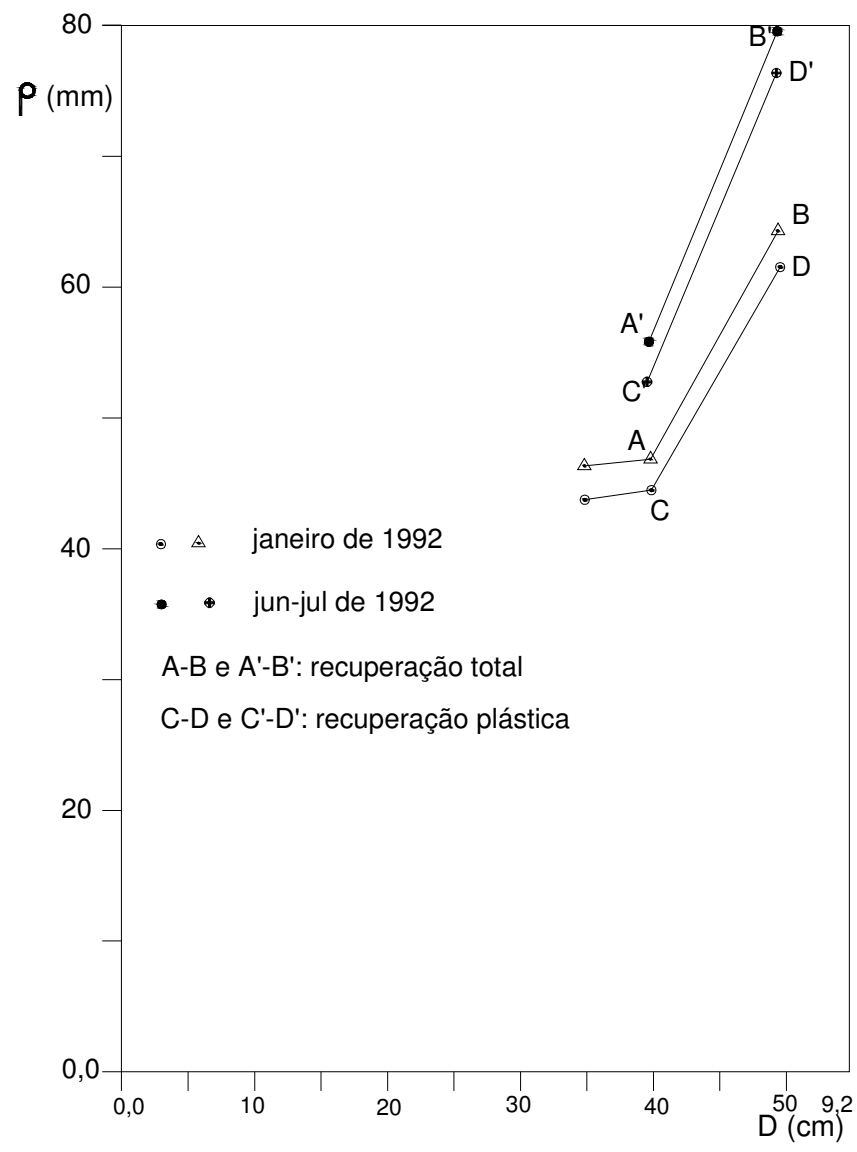

FIGURA 6.12 - Relação entre recalques e diâmetros para as estacas ensaiadas, com e sem inundação

Conhecendo-se as cargas últimas de alguma prova de carga anterior da sequência de ensaios, com o solo em condição de umidade natural, e aplicando a elas um fator de segurança igual a 1,5, são obtidas as cargas de trabalho de $487 \mathrm{kN}$ e 608 $\mathrm{kN}$, respectivamente (estacas $\mathrm{D}_{40}$ e $\mathrm{D}_{50}$ ). Como se pode perceber, quando inundadas, 
as estacas experimentam (ou estão na iminência de suportar) recalques bastante superiores aos toleráveis usualmente pelas estruturas.

Do ponto de vista estritamente prático, esta constatação põe em xeque a adoção indiscriminada do fator de segurança igual a 1,5 em solos colapsíveis, quando a garantia de não ocorrência da inundação do solo não puder ser preservada.

Isto deve ser motivo de reflexão para a prática das fundações. A constatação de colapsibilidade de um solo deve levar os construtores à adoção de medidas preventivas contra a inundação por motivos de natureza econômica, já que a aceitação deste risco e sua incorporação ao fator de segurança conduziria a projetos muito caros.

A comparação do recalque elástico com o recalque total pode ser encarada como indicativa do enrijecimento do sistema solo-estaca. Com efeito, nem mesmo a inundação foi capaz de atenuar esta tendência. Observa-se um aumento da relação

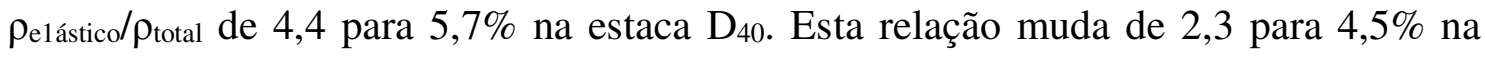
estaca $\mathrm{D}_{50}$. Os primeiros representam a sequência (4) das provas de carga (portanto, sem inundação) e os segundos representam a sequência (5), com inundação.

$\mathrm{Na}$ estaca $\mathrm{D}_{40}$ (FIGURA 5.1) pode ser notado um discreto efeito da inundação, traduzido sob a forma de aumento dos recalques, dentro do trecho de deformações elásticas da curva "carga x recalque". Este efeito é imperceptível na estaca $D_{50}$ (FIGURA 5.2).

Além disso, pode-se notar que a inundação exerce, de fato, apreciável efeito sobre os recalques. Esta constatação é melhor apreciada quando se observa a FIGURA 5.3, em escala ampliada, refletindo o comportamento "carga x recalque" da prova de carga $\mathrm{D}_{50(6)}$.

\section{8 - ANÁLISE DAS CARGAS RESIDUAIS}

Com a FIGURA 6.13 se pode analisar a transferência de carga durante o descarregamento de uma prova de carga. A magnitude das tensões aprisionada no fuste e a da carga residual na ponta, após o descarregamento total da estaca, não é 
pouco expressiva e, visto deste modo, o comportamento da estaca $\mathrm{D}_{50}$ apresenta um comportamento bastante característico de estaca escavada (COOKE, 1979).

O formato da curva apresenta-se semelhante ao modelo fornecido por DARRAG \& LOVELL (1989), onde se notam pontos singulares como um ponto de inflexão e um máximo, situando-se mais próximo à ponta da estaca. A prova de carga que deu origem à FIGURA 6.13 foi conduzida até uma carga de $500 \mathrm{kN}$ e imediatamente descarregada, porém esta prova de carga sucedeu, com um intervalo de apenas 24 horas, a descarga da prova de carga $\mathrm{D}_{50(5)}$ que foi levada à ruptura.

Infelizmente, não puderam ser verificadas as cargas residuais provenientes das provas de carga da sequência (4), em virtude dos dispositivos de medição terem sido desligados ao final das provas de carga $\mathrm{D}_{40(4)}$ e $\mathrm{D}_{50(4)}$. Desta forma, uma questão de razoável interesse, que é a dúvida se a carga residual permanece mesmo após o decurso de um tempo da ordem de alguns meses, não pode ser aqui esclarecida.

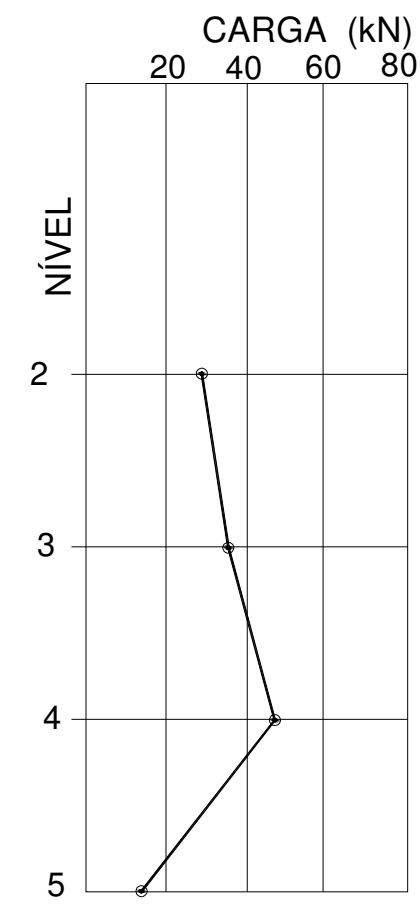

FIGURA 6.13 - Carga aprisionada ao final do descarregamento da prova de carga $\mathrm{D}_{50(6)}$

\section{9 - SEPARAÇÃO DAS CARGAS LATERAL E DE PONTA}


A separação das cargas, lateral e de ponta, obtidas através das provas de carga $\mathrm{D}_{40(5)}$ e $\mathrm{D}_{50(5)}$ se vê na TABELA 6.9 a seguir.

Nas FIGURAS 6.14 e 6.15 são mostradas estas variações de carga em relação aos recalques de superfície (no topo da estaca). Observa-se que a parcela de carga lateral cresce na fase correspondente às deformações elásticas do sistema e depois mergulha, praticamente reta e verticalmente (com crescimento muito discreto), enquanto a carga de ponta apresenta um comportamento quase paralelo à curva da

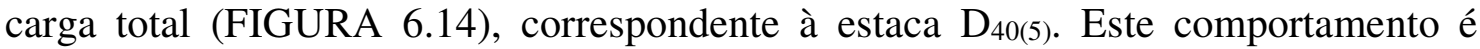
bastante previsível (veja-se, por exemplo, GWIZDALLA, 1984).

TABELA 6.9 - Separação das cargas, lateral e de ponta, nas provas de carga

\begin{tabular}{|c|c|c|c|c|c|c|c|}
\hline \multicolumn{6}{|c|}{$\mathrm{D}_{50(5)}$} & \multicolumn{4}{c|}{$\mathrm{D}_{40(5)}$} \\
\hline $\mathrm{Q}_{0}(\mathrm{kN})$ & $\mathrm{Q}_{\mathrm{p}}(\mathrm{kN})$ & $\mathrm{Q}_{\mathrm{s}}(\mathrm{kN})$ & $\rho_{0}(\mathrm{~mm})$ & $\mathrm{Q}_{0}(\mathrm{kN})$ & $\mathrm{Q}_{\mathrm{p}}(\mathrm{kN})$ & $\mathrm{Q}_{\mathrm{s}}(\mathrm{kN})$ & $\rho_{0}(\mathrm{~mm})$ \\
\hline 80 & 16,6 & 63,4 & 0,04 & 60 & 8,5 & 51,5 & 0,02 \\
\hline 160 & 50,4 & 109,6 & 0,19 & 120 & 39,1 & 30,9 & 0,09 \\
\hline 240 & 84,9 & 155,1 & 0,43 & 180 & 57,9 & 122,1 & 0,17 \\
\hline 320 & 129,5 & 190,5 & 0,75 & 240 & 85,2 & 154,8 & 0,37 \\
\hline 400 & 148,4 & 251,6 & 1,17 & 300 & 125,3 & 174,7 & 0,80 \\
\hline 480 & 166,2 & 313,8 & 1,56 & 330 & 147,8 & 182,2 & 0,83 \\
\hline 533 & 193,7 & 339,3 & 2,32 & 360 & 175,5 & 184,5 & 0,89 \\
\hline 560 & 214,4 & 345,6 & 2,32 & 390 & 198,5 & 191,5 & 1,02 \\
\hline 600 & 248,0 & 352,0 & 22,52 & 420 & 221,1 & 198,9 & 1,29 \\
\hline 630 & 279,9 & 350,1 & 36,82 & 450 & 249,5 & 200,5 & 18,29 \\
\hline 660 & 306,4 & 353,6 & 54,22 & 480 & 276,1 & 203,9 & 28,19 \\
\hline 690 & 353,5 & 336,5 & 79,32 & 510 & 283,8 & 226,2 & 55,29 \\
\hline
\end{tabular}

O comportamento exibido pela prova de carga $\mathrm{D}_{50(5)}$ - FIGURA 6.15 - mostra algumas diferenças marcantes. A carga lateral permanece como a componente principal, mesmo para grandes recalques, dentro da zona de comportamento elastoplástico do solo. Além disso, possui a singularidade de diminuir de valor para grandes deslocamentos, talvez devido ao efeito de inundação. Contudo, anomalias desta natureza não constituem mera exceção e são parte de uma certa rotina de observações experimentais. SACILOTTO (1993) encontra comportamento bem parecido nas provas de carga $\mathrm{D}_{40(2)}$ e $\mathrm{D}_{40(1)}$. A evolução das componentes de carga da estaca $\mathrm{D}_{50}$, também analisada por SACILOTTO (1993) já mostra que esta tendência poderia ser esperada. A inundação parece apenas ter exacerbado este comportamento, fazendo 
com que a resistência lateral diminuísse após as grandes deformações plásticas produzidas pelo colapso.

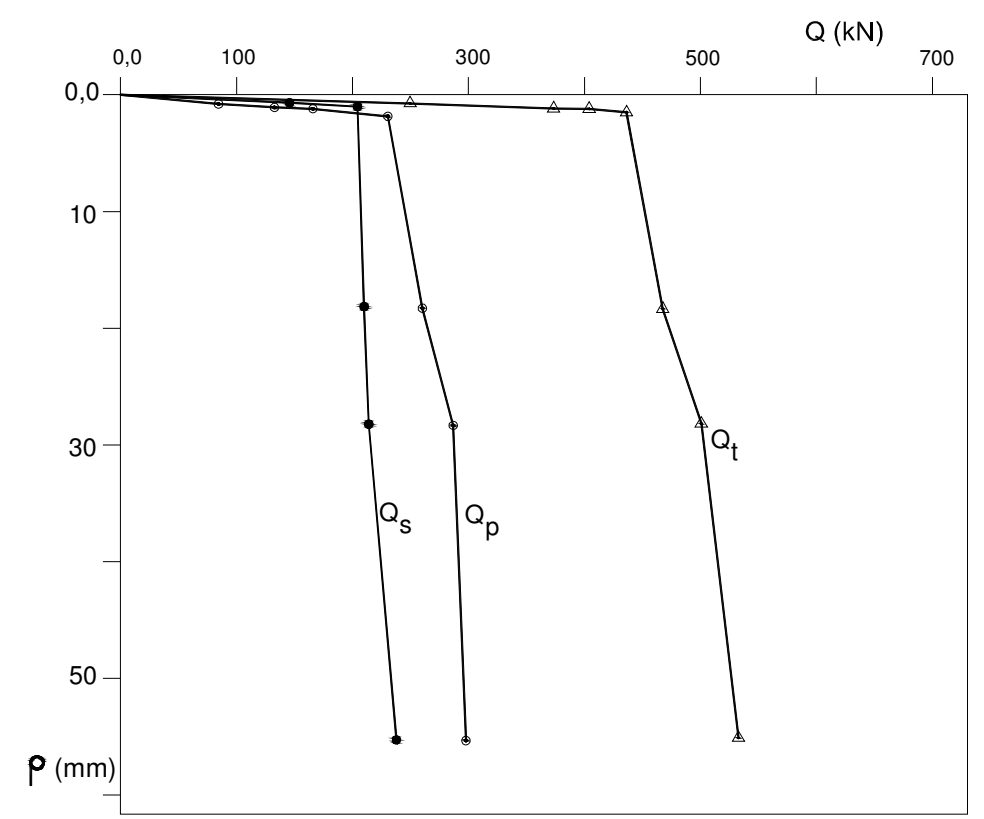

FIGURA 6.14 - Separação das cargas, lateral e de ponta $\left(\mathrm{D}_{40(5)}\right)$

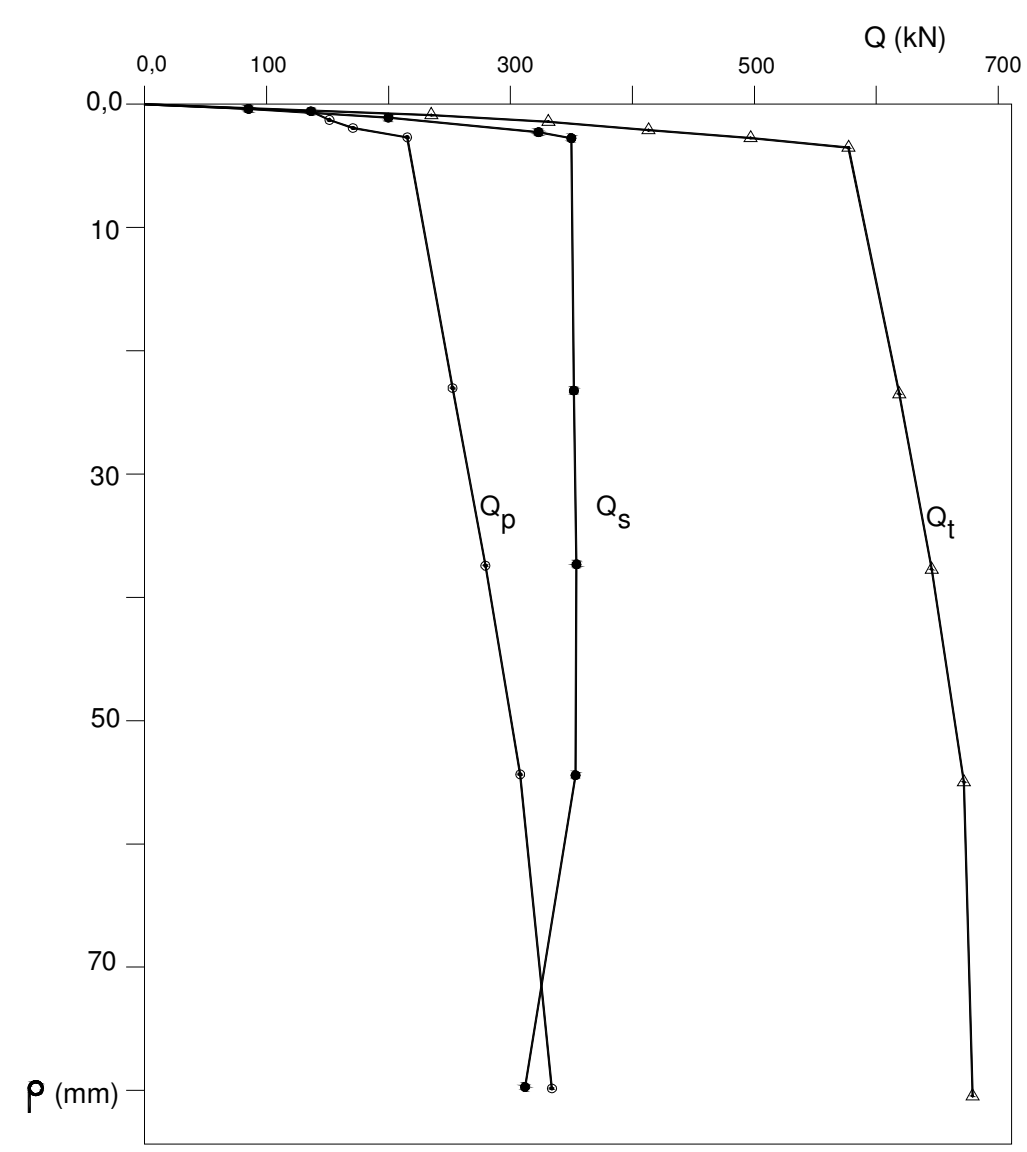

FIGURA 6.15 - Separação das cargas, lateral e de ponta $\left(\mathrm{D}_{50(5)}\right)$ 
A comparação destes resultados esbarra na dificuldade de se localizar em fontes bibliográficas experiências similares, quiçá inexistentes. O processo teórico de discuti-los, como sugerido por VARGAS (1985) não é aplicável, pois a hipótese de constância da distribuição da resistência lateral unitária no fuste não é verdadeira neste caso.

\subsection{0 - EQUIVALÊNCIA DE CHUVA AO PROCESSO DE INUNDAÇÃO ADOTADO}

Sendo a altura de chuva $\mathrm{H}(\mathrm{mm})$ uma relação entre o volume $\mathrm{V}$ de água e a

área $\mathrm{A}\left(\mathrm{m}^{2}\right)$ onde ela é coletada, referida a uma unidade de tempo $\mathrm{t}$ (hora), pode-se interpretar a inundação imposta ao solo durante a realização das provas de carga em termos de uma possível precipitação pluviométrica, constante durante o tempo dos experimentos. Assim:

$$
\begin{aligned}
& \mathrm{V}=300.000 \text { litros }=3 \times 10^{11} \mathrm{~mm}^{3} \\
& \mathrm{t}=13 \text { dias }=312 \text { horas } \\
& \mathrm{A}=1,96 \mathrm{~m}^{2}=1,96 \times 10^{6} \mathrm{~mm}^{2} \\
& \text { Logo, } \mathrm{H}=\mathrm{V} /(\text { A.t })=\left(3 \times 10^{11}\right) \mathrm{mm}^{3} /\left(312 \mathrm{~h} \times 1,96 \times 10^{6} \mathrm{~mm}^{2}\right)=490 \mathrm{~mm} / \mathrm{hora} .
\end{aligned}
$$

A julgar pelo inusitado deste número, as condições das provas de carga jamais poderiam ser reproduzidas em uma situação real, embora deva ser reconhecido que grande parte do volume infiltrado se deu através dos furos feitos nos cantos da cava, passando diretamente ao lençol freático. 


\section{CAPÍTULO 7 - CONCLUSÕES}

Em coerência com os objetivos relacionados em (4.1.1), relacionam-se, a seguir, as conclusões mais importantes produzidas por esta pesquisa. Contudo, algumas ressalvas que condicionam sua validade devem ser colocadas à guisa de esclarecimento:

$\left.1^{a}\right)$ Tanto o modo de execução quanto o histórico de carregamento são fatores importantes no comportamento de estacas. Ao se analisar o seu desempenho, deve-se considerar que as sucessivas penetrações no solo, densificando-o sob a ponta e realinhando as partículas no contato solo-estaca, à feição de um solo amolgado por efeito de cravação, tendem a fazer desaparecer desta pesquisa as principais características das estacas escavadas virgens.

2 $2^{a} \mathrm{O}$ comportamento "carga x recalque" verificado não pode ser uma expressão universal para os solos de São Carlos. Duas razões devem ser consideradas: 1) ao se desconhecer a variação do grau de saturação do solo após a inundação e, por conseguinte, a sua umidade final, nada se pode afirmar sobre os parâmetros de resistência que governam a capacidade de carga da estaca, podendo-se dizer o mesmo em relação aos índices de penetração estática ou dinâmica, nesta condição final; 2) o número de observações é pequeno e as circunstâncias de ensaio muito particulares, o que impede a generalização destas conclusões, que devem ser tomadas como simples contribuição.

Após estas considerações, apresentam-se as conclusões:

\section{1) Sobre o comportamento "carga $x$ recalque"}

a. A inundação exerceu importante efeito na redução da capacidade de carga das estacas. Verificou-se uma redução de $28 \%$ na estaca $\mathrm{D}_{50} \mathrm{e}$ de $34 \%$ na estaca $\mathrm{D}_{40}$, quando os resultados foram comparados com as provas de carga da sequência (4) anterior, para estes mesmos diâmetros, em condição de solo natural. Esta diminuição é 
comparável com os resultados obtidos em localidade próxima (Bauru - SP), em estacas escavadas virgens, a menos de 10\%. Melhor comparação é obtida através dos resultados de provas de carga em Córdoba (Argentina) e relatados por NADEO \& VIDELA (1975a). Em outras regiões do país, tais como Bom Jesus da Lapa (BA) e região noroeste do estado de São Paulo, a redução verificada foi bem superior (50\% a $80 \%$ ). No entanto, deve-se considerar que as estacas desta pesquisa apresentaram grande evolução na capacidade de carga, à medida da evolução do histórico do carregamento. É de se esperar que na sequência (5), correspondente a esta pesquisa, as cargaslimites teriam sido ainda maiores, no caso de não inundação. Provavelmente, nessa circunstância, as perdas de capacidade de carga teriam sido maiores.

b. A aplicação de um fator de segurança convencional de 1,5 sobre a carga de ruptura, estimada através de qualquer processo, para o solo em condição de umidade natural, conduz a cargas de trabalho perigosamente próximas às cargas de colapso das estacas, devendo, por isso, ser julgado insuficiente. A aceitação do risco de inundação por acidente em projetos reais implica, automaticamente, a sua majoração para um valor a ser convenientemente estudado, no caso de estacas virgens. Esta solução desfavorece os objetivos de economicidade das fundações seguras e, como solução, é sugerida a eliminação do risco através de medidas preventivas triviais. Entre estas, pode-se incluir uma maior conscientização envolvendo proprietários, construtores e projetistas, no sentido de melhorar o controle de qualidade nas instalações de água e esgotos. Deve-se ainda recomendar a cimentação de pisos no contorno das construções, evitando também aproximação de áreas ajardinadas.

c. A inundação parece exercer um discreto efeito sobre os recalques elásticos, aumentando-os em relação aos recalques totais. Entretanto, não se deve concluir, com convicção, que este aumento se deve, 
exclusivamente, à inundação por causa do possível aumento da rigidez do sistema solo-estaca, na sucessão de carregamentos.

d. A carga para a qual o solo entra em colapso é dependente do diâmetro das estacas. Foi constatada uma grande proximidade entre a carga de colapso e a carga de ruptura. Verifica-se que, após a estabilização das deformações correspondentes à carga de colapso, um novo incremento de carga, ainda que pequeno, é capaz de produzir novos deslocamentos de grande magnitude. O raciocínio clássico para explicar os mecanismos de colapso é montado sobre o tripé: alto índice de vazios inicial + inundação capaz de atingir um grau de saturação crítico, geralmente inferior a $100 \%$, para o qual se dá o máximo colapso + uma pressão-limite a partir da qual desencadeia-se a ruptura por cisalhamento do solo envolvente à estaca, com uma resistência inferior à de campo em condições de umidade natural. No caso de estacas reensaiadas, esta superfície de cisalhamento tem um índice de vazios bem inferior à situação original e, portanto, não serve de argumento para esta conclusão. A inundação, por seu turno, serve para atuar na diminuição da resistência ao cisalhamento, reduzindo as tensões capilares oriundas da dissecação do solo na camada colapsível superior e desfazer as ligações cimentantes da matriz argilosa do solo. Por conseguinte, ela impõe ao solo a condição de metaestabilidade exigida para iniciação do colapso. Uma vez atingida, o solo se deforma plasticamente para o nível de pressões a que está submetido, até a completa estabilização. Quando se incrementa a carga e se introduz um novo nível de pressões no solo, o colapso então prossegue para este novo nível, seguindo uma curva de colapso que tende para um limite, sugerido por VARGAS (1974), após o qual qualquer deformação adicional deve ter outro mecanismo de formação que não o colapso. Portanto, a inundação não mais exerceria o menor efeito sobre os recalques. Parece coerente invalidar as tentativas de deduzir esta pressão-limite (superior) através de ensaios 
edométricos de laboratório, requerendo uma solução particular de campo, para cada tipo de solo.

e. Verificou-se, no caso de prova de carga para o solo "saturado" desde o início dos carregamentos, que os recalques são majorados em relação àqueles medidos na situação de umidade de campo, não obstante referir-se à fase de deformações elásticas do material. Portanto, pode-se concluir que o solo inundado é menos rígido do que o que se verifica em sua condição natural. Algumas sugestões disponíveis no sentido de se inundar previamente os solos problemáticos antes do carregamento, com a finalidade de minimizar os recalques futuros, carecem de significado prático.

f. Na ausência do conhecimento sobre o teor de umidade final do solo após a inundação e, por conseguinte, também ignorando os parâmetros de resistência do solo, não faz sentido a aplicação dos métodos de previsão de carga-última, tanto os elásticos, quanto os empíricos e semi-empíricos baseados em transferência de carga. A determinação da carga última pelos modelos matemáticos, tais como VAN DER VEEN, parece desnecessária por causa da boa definição da carga de ruptura obtida nestes ensaios. As previsões empíricas de recalques, em função do diâmetro da estaca, não devem ser aplicadas às situações de estacas escavadas virgens instaladas em solos colapsíveis sujeitos a inundação, já que o volume de experiências acumulado acerca das deformações por colapso é insuficiente para credibilizar uma solução neste sentido. Face a estas questões, o conhecimento da curva "carga x recalque" completa, em um maior número de casos, em nível regional, torna-se mais e mais necessária para validar sugestões a serem adotadas na prática de projetos de fundações.

g. A velocidade de recalques $\left(\dot{w}=\frac{\Delta \rho}{\Delta t}\right)$ diminui consideravelmente quando as perdas de carga do macaco hidráulico não são repostas. Em 
situações de prova de carga especial, de longa duração, onde este fato é passível de ocorrência, deve-se ter em mente que a recuperação dos recalques não é instantânea (simultaneidade com a reposição de cargas). Há uma dependência do tempo para esta recuperação e sua avaliação genérica é difícil. A única forma segurança de fazê-lo é através do acompanhamento da prova de carga com um gráfico "recalque $\mathrm{x} \log \mathrm{t}$ ".

h. A previsão da carga de colapso a ser atingida por uma estaca, por extrapolação dos resultados de outras estacas próximas, não é confiável. Embora tenha ficado claro que esta carga depende do diâmetro, a proporcionalidade entre carga e diâmetro mostra a existência de coeficientes angulares diferentes para as relações obtidas com o solo em umidade natural e inundado. Portanto, não deve ser aceita a relação seguinte:

$$
\frac{Q_{1, c}}{Q_{2, c}}=\frac{D_{1}}{D_{2}}
$$

Onde $\mathrm{Q}_{1, \mathrm{c}}$ é a carga que a estaca $\mathrm{D}(\mathrm{i}=1,2)$ entra em colapso.

\section{2) Sobre a transferência de carga}

a. A inundação exerceu um notável efeito na diminuição do atrito lateral, quando comparado com as provas de carga anteriores, feitas nas mesmas estacas com o solo natural. Estas perdas serviram para mobilizar mais os trechos da metade inferior (solo residual não colapsível do Grupo Bauru) da estaca, seja por menor sensibilidade ao efeito da inundação, seja por causa de uma provável ineficiência deste processo em profundidade.

b. A perda de resistência lateral mobilizou a resistência de ponta, tendo a resposta se apresentado através de parcelas superiores às de qualquer prova de carga da sequência anterior. Pode-se atribuir à densificação do solo abaixo da ponta como a causa principal deste fato observado. $O$ pequeno efeito exercido pela inundação, no sentido de inibir esta 
grande mobilização de ponta, além da hipótese levantada anteriormente sobre a provável ineficiência da inundação na região da ponta, é que, mais provavelmente ainda, o solo não tenha experimentado nenhuma diferença em termos de aumento de saturação, já que ali se encontra muito próximo do N. A. médio.

c. Não há coincidência nas posições das curvas de transferência de carga obtidas, para estágios correspondentes, nos ciclos de carta e de descarga. Por falta de informações anteriores, não se pode inferir, aqui, nenhum possível efeito da inundação, além dos já conhecidos mecanismos de formação de cargas residuais. Foi constado que as cargas aprisionadas pelo fuste crescem com a profundidade até um valor máximo, abaixo da metade do comprimento da estaca (trabalho de VESIC, 1967, em estacas cravadas, mostra algo bem comparável; também DARRAG \& LOVELL, 1989, dispõe argumento em favor desta observação). A prova de carga $\mathrm{D}_{50(6)}$ levada até uma carga de $500 \mathrm{kN}$ (imediatamente após a descarga de prova anterior levada à ruptura) e descarregada, mostrou uma carga de ponta, residual, de 20 $\mathrm{kN}$. Este baixo valor é típico de estacas escavadas (COOKE, 1979).

d. O modelo clássico de separação das parcelas de carga (lateral e de ponta), segundo o qual a carga lateral, após o regime de deformações elásticas permanece constante para qualquer nível de deslocamentos, não tem validade para o caso estudado. Entretanto, esta constatação fora também feita para as provas de carga anteriores, com o solo em condição de umidade natural. Assim, deve ser descartada a possibilidade de que a anomalia seja reflexo da inundação.

\section{3) Sobre o processo de inundação adotado nas provas de carga}

a. Não foi constatada diferença significativa entre os volumes de água infiltrados pelo fundo $\left(\mathrm{k}_{\mathrm{v}}\right)$ e radialmente, pelos furos $\left(\mathrm{k}_{\mathrm{h}}\right)$.

b. O máximo volume acumulado, em 13 dias de inundação, foi de 1.000 litros. Cerca de 300.000 litros de água foram consumidos neste 
intervalo de tempo, em cada uma das provas de carga (o que corresponderia a uma hipotética chuva de $490 \mathrm{~mm} / \mathrm{h}$, ininterrupta durante todo este tempo). A elevada permeabilidade do solo e a ligação de dois níveis de água (cava de inundação e N. A.) podem servir de explicação para um consumo tão grande. Em situações similares deve-se dispensar o uso dos furos, bastando inundar o solo por meio de cavas continuamente alimentadas. 


\section{CAPÍtUlo 8 - SUGESTÕes PARA CONTINUAÇÃo dAS PESQUISAS}

Pesquisas anteriores a esta, em condições análogas, são provavelmente raras, já que associam algumas características, por si só, eventuais: a) estacas escavadas; b) reensaiadas; c) em solos colapsíveis; d) sob inundação; e) instrumentadas em profundidade.

Apesar do grande número de informações conseguidas, elas são ainda insuficientes e algumas lacunas importantes devem ser preenchidas com certa prioridade.

Após a experiência deste projeto, alguns pontos podem ser recomendados e passa-se então à sua descrição.

1) Parece ser mais importante testar estacas virgens, posto que esta é a condição real que governa as decisões de um projeto de fundações.

2) A determinação precisa do avanço da frente de saturação, em condições de campo, é uma questão importante, que merece o enquadramento em linha específica de pesquisa e deve ser considerada uma questão preliminar, juntamente com a determinação in situ dos coeficientes de permeabilidade horizontal e vertical, em diversos níveis, ao longo de toda a profundidade das estacas instaladas.

3) Após o mapeamento de zonas de saturação, em perfil e em planta, é necessário conhecer, para cada tipo de solo estudado, os índices de penetração estática e dinâmica (in situ) e correlacioná-los com parâmetros obtidos em laboratório, em amostras virgens, ensaiadas em diversos grupos com teores de umidade diferentes e características de cada zona de saturação

4) A identificação de uma pressão-limite inferior, abaixo da qual uma eventual inundação não mais produziria deslocamentos por colapso em 
estacas, é uma peça importante neste estudo. O raciocínio que a justifica é simples: se esta pressão for uma característica do solo, é possível conhecê-la a partir de uma pesquisa específica envolvendo diversas provas de carga. Com o seu conhecimento, será possível detectar a grandeza da menor carga de trabalho, abaixo da qual o rompimento de uma tubulação de água ou esgoto em uma construção não produziria o colapso no solo, e assim criar uma "linha de proteção" para orientar projetos de fundações profundas por meio de estacas escavadas. Em solos com distribuição de camadas bem previsível, como é o caso da região de São Carlos, o problema pode ser bem simplificado, bastando considerar apenas duas variáveis para o projeto de pesquisas, conforme a FIGURA 8.1: 1) o diâmetro das estacas; 2) o comprimento das estacas.

5) Seria interessante fazer um estudo com modelos em escala reduzida para testar o efeito do $\mathrm{pH}$ da água de inundação, procurando associar $\mathrm{pHs}$ diferentes (água de abastecimento, pluvial e de esgotos).

6) Sugere-se um estudo mais aprofundado da camada de solo residual do Grupo Bauru, principalmente quanto às suas características de expansibilidade e/ou colapsibilidade, permeabilidade e constituição mineral.

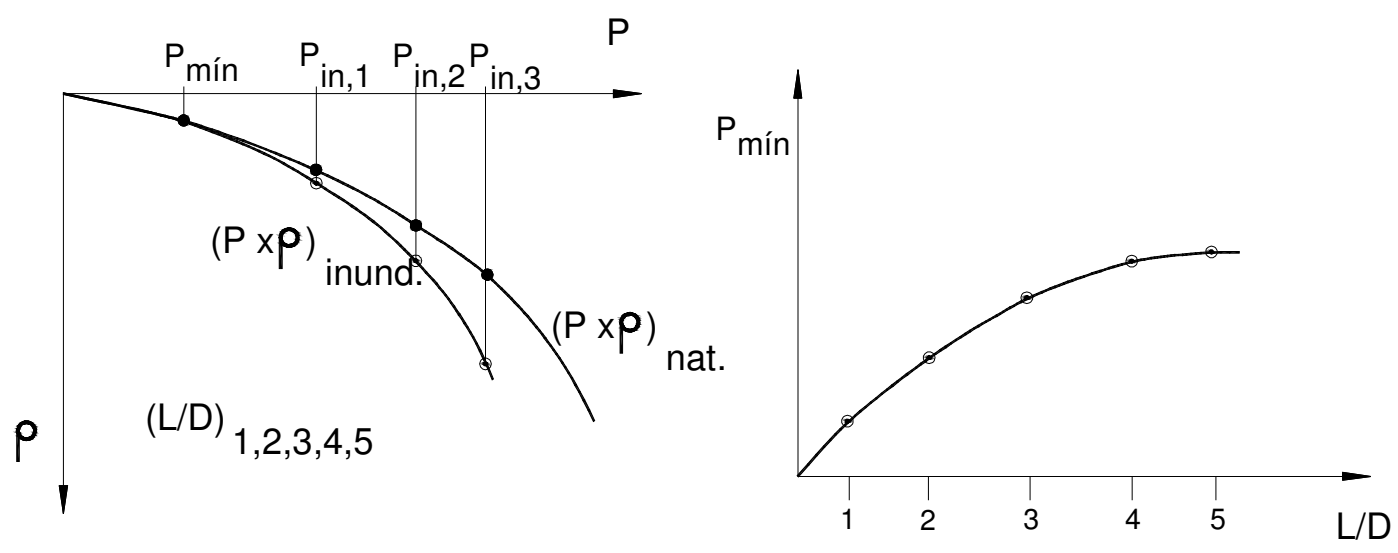




\section{REFERÊNCIAS BIBLIOGRÁFICAS}

ABDRABBO, F. M.; MAHMOUD, M. A. (1988). A practical note on the evaluation of a pile load using cone penetration test results. PENETRATION TESTING, ISOPT 1. De Ruiter (ed), Balkema, Rotterdam (1988), v. 2: 599-605

AGNELli, N. (1992). Estudo da colapsividade do solo de Bauru através de provas de carga diretas. Dissertação de Mestrado, São Carlos, EESC-USP, 1992. $172 \mathrm{p}$.

ALBIERO, J. H. (1972). Comportamento de estacas escavadas, moldadas in loco. Tese de Doutorado, São Carlos, EESC-USP (1972). 108 p.

ALBIERO, J. H. (1990). Correlação entre resistência de cone $\left(\mathrm{q}_{\mathrm{c}}\right)$ e resistência à penetração (SPT) para solos lateríticos. In: IX CONGRESSO BRASILEIRO DE MECÂNICA DOS SOLOS E ENGENHARIA DE FUNDAÇÕES, Salvador (1990), v. 2: $187-194$

ALONSO, U. R. (1991). Carga admissível de estacas utilizando-se o ensaio CPT. In: SEFE II, São Paulo (1991), v. 2: 313-333

AOKI, N.; LOPES, F. R. (1975). Estimating stress and settlement due to deep foundations by the theory of elasticity. In: V CONGRESSO PAN AMERICANO DE MECANIA DE SUELOS Y INGENIERIA DE FUNDACIONES, Buenos Aires, v. I: 377-386

AOKI, N.; VELLOSO, D. A. (1975). Na approximate method to estimate the bearing capacity of piles. In: V CONGRESSO PAN AMERICANO DE MECANIA DE SUELOS Y INGENIERIA DE FUNDACIONES, Buenos Aires, V. I: 367-376

AURORA, R. R.; REESE, L. C. (1977). Field tests of drilled shafts in clay-shales. In: Proceedings of $9^{\text {th }}$ INTERNATIONAL CONFERENCE ON SOIL MECHANICS AND FOUNDATION ENGINEERING, Tokyo (1977), v.2: 371-376

AZEVEDO Jr., N.; NIYAMA, S. (1990). Determinação do módulo de elasticidade de estacas de concreto. Anais: $6^{\circ}$ CONGRESSO BRASILEIRO DE GEOLOGIA DE ENGENHARIA/IX CONGRESSO BRASILEIRO DE MECÂNICA DOS SOLOS E ENGENHARIA DE FUNDAÇÕES, Salvador (1990), v. 2: 519-522

BANERJEE, P. D.; DAVIS, T. G. (1978). The behavior of axially and laterally single piles embedded in non-homogeneous soils. GEOTECNIQUE, 28, n. 3: 309-326 
BANERJEE, P. K. (1978). Analysis of axially and laterally loaded pile group. In: DEVELOPMENTS IN SOIL MECHANICS, ed. By C. SCOTT, London (1978). Applied Science Publications

BARA, J. P. (1975). Pre-collapsing foundation soils by wetting. In: Proceedings VI CONGRESSO PAN AMERICANO DE MECANICA DE SUELOS E ENGINERIA DE FUNDACIONS, Buenos Aires (1975), v. 1: 261-270

BARDEN, L.; McGOWN, A.; COLLINS, K. (1973). The collapse mechanism in partly saturated soil. ENGINEERING GEOLOGY, Amsterdam, 7: 49-60

BORTOLUCCI, A. A. (1983). Caracterização geológico-geotécnica da região urbana de São Carlos - SP a partir de sondagens de simples reconhecimento. Mestrado: Dissertação. São Carlos, EESC-USP, 1983, 61 p.

BRIAUD, J. L.; TUCKER, L. M. (1984). Coefficient of variation of in situ test results in sands. In: SYMPOSIUM AT AMERICAN SOCIETY OF CIVIL ENGINEERS CONVENTION IN ATLANTA, may 1984

BURLAND, J. B. (1965). Some aspects of the mechanical behavior of partly saturated soils. In: MOISTURE EQUILIBRIA AND MOISTURE CHANGES IN SOILS BENEATH COVERED AREAS. Butterworths, Sydney, Australia, p. 270-278

BUTTERFIELD, R.; BANERJEE, P. E. (1971). The elastic analysis of compressive piles and piles groups. Geotechnique, 21, n. 1: 43-60

CAMBEFORT, M. H. (1953). Le comportement des pieux forés et les essais de penetration. Proceedings: $3^{\text {rd }}$ INTERNATIONAL CONFERENCE OF SOIL MECHANICS AND FOUNDATION ENGINEERING, Zurich

CAMBEFORT, M. H. (1964). Essai sur le comportement en terrain homogène des pieux isolées et des groupes de pieux. ANNALES DE L'INSTITUT DU BATIMENT ET DES TRAVAUS PUBLIC, n. 204, dec.1964

CARVALHO, D.; SOUZA, A. (1990). Análise do efeito de umedecimento do solo em fundações rasas e profundas em solos porosos. In: $6^{\circ}$ CONGRESSO BRASILEIRO DE MECÂNICA DOS SOLOS E ENGENHARIA DE FUNDAÇÕES, Salvador, 1990, v. 2: $107-114$

CARVALHO, D. (1991). Análise de cargas últimas à tração de estacas escavadas, instrumentadas, em campo experimental de São Carlos - SP. Tese de doutorado, São Carlos, EESC-USP, 1991. 204p

CARVALHO, D.; MANTILLA, J. N. R.; ALBIERO, J. H.; CINTRA, J. C. A. (1991). Provas de carga à tração e à compressão em estacas instrumentadas do tipo raiz. In: SEFE II, São Paulo, 1991, v. 1: 79-87 
CHANG, M. F.; BROMS, B. B. (1991). Design of bored piles in residual soil based on field-performance data. Canadian Geotechnical Journal, 28, n. 2: 200-209

CHELLIS, R. D. (1961). Pile Foundations. New York, McGraw-Hill Book Co., $2^{\text {nd }}$ ed.

CHIN, F. K. (1970). Estimation of the ultimate load of piles not carried to failure. Proceedings: $2^{\text {nd }}$ SOUTHEAST ASIAN CONFERENCE ON SOIL ENGINEERING: $81-90$

CINTRA, J. C. A. (1987). Comportamento de modelos instrumentados de grupos de estacas cravadas em areia. Tese de doutorado, EESC-USP, São Carlos (1987), $117 \mathrm{p}$.

CINTRA, J. C. A.; CARVAlHO, D.; GIACHETTI, H. L.; BORTOLUCCI, A. A.; ALBIERO, J. H. (1991). Campo experimental de fundações de São Carlos. In: SEFE II, São Paulo (1991), v. 1: 96-105

CLAYTON, C. R. I. (1980). The colapse of compacted chalk fill. Proceedings: INTERNATIONAL CONFERENCE ON COMPACTION, Paris, 1980: session 2

COOKE, R. W.; WHITAKER, I. (1961). Experiments on model piles with enlarged bases. Geotechnique, 11, n.1

COOKE, R. W. (1979). Influence of residual installation forces on the stress transfer and settlement under working loads of jacked and bored piles in cohesive soils. In: BEHAVIOR OF DEEP FOUNDATIONS, ASTM STP 670, Ed. ASTM: 231-249

COOKE, R. W. (1979): Load transfer from bored, cast-in-situ piles in London clay. In: AMERICAN STANDARD OF TESTING MATERIALS, STP 670: 250-263

COSTA NUNES, A. J.; NOVAES, J. L.; SILVA, S. R. B. (1979). Instrumented load tests in driven precast-concrete piles. In: $6^{\circ}$ CONGRESSO PAN AMERICANO DE MECANICA DE SUELOS E ENGINERIA DE FUNDACIONS, Lima, 1979

COX, D. W. (1978). Volume change of compacted clay fill. Proceedings, INSTITUTION OF CIVIL ENGINNERS CONFERENCE ON CLAY FILLS, London: $79-86$

COYLE, H. M.; REESE, L. C. (1966). Load-transfer for axially loaded piles in clay. Journal of Soil Mechanics and Foundation Division, ASCE, v. 92, SM6: 1-26

COYLE, H. M.; SUlAIMAN, I. H. (1967). Skin friction for steel piles in sand. Journal of Soil Mechanics and Foundation Division, ASCE, v. 93, SM6: 261-278

CROWTER, C. (1988). Load Testing of Deep Foundations. New York. John Wiley \& Sons 
D’APPOLONIA, E.; HRIBAR, J. (1963). Load-transfer in a step-taper pile. Journal of Soil Mechanics and Foundation Engineering, ASCE, 89, SM6

D’APPOLONIA, E.; ROMUALDI, J. (1963). Load-transfer in end-bearing H-piles. Journal of Soil Mechanics and Foundation Division, ASCE, v. 89, SM2

DARRAG, A. A.; LOVELL, C. W. (1989). A simplified procedure for predicting residual stresses for piles. In: XII INTERNATIONAL CONFERENCE ON SOIL MECHANICS AND FOUNDATION ENGINEERING, Rio 1989, v.1: 1127-1130

DECOURT, L.; QUARESMA, A. R. (1978). Capacidade de carga de estacas a partir de valores do SPT. In: $6^{\circ}$ CONGRESSO BRASILEIRO DE MECÂNICA DOS SOLOS E ENGENHARIA DE FUNDAÇÕES, Rio (1978), v. 1: 45-53

DENISOV, N. J. (1951). The engineering properties of loess and loess loams. Gosstroirzdat, Moscow, 136p (em russo) - In: FEDA, J. 1966

DONALDSON, G. W. (1967). The measurement of stress in anchor piles. In: Proceedings of REGIONAL CONFERENCE FOR AGRICA ON SOIL MECHANICS AND FOUNDATION ENGINEERING, 4, Cape Town, 1: 253-256

DUBOSE, L. (1957). Small-scale load tests on drilled and cast-in-place concrete pile. Highway Research Board, USA: 36-32

DUDLEY, J. H. (1970). Review of collapsing soils. Journal of Soil Mechanics and Foundation Division, ASCE, 96, SM3: 925-947

ELLISON, R. D.; D’APPOLONIA, E.; THIERS, G. R. (1971). Load-deformation on mechanism for bored piles. Journal of Soil Mechanics and Foundation Division, ASCE, 97, SM4: 661-678

ESCARIO, V.; SAEZ, J. (1973). Measurement of the properties of swelling and collapsing soils under controlled suction. Proceedings: $3^{\text {rd }}$ INTERNATIONAL CONFERENCE ON EXPANSIVE SOILS. Haifa, Israel, 1973, v. I: 195-200

FEDA, J. (1966). Structural stability of subsident loess soil from Praha-Dejvice. Engineering Geology (Amsterdam). Elsevier Publishing 2: 201-219

FELLENIUS, B. H. (1975). Test load of piles and new proof testing procedure. ASCE, Journal of Geotechnical Engineering Division, n. 101, GT9: 855-869

FERREIRA, A. C.; LOPES, F. R. (1985). Contribuição ao estudo do efeito do tempo de carregamento no comportamento de estacas de prova. In: SEFE I, São Paulo, 1985, v. 2: $185-192$

FOCHT, J. A. (1967). Discussion to paper by COYLE \& REENSE, ASCE, Journal of Soil Mechanics and Foundation Engineering, 93, SM1: 133-138 
FONTOURA, S. A. B. (1982). Mecanismos de transferência de carga em sistemas solo-estaca escavadas. In: Anais do SIMPÓSIO SOBRE COMPORTAMENTO DE FUNDAÇÕES. DEC-PUC (RJ), 1982: 91-136

FONTOURA, S. A. B.; VElloso, P. P. C.; PEDROSA, M. G. A. (1982). Análise da capacidade de carga de uma estaca escavada com instrumentação no fuste. In: Anais VII CONGRESSO BRASILEIRO DE MECÂNICA DOS SOLOS E ENGENHARIA DE FUNDAÇÕES, Olinda/Recife (1982), II: 221-235

FOSS, I. (1973). Red soil from Kenya as a foundation material. Proceedings, $8^{\text {th }}$ INTERNATIONAL CONFERENCE ON SOIL MECHANICS AND FOUNDATION ENGINEERING, Moscow, v. 2: 73-80

FRANK, R. (1985). Recent developments in the prediction of pile behavior from pressurimeter results. In: Proceedings of SYMPOSIUM FROM THEORY TO PRACTICE ON DEEP FOUNDATIONS. Porto Alegre, v.1: 69-99

FREDLUND, D. G. (1976). Density and compressibility characteristics of air-water mixtures. Canadian Geotechnical Journal, 13: 386-396

FREDLUND, D. G.; MORGENSTERN, N. R. (1977). Stress state variable for unsaturated soils. ASCE, Journal of Geotechnical Engineering Division, 103, GT5: 447-466

FREDLUND, D. G. (1979). Appropriate concepts ant technology for unsaturated soils. Canadian Geotechnical Journal, 16, v.1: 121-139

GAMA E SILVA, R. L.; MORI, M.; CASTRO, G. R. (1982). Estimativa do comportamento das estacas escavadas de grande diâmetro. Anais: $7^{\circ}$ CONGRESSO BRASILEIRO DE MECÂNICA DOS SOLOS E ENGENHARIA DE FUNDAÇÕES. Recife, v.3: 276-287

GIACHETTI, H. L. (1991). Estudo experimental de parâmetros dinâmicos de alguns solos tropicais do estado de São Paulo. Tese de doutorado, São Carlos, EESC-USP, 1991, 232 p.

GIBBS, H. J.; BARA, J. P. (1967). Stability problems of collapsing soils. ASCE, Journal of the Soil Mechanics and Foundation Division, 93, SM4: 577-594

GOLOMBEK, S. (1985): Building Foundations. In: Peculiarities of Geotechnical Behavior of tropical laterite and saprolite soils - Progress Report (1982-1985). São Paulo, 1985: 222-238

GRANDE, L.; NORDAL, S. (1980). Pile-soil interaction analysis on effective stress basis. In: Recent Developments in the Design and Construction of Piles. London, I. C. E., 1980: 365-375 
GRIM, R. E.; BRADLEY, W. F. (1963). Clay mineral composition and properties of deep residual soils from São Paulo, Brasil. In: $2^{\circ}$ CONGRESSO PAN AMERICANO DE MECANICA DOS SOLOS E ENGENHARIA DE FUNDAÇÕES. São Paulo, v. 1: $63-72$

GWIZDALA, K. (1984). Determination of the bearing capacity and settlement from results of static penetration tests CPT and standard penetration tests SPT. SGI, Report n. 26, 1, 29, Linkoping

HANNA, T. H. (1971). The distribution of load in long piles. Soils, v. 6, n. 22, Paris

HIRAYAMA, H. (1990). Load-settlement analysis for bored piles using hyperbolic transfer functions. Soil and Foundation, 30, n. 1: 55-64

HOLTZ, H. G. (1948). The determination of limits for the control of placement moisture in high rolled earth dams. ASMT, Proceedings, 48: 1240-1248

HOLTZ, W. G.; GIBBS, H. J. (1953). Field test to determine the behavior of piles in loess. In: Proceedings of $3^{\text {rd }}$ INTERNATION CONFERENCE ON SOIL MECHANICS AND FOUNDATION ENGINEERING, Paris, v. I: 673-679

HORIUCHI, T. (1985). Bearing capacity of cast-in-situ piles. In: Proceedings XI INTERNATIONAL CONFERENCE ON SOIL MECHANICS AND FOUNDATION ENGINEERING, San Francisco (q1985) v. 3: 1393-1396

HOUNSTON, S. L.; HOUSTON, W. N.; SPADOLA, D. J. (1988). Prediction of field collapse of soils due to wetting. ASCE, Journal of Geotechnical Engineering Division, 114, GT1: 40-58

HUNTER, A. H.; DAVISSON, M. T. (1969). Performance of deep foundations. ASTM, STP 444: 106-117

JENNINGS, J. E.; KNIGHT, K. (1957). The additional settlement of foundations due to collapse of structure of sandy subsoils on wetting. In: Proceedings $4^{\text {th }}$ INTERNATIONAL CONFERENCE ON SOIL MECHANICS AND FOUNDATION ENGINEERING, v.1

KÉRISEL, J.; ADM, M. (1969). Charges limits d'un pieux en milieu argileux et limoneux. In: Proceedings $7^{\text {th }}$ INTERNATIONAL CONFERENCE ON SOIL MECHANICS AND FOUNDATION ENGINEERING, v. 2: 131-139

KOIZUMI, Y.; ITO, K. (1967). Field tests with regard to pile driving and bearing capacity of piled foundations. Soil and Foundations, n. 3 
JIMENEZ SALAS, J. A. (1987). Problemas de geologia para el ingeniero en las cimentaciones sobre suelos. Boletin de La Sociedad Española de Mecanica del Suelo y Cimentaciones, n. 86: 3-21

LAMBE, T. W.; WHITMAN, R. V. (1979). Soil Mechanics, SI Version. New York, John Wiley \& Sons, 1979, $553 \mathrm{p}$

LLOYD, T.; GOWAN, M. J. (1975). The effect of the variation of consistency in residual soils on load transfer by bored piles. In: Proceedings of $6^{\text {th }}$ REGIONAL CONFERENCE FOR AFRICA ON SOIL MECHANICS AND FOUNDATION ENGINEERING, Durban, South Africa: 177-182

LOBO, A. S. (1991). Colapsividade do solo de Bauru e sua influência em estacas de pequeno porte. Tese de Doutorado, São Carlos, EESC-USP

LOBO, AS.; ALBIERO, J. H.; FERREIRA, C. V. (1991a). Comparação entre carga última prevista por diversas fórmulas e obtidas em provas de carga executadas em estacas de pequeno porte. In: SEFE II, São Paulo, 1991, v.1: 197-206

LOBO, A. S.; ALBIERO, J. H.; FERREIRA, C. V. (1991b). Influência da inundação na carga última de estacas de pequeno porte. In: SEFE II, São Paulo, v. 2: 217-226

LOPES, F. R. (1986). Medições de transferência de carga em estacas. Anais: VIII CONGRESSO BRASILEIRO DE MECÂNICA DOS SOLOS E ENGENHARIA DE FUNDAÇÕES, Porto Alegre (1986), v. 8: 25-42

MANSUR, C.; KAUFMANN, R. (1958). Pile tests, low-still structure, Old-River, Lousiana. In: AMERICAN SOCIETY OF CIVIL ENGINEERS TRANSACTIONS, 123

MANTILLA, J. N. R. (1993). Comportamento de estacas escavadas, instrumentadas, à compressão. Tese de Doutorado, EESC-USP, 1992. 251p

MASSAD, R. (1991a). Análise de transferência de carga em duas estacas instrumentadas, quando submetidas à compressão axial. In: SEFE II, São Paulo, v. 1: 235-244

MASSAD, F. (1991b). Comportamento de estacas escavadas de elevada compressibilidade. In: SEFE II, São Paulo, v.1: 245-254

MASSAD, F. (1991c). Estacas escavadas em compressão axial: comportamento e parâmetros, visando a estimativa de recalques. In: SEFE II, v. 2: 255-264

MASSAD, F. (1992). Sobre a interpretação de provas de carga em estacas, considerando as cargas residuais na ponta e a reversão do atrito lateral. Parte I: solos perfeitamente homogêneos. Solos e Rochas, 15(2): 103-115 
MAZURKIEWICZ, B. K. (1972). Test loading of piles according to Polish regulations. Royal Academy of Engineering Sciences, Comm. on Pile Research, Report n. 35, Stockholm. 20p

MELLIOS, G. A. (1985). Provas de carga em solos porosos. In: SEFE I, São Paulo, v. 2: $73-102$

MENEZES, S. M. (1990). Correlações entre os ensaios de penetração (SPT, CPT) e os resultados de ensaios de laboratório para a região de São Carlos - SP. Dissertação de Mestrado, São Carlos, EESC-USP, 1990

MENEZES, S. M.; ALBIERO, J. H.; CARVALHO, D., MANTILLA, J. N. R. (1991). Algumas correlações entre os ensaios de penetração (SPT, CPT) e os resultados de ensaios de laboratório para a região de São Carlos - SP. In: SEFE II, São Paulo, v. 1: 265-275

MEYERHOF, G. G. (1951). The ultimate bearing capacity of foundation. Geotechnique, 2

MEYERHOF, G. G. (1959). Compaction of sands and bearing capacity of piles. ASCE, Journal of Soil Mechanics and Foundation Division, v.85, SM6: 1-29

MEYERHOF, G. G. (1976). Bearing capacity and settlement of pile foundation. Journal of Geotechnical Engineering Division, ASCE v. 102, GT3: 195-228

MEYERHOF, G. G. (1982). Bearing capacity and settlement of foundations in sand based on static cone penetration tests. In: Amici et Alumni Em. Prof. Dr. Ir E. E. DE BEER, 1982: 217-222

MEYERHOF, G. G. (1983). Scale effects of ultimate pile capacity. ASCE, Journal of the Geotechnical Engineering Division, v. 109, n. 6: 797-806

MIHEEV, V. V. (1962). On classification criteria for water sensible soils. Soil ground, foundations and soil mechanics, 5, Moscow (em russo). In: BELES, A. A.; STANCULESCU, I. I.; SCHALLY, V. R. (1969), Proceedings, I9CSMFE, Mexico, v. 2: $17-25$

MILITITSKY, J. (1986). Relato do estado atual de conhecimento: Fundações. In: Anais VIII CONGRESSO BRASILEIRO DE MECÂNICA DOS SOLOS E ENGENHARIA DE FUNDAÇÕES. Porto Alegre, 1986, v. VIII: 191-260

MILITITSKY, J. (1991). Provas de carga estáticas. In: SEFE II, São Paulo, v. 2: 203228

MOHAN, D.; CHANDRA, S. (1961). Frictional resistance of bored piles in expansive clays. Geotechnique, 11, n. 4: 294-301 
MOHAN, D.; JAIN, G. S.; KUMAR, V. (1963). Load bearing capacity of piles. Geotechnique, 17: 274-283

MOLL, L. L. (1975). Analisis del problema de los suelos colapsibles. In: V CONGRESSO PAN AMERICANO DE MECANIA DE SUELOS Y INGENIERIA DE FUNDACIONES, Buenos Aires, v. 5: 359-368

MONTEIRO, L. B. (1985). Alguns aspectos da capacidade de carga de solos colapsíveis. In: SEFE I, São Paulo, v. 2: 293-213

NADEO, J. R.; VIEDELA, E. P. (1975a). Comportamiento de pilotes en suelos colapsibles. In: V CONGRESSO PAN AMERICANO DE MECANIA DE SUELOS Y INGENIERIA DE FUNDACIONES, Buenos Aires, 1975, v. 5: 303-312

NADEO, J. R.; VIDELA, E. P. (1975b). El fenomeno de la humectation "in situ" de suelos colapsibles. In: V CONGRESSO PAN AMERICANO DE MECANIA DE SUELOS Y INGENIERIA DE FUNDACIONES, Buenos Aires, v. 5: 313-319

NAIR, K. (1967). Load-settlement and load transfer characteristics of a friction pile subjected to a vertical load. In: Proceedings $3^{\text {rd }}$ PAN-AMERICAN CONFERENCE OF SOIL MECHANICS AND FOUNDATION ENGINEERING, 1: 565-590

NEVES, M. (1987). Estudo da permeabilidade do solo colapsível da região de São Carlos. Dissertação de Mestrado, EESC-USP, 1987, 139p

NOGUEIRA, J. B.; LIMA SOBRINHO, O. O.; GANDOLFI, N. (1985). Characteristics of compressibility of soil from cenozoic sediments. In: $1^{\text {st }}$ INTERNATIONAL CONFERENCE ON GEOMECHANICS IN TROPICAL LATERITIC AND SAPROLITC SOILS, Brasília, 2985, v. 1: 471-475

NUÑEZ, E. (1975). Suelos colapsibles y preconsolidados por dessecacion. In: V CONGRESSO PAN AMERICANO DE MECANIA DE SUELOS Y INGENIERIA DE FUNDACIONES, Buenos Aires, v. 4: 45-73

O’NEILL, M. W.; REESE, L. C. (1972). Behavior of bored piles in Beaumont Clay. ASCE, Journal of the Soil Mechanics and Foundation Division, 98, SM2: 195-213

O'RIORDAN, N. J. (1982). The mobilization of shaft adhesion down a bored, cast-insitu piles in the woolwich and Reading Beds, U. K. Ground Engineering, 15, n. 3: 1726

PHILIPPONNAT, G. (1979). Método prático de cálculo de estacas isoladas com emprego do penetrômetro estático (tradução ABMS, jul/86, 22p)

POPESCU, M. E. (1986). A comparison between the behavior of swelling and collapsing soils. Engineering Geology, Amsterdam, 23: 145/163 
POULOS, H. G.; DAVIS, E. H. (1968). The settlement behavior of single axially loaded incompressible piled and piers. Geotechnique, 18

POULOS, H. G. (1972). Load-settlement prediction for piles and piers. ASCE, Journal of Soil Mechanics and Foundation Division, 98, SM9

POULOS, H. G. (1979). Settlement of single piles in non-homogeneous soil. Journal of Geotechnical Engineering Division, ASCE 105, GT5: 627-641

POUlOS, H. G.; DAVIS, E. H. (1980). Pile Foundation Analysis and Design. New York, John Wiley \& Sons

POULOS, H. G. (1987). Analysis of residual stress effects in piles. ASCE, Journal of the Geotechnical Engineering Division, v. 113, n. 3: 216-229

POULOS, H. G. (1989). Pile behavior, theory and application. Geotechnique, 39, n. 3: $365-415$

PRIKLONSKIJ, V. A. (1952). Grountovedenie-Vtoraira Chast Gogeolizdot (em russo). In: FEDA, 1966

REESE, L. C.; MATLOCK, H.; DOWSON, R. F. (1951). Load distribution along a model bearing pile. Circular n. 20, Bureau of Engineering Research University of Texas, Austin

REESE, L. C. (1955). Pressure distribution along friction piles. In: Proceedings AMERICAN STANDARD OF TESTING MATERIALS, 56

REESE, L. C.; HUDSON, B. S.; VIJAYVERGJYA, B. S. (1969). An investigation of the interaction between bored piles and soil. In: Proceedings $7^{\text {th }}$ INTERNATIONAL CONFERENCE ON SOIL MECHANICS AND FOUNDATION ENGINEERING, Mexico, 1969, v. 2: 211-215

REESE, L. C. (1972). Axial capacity. In: PERFORMANCE OF EARTH AND EARTH-SUPPORTED STRUCTURES. ASCE, v. 111: 201-206

REESE, L. C.; TOUMA, F. T.; O’NEILL, M. W. (1976). Behavior of drilled piers under axial loading. ASCE, Journal of Geotechnical Engineering Division, 102, GT5: 493-510

REGINATO, A. R.; FERRERO, J. C. (1973). Collapse potencial of soils and soilswater chemistry. In: INTERNATIONAL CONFERENCE ON SOIL MECHANICS AND FOUNDATION ENGINEERING, Moscow, 8, v. 2.2: 177-183

RIEKE, R. D.; CROWSER, J. C. (1987). Interpretation of pile load test considering residual stresses. ASCE, Journal of the Geotechnical Engineering Division, v. 112, n. 4: 320-334 
ROCHA FILHO, P.; AMARAL, C. S. (1986). Obtenção de parâmetros de deformabilidade do solo a partir de resultados de provas de carga em estacas instrumentadas. In: VIII CONGRESSO BRASILEIRO DE MECÂNICA DOS SOLOS E ENGENHARIA DE FUNDAÇÕES. Porto Alegre, 1986, v. 1: 211-222

ROCHA, R.; DANTAS, F. A. S. (1986). Análise do comportamento da argamassa de preenchimento e das provas de carga instrumentadas em estacas tipo raiz. In: VIII CONGRESSO BRASILEIRO DE MECÂNICA DOS SOLOS E ENGENHARIA DE FUNDAÇÕES, Porto Alegre, 1986, v. 6: 181-192

SACILOTTO, A. C. (1993). Comportamento de estacas escavadas instrumentadas, submetidas a carregamentos sucessivos. Dissertação de Mestrado, EESC-USP, 1992, 163p.

SANTOS JUNIOR, O. F. (1988). Previsão do comportamento carga-recalque de estacas pré-moldadas de concreto. Dissertação de Mestrado, EESC-USP, São Carlos, 1988, $121 \mathrm{p}$.

SEARLE, I. W. (1979). The design of bored piles in overconsolidated clays using effective stresses. In: RECENT DEVELOPMENTS IN THE DESIGN AND CONSTRUCTION OF PILES. Institute of Civil Engineering, 355-363

SEED, H. B.; REESE, L. C. (1957). The action of soft clay along friction piles. Transaction of ASCE, 122: 731-734

SEED, H. B.; REESE, L. C. (1964). Predicting the performance of friction piles in saturated clays. In: CONGRESSO DE CIMIENTOS PROFUNDOS, Mexico, v. I

SILVA, J. C. B. J. (1990). Análise dos resultados de provas de carga em estacas de pequeno diâmetro em solo colapsível. In: $6^{\circ}$ CONGRESSO BRASILEIRO DE MECÂNICA DOS SOLOS, Recife/Campina Grande, v. 1: 77-110

SKEMPTON, A. W. (1959). Cast-in-sit bored piles in London-clay. Geotechnique, v. 9: $152-173$

TADEPALLI, R.; FREDLUND, D. G. (1991). The collapse of a compacted soil during inundation. Canadian Geotechnical Journal, v. 18: 477-488

TEJCHMAN, A.; GWIZDALA, K. (1987). Determination of the load-settlement curve for large diameter piles base on CPT results. In: PENETRATION TESTINT, 1988 (ISPT, 1), ed. by De Ruiter, v. 2: 1015-1020

THURMAN, A. G.; D’APPOLONIA, E. (1965). Computed movement of friction and end bearing piles embedded in uniform and stratified soils. In: Proceedings $6^{\text {th }}$ INTERNATIONAL CONFERENCE ON SOIL MECHANICS AND FOUNDATION ENGINEERING, Montreal, v. 2 
TOH, T.; OOI, T. A.; CHIU, H. K.; TING, W. N. (1989). Design parameters for bored piles in a wheathered sedimentary formation. In: 12 $2^{\text {th }}$ INTERNATIONAL CONFERENCE ON SOIL MECHANICS AND FOUNDATION ENGINEERING, Rio, v. 2: 1073-1078

VAN DER VEEN, C. (1953). The bearing capacity of a pile. In: $3^{\text {rd }}$ INTERNATIONAL CONFERENCE ON SOIL MECHANICS AND FOUNDATION ENGINEERING, Zurich, v. 2: 84-90

VAN DER VEEN, C.; BOERSMA, L. (1957). The bearing capacity of a pile predetermined by a cone penetration test. In: $4^{\text {th }}$ INTERNATIONAL CONFERENCE ON SOIL MECHANICS AND FOUNDATION ENGINEERING, v. 2: 72-75

VAN WEELE, A. F. (1957). A method of separating the bearing capacity of a test pile into skin friction and point resistance. In: $4^{\text {th }}$ INTERNATIONAL CONFERENCE ON SOIL MECHANICS AND FOUNDATION ENGINEERING, v. 2: 76-80

VAN WEELE, A. F. (1982). Wich load is allowable on a given foundation pile when its actual load-settlement behavior is available through a load test? In: AMICI ET ALUMNI, Em. Dr. IR E. E. DE BEER, 1982: 287-296

VARGAS, M. (1974). Engineering properties of residuals soils from South-Central Regional of Brazil. In: $2^{\text {nd }}$ INTERNATIONAL CONGRESS ASSOCIATION OF ENGINEERING GEOLOGY. São Paulo, 1, IV: PC-5.1

VARGAS, M. (1983). Resposta à discussão interação solo-estaca. Revista de Engenharia, n. 440, São Paulo

VARGAS, M. (1990). Provas de carga em estacas. Uma apreciação história. In: Solos e Rochas. São Paulo, 13 (único): 3-12

VELlOSO, D. A.; AOKI, N.; SALAMONI, J. A. (1978). Fundação para o silo vertical de 100.000 t no Porto de Paranaguá. In: VI CONGRESSO BRASILEIRO DE MECÂNICA DOS SOLOS E ENGENHARIA DE FUNDAÇÕES, Rio (1978)

VELlOSO, P. P. C. (1981). Fundações - Aspectos Geotécnicos. PUC - Rio de Janeiro (3 volumes)

VESIC, A. S. (1965). Ultimate loads and settlements of deep foundations in sand. In: SYMPOSIUM ON BEARING CAPACITY AND SETTLEMENTS OF FOUNDATION, Duke University

VESIC, A. S. (1970a). Design of pile foundations. Research Report to Transportation Research Board, National Research Council, Washington, D. C. 1970, 68p 
VESIC, A. S. (1970b). Load transfer in pile-soil systems. In: CONFERENCE ON DESIGN AND INSTALATION OF PILE FOUNDATION AND CELLULAR STRUCTURE, Lehigh University Bethlehem, Pa

VESIC, A. S. (1970c). Tests on instrumented piles, Ogeechee River Site. Journal of the Soil Mechanics and Foundation Division, v. 96, SM3: 561-583

VESIC, A. S. (1975). Principles of pile foundation Design. Soil Mechanics Series, n. 38, Duke University

VESIC, A. S. (1977). On significance of residuals loads for load response of piles. In: IX INTERNATIONAL CONFERENCE ON SOIL MECHANICS AND FOUNDATION DIVISION, v. 3, 1977: 374-379

VILAR, O. M. (1979). Estudo da compressão unidirecional do sedimento moderno (solo superficial) da cidade de São Carlos. Dissertação de Mestrado. São Carlos, EESC-USP, 1979, 110p.

WARD, W. H.; GREEN, H. (1952). House foundation the short-bored piles. Publication Work and Municipal Service Congress, London

ZEEVAERT, L. (1972). Foundation Engineering for Difficult Subsoil Conditions. Van Nostrand Reinold Co., New York

WHITAKER, T. (1957). Experiments with model piles in groups. Geotechnique, London, v.7: 147-167

WHITAKER, T.; COOKE, R. W. (1961). A new approach to the pile testing. In: $5^{\text {th }}$ INTERNATIONAL CONFERENCE ON SOIL MECHANICS AND FOUNDATION ENGINEERING, Paris, v. 2: 171-176

WHITAKER, T. (1962). The constant rate of penetration test for the determination of the ultimate bearing capacity of a pile. Proceedings, Institution of Civil Engineers, v. 26, London: 119-123

WHITAKEER, T.; COOKE, R. W. (1966). An investigation of the shaft and base resistance of large bored piles in London-clay. In: SYMPOSIUM OF LARGE BORED PILES, I. C. E., London: 7-49

WOODWARD, R. J.; GARDNER, W. S.; GREEN, D. M. (1972). Drilled Piers Foundations. New York, McGraw-Hill, Inc. 


\section{ANEXO \\ CRONOGRAMA DE ATIVIDADES DE CAMPO}

\begin{tabular}{|l|l|l|}
\hline MÊS/ANO & DIA & \\
\hline Maio/1992 & 07 & Escavação (abertura de cavas) \\
\hline & 08 & Continuação \\
\hline & 09 & Continuação \\
\hline & 10 & Continuação \\
\hline & 11 & Execução de furos a trado (diâmetro de 15 cm) \\
\hline & 12 & Continuação \\
\hline & 13 & Continuação \\
\hline & 14 & Continuação \\
\hline & 15 & Continuação \\
\hline & 16 & Continuação \\
\hline & 17 & Continuação \\
\hline & 18 & Continuação \\
\hline & 19 & Continuação \\
\hline & 20 & Continuação \\
\hline & 21 & Continuação \\
\hline & 22 & Continuação \\
\hline & 23 & Continuação \\
\hline & 24 & Continuação \\
\hline & 25 & Continuação \\
\hline & 26 & Continuação \\
\hline & 27 & Continuação \\
\hline & 28 & Continuação \\
\hline & 29 & Continuação \\
\hline & 30 & Continuação \\
\hline & 31 & Continuação \\
\hline & 01 & Enchimento dos furos com areia \\
\hline & 02 & Revestimento dos furos s1, s2 e s3 (tubos com diâmetro de 60 mm) \\
\hline & 03 & Transferência da viga de reação para a estaca E 2 \\
\hline & 04 & Montagem da prova de carga \\
\hline & 05 & Continuação \\
\hline & 06 & Instalação hidráulica para inundação das cavas \\
\hline & 07 & Continuação \\
\hline & 08 & Continuação \\
\hline & & \\
\hline &
\end{tabular}




\begin{tabular}{|l|l|l|}
\hline & 09 & Continuação \\
\hline & 10 & Início da primeira prova de carga (D40(5)) \\
\hline 11 & Início da inundação, na carga de 300 kN \\
\hline & 12 & Observações e leituras \\
\hline & 13 & Continuação \\
\hline & 14 & Continuação \\
\hline & 15 & Continuação \\
\hline & 16 & Incremento para estágios de 330, 360 e 390 kN \\
\hline & 17 & Incremento para estágios de 420, 450 kN com início de colapso \\
\hline & 18 & Acompanhamento do colapso, com observações e leituras \\
\hline & 19 & Continuação \\
\hline & 20 & Continuação \\
\hline & 21 & Continuação \\
\hline & 22 & Continuação \\
\hline & 23 & Incremento para estágios de 480 e 510 kN (ruptura) \\
\hline & 24 & Descarga da prova de carga. Água desligada \\
\hline & 25 & Sem atividade \\
\hline & 26 & Sem atividade \\
\hline & 27 & Sem atividade \\
\hline & 28 & Sem atividade \\
\hline & 29 & Transferência da viga de reação para E3 \\
\hline & 30 & Continuação \\
\hline & 01 & Montagem da prova de carga D $50(5)$ - início dos trabalhos \\
\hline & 02 & Paralisação das atividades \\
\hline & 03 & Paralisação das atividades \\
\hline & 04 & Paralisação das atividades \\
\hline & 05 & Paralisação das atividades \\
\hline & 06 & Paralisação das atividades \\
\hline & 07 & Paralisação das atividades \\
\hline & 08 & Início da prova de carga D50(5) até o estágio de 480 kN \\
\hline & 09 & Início da inundação, com observações e leituras \\
\hline & 10 & Observações e leituras \\
\hline & 11 & Observações e leituras \\
\hline & 12 & Observação e leituras \\
\hline & 13 & Incremento para 530 kN. Observações e leituras \\
\hline & 14 & Incremento para 560 kN. Observações e leituras \\
\hline & 16 & Incremento para 600 kN. Início do colapso \\
\hline & Observações e acompanhamento do colapso \\
\hline & & \\
\hline & &
\end{tabular}




\begin{tabular}{|l|l|l|}
\hline & 17 & Estabilização do colapso. Incremento até $690 \mathrm{kN}\left(\mathrm{Q}_{\mathrm{u}}\right)$ \\
\hline & 18 & Acompanhamento da ruptura. Observações e leituras \\
\hline & 19 & Idem \\
\hline & 20 & Descarga \\
\hline & 21 & Recarregamento (prova de carga D $\left._{50(6)}\right)$ sem desligar a água \\
\hline & 22 & Descarga. Água desligada. Encerramento. \\
\hline
\end{tabular}


